Sludge Particle

Separation Efficiencies

During Settler Tank

Retrieval Into SCS-CON-

230

Prepared for the U.S. Department of Energy

Assistant Secretary for Environmental Management

Contractor for the U.S. Department of Energy

under Contract DE-AC06-08RL14788

CH2MHILL

P.O. Box 1600

Richland, Washington 99352

Approved for Public Release;

Further Dissemination Urimited 
PRC-STP-00011

Revision 0

EDC \#: PRC-EDC-09-41884

\section{Sludge Particle Separation Efficiencies During Settler Tank Retrieval Into SCS-CON-230}

Project No: A21C

Document Type: RPT

Program/Project: STP

J. I. Dearing

CH2M HILL Plateau Remediation Company

M. Epstein

M. G. Plys

Fauske \& Associates, LLC

Date Published

July 2009

Prepared for the U.S. Department of Energy

Assistant Secretary for Environmental Management

Contractor for the U.S. Department of Energy

under Contract DE-AC06-08RL14788

CH2MHILL

Plateau Remediation Company

P.O. Box 1600

Richland, Washington

$\frac{\text { Nancy Arouad }}{\text { Release Approval }} \frac{7-16-09}{\text { Date }}$

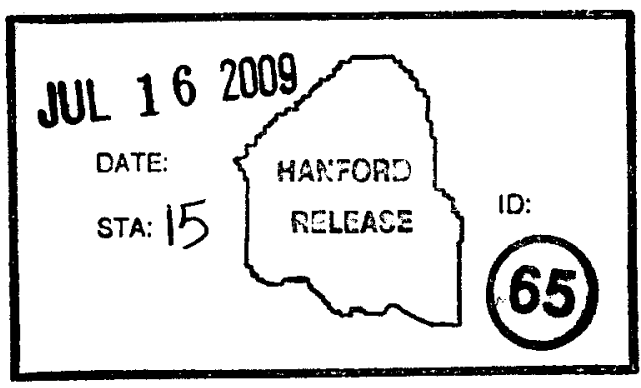

Release Stamp 
PRC-STP-00011

Revision 0

TRADEMARK DISCLAIMER

Reference herein to any specific commercial product, process, or service by trade name, trademark, manufacturer, or otherwise, does not necessarily constitute or imply its endorsement, recommendation, or favoring by the United States Government or any agency thereof or its contractors or subcontractors.

This report has been reproduced from the best available copy.

Printed in the United States of America

Total Pages: $\quad 156$ 


\section{Sludge Particle Separation Efficiencies \\ During Settler Tank Retrieval \\ Into SCS-CON-230}

\section{Table of Contents}

1.0 INTRODUCTION

2

2.0 ANALYSIS RESULTS

\section{Attachments}

Attachment A, FAI/09-091, Sludge particle Separation Efficiencies for the Rectangular SCS-CON230 Container

Attachment B, Review and Verification Files

Attachment B1, Review of FAl/09-91 Portions Modeled in MathCAD

Attachment B2, MGP062609, Review of FAl/09-91 Portions Authored by Michael Epstein Attachment B3, MGP062909A, MathCAD Files for FAl/09-91 (listing of file names only) 
PRC-STP-00011, Rev. 0

\section{Sludge Particle Separation Efficiencies \\ During Settler Tank Retrieval \\ Into SCS-CON-230}

\subsection{INTRODUCTION}

The purpose of this document is to release, into the Hanford Document Control System, FAI/0991, Sludge Particle Separation Efficiencies for the Rectangular SCS-CON-230 Container, by M. Epstein and M. G. Plys, Fauske \& Associates, LLC, June 2009.

The Sludge Treatment Project (STP) will retrieve sludge from the 105-K West Integrated Water Treatment System (IWTS) Settler Tanks and transfer it to container SCS-CON-230 using the Settler Tank Retrieval System (STRS). The sludge will enter the container through two distributors. The container will have a filtration system that is designed to minimize the overflow of sludge fines from the container to the basin. FAl/09-91 was performed to quantify the effect of the STRS on sludge distribution inside of and overflow out of SCS-CON-230.

Selected results of the analysis and a system description are discussed below.

\subsection{ANALYSIS RESULTS}

The principal result of the analysis is that the STRS filtration system reduces the overflow of sludge from SCS-CON-230 to the basin by roughly a factor of 10 . Some turbidity can be expected in the center bay where the container is located. The exact amount of overflow and subsequent turbidity is dependent on the density of the sludge (which will vary with location in the Settler Tanks) and the thermal gradient between the SCS-CON-230 and the basin.

Attachment A presents the full analytical results. These results are applicable specifically to SCSCON-230 and the STRS filtration system's expected operating duty cycles. Some important results are:

1. The analysis ran several sensitivity cases for varying particle densities and temperature differences. The results are presented in Table 5-2 of Attachment A. The conclusion states "The escape fraction for particles of average expected density $(6 \mathrm{~g} / \mathrm{cc})$ is between about $1 \%$ and $2 \%$ depending on the inlet water temperature (Cases $2 \mathrm{~A}$ and $3 \mathrm{~A}$ ). The escape fraction for particles of less than average expected density $(4 \mathrm{~g} / \mathrm{cc}$ ) is between about $2 \%$ and $6 \%$ (Cases 2B and 3B). The escape fraction for extremely light particles could range from about $8 \%$ to $13 \%$ (Cases $2 \mathrm{C}$ and $3 \mathrm{C}$ )."

2. The analysis estimates that $3.4 \%$ of the sludge transferred to the container will escape for a typical sludge composition of $60 \%$ at $6 \mathrm{~g} / \mathrm{cc}, 30 \%$ at $4 \mathrm{~g} / \mathrm{cc}$, and $10 \%$ at $2 \mathrm{~g} / \mathrm{cc}$ with an inlet temperature difference of $2^{\circ} \mathrm{C}$ (Using cases $1 \mathrm{~A}, 1 \mathrm{~B}$, and $1 \mathrm{C}$ of Table 5-2 of FAI/09-091). 
However this is only an example and the actual value will vary with sludge density and temperature difference.

3. The analysis estimates that up to $38 \%$ of the total sludge transferred would flow out of the container if there were no filtration system.

4. The most important sludge property governing potential particle escape is density. The less dense particles have the most potential of escaping.

5. The most important environmental factor governing potential particle escape is the thermal gradient between the inside of the container and the basin. The potential for particle escape increases as the temperature difference increases.

6. The most important overall factor in preventing potential particle escape is maintaining adequate inflow of basin water through the gap between the lid and the upper flange of SCS-CON-230.

7. Sludge will not escape from SCS-CON-230 when all four filter assemblies are operating under credible thermal gradients.

8. Sludge can only flow out of SCS-CON-230 when the following conditions exist

a. The filters are being back flushed and a thermal gradient exists between the container and the basin water (even $0.1 \mathrm{C}$ is sufficient to induce flow).

b. The flow into and out of the container is stopped and thermal gradients cause convection currents.

9. The bounding inlet temperature of sludge pumped into SCS-CON-230 by the STRS is $4^{\circ} \mathrm{C}$ above the basin temperature (based on accounting for the power added by all pumps in the system). This equates to a bulk thermal gradient of $1.2^{\circ} \mathrm{C}$ between SCS-CON-230 and the basin. Under this bounding condition, sludge particle loss from the container can be prevented by maintaining a net container suction flow of $8 \mathrm{gpm}$. In other words, the filters must remove at least $8 \mathrm{gpm}$ more fluid than is being pumped into the container by the STRS.

10. Continuing to run the filter system after shutdown of the retrieval system is beneficial to reduce thermal gradient induced release of sludge to the basin. However, running the filters too long could cause the finest particles to imbed in the filters in such a way that they cannot be removed by back flushing. The report recommends running the filters for 30 minutes after shutting down the retrieval system.

\subsection{SYSTEM DESCRIPTION}

Sludge from washing spent nuclear fuel has accumulated in the KW basin Settler Tanks. This sludge will be pumped from the Settler Tanks to SCS-CON-230 at a rate of approximately 15 to $18 \mathrm{gpm}$. The sludge will flow into the container through two distributors. Sludge flow into SCSCON-230 will vary depending on the instantaneous concentration of the sludge water mixture.

SCS-CON-230 is 60 " wide by 142 " long (inside dimensions) with an "egg crate" shaped bottom. The top of the egg crate bottom is $128^{\prime \prime}$ below the top of the tank. The egg crate bottom is $26^{\prime \prime}$ tall. The container has a polycarbonate cover that is raised above the top flange of the container by approximately 1 ". The short ends and part of the adjoining long sides are open to 
the basin. The majority of each long side is closed. See Figures 1-1 through 1-6 in Attachment A for additional tank details.

Four filter assemblies containing three filter cartridges each are installed in the top of container SCS-CON-230. Each filter assembly has a flow of $7 \mathrm{gpm}$. The combined filtration system has a net flow of $28 \mathrm{gpm}$ when all four filters are operating or $21 \mathrm{gpm}$ when one of the filters is back flushing. The hydraulic analysis for the filter system is provided in KBC-39812, K Basin Settler Tank Retrieval System (STRS) Hydraulic Calculations.

The back flush sequence is initiated when the filter system reaches a preset differential pressure. Each of the four assemblies is first pulsed with back flush water briefly ( 3 seconds) to dislodge a large part of the filter cake. This helps ensure that the $21 \mathrm{gpm}$ flow rate through the system is maintained during the full back flush. The filtration control system then starts the sequence of injecting low volume ( 0.083 gallon), "high" pressure ( $80 \mathrm{psig}$ ) water pulses through each isolated filter assembly in turn. This sequence introduces pulsed flow for approximately 15 seconds at an approximate rate of 1 pulse per second. It provides an average flow rate of less than $5 \mathrm{gpm}$ ( 1.25 gallons is injected during the flush of each filter assembly). This is followed by a 2 to 3 minute wait period to allow material to fall away from the filter element before placing the element back online. The total volume of back flush water introduced into SCS-CON-230 during each backwash cycle will be approximately 5 gallons. The analysis demonstrates that, while the retrieval system is operating, sludge can only escape from the container during these brief back flushes. Sludge can also escape due to thermal gradients after the filtration system is stopped. 
PRC-STP-00011, Rev. 0

Attachment A

Attachment A

FAI/09-091, Sludge particle Separation Efficiencies for the Rectangular SCS-CON-230 Container

A - 1 
PRC-STP-00011, Rev. 0

Attachment A

WORLD LEADER IN NUCLEAR AND CHEMICAL PROGEgg SAFETY

Report No.: FAI/09-091

Sludge Particle Separation Efficiencies

for the Rectangular SCS-CON-230 Container

Submitted To:

CH2M Hill Plateau Remediation

Richland, Washington

\author{
Prepared By: \\ Michael Epstein and Martin G. Plys \\ Fauske \& Associates, LLC \\ 16W070 $83^{\text {rd }}$ Street \\ Burr Ridge, Illinois 60527
}

June, 2009 
PRC-STP-00011, Rev. 0

Attachment A

$-\mathrm{i}-$

TABLE OF CONTENTS

$\underline{\text { Page }}$

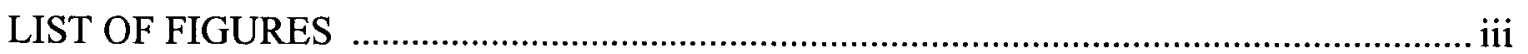

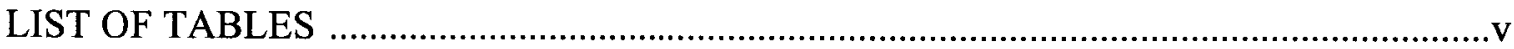

$1.0 \quad$ INTRODUCTION AND SUMMARY …………......................................1-1 of 1-9

2.0 SLUDGE-PARTICLE-LADEN PLUME DISCHARGES AND THE EVOLUTION OF THE PARTICLE CONCENTRATION IN THE

CONTAINER $.2-1$ of $2-6$

2.1 Description of Sludge-Plume-Filling-Container Problem ................................ 2-1

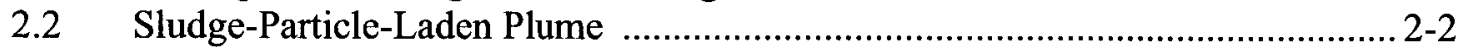

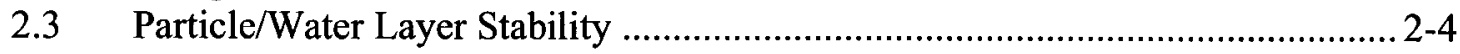

3.0 CONTAINER OUTFLOW ….....................................................................

3.1 Discussion of Container Outflow Mechanisms ............................................... 3-1

3.2 Outflow Due to Sludge Discharge Flow or Filter Back Flushing ...................... 3-3

3.3 Container Outflow Due to the Basin Current .................................................... 3-4

3.4 Outflow Induced by Container Temperature Rise Above the Basin Temperature ....................................................................................... 3-7

4.0 SLUDGE PARTICLES SEDIMENTATION, FILTRATION, AND

OUTFLOW IN CONTAINER SCS-CON-230 4-1 of $4-9$

4.1 Model Assumptions ........................................................................................... 4-1

4.2 Conversion of the Particle Size Distribution Equation to a System of Ordinary Differential Equations

$5.0 \quad$ TRANSIENT MODEL RESULTS .................................................................... $5-1$ of 5-40

5.1 Particle Size Distribution and Particle Density .............................................. 5-1

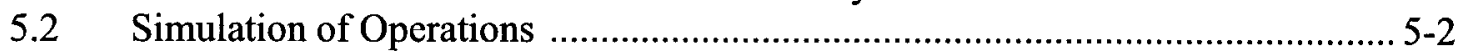

5.3 Case Selection and Input Summary ……..................................................... 5-8

5.4 Detailed Results Discussion ......................................................................... 5-9

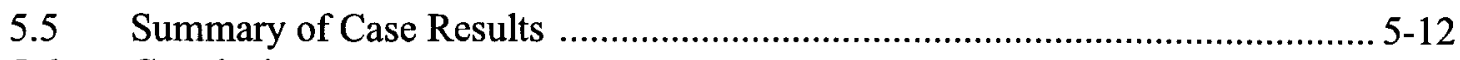

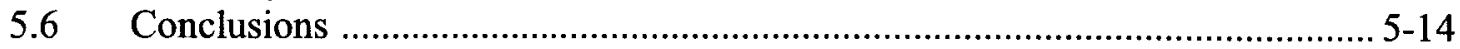

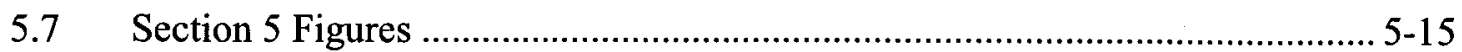

5.8 Simulation Model Implementation Notes ................................................... 5-37 
PRC-STP-00011, Rev. 0

- ii -

TABLE OF CONTENTS - (Cont'd)

Page

6.0 REFERENCES

6-1 of 6-2

APPENDIX A: $\quad$ Resuspension of Sludge Particles

A-1 of A-6

APPENDIX B: $\quad$ Gravitational Coagulation Integrals for Moment Equations .

B-1 of B-3

APPENDIX C: $\quad$ Validity of Stokes Law Particle Settling Rate

C-1 of $\mathrm{C}-2$

APPENDIX D:

Quality Assurance Documents

D-1 of D-3 


\section{LIST OF FIGURES}

Page

Figure 1-1 SCS-CON-230 lengthwise elevation and top plan views from drawing H-1-88419-03, Rev. 4 $1-4$

Figure 1-2 SCS-CON-230 widthwise elevation and gaslet plan views from drawing H-1-88419-03, Rev. 4

Figure 1-3 SCS-CON-230 top lid and gasket detail ................................................ 1-6

Figure 1-4 SCS-CON-230 lengthwise cutaway view ................................................. 1-7

Figure 1-5 SCS-CON-230 widthwise cutaway view .............................................. 1-8

Figure 1-6 SCS-CON-230 isometric cutaway view ................................................. 1-9

Figure 2-1 Model of particle plume in the container ................................................ 2-6

Figure 3-1 Countercurrent exchange flow between container and basin as function of container water temperature

Figure 3-2 Countercurrent exchange flow between basin and container for various container water temperatures above the basin temperature as function of net suction

Figure 3-3 Container water temperature history for various inlet water temperatures

Figure 5-1 PNNL particle size and data [Schmidt and Zacher, 2007] ............................ 5-15

Figure 5-2 Comparison of log-normal distributions and data .................................... 5-16

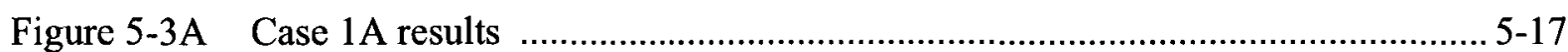

Figure 5-3B Case 1A results, continued .................................................................. 5-18

Figure 5-4A Case 1B results ................................................................................... 5-19

Figure 5-4B Case 1B results, continued ................................................................. 5-20

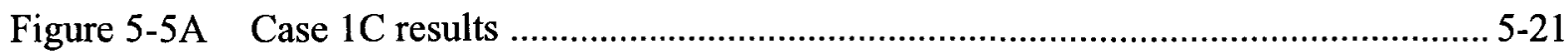

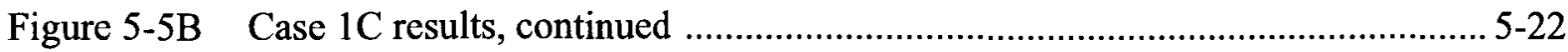


PRC-STP-00011, Rev. 0

- iv -

\section{LIST OF FIGURES - (Cont'd)}

Page

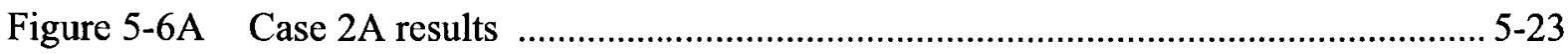

Figure 5-6B Case 2A results, continued …....................................................................... 5-24

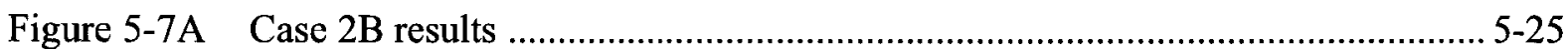

Figure 5-7B Case 2B results, continued …................................................................ 5-26

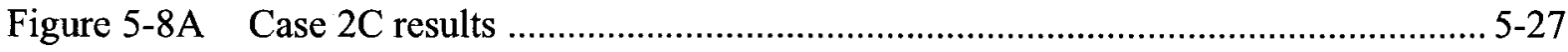

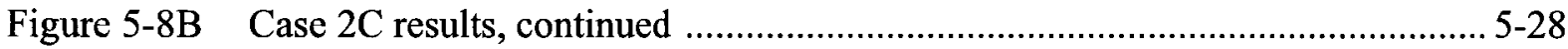

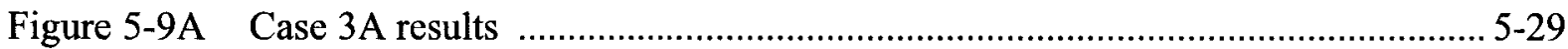

Figure 5-9B Case 3A results, continued ….............................................................. 5-30

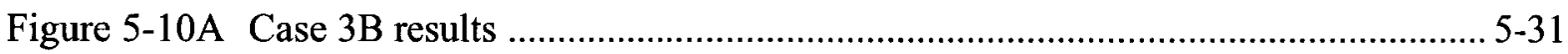

Figure 5-10B Case 3B results, continued …..................................................................... 5-32

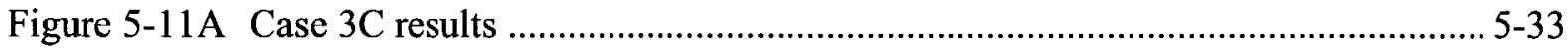

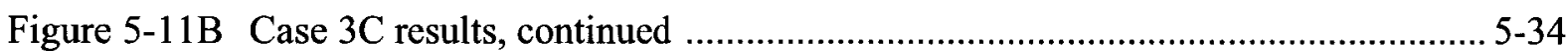

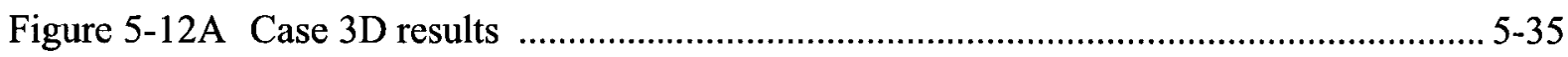

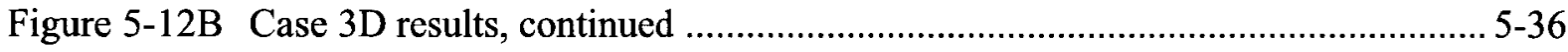


PRC-STP-00011, Rev. 0

Attachment A

$-\mathrm{v}-$

\section{LIST OF TABLES}

Page

Table 5-1 Settler Sludge Retrieval Case Summary …................................................. 5-8

Table 5-2 Particle Escape Results Summary ….......................................................... 5-12 
PRC-STP-00011, Rev. 0

Attachment A

$1-1$

\subsection{INTRODUCTION AND SUMMARY}

Sludge is to be supplied to the central region of the rectangular SCS-CON-230 container through two downward facing ports (distributors). Water is withdrawn from the tank through four vertical-cylindrical filters located in the upper region of the tank. The tank is open to the KBasin pool through a 1.0" gap along the periphery of the short sides of the tank at the top of the tank. Figures 1-1 through 1-3 provide drawings and dimensions of SCS-CON-230. Figures 1-4 through 1-6 provide useful cutaway elevation and isometric views illustrating the placement of inlet ports, filters, and the egg crate section.

When all the filters are operating the flow through the gap should be from the K-Basin pool into the tank; however, it is possible that a segment of the gap may experience outflow from the tank to the K-Basin pool, if a significant water current moves through the basin and/or if there is a temperature difference between the container water and the surrounding basin water.

The goals of the analysis described below are to quantify the fraction of the sludge particles that do not settle to the bottom of the tank but instead are intercepted by the filters and the fraction of the sludge particles that escape the tank and enter the basin due to outflow through the gap. Two cases are considered: all four filters are operating or only three filters are operating and one is backwashing.

The stated goals were accomplished as follows:

(1) An analysis of the sludge particle-laden plumes that form as a result of continuous sludge injection was made.

(2) The plume analysis was combined with a stability analysis of the particle-laden lower layer that initially forms at the bottom of the container, from which it is concluded that the container environment is in a transition zone between a stably stratified environment (particle-laden layer at the bottom and clear water above) and a well-mixed container with 
PRC-STP-00011, Rev. 0

Attachment A

a spatially uniform particle concentration. To err on the conservative side a well-mixed container was assumed.

(3) A number of physical processes that could potentially result in an outflow were examined. Only one process was identified that could result in container outflow, namely thermal convection. A thermal analysis of the container was performed which clearly indicated that the thermal convection mechanism of sludge particle escape is operative only during back washing.

(4) A uniform particle concentration model was developed in which the fraction of particles that separate at the bottom of the container depends on the relative rates of particle removal by coagulation and by sedimentation at the container bottom, by flow into the filters and by outflow through the gap. A realistic log-normal particle size distribution was incorporated into the model.

From the theoretical studies listed above, the following conclusions are drawn:

(1) The effect of a one-way flow through the basin on flow out of the container was examined and found not to be significant. The reason is that the pressure drop induced by the basin flow velocity on the downstream side of the container is less than the pressure difference required to drive inlet flow across the gap.

(2) Small temperature differences between the container water and the surrounding basin water will generate significant buoyancy-driven countercurrent flows and, therefore, container outflows, but only during back washing. During normal operation, there is no countercurrent flow unless the container water is about $3.0^{\circ} \mathrm{C}$ above the basin water temperature. A thermal analysis of the container was performed that showed that a sludge inlet temperature of slightly over $11.0^{\circ} \mathrm{C}$ relative to the basin temperature is required for the container water temperature to be $3^{\circ} \mathrm{C}$ above the basin water temperature. Therefore sludge particles can only escape the container during back flushing. 
From numerical simulations of particle behavior to simulate particle settling, particle escape, and the impact of filters, the following conclusions may be drawn:

(1) Results for long-term suspended particle volume demonstrate that daily retrieval campaigns are independent of one another with respect to the potential for particle escape. Also, results are not very sensitive to assumed idealizations of operations.

(2) Particles can only escape from the container during a filter back flush and when the water supply and suction from the container are shut off after daily operations. Most particle escape seen in simulated operations occurred after water is shut off.

(3) The most important sludge property that governs the potential for particle escape is particle density. The escape fraction for particles of average expected density $(6 \mathrm{~g} / \mathrm{cc})$ is between about $1 \%$ and $2 \%$ depending on the inlet water temperature, the escape fraction for particles of less than average expected density $(4 \mathrm{~g} / \mathrm{cc})$ is between about $2 \%$ and $6 \%$, and the escape fraction for extremely light particles $(2 \mathrm{~g} / \mathrm{cc}$ ) could range from about $8 \%$ to $13 \%$. The parameter of second interest to results is the temperature of water entering the container.

(4) It is recommended that filters be operated for at least 30 minutes after the last particle retrieval of a daily operation. Filter operation for about two hours after the last particle retrieval is also beneficial.

(5) The impact of filters is substantial; without them, about 1/3 of added particles would escape. 
PRC-STP-00011, Rev. 0

$1-4$

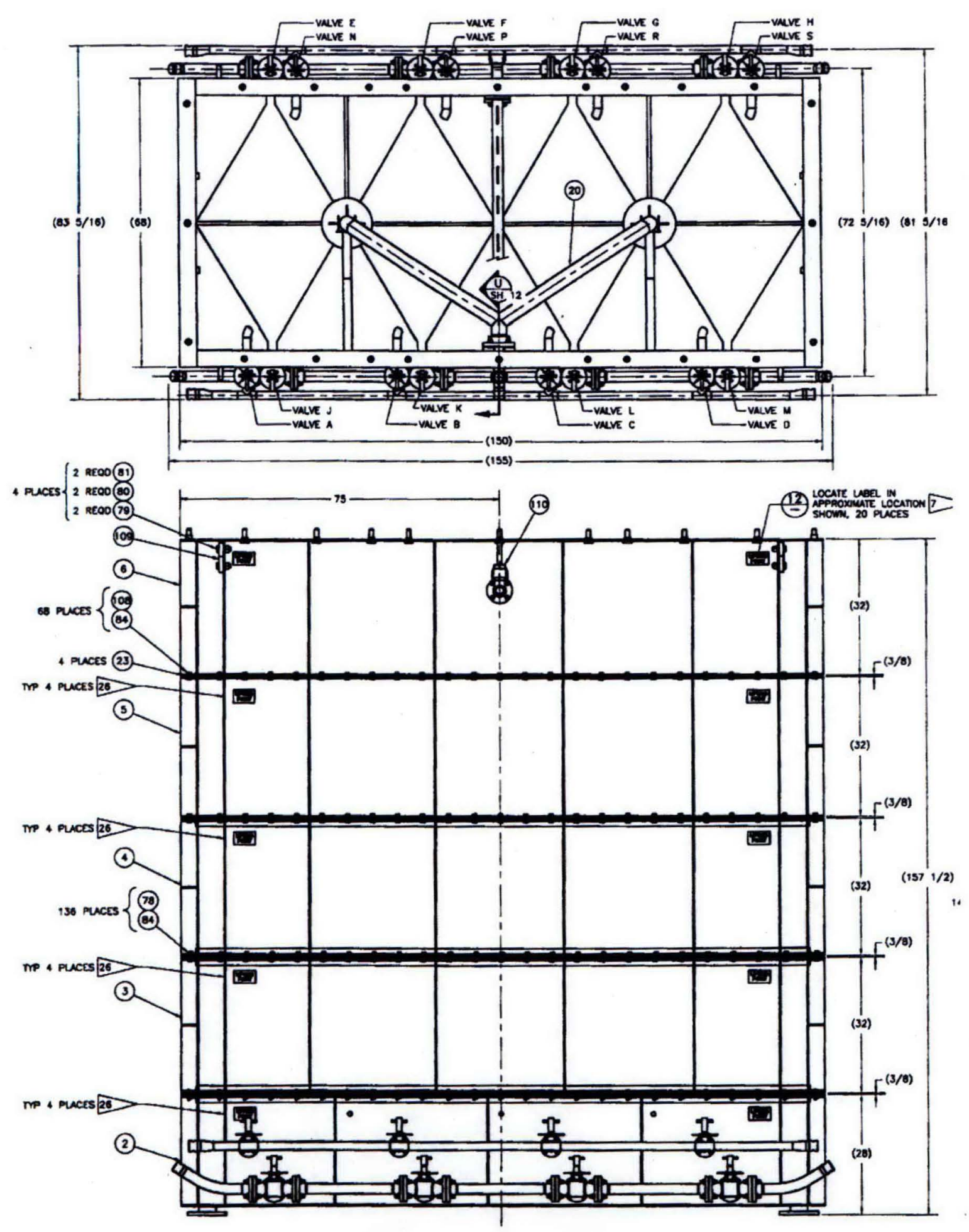

Figure 1-1 SCS-CON-230 lengthwise elevation and top plan views from drawing H-1-88419-03, Rev. 4. 


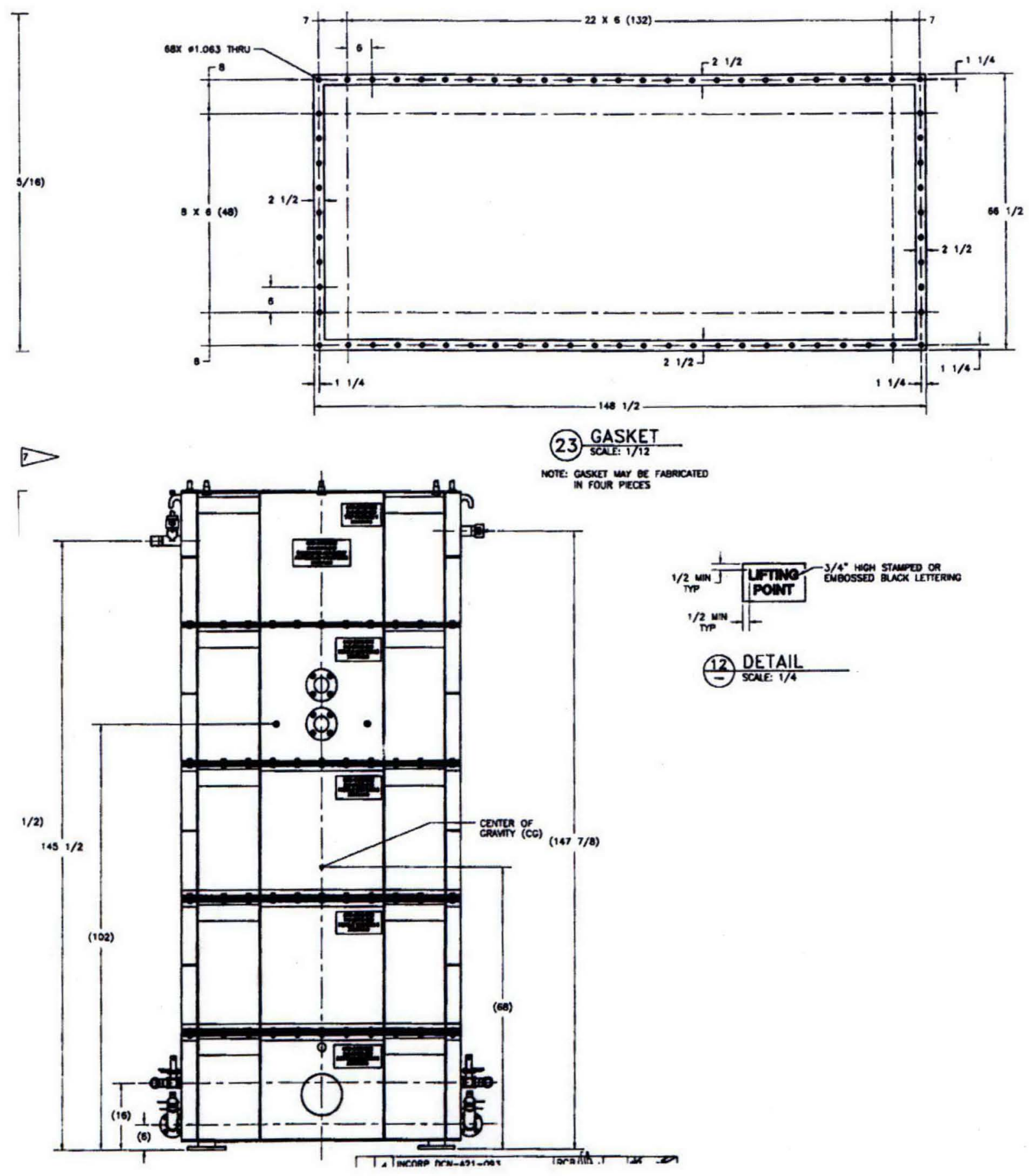

Figure 1-2 SCS-CON-230 widthwise elevation and gaslet plan views from drawing H-1-88419-03, Rev. 4. 
PRC-STP-00011, Rev. 0 Attachment A

$1-6$

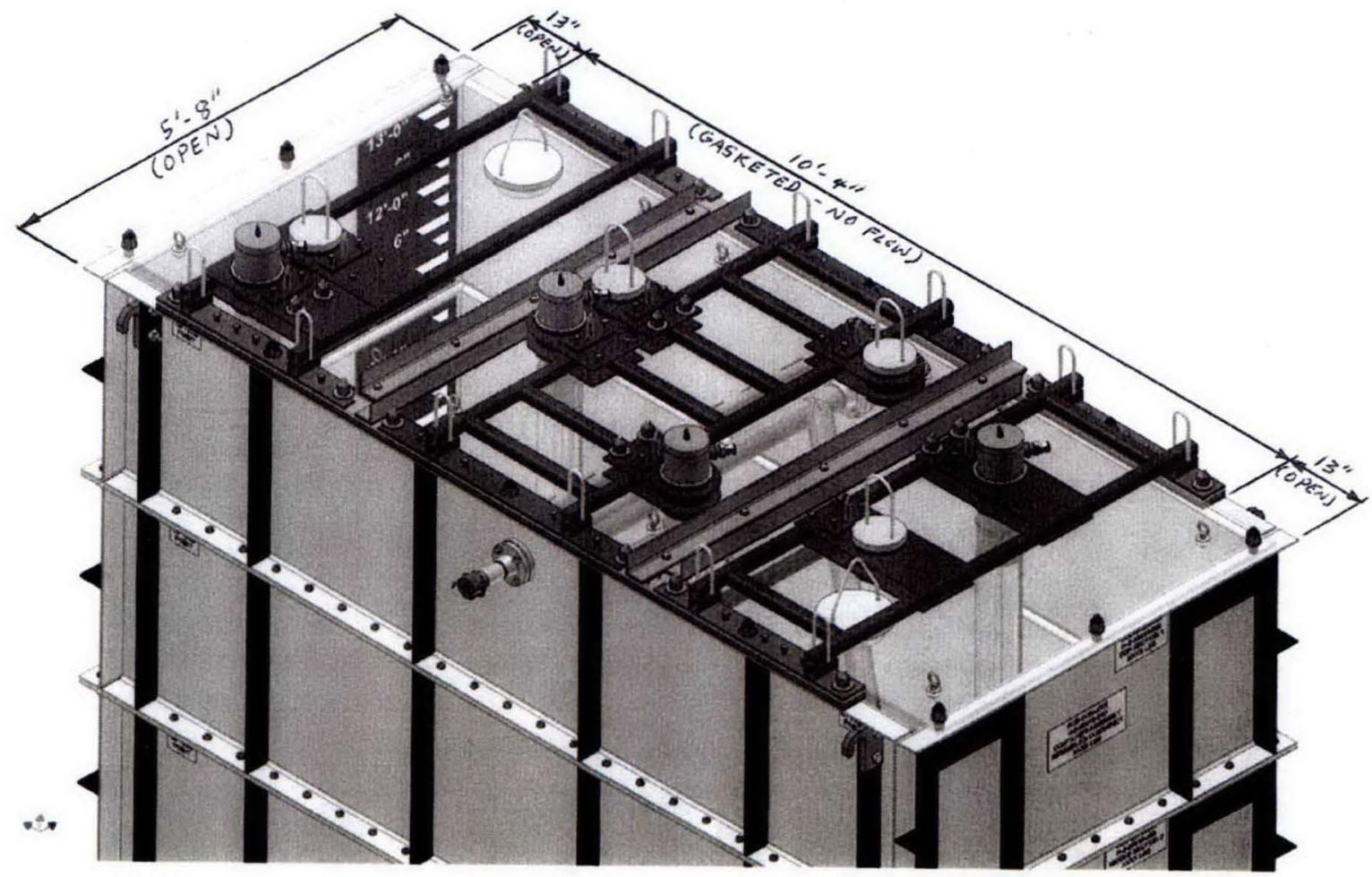

Figure 1-3 SCS-CON-230 top lid and gasket detail. 
PRC-STP-00011, Rev. 0 Attachment $\mathrm{A}$

$1-7$

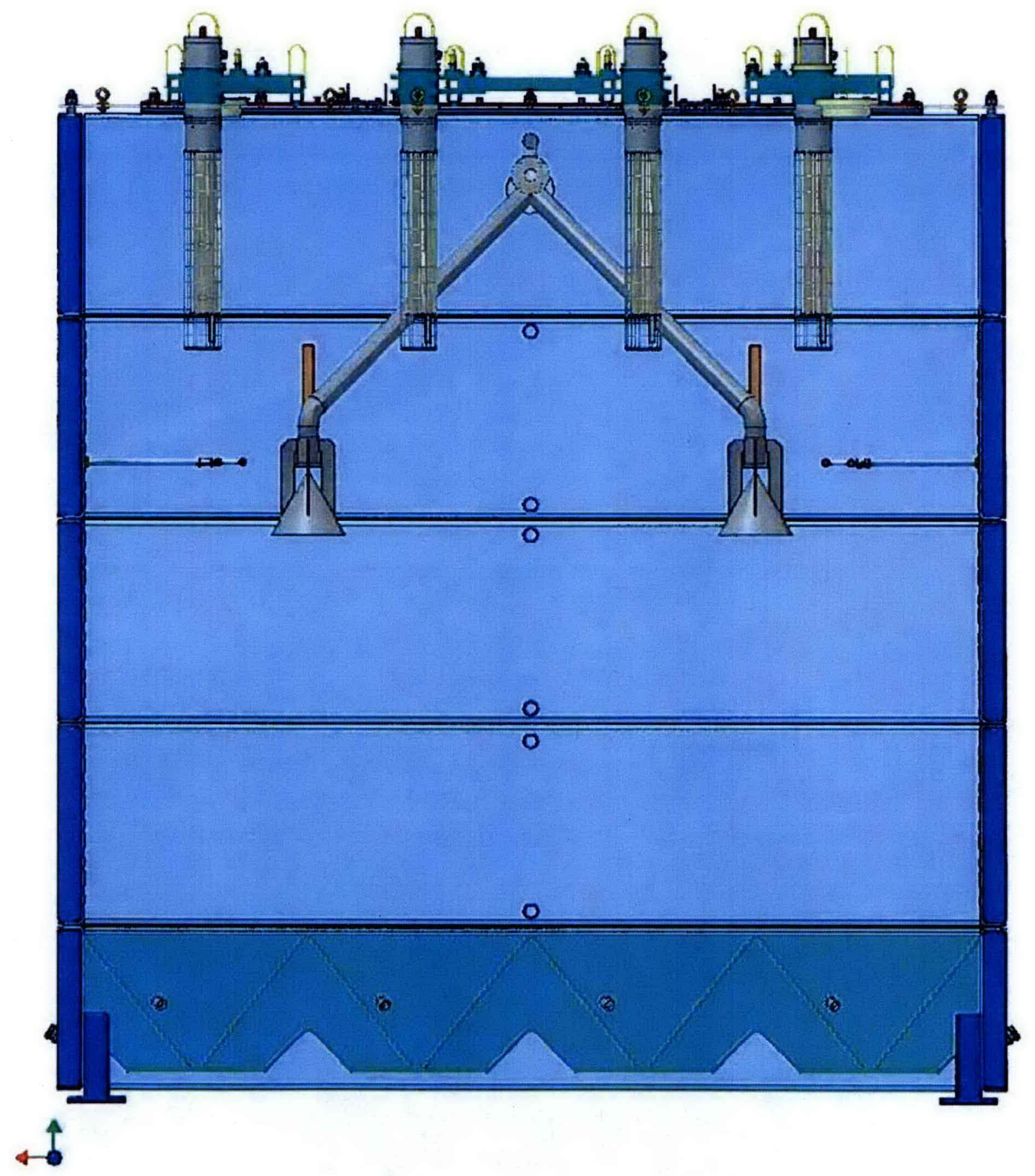

Figure 1-4 SCS-CON-230 lengthwise cutaway view. 
PRC-STP-00011, Rev. 0

Attachment A

$1-8$

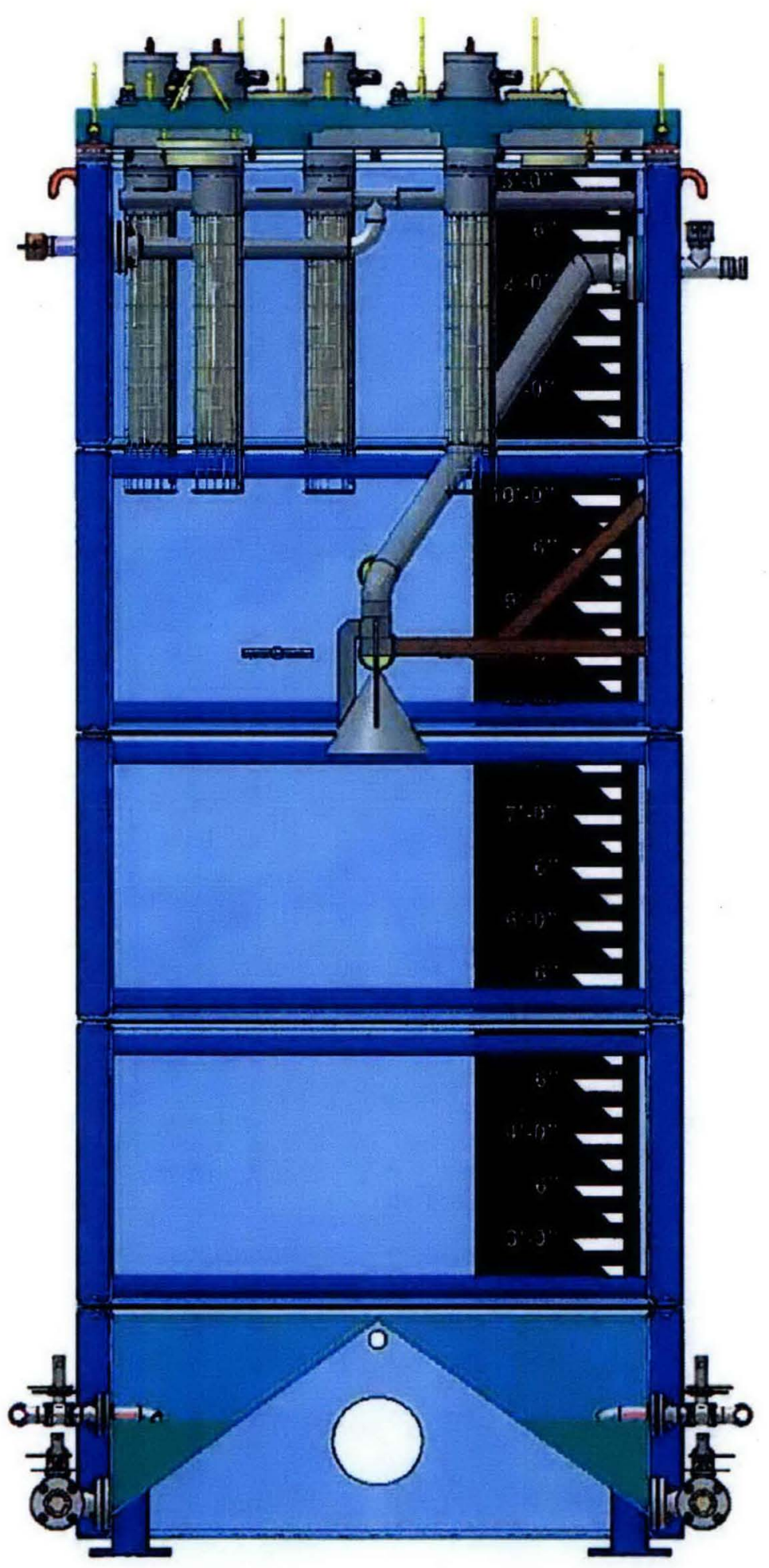

Figure 1-5 SCS-CON-230 widthwise cutaway view. 
PRC-STP-00011, Rev. 0

Attachment A

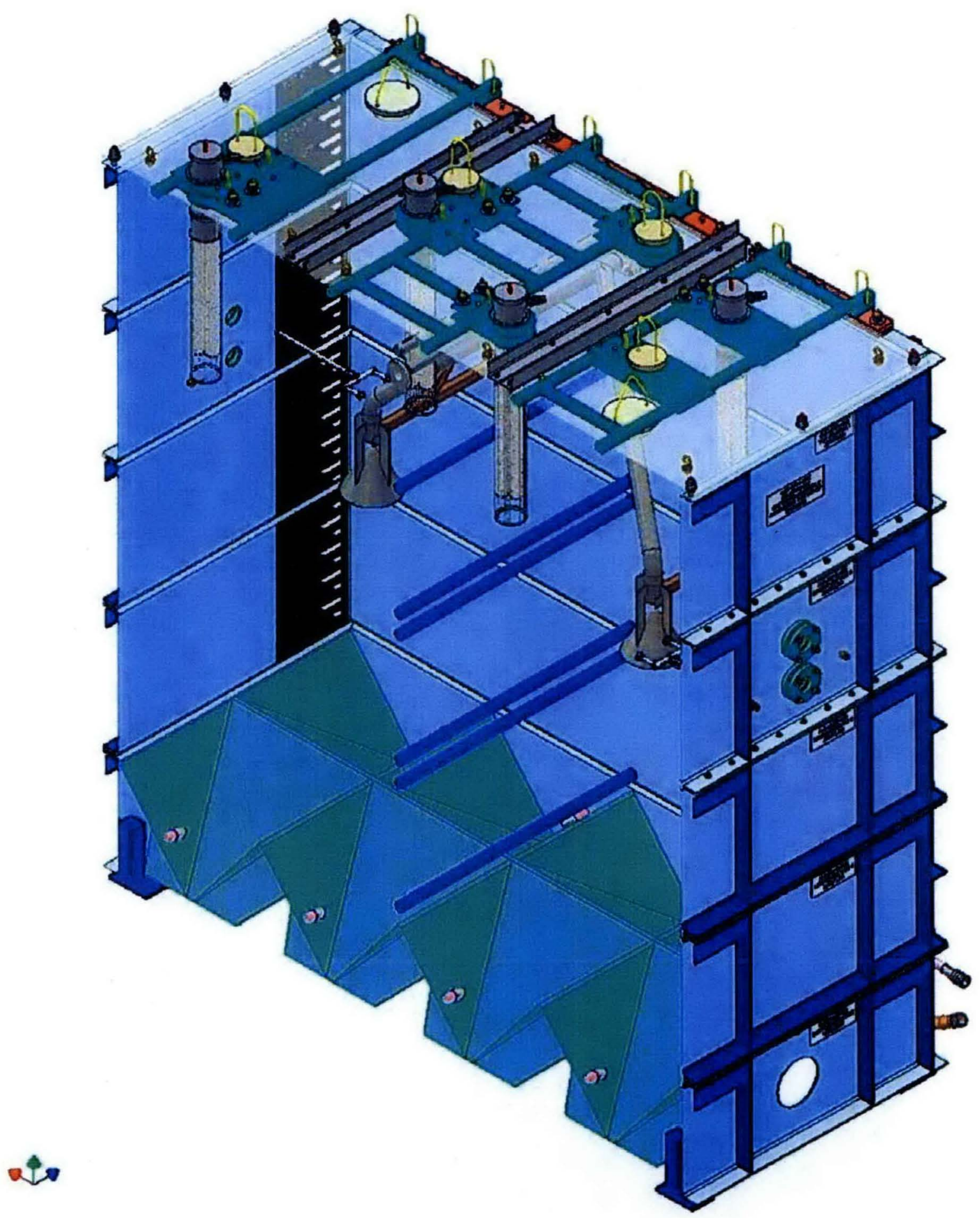

Figure 1-6 SCS-CON-230 isometric cutaway view. 
PRC-STP-00011, Rev. 0

Attachment A

\subsection{SLUDGE-PARTICLE-LADEN PLUME DISCHARGES AND THE EVOLUTION OF THE PARTICLE CONCENTRATION IN THE CONTAINER}

\subsection{Description of Sludge-Plume-Filling-Container Problem}

If the sludge discharge time is long, a plume of sludge particles and water is formed below each of the two sludge distributor ports. The plume may be regarded as a continuum of particles and water (Cary et al., 1988). The presence of the heavy sludge particles increases the bulk density of the continuum plume in comparison to the surrounding container water. Thus the emerging sludge flow has a significant downward buoyancy flux which can potentially stir the container fluid and mix the sludge particles from top to bottom of the container.

When the dense particle-laden plume discharged from one of the distributors reaches the egg crate bottom of the container, the two-phase mixture will displace the lighter water from the pockets that comprise the egg crate design and lie within the plume's impingement zone. Once the pockets are full of particle-laden water, the two phase mixture will spread out and fill the pockets that are located outside the plume's impingement zone, and will ultimately merge with the spreading two-phase mixture produced by the discharge from the other sludge distributor on the opposite of the container. The result is the formation of one coherent layer of particles and water beneath a deep layer of overlying pure container water.

The stability of the heavy layer of particles and water becomes very important in the subsequent development of the vertical distribution of sludge particles. The stable layer is defined by a distinctive interface which separates the lower particle-containing water form the upper clear water. In the stable layer there is a significant vertical variation in particle concentration, with the location of maximum particle concentration at the bottom of the layer, that is at the bottom of the container. This vertical particle concentration profile tends to enhance the particle settling rate at the bottom of the container. On the other hand, if the layer is unstable, a large scale vertical circulation is set up in the container which quickly mixes the particle/water mixture from the bottom of the container to the elevation of the sludge 
distributors. As a result of continued addition of water through the distributors and water withdrawal at the filters, the well-mixed layer will ultimately fill the entire container from top to bottom.

The stability of the lower layer of particle-laden water is examined below. The examination begins with a model of the sludge plume.

\subsection{Sludge-Particle-Laden Plume}

Consider a turbulent, axisymmetric particle-laden plume created by the downward release of a negatively buoyant (heavier than water) sludge suspension from a sludge distributor. Owing to the presence of the cone-shaped sludge deflector just below the distributor orifice, it is assumed that the plume has no initial momentum and, therefore, that the distributor acts as a point source of negative buoyancy. On leaving the source the turbulent plume entrains surrounding container water as it descends and, hence, its bulk density decreases as it descends (Figure 2-1). On the other hand, due to entrainment, the plume radius increases as it descends. With respect to plume buoyancy (negative), plume growth wins out over plume dilution and the plume gains buoyancy as it descends.

Therefore, even in the absence of the sludge particle deflector at the source, at some distance below the source the plume begins to behave as a purely buoyant plume with no initial momentum. It can be shown that the vertical distance below the sludge distributor at which the plume transitions to a point source buoyant plume is less than the distance to the settled particle layer (see, e.g., Epstein and Fauske, 2001 for a general discussion of the behavior of fluid releases with initial momentum and buoyancy). The justifiable assumption is made that the particle and water phases move with the same velocity at any point within the plume.

The plume is modeled in the usual way (Morton, Taylor and Turner, 1956). Top-hat profiles for the lateral (radial) velocity and particle concentrations distributions in the plume are assumed. The Boussinesq approximation is made which states that the plume density is constant and equal to the density of the surrounding water except in the buoyancy term of the momentum 
equation. The lateral inflow (entrainment) velocity $u_{e}$ into the plume is proportional to the vertical velocity $\mathrm{v}$ in the plume:

$$
\mathrm{u}_{\mathrm{e}}=\mathrm{E}_{0} \mathrm{v}
$$

where the empirical coefficient $\mathrm{E}_{0} \cong 0.12$ for buoyant (or negatively buoyant) plumes.

The equations expressing the conservation of volume, momentum and sludge-particle mass for an axisymmetric plume are

$$
\begin{aligned}
& \frac{d}{d z}\left(v R^{2}\right)=2 E_{0} v R \\
& \frac{d}{d z}\left(v^{2} R^{2}\right)=\frac{g\left(\rho_{s}-\rho_{f}\right)}{\rho_{f}} \alpha R^{2} \\
& \dot{m}_{s}=\pi \rho_{s} \alpha v R^{2}
\end{aligned}
$$

where $\alpha$ is the local volume fraction of the sludge particles within the plume (at vertical location $\mathrm{z}$ measured downward from the sludge distributor), $\mathrm{v}$ is the local downward plume velocity at location $\mathrm{z}, \mathrm{R}$ is the plume radius at location $\mathrm{z}, \mathrm{g}$ is the gravitational constant, $\dot{\mathrm{m}}_{\mathrm{s}}$ is the mass flow (in $\mathrm{kg} \mathrm{s}^{-1}$ ) of the sludge-solid-particles supplied to the plume at the distributor orifice, and $\rho_{\mathrm{s}}$ and $\rho_{\mathrm{f}}$ are the constant material densities of the sludge solid and the water, respectively.

It is well known that the asymptotic (point source) solutions of Eqs. (2-2) to (2-4) are expressed in terms of fractional power functions of $z$. Substituting these mathematical forms into Eqs. (2-2) to (2-4) and solving for the unknown coefficients and exponents gives

$$
v=\left(\frac{25}{48 \pi}\right)^{1 / 3}\left(\frac{b}{z}\right)^{1 / 3}
$$


PRC-STP-00011, Rev. 0

Attachment A

$$
\begin{aligned}
& \alpha=\frac{4}{3}\left(\frac{25}{48 \pi}\right)^{2 / 3} \frac{b^{2 / 3}}{g\left(\rho_{s} / \rho_{f}-1\right) z^{5 / 3}} \\
& R=\frac{6}{5} E_{0} z
\end{aligned}
$$

where

$$
\mathrm{b}=\frac{\mathrm{g}\left(\rho_{\mathrm{s}} / \rho_{\mathrm{f}}-1\right) \dot{\mathrm{m}}_{\mathrm{s}}}{\rho_{\mathrm{s}} \mathrm{E}_{0}^{2}}=\frac{\mathrm{g}\left(\rho_{\mathrm{s}} / \rho_{\mathrm{f}}-1\right) \alpha_{0} \mathrm{Q}_{0}}{\mathrm{E}_{0}^{2}}
$$

In the definition of $b$ above $\alpha_{0}$ is the volume fraction of particles in the sludge at the sludge release orifice (distributor) and $\mathrm{Q}_{0}$ is the volumetric rate of sludge flow through the distributor.

In deriving Eqs. (2-5) to (2-7) it was implicitly assumed that the cross-sectional area in a horizontal plane of the container occupied by plumes is a small fraction of the total crosssectional area of the container. That is, it was assumed that (see Eq. 2-7)

$$
\frac{2 \pi(6 / 5)^{2} E_{0}^{2} H_{d}^{2}}{A_{c}}<<1.0
$$

where the factor 2 accounts for two sludge distributor plumes, $H_{d}$ is the elevation of the sludge distributors above the egg crate $(1.9 \mathrm{~m})$ and $\mathrm{A}_{\mathrm{c}}$ is the cross-sectional area of the sludge container $\left(5.5 \mathrm{~m}^{2}\right)$. The left-hand side of Eq. (2-9) is 0.086 . This result ensures that the plume flow is uncoupled from the container wide upward displacement of water due to sludge injection and/or filter flow.

\subsection{Particle/Water Layer Stability}

The stability condition derived in this section was apparently first suggested by Baines and Turner (1969). 
PRC-STP-00011, Rev. 0

Attachment A

\section{$2-5$}

The force that stabilizes the lower particle-laden layer of water of thickness of the order of the plume radius at the bottom of the container (top of the egg crate pattern) is the buoyancy force

$$
F_{B}=A_{c} R\left(H_{d}\right) g\left(\rho_{s}-\rho_{f}\right) \alpha
$$

The vertically (downward) directed momentum (or inertial force $F_{M}$ ) due to two discharge sludge plumes entering the lower particle-laden water layer, namely,

$$
F_{M}=2 \pi\left[R\left(H_{d}\right)\right]^{2}\left[v\left(H_{d}\right)^{2}\right] \rho_{f}
$$

is the destabilizing force. Forming the ratio $F_{M} / F_{B}$ and using Eqs. (2-5) to (2-7), all evaluated at $\mathrm{z}=\mathrm{H}_{\mathrm{d}}$, yields after some algebra

$$
\frac{F_{M}}{F_{B}}=\frac{(9 / 5) \pi E_{0} H_{d}^{2}}{A_{c}}
$$

The ratio $F_{M} / F_{B}$ turns out to be strictly a function of container geometry and the location of the sludge discharge ports. The rate at which the sludge is discharged does not influence the stability of the heavy lower-layer. This is because an increase in the sludge discharge rate (or discharge momentum) is neutralized by a corresponding increase in the buoyancy (negative) of the lower particle-laden layer. The experimental work of Baines and Turner (1969) and Kumagai (1984) indicate that a transition from a stably stratified container to a vertically wellmixed container occurs as $\mathrm{F}_{\mathrm{M}} / \mathrm{F}_{\mathrm{B}}$ increases from about 0.25 to 0.7 . For the container SCS-CON230 the ratio $F_{M} / F_{B}=0.45$. The conclusion to be drawn from this result is that the container is partially mixed, in the sense that a semi-stably stratified layer exists at the bottom of the container, but waves grow at the interface at the top of the layer and overturn to release particles to the upper portion of the container. To err on the conservative side, a well-mixed container with a spatially uniform particle concentration distribution is assumed. 
PRC-STP-00011, Rev. 0

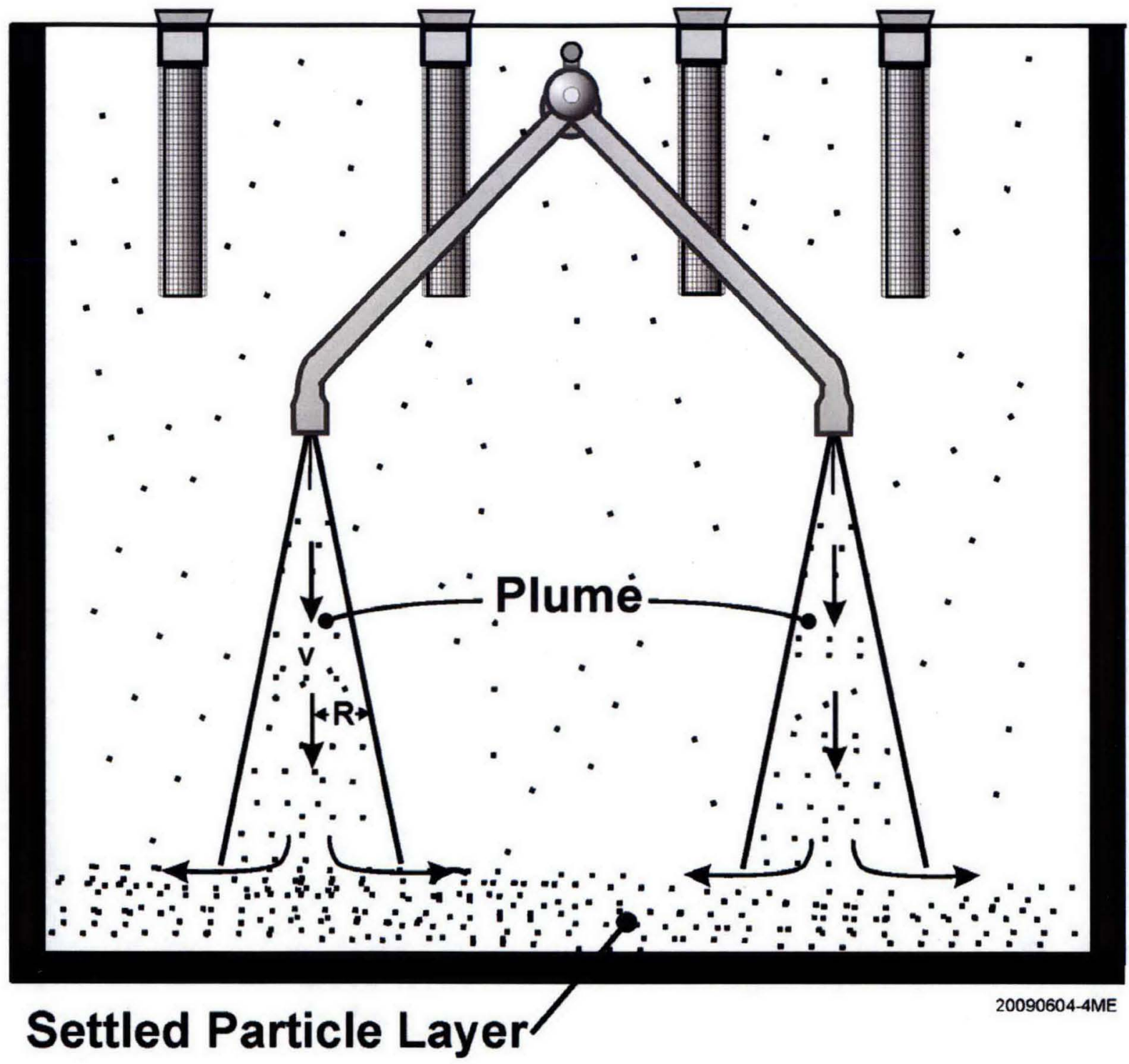

Figure 2-1 Model of particle plume in the container. 
PRC-STP-00011, Rev. 0

Attachment A

\section{3-1}

\subsection{CONTAINER OUTFLOW}

\subsection{Discussion of Container Outflow Mechanisms}

Suppose all four filters are operating and the flow through the gap is everywhere inward. Denoting the sink flow into each filter by the symbol $\mathrm{Q}_{\mathrm{fl}}\left(\right.$ in $\left.^{3} \mathrm{~s}^{-1}\right)$ and the sludge source flow at each of the two distributors by the symbol $\mathrm{Q}_{0}$ the net withdrawal (suction) rate of water $\mathrm{Q}_{\text {suc }}$ within the container is

$$
\mathrm{Q}_{\mathrm{suc}}=4 \mathrm{Q}_{\mathrm{fl}}-2 \mathrm{Q}_{0} \quad \text { (no back flush) }
$$

During back flush, one of the four filters is adding water to the container at the rate $Q_{\mathrm{fl}, \mathrm{bf}}$. In this case water is being withdrawn from the container at the net rate

$$
\mathrm{Q}_{\mathrm{suc}}=3 \mathrm{Q}_{\mathrm{fl}}-\mathrm{Q}_{\mathrm{fl}, \mathrm{bf}}-2 \mathrm{Q}_{0} \quad \text { (back flush) }
$$

This suction rate must equal the flow into the gap which, in accord with the Bernoulli equation, is

$$
Q_{\text {suc }}=C_{D} A_{g}\left[\frac{2\left(P_{\infty}-P_{c}\right)}{\rho_{f}}\right]^{1 / 2}
$$

where $C_{D}$ is the "orifice" coefficient for the gap flow, $A_{g}$ is the flow area of the gap, $P_{\infty}$ is the pressure in the basin water surrounding the gap, $P_{c}$ is the effective uniform pressure within the container and $\rho_{f}$ is the density of water. Solving Eq. (3-3) for $P_{\infty}-P_{c}$ yields

$$
P_{\infty}-P_{c}=\frac{1}{2} \rho_{f}\left(\frac{Q_{\text {suc }}}{C_{D} A_{g}}\right)^{2}
$$


It is of interest to evaluate the magnitude of the pressure drop $\mathrm{P}_{\infty}-\mathrm{P}_{\mathrm{c}}$. Consider first the case of no back flush. The flow into each filter is $\mathrm{Q}_{\mathrm{fl}}=4.42 \times 10^{-4} \mathrm{~m}^{3} \mathrm{~s}^{-1}(7.0 \mathrm{gpm})$ and the sludge source flow at each distributor is $Q_{0}=4.73 \times 10^{-4} \mathrm{~m}^{3} \mathrm{~s}^{-1}(7.5 \mathrm{gpm})$. Thus the net suction flow from Eq. (3-1) is

$$
\mathrm{Q}_{\text {suc }}=8.20 \times 10^{-4} \mathrm{~m}^{3} \mathrm{~s}^{-1}(13.0 \mathrm{gpm}) \quad \text { (no back flush) }
$$

The area of the $1.0 \times 156.0 \mathrm{in}^{2}$ gap is $\mathrm{A}_{\mathrm{g}}=0.1 \mathrm{~m}^{2}$. Thus from Eq. (3-4) with $\mathrm{C}_{\mathrm{D}}=0.7$ (see, e.g., Steckler et al., 1984) and $\rho_{\mathrm{f}}=10^{3} \mathrm{~kg} \mathrm{~m}^{-3}$

$$
\mathrm{P}_{\infty}-\mathrm{P}_{\mathrm{c}}=6.89 \times 10^{-2} \mathrm{~Pa} \quad \text { (no back flush) }
$$

When back flush occurs $\mathrm{Q}_{\mathrm{fl}, \mathrm{b}}=3.15 \times 10^{-4} \mathrm{~m}^{3} \mathrm{~s}^{-1}(5.0 \mathrm{gpm})$ and from Eq. (3-2)

$$
\mathrm{Q}_{\mathrm{suc}}=6.31 \times 10^{-5} \mathrm{~m}^{3} \mathrm{~s}^{-1}(1.0 \mathrm{gpm}) \quad \text { (back flush) }
$$

The pressure drop across the gap is now

$$
\mathrm{P}_{\infty}-\mathrm{P}_{\mathrm{c}}=4.06 \times 10^{-4} \mathrm{~Pa} \quad \text { (back flush) }
$$

Indeed the pressure in the container with or without back flush is only slightly below that just outside the gap in the basin water. These results suggest a number of physical processes that could potentially result in an outflow either locally or over the entire gap. These are

(1) The sludge inlet flow may locally reverse the inflow.

(2) Back flushing a filter that is close to the gap may locally overwhelm the inflow.

(3) A streaming motion of basin water around the container may cause the pressure on the downstream side of the container to drop below $\mathrm{P}_{c}$, potentially causing outflow on the downstream side. 
PRC-STP-00011, Rev. 0

Attachment A

(4) A sufficiently high temperature difference between the surrounding basin water and the container water will result in a buoyantly driven outflow over the entire length of the gap.

\subsection{Outflow Due to Sludge Discharge Flow or Filter Back Flushing}

Process 1 does not result in an outflow. The sludge distributors are too far away from the gap to have an effect on the flow in the vicinity of the gap. This can be demonstrated by treating a sludge distributor as a point source for which the radial velocity field $v_{r}$ is given by the simple formula

$$
\mathrm{v}_{\mathrm{r}}=\frac{\mathrm{Q}_{0}}{4 \pi \mathrm{r}^{2}}
$$

where $\mathrm{r}$ is the radial distance from the distributor. From Bernoulli's equation the pressure field surrounding the distributor is

$$
\mathrm{P}=\mathrm{P}_{\mathrm{c}}-\frac{1}{2} \rho \mathrm{v}_{\mathrm{r}}^{2}=\mathrm{P}_{\mathrm{c}}-\frac{1}{2} \rho\left(\frac{\mathrm{Q}_{0}}{4 \pi \mathrm{r}^{2}}\right)^{2}
$$

The pressure rises to within $0.01 \%$ of $P_{c}$ in a radial distance of only about $0.01 \mathrm{~m}$. Thus the sludge flow into the tank has a negligible effect on pressure drop and flow in the vicinity of the gap.

Much like the sludge distributors, the influence of the two-dimensional line source flow from a filter during back flush can be shown to diminish to zero a few centimeters away from the filter. Thus it is reasonable to assume that the container pressure $P_{c}$ is below the surrounding basin pressure everywhere in the container. In other words, the normal operation of the filters and the sludge distributors will not by itself result in outflow. 
PRC-STP-00011, Rev. 0

Attachment A

\subsection{Container Outflow Due to the Basin Current}

The basin current gives rise to a pressure distribution along the outside surface of the container. The wake that forms on the downstream side of the container is mainly responsible for this distribution. The current is known to flow normal to one of the small sides of the container (hereafter referred to as the upstream side). A simple pressure distribution is assumed. The pressure along the upstream side and along the essentially sealed (no gap) large sides of the container, which are parallel to the current, is the basin pressure $\mathrm{P}_{\infty}$. On the downstream side (end surface) of the container the pressure $P_{d}$ is

$$
P_{d}=P_{\infty}-\frac{K}{2} \rho_{f} u_{\infty}^{2}
$$

where $\mathrm{u}_{\infty}$ is the basin current velocity and $\mathrm{K}$ is a constant whose value is between zero and unity. The basin cross-flow velocity can be bounded by a value of $u_{\infty}=10^{-3} \mathrm{~m} \mathrm{~s}^{-1}$. This is based upon assuming $120 \mathrm{gpm}$ flow through a basin bay through a cross-sectional area defined by 30 feet wide (less than the approximately 40 feet width of a bay) and 3 feet deep (the container top is submerged by about 2.5 feet). The actual cross-flow value is likely lower. Measurements of pressure distributions around a circular cylinder indicate that $\mathrm{K} \cong 0.75$ (Churchill, 1988). We will assume that this value is valid for the rectangular container. Thus from Eq. (3-11) the pressure drop across the outside of the container, from the upstream side to the downstream side, is $\mathrm{P}_{\infty}-\mathrm{P}_{\mathrm{d}}=3.75 \times 10^{-4} \mathrm{~Pa}$, and from Eqs. (3-6) and (3-8)

$$
\begin{array}{lr}
P_{d}-P_{c}=6.83 \times 10^{-2} \mathrm{~Pa} & \text { (no back flush) } \\
P_{d}-P_{c}=3.12 \times 10^{-5} \mathrm{~Pa} & \text { (back flush) }
\end{array}
$$

Since $P_{\infty}>P_{d}>P_{c}$ no flow leaves the container through the gap along the upstream side and no flow leaves the container through the gap along the downstream side. 
PRC-STP-00011, Rev. 0

Attachment $A$

The critical basin flow velocity $u_{\infty, c r}$ above which flow will enter the gap of area $A_{g} / 2$ along the downstream end is obtained by setting $P_{d}$ in Eq. (3-11) equal to $P_{c}$ in Eq. (3-3) and solving the result for $u_{\infty}$ :

$$
u_{\infty, c r}=\frac{1}{K^{1 / 2}}\left(\frac{2 Q_{\text {suc }}}{C_{D} A_{g}}\right)
$$

The predicted critical basin flow velocities are $u_{\infty, \mathrm{cr}}=2.08 \times 10^{-3} \mathrm{~m} \mathrm{~s}^{-1}$ with back flushing and $\mathrm{u}_{\infty, \mathrm{cr}}=2.71 \times 10^{-2}$ with no back flushing. Both of these estimates are above the basin cross flow velocity $\mathrm{u}_{\infty}=10^{-3} \mathrm{~m} \mathrm{~s}^{-1}$.

Because of the basin current the flow into the upstream end of the container will be somewhat higher than the flow into the downstream end. A volume flow rate balance on the container provides the following equation:

$$
C_{D}\left(\frac{A_{g}}{2}\right)\left[\frac{2\left(P_{\infty}-P_{c}\right)}{\rho_{f}}\right]^{1 / 2}+C_{D}\left(\frac{A_{g}}{2}\right)\left[\frac{2\left(P_{d}-P_{c}\right)}{\rho_{f}}\right]^{1 / 2}=Q_{s u c}
$$

The first and second terms in the above equation are, respectively, Bernoulli's equation for flow into the upstream-end gap of area $1 / 2 \mathrm{~A}_{\mathrm{g}}$ and Bernoulli's equation for flow into the downstreamend gap of area 1/2 $A_{g}$. Eliminating $P_{d}$ between Eqs. (3-11) and (3-15) yields the following equation for $\mathrm{P}_{\infty}-\mathrm{P}_{\mathrm{c}}$ in dimensionless form

$$
\mathrm{x}+\left(\mathrm{x}^{2}-\mathrm{K}\right)^{1 / 2}=\mathrm{q}
$$

where

$$
x=\frac{\left[2\left(P_{\infty}-P_{c}\right) / \rho_{f}\right]^{1 / 2}}{u_{\infty}}
$$


PRC-STP-00011, Rev. 0

Attachment A

$$
q=\frac{2 Q_{\text {suc }}}{C_{D} A_{g} u_{\infty}}
$$

Physical solutions to Eq. (3-16) for $x$ obey the condition $u_{\infty} \leq u_{\infty, c r}$ (or, equivalently, $q>K^{1 / 2}$ ). Solving Eq. (3-16) for $\mathrm{x}$ yields

$$
x=\frac{q}{2}+\frac{K}{2 q}
$$

Once $\mathrm{x}$ is obtained from Eq. (3-19), the flows into the container are

$$
\begin{aligned}
& Q_{\text {suc }, u}=C_{D}\left(\frac{A_{g}}{2}\right)\left[\frac{2\left(P_{\infty}-P_{c}\right)}{\rho_{f}}\right]^{1 / 2}=C_{D}\left(\frac{A_{g}}{2}\right) u_{\infty} x \\
& Q_{\text {suc }, d}=C_{D}\left(\frac{A_{g}}{2}\right)\left[\frac{2\left(P_{c}-P_{d}\right)}{\rho_{f}}\right]^{1 / 2}=C_{D}\left(\frac{A_{g}}{2}\right) u_{\infty}\left(x^{2}-K\right)^{1 / 2}
\end{aligned}
$$

where the subscripts suc, $u$ and suc,d, refer to the upstream and downstream inlet flows. As already mentioned, the appropriate parameter values for insertion into Eqs. (3-18) to (3-21) are $A_{g}=0.1 \mathrm{~m}^{2}, C_{D}=0.7, u_{\infty}=10^{-3} \mathrm{~m} \mathrm{~s}^{-1}$, and $\mathrm{K}=0.75$. If all the filters are operating the net withdrawal rate of water in the container is, as previously calculated, $Q_{\text {suc }}=8.20 \times 10^{-4} \mathrm{~m}^{3} \mathrm{~s}^{-1}$ (see Eq. 3-5). During back flush, one of the four filters is adding water to the container and water is being withdrawn from the container at the net rate $Q_{\text {suc }}=6.31 \times 10^{-5} \mathrm{~m}^{3} \mathrm{~s}^{-1}$ (see Eq. 3-7). The dimensionless suction rates for the case of all filters operating and for back flushing are respectively $\mathrm{q}=23.5$ and $\mathrm{q}=1.84$.

The corresponding dimensionless container pressures for no back flush and back flush are, from Eq. (3-19), $x=11.8$ and $x=1.12$. From Eqs. (3-20) and (3-21) the basin flow rates through the upstream and downstream sides of the container when all four filters are operating are essentially equal to one another and are 
PRC-STP-00011, Rev. 0

Attachment A

$$
\mathrm{Q}_{\mathrm{suc}, \mathrm{u}}=4.11 \times 10^{-4} \mathrm{~m}^{3} \mathrm{~s}^{-1} \quad, \quad \mathrm{Q}_{\text {suc }, \mathrm{d}}=4.10 \times 10^{-4} \mathrm{~m}^{3} \mathrm{~s}^{-1} \quad \text { (no back flush) }
$$

For the back flush case there is a difference between the upstream and downstream inlet flows.

$$
Q_{s u c, u}=3.88 \times 10^{-5} \mathrm{~m}^{3} \mathrm{~s}^{-1} \quad, \quad Q_{\text {suc }, \mathrm{d}}=2.43 \times 10^{-5} \mathrm{~m}^{3} \mathrm{~s}^{-1} \quad \text { (back flush) }
$$

\subsection{Outflow Induced by Container Temperature Rise Above the Basin Temperature}

The temperature of the container can be higher than that of the basin because of pumping power and the perhaps because of water sources used for sludge retrieval. The container water temperature is driven by the inlet flow rate and supply temperature (this is the water source from the settlers), the net suction flow rate into the container (which carries in water at the basin temperature), and by convective heat transfer through the container walls. Decay power can be shown to be negligible when the inlet water temperature is more than about $1{ }^{\circ} \mathrm{C}$ above the basin temperature. In the discussion that follows, the container water temperature is assumed to be greater than the basin water temperature, but the induced flow depends only on the absolute value of the temperature difference, not its sign.

The flow induced by container-to-basin temperature differences is a counter-current natural exchange flow. Warmer, slightly less dense water inside the container flows outward through the gap and is replaced by cooler, slightly more dense water from the basin. The counter-current flow can be prevented or "purged" by a sufficiently strong pressure-induced upstream- or downstream suction flow into the container, $\mathrm{q}_{\mathrm{p}}$. The relationship between suction flow that prevents counter-current flow and the container-basin temperature difference $\Delta \mathrm{T}$ is given by (Epstein and Kenton, 1989):

$$
\mathrm{q}_{\mathrm{p}}=\frac{2 \mathrm{C}_{\mathrm{D}}}{3}\left[2\left(\mathrm{~A}_{\mathrm{g}} / 2\right)^{2} \delta_{\mathrm{g}} \mathrm{g} \beta \Delta \mathrm{T}\right]^{1 / 2}
$$


where $\delta_{g}$ is the height of the gap $(0.0254 \mathrm{~m})$, $\mathrm{g}$ is the acceleration of gravity, and $\beta$ is the coefficient of thermal expansion $\left(\beta=2.07 \times 10^{-4} \mathrm{~K}^{-1}\right)$. Solving for $\Delta \mathrm{T}$ gives the temperature difference above which countercurrent exchange flow will appear in the gap:

$$
\Delta T=\frac{9 q_{p}^{2}}{2 C_{D}^{2} A_{g}^{2} \delta_{g} g \beta}
$$

During normal operation $\mathrm{q}_{\mathrm{p}}$ is the suction flow rate through the upstream or downstream gap $\left(4.13 \times 10^{-4} \mathrm{~m}^{3} \mathrm{~s}^{-1}\right.$, see Eq. 3-22) and from Eq. (3-25) we estimate that countercurrent outflow requires the container water temperature to be $\Delta \mathrm{T}=3^{\circ} \mathrm{C}$ above the basin water temperature. During back flush, $\mathrm{q}_{\mathrm{p}}=\mathrm{Q}_{\text {suc, }}=2.61 \times 10^{-5} \mathrm{~m}^{3} \mathrm{~s}^{-1}$, and outflow through the downstream gap will occur when the temperature in the container is only $\Delta \mathrm{T}=0.012^{\circ} \mathrm{C}$ above the basin value.

When there is no pressure-driven flow (no suction) at all, the counter-current flow rate attains its maximum value given by

$$
\mathrm{Q}_{\mathrm{cco}}=\frac{\mathrm{C}_{\mathrm{D}}}{3}\left[\left(\mathrm{~A}_{\mathrm{g}} / 2\right)^{2} \delta_{\mathrm{g}} \mathrm{g} \beta \Delta \mathrm{T}\right]^{1 / 2}
$$

When the suction flow is less than the purge flow, $0<\mathrm{Q}_{\text {suc }}<\mathrm{q}_{\mathrm{p}}$, the counter-current exchange flow rate is given by

$$
Q_{c c}=Q_{c c o}\left(1-\frac{Q_{\text {suc }}}{q_{p}}\right)^{3 / 2}
$$

The counter-current flow rate as a function of container water temperature rise above the basin is shown in Fig. 3-1. Again the value of suction flow $\mathrm{Q}_{\text {suc }}=13 \mathrm{gpm}$ during normal operation, and $\mathrm{Q}_{\mathrm{suc}}=1 \mathrm{gpm}$ during back flush. As noted in the foregoing, during normal operation there is no counter-current flow until the container water temperature is $3{ }^{\circ} \mathrm{C}$ above the basin value. 
It is more instructive to examine the counter-current exchange flow that can occur for various values of the net suction flow. In Fig. 3-2, the value of $Q_{\text {suc }}$ is varied between 1 and 15 gpm, and the counter-current exchange flow is plotted for various values of the temperature difference between the container and basin. In the construction of Fig. 3-2 the temperature difference was related to the value of $\mathrm{q}_{\mathrm{p}}$ via Eq. (3-24). The flows are nonzero when the suction flow is less than the threshold value for purging.

Figure 3-2 can be used to choose a container suction flow that will prevent escape of sludge particles for a given container water temperature. The next step is to examine possible values of container water temperatures. Container water temperature $T_{w c}$ evolves according to the following energy balance:

$$
\rho_{f} c_{p f} \frac{d\left(T_{w c}-T_{\infty}\right)}{d t}=\rho_{f} c_{p f}\left(2 Q_{o}\right)\left(T_{o}-T_{\infty}\right)-\rho_{f} c_{p f}\left(4 Q_{f}+Q_{c c}\right)\left(T_{w c}-T_{\infty}\right)-h A_{w c}\left(T_{w c}-T_{\infty}\right)
$$

where $T_{\infty}$ is the basin water temperature, $T_{o}$ is the inlet water temperature, $\rho_{f}=1000 \mathrm{~kg} / \mathrm{m}^{3}$ and $c_{\mathrm{pf}}=4184 \mathrm{~J} / \mathrm{kg} / \mathrm{K}$ are the water density and specific heat, respectively, $Q_{o}$ and $Q_{f l}$ are the inlet and filter flows per inlet and filter, respectively, $Q_{c c}$ is the total counter-current flow through the upstream and downstream gaps, $A_{w c}$ is the container wall area, the heat transfer coefficient for natural convection is given by

$$
h=0.103 k_{f}\left(\frac{g \beta\left(T_{w c}-T_{\infty}\right)}{v_{f} \alpha_{f}}\right)^{1 / 3}
$$

and additional properties appearing are thermal conductivity $\mathrm{k}_{\mathrm{f}}=0.60 \mathrm{~W} / \mathrm{m} / \mathrm{K}$, kinematic viscosity $v_{\mathrm{f}}=10^{-6} \mathrm{~m}^{2} / \mathrm{s}$, and thermal diffusivity $\alpha_{\mathrm{f}}=1.4 \times 10^{-7} \mathrm{~m}^{2} / \mathrm{s}$.

Container water temperature versus time is shown for various assumed inlet water temperatures in Fig. 3-3. Note that even if the inlet water temperature is $5{ }^{\circ} \mathrm{C}$ above the basin, 
the container water temperature is only $1.5^{\circ} \mathrm{C}$ above the basin. In fact, an inlet temperature of slightly over $11{ }^{\circ} \mathrm{C}$ above the basin is required for the basin water temperature to be $3{ }^{\circ} \mathrm{C}$ above the basin value. This does not seem realistic, and strongly suggests that counter-current flow cannot occur during normal operations, only during back flushing. Finally, note that the time scale to attain steady container water temperature is about 5 hours.

The following conclusions may be drawn from this discussion:

(1) For the given water addition, filter flow, and back flush flow rates, sludge particle loss from SCS-CON-230 is not credible except by thermal convection during back flushing. This is based on demonstrating that it is not credible for the container inlet water temperature to be consistently $11^{\circ} \mathrm{C}$ or more greater than the basin temperature.

(2) For an assumed bounding inlet water temperature $4{ }^{\circ} \mathrm{C}$ above the basin temperature, the water container temperature will be about $1.2{ }^{\circ} \mathrm{C}$ above the basin temperature, and this will be attained on a time scale that is short compared to the filling time. Counter-current flow will occur during back flushing. Sludge particle loss to the basin is expected during back flushing.

(3) Sludge particle loss from the container can be prevented by maintaining a net container suction flow of $8 \mathrm{gpm}$ if the bounding container inlet water temperature is $4{ }^{\circ} \mathrm{C}$ above the basin temperature (which leads to a container temperature about $1.2^{\circ} \mathrm{C}$ above the basin).

(4) For operation periods during which particles are settling in the container but no retrieval is occurring, continued water supply and filter operation might be beneficial because this maintains net suction from the basin and prevents particle escape due to counter-current flow except in the event of a backflush. 
PRC-STP-00011, Rev. 0

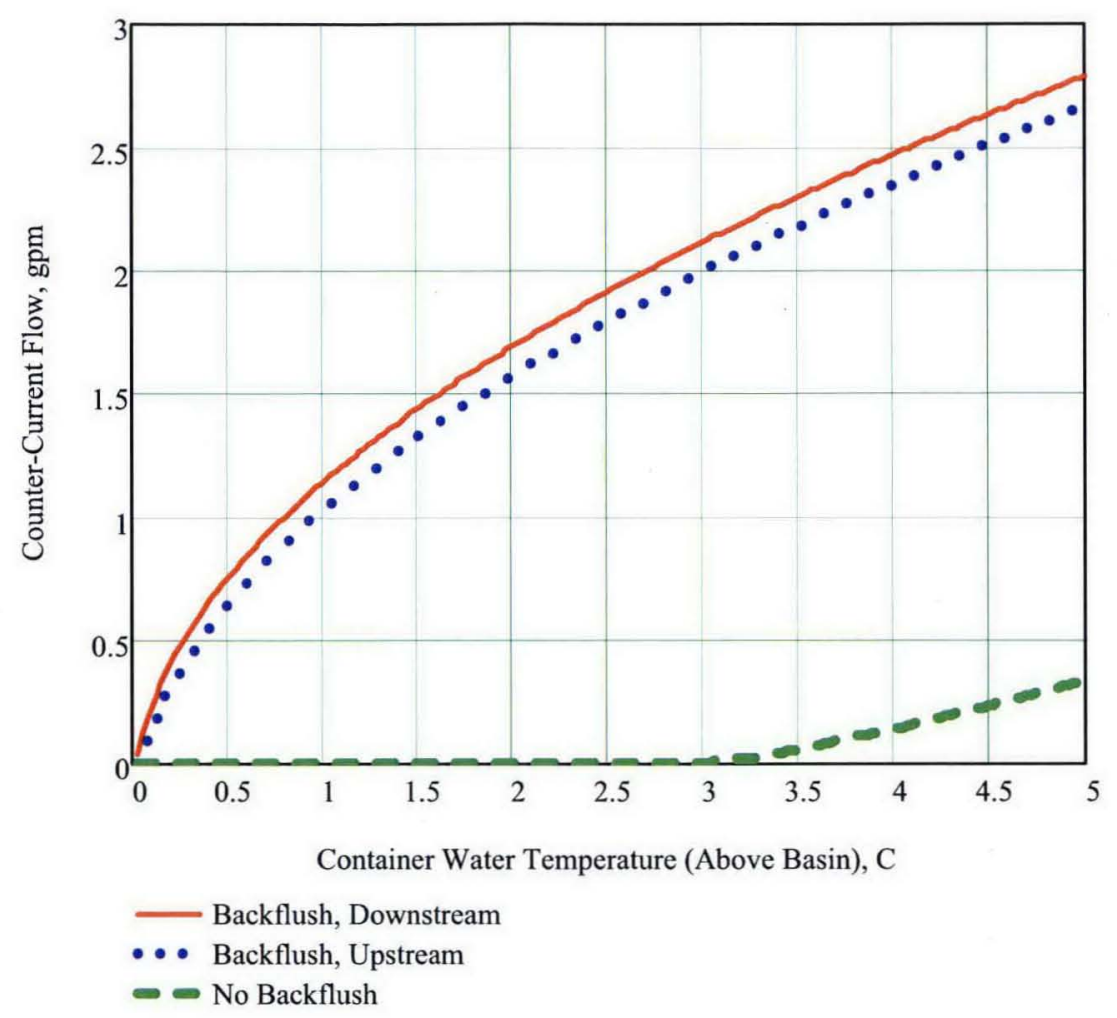

Figure 3-1 Countercurrent exchange flow between container and basin as function of container water temperature. 
PRC-STP-00011, Rev. 0

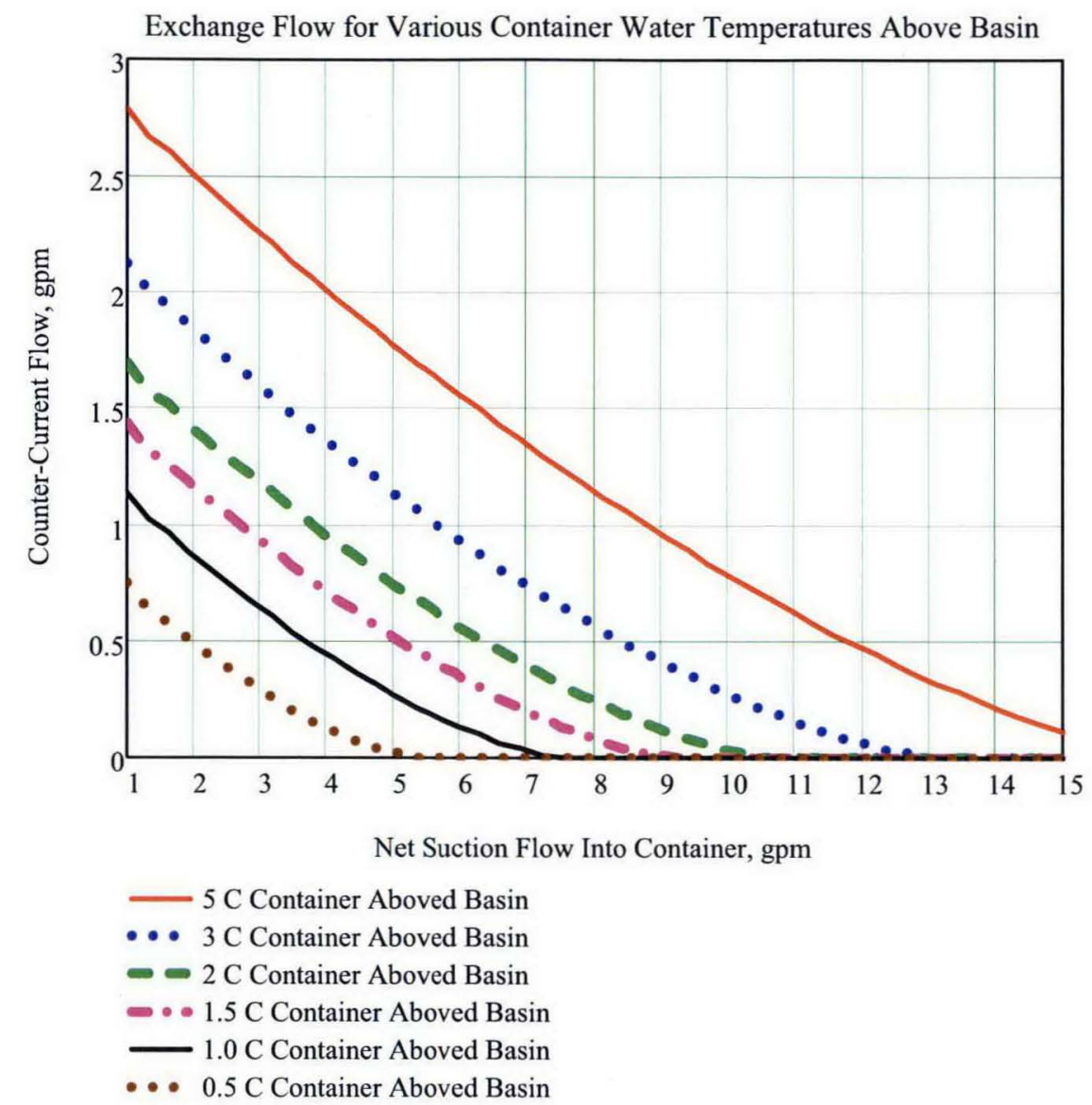

Figure 3-2 Countercurrent exchange flow between basin and container for various container water temperatures above the basin temperature as function of net suction. 
PRC-STP-00011, Rev. 0

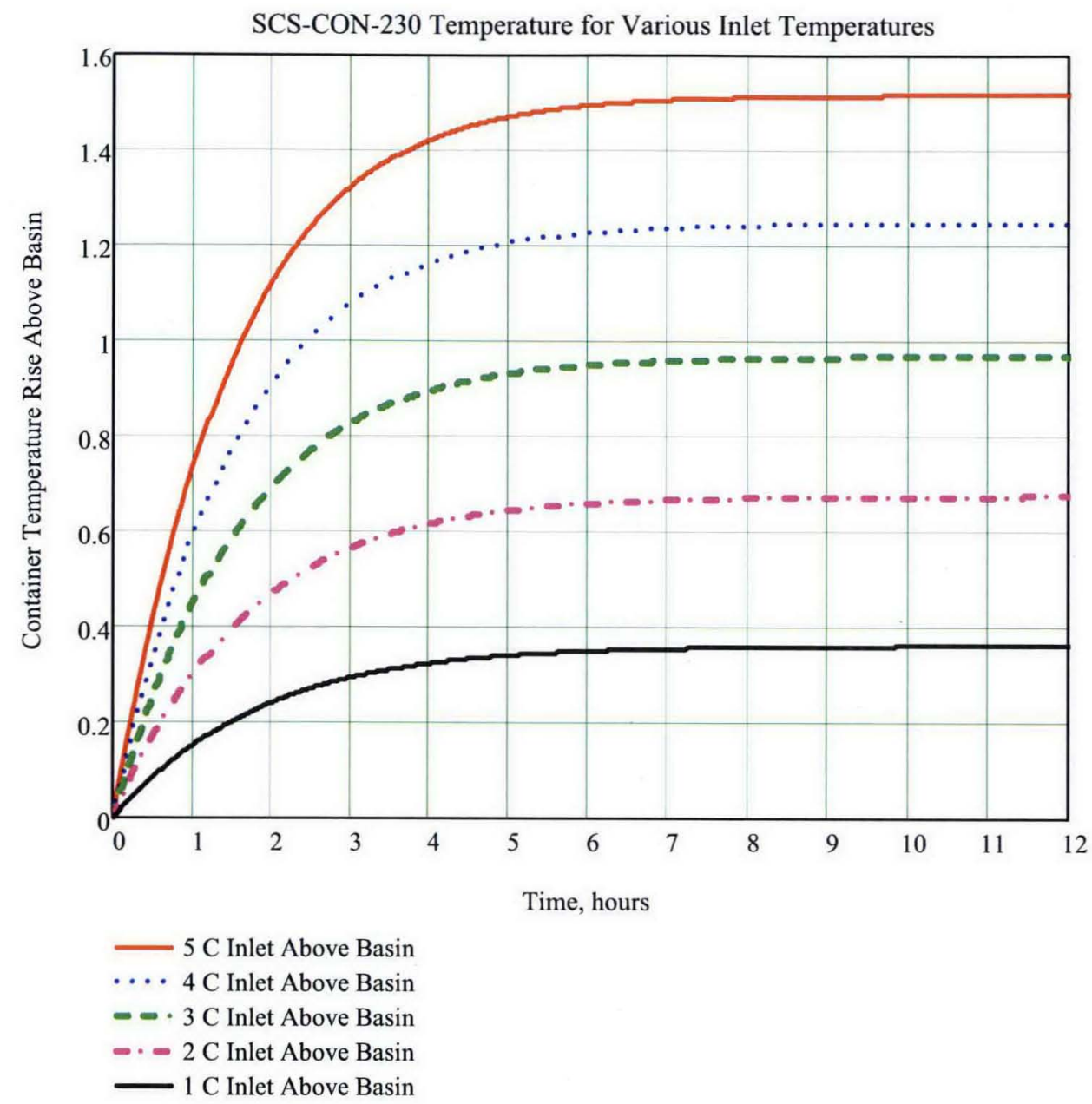

Figure 3-3 Container water temperature history for various inlet water temperatures. 


\subsection{SLUDGE PARTICLES SEDIMENTATION, FILTRATION AND OUTFLOW IN CONTAINER SCS-CON-230}

\subsection{Model Assumptions}

In this section a theory is developed and applied to predict the fractions of the sludge particles discharged to the container that settle to the bottom of the container, arrive at the filters and flow out of the container. The major assumptions underlying the theory are:

(1) The container is well-mixed by the sludge discharge buoyancy so that the particle concentration is uniform throughout the container (see Section 2.0).

(2) The sludge particle size distribution is log-normal.

(3) Most of the particles are small enough so that their settling velocity is accurately represented by Stoke's law.

(4) Resuspension of settled sludge particles by the negatively buoyant sludge plume is neglected.

(5) The sludge particles are spherical or they can be represented by equivalent spheres.

Assumptions 1 is conservative. Many particle size distributions that occur in nature and industry have been found to follow the log-normal distribution (Assumption 2). It is shown in Appendix $C$ that for the maximum effective particle density assumed here $\left(6000 \mathrm{~kg} \mathrm{~m}^{-3}\right)$ and for the log-normal particle size distribution characteristics selected (mass median particle diameter $\mathrm{d}_{1 / 2}=10 \mu \mathrm{m}$ and maximum particle diameter $\left.\mathrm{d}_{\max }=500 \mu \mathrm{m}\right)$, most of the particles $(94 \%$ by mass) settle at a rate given by Stokes law (Assumption 3). A detailed discussion and justification of Assumption (4) is given in Appendix A. Assumption (5) involves the neglect of deviations from Stokes law by irregular particle shapes and the neglect of the fact that when two spherical solid particles collide they do not form another spherical particle. One can introduce shape 
factors to correct the equations for nonspherical particle behavior. However the numerical values of these shape factors are usually unknown. In the authors' experience one can just as well investigate departures from spherical particle behavior by retaining the spherical particle assumption and varying the particle density in Stokes law and by varying the capture coefficient that appears in the particle coagulation terms.

\subsection{Conversion of the Particle Size Distribution Equation to a System of Ordinary Differential Equations}

The basic equation describing the change with time of the size distribution of a spatially homogeneous suspension due to particle coagulation and due to removal by sedimentation, filtration and outflow and particle addition due to the presence of a source (sludge distributors) is

$$
\begin{aligned}
\frac{\partial n(v, t)}{\partial t}= & -\frac{n(v, t) u_{\text {sed }}(v)}{h_{\text {sed }}}-\frac{n(v, t) u_{f 1}}{h_{f l}}-\frac{n(v, t) u_{\text {out }}}{h_{\text {out }}}+\dot{n}_{p}(v) \\
& +\frac{1}{2} \int_{0}^{v} K_{g}(\bar{v}, v-\bar{v}) n(\bar{v}, t) n(v-\bar{v}, t) d \bar{v}-\int_{0}^{\infty} K_{g}(\bar{v}, v) n(\bar{v}, t) n(v, t) d \bar{v}
\end{aligned}
$$

Here $n(v, t)$ is the size distribution function, defined such that $n(v, t) d v$ is the number concentration of particles (particles $\mathrm{m}^{-3}$ ) in the particle volume size range $v$ to $v+d v$ at time $t$, $u_{s e d}(v)$ is the Stoke's gravitational (sedimentation) velocity, $u_{f l}$ is the filter inlet velocity that carries particles of all sizes to the filters, $u_{\text {out }}$ is the outlet flow velocity that carries particles of all sizes through the gap and out of the container and $\dot{n}_{p}(v) d v$ is the rate of introduction of particles per unit volume of the suspension (container) in the size range $v$ to $v+d v$. The symbol $h$ denotes the effective heights for sedimentation (sed), filtration (fl), and outflow (out); it is the suspension (container) volume divided by sedimentation area (container floor), or total filter area, or gap outflow area, respectively. The integral terms are the gravitational particle coagulation term that represent the collection of small particles by larger falling particles. The kernel $K_{g}(\bar{v}, v)$ that appears in the coagulation terms is the frequency of binary collisions between particles of volume $v$ and $\bar{v}$ (in units $\mathrm{m}^{3} \mathrm{~s}^{-1}$ ). 
PRC-STP-00011, Rev. 0

\section{4-3}

Equation (4-1) may be converted to an ordinary differential equation by multiplying it by $\mathrm{v}^{\gamma}$, where $\gamma$ is a constant, and integrating over particle volume $\mathrm{v}$ from 0 to $\infty$; namely,

$$
\begin{aligned}
\frac{d}{d t} \int_{0}^{\infty} v^{\gamma} n(v, t) d v= & -\frac{1}{h_{\text {sed }}} \int_{0}^{\infty} v^{\gamma} n(v, t) u_{\text {sed }}(v) d v \\
& -\frac{u_{f 1}}{h_{f 1}} \int_{0}^{\infty} v^{\gamma} n(v, t) d v-\frac{u_{\text {out }}}{h_{\text {out }}} \int_{0}^{\infty} v^{\gamma} n(v, t) d v+\int_{0}^{\infty} v^{\gamma} \dot{n}_{p}(v) d v \\
& +\frac{1}{2} \int_{0}^{\infty} \int_{0}^{v} v^{\gamma} K_{g}(\bar{v}, v-\bar{v}) n(\bar{v}, t) n(v-\bar{v}, t) d \bar{v} d v \\
& -\int_{0}^{\infty} \int_{0}^{\infty} v^{\gamma} K_{g}(\bar{v}, v) n(\bar{v}, t) n(v, t) d \bar{v} d v
\end{aligned}
$$

The integral,

$$
X_{\gamma}(t)=\int_{0}^{\infty} v^{\gamma} n(v, t) d v
$$

that appears in the time derivative on the left-hand-side of Eq. (4-2) can represent a general property of the sludge suspension. For example, for $\gamma=0, \mathrm{X}_{0}$ is simply equal to the total number concentration of suspension particles:

$$
N(t)=X_{0}(t)=\int_{0}^{\infty} n(v, t) d v
$$

If $\gamma=1, X_{1}(t)$ is the total volume (or mass) concentration of suspension particles in units of volume of particles per volume of space:

$$
V(t)=X_{1}(t)=\int_{0}^{\infty} v n(v, t) d v
$$

If $\gamma=2 / 3, X_{2 / 3}(t)$ is proportional to the suspension surface area distribution. 
The integral represented by $X_{\gamma}(t)$ is referred to in the literature as the $\gamma^{\prime}$ th moment of the particle size number density distribution function. Thus Eq. (4-2) represents a set of ordinary differential equations for the moments. The moments and the integrals on the right-hand-side of Eq. (4-2) can be integrated once the functional form of the distribution function $n(v, t)$ is assumed. The exact number of "moment equations" (4-2) that must be solved is equal to the number of time-dependent parameters that appear in the distribution. The number density distribution function is assumed to be of the following log-normal form:

$$
n(v, t) d v=\frac{N(t)}{\sqrt{2 \pi} \ln [\sigma(t)]} \cdot \exp \left[-\frac{\left\{\ln \left(\frac{v}{v_{g}(t)}\right)^{1 / 3}\right\}^{2}}{2 \ln ^{2}[\sigma(t)]}\right] d \ln v^{1 / 3}
$$

where $N(t)$ is the total instantaneous number concentration of particles in the suspension, $v_{g}(t)$ is the instantaneous number median particle volume of the suspension, and $\sigma(t)$ is the instantaneous geometric standard deviation of the suspension.

Substitution of Eq. (4-6) into Eq. (4-3) yields the following expression for the moments of the log-normal distribution:

$$
X_{\gamma}(t)=N(t)\left[v_{g}(t)\right]^{\gamma} \exp \left\{\frac{9 \gamma^{2}}{2}[\ln \sigma(t)]^{2}\right\}
$$

Using the zeroth, first and second moments:

$$
\begin{aligned}
& X_{0}(t)=N(t) \\
& X_{1}(t)=N(t) v_{g}(t) \exp \left\{\frac{9}{2}[\ln \sigma(t)]^{2}\right\} \\
& X_{2}(t)=N(t)\left[v_{g}(t)\right]^{2} \exp \left\{18[\ln \sigma(t)]^{2}\right\}
\end{aligned}
$$


PRC-STP-00011, Rev. 0

Attachment A

As already mentioned, the zeroth and first moments can be associated with those quantities which are capable of experimental measurement - the total number of particles and the total mass of particles, respectively. The second moment given by Eq. (4-10) has little physical significance and is chosen because it has been used successfully in the past by log-normal aerosol code developers and because it is convenient to deal with mathematically. A better choice for the required third moment might be $\mathrm{X}_{2 / 3}$, which represents the total suspension surface area.

It will prove convenient to invert Eqs. (4-8) to (4-10) so that the time-dependent parameters of the log-normal distribution are expressed in terms of the three moments of the distribution function. The results of the required algebraic manipulations are

$$
\begin{aligned}
& N(t)=X_{0}(t) \\
& v_{g}(t)=\frac{X_{1}(t)^{2}}{X_{0}(t)^{3 / 2} X_{2}(t)^{1 / 2}} \\
& \ln \sigma(t)=\frac{1}{3}\left\{\ln \left(\frac{X_{0}(t) X_{2}(t)}{X_{1}^{2}(t)}\right)\right\}^{1 / 2}
\end{aligned}
$$

It remains to establish the functional forms for the sedimentation velocity $u_{\text {sed }}(v)$ and the gravitational coagulation kernal $\mathrm{K}_{\mathrm{g}}(\overline{\mathrm{v}}, \mathrm{v})$ in Eq. (4-2). Once this is accomplished differential equations for $\mathrm{X}_{\gamma}$ (or for $\mathrm{N}, \mathrm{v}_{\mathrm{g}}$ and $\sigma$ ) can be obtained by direct integration of the integrals in Eq. (4-2). The sedimentation velocity for the sludge particles is given by Stoke's law (see Assumption 3 in Section 4.1). The deposition velocity for spherical particles is

$$
u_{\text {sed }}(v)=\frac{2}{9}\left(\frac{3}{4 \pi}\right)^{\frac{2}{3}} \frac{\left(\rho_{s}-\rho_{f}\right) g v^{2 / 3}}{\mu_{f}}
$$

where $g$ is the gravitational constant, $\rho_{\mathrm{s}}$ is the density of the particle material, and $\rho_{\mathrm{f}}, \mu_{\mathrm{f}}$ are the density and viscosity of the water component of the sludge suspension. 
PRC-STP-00011, Rev. 0

Attachment A

Particles of different sizes will settle at different rates under the influence of gravity and thereby create relative motion between them that leads to collisions and coagulation. Consider a large particle of radius $\bar{r}$ as it settles through a suspension of smaller particles of radius $r$. The smaller particles will collide with the larger particle by the mechanisms of inertia and interception. A particle capture coefficient $\varepsilon(r, \bar{r})$ is defined as the ratio of the actual frequency of collisions to the frequency that would obtain if the small particles were fixed and not pushed aside by the flow around the large particle. Clearly, the collision frequency kernel for gravitational coagulation is

$$
\mathrm{K}_{\mathrm{g}}(\mathrm{r}, \overline{\mathrm{r}})=\varepsilon(\mathrm{r}, \overline{\mathrm{r}}) \pi(\mathrm{r}+\overline{\mathrm{r}})^{2}\left[\mathrm{u}_{\text {sed }}(\overline{\mathrm{r}})-\mathrm{u}_{\text {sed }}(\mathrm{r})\right] ; \mathrm{r} \leq \overline{\mathrm{r}}
$$

The value of $\varepsilon(\mathrm{r}, \overline{\mathrm{r}})$ is less than unity and is not known to good accuracy. The following functional form based on the work of Fuchs (1964) and Pruppacher and Klett (1978) is adopted here:

$$
\varepsilon(\mathrm{r}, \overline{\mathrm{r}})=\frac{3 \varepsilon_{0}}{2}\left(\frac{\mathrm{r}}{\mathrm{r}+\overline{\mathrm{r}}}\right)^{2} ; \quad \mathrm{r} \leq \overline{\mathrm{r}}
$$

There is a controversy over the proper numerical value of the constant coefficient $\varepsilon_{0}$ in the above equation which to the best of the authors' knowledge has not yet been resolved. In the Fuchs' model $\varepsilon_{0}=1.0$ and in the Pruppacher-Klett model $\varepsilon_{0}=1 / 3$. Of course lower numerical values of $\varepsilon_{0}$ may be employed to model nonspherical particles. Combining Eqs. (4-15) and (4-16) gives

$$
\mathrm{K}_{\mathrm{g}}(\overline{\mathrm{r}}, \mathrm{r})=\frac{3 \pi}{2} \varepsilon_{0} \mathrm{r}^{2}\left[\mathrm{u}_{\mathrm{sed}}(\overline{\mathrm{r}})-\mathrm{u}_{\mathrm{sed}}(\mathrm{r})\right] ; \mathrm{r} \leq \overline{\mathrm{r}}
$$

or, by converting particle radii to volume:

$$
\mathrm{K}_{\mathrm{g}}(\overline{\mathrm{v}}, \mathrm{v})=\frac{\pi}{3}\left(\frac{3}{4 \pi}\right)^{4 / 3} \frac{\varepsilon_{0}\left(\rho_{\mathrm{s}}-\rho_{\mathrm{f}}\right) \mathrm{g}}{\mu_{\mathrm{f}}} \mathrm{v}^{2 / 3}\left(\overline{\mathrm{v}}^{2 / 3}-\mathrm{v}^{2 / 3}\right) ; \quad \mathrm{v} \leq \overline{\mathrm{v}}
$$


Repeating the above development for a large particle of radius $r$ settling through a suspension of smaller particles of radius $\bar{r}$, the appropriate coagulation equation for $v>\bar{v}$ is obtained:

$$
\mathrm{K}_{\mathrm{g}}(\overline{\mathrm{v}}, \mathrm{v})=\frac{\pi}{3}\left(\frac{3}{4 \pi}\right)^{4 / 3} \frac{\varepsilon_{0}\left(\rho_{\mathrm{s}}-\rho_{\mathrm{f}}\right) \mathrm{g}}{\mu_{\mathrm{f}}} \overline{\mathrm{v}}^{2 / 3}\left(\mathrm{v}^{2 / 3}-\overline{\mathrm{v}}^{2 / 3}\right) ; \quad \mathrm{v}>\overline{\mathrm{v}}
$$

Substituting Eqs. (4-6), (4-14), (4-18) and (4-19) into the integral terms in Eq. (4-2), performing the indicated integrations for $\gamma=0,1,2$ and using Eqs. (4-11) to (4-13) to express all quantities in terms of $X_{0}, X_{1}$, and $X_{2}$ gives the differential equations for the first three integral moments:

$$
\begin{aligned}
\frac{d X_{0}}{d t} & =-\frac{B}{h_{\text {sed }}} X_{0}\left(\frac{X_{1}^{8}}{X_{0}^{7} X_{2}}\right)^{\frac{1}{9}}-\left(\frac{u_{f l}}{h_{f l}}+\frac{u_{\text {out }}}{h_{\text {out }}}\right) X_{0}+\dot{N}_{p} \\
& -\frac{3 \pi}{4}\left(\frac{3}{4 \pi}\right)^{2 / 3} \varepsilon_{0} B X_{0}^{2}\left(\frac{X_{1}^{8}}{X_{0}^{7} X_{2}}\right)^{\frac{2}{9}}\left\{1-\left(\frac{X_{0} X_{2}}{X_{1}^{2}}\right)^{\frac{4}{9}} \operatorname{erfc}[2 \ln \sigma(t)]\right\} \\
\frac{d X_{1}}{d t}= & -\frac{B}{h_{\text {sed }}} X_{0}\left(\frac{X_{1} X_{2}}{X_{0}^{2}}\right)^{\frac{5}{9}}-\left(\frac{u_{f 1}}{h_{f l}}+\frac{u_{\text {out }}}{h_{\text {out }}}\right) X_{1}+\dot{N}_{p} v_{g, p} \exp \left[\frac{9}{2}\left(\ln \sigma_{p}\right)^{2}\right] \\
\frac{d X_{2}}{d t}= & -\frac{B}{h_{s}} X_{0}\left(\frac{X_{2}^{5}}{X_{0} X_{1}^{4}}\right)^{\frac{4}{9}}-\left(\frac{u_{f l}}{h_{f l}}+\frac{u_{\text {out }}}{h_{\text {out }}}\right) X_{2}+\dot{N}_{p} v_{g, p}^{2} \exp \left[18\left(\ln \sigma_{p}\right)^{2}\right] \\
& +\frac{3 \pi}{2}\left(\frac{3}{4 \pi}\right)^{2 / 3} \varepsilon_{0} B X_{0}^{2}\left(\frac{X_{1}^{10} X_{2}^{10}}{X_{0}^{20}}\right)^{\frac{1}{9}}\left\{1-\left(\frac{X_{0} X_{2}}{X_{1}^{2}}\right)^{\frac{4}{9}} \operatorname{erfc}[2 \ln \sigma(t)]\right\}
\end{aligned}
$$

In the above equations the subscript $\mathrm{p}$ pertains to the known (specified) particle size distribution properties at the source (sludge distributors; see below), and 
PRC-STP-00011, Rev. 0

$$
\mathrm{B}=\frac{2}{9}\left(\frac{3}{4 \pi}\right)^{2 / 3} \frac{\mathrm{g}\left(\rho_{\mathrm{s}}-\rho_{\mathrm{f}}\right)}{\mu_{\mathrm{f}}}
$$

The details of integrating the double integrals in the particle coagulation rate terms are not straightforward and are given in Appendix B.

Since $N(t), v_{g}(t)$ and $\sigma(t)$ are related to the moments $X_{0}, X_{1}$, and $X_{2}$ via Eqs. (4-11) to (413), the differential equation set (4-20) to (4-22) is sufficient to determine the evolution of the sludge suspension particle size distribution once the source particle size distribution properties $\mathrm{v}_{\mathrm{g}, \mathrm{p}}$ and $\sigma_{\mathrm{p}}$ are specified. Of course, the source-sludge particle size spectrum must be of the lognormal form

$$
\dot{\mathrm{n}}_{\mathrm{p}}(\mathrm{v}) \mathrm{dv}=\frac{\dot{\mathrm{N}}_{\mathrm{p}}}{\sqrt{2 \pi} \ln \sigma_{\mathrm{p}}} \exp \left[-\frac{\left\{\ln \left(\frac{\mathrm{v}}{\mathrm{v}_{\mathrm{g}, \mathrm{p}}}\right)^{1 / 3}\right\}^{2}}{2 \ln ^{2} \sigma_{\mathrm{p}}}\right] \mathrm{d} \ln \mathrm{v}^{1 / 3}
$$

where $\dot{N}_{p}$ is the total rate of introduction of particles per unit volume of the container. In setting up the numerical calculations that follow it is convenient to work only with representative particle diameters of the source-sludge particle size distribution instead of the quantities $v_{g, p}$ and $\sigma_{\mathrm{p}}$. The two diameters selected here are $\mathrm{d}_{1 / 2}$ and $\mathrm{d}_{\max }$ defined as the particle diameters such that $50 \%$ and $99.9 \%$ of the total mass (or volume) of the particles is in particles of diameters smaller than $d_{1 / 2}$ and $d_{\max }$, respectively. For a log-normal particle suspension

$$
\begin{aligned}
& \frac{d_{1 / 2}}{d_{g, p}}=\exp \left[3\left(\ln \sigma_{p}\right)^{2}\right] \\
& \frac{d_{\max }}{d_{g, p}}=\exp \left[3\left(\ln \sigma_{p}\right)^{2}+\frac{11}{5} \sqrt{2} \ln \sigma_{p}\right]
\end{aligned}
$$


PRC-STP-00011, Rev. 0

Attachment A

\section{4-9}

when $d_{g, p}$ is the number median particle diameter related to the number median particle volume through

$$
d_{g, p}=\left(\frac{6 v_{g, p}}{\pi}\right)^{1 / 3}
$$

Dividing Eq. (4-26) by Eq. (4-25) yields the desired expression for $\sigma_{\mathrm{p}}$

$$
\ln \sigma_{p}=\frac{5}{11 \sqrt{2}} \ln \left(\frac{d_{\max }}{d_{1 / 2}}\right)
$$

Also, from Eqs. (4-25) and (4-27)

$$
\mathrm{v}_{\mathrm{g}, \mathrm{p}}=\frac{\pi}{6} \mathrm{~d}_{\mathrm{g}, \mathrm{p}}^{3}=\frac{\pi}{6} \mathrm{~d}_{1 / 2}^{3} \exp \left[-9\left(\ln \sigma_{\mathrm{p}}\right)^{2}\right]
$$

or

$$
d_{g, p}=d_{1 / 2} \exp \left[-\frac{9}{3}\left(\ln \sigma_{p}\right)^{2}\right]
$$




\subsection{TRANSIENT MODEL RESULTS}

In this section, transient simulations are performed using the model equations for the suspended particle size distribution developed in the preceding section. Transient simulations are capable of providing the volume of particles that escape from the container, the volume suspended, the volume on filters, and the volume settled as a function of time while conditions such as the incoming particle volume fraction and back flush operations are allowed to vary with time. Crucial input parameters regarding particle size distribution, particle density, and simulation of operations are discussed first. Case selection and inputs are then summarized. A detailed results example is provided in order to explain the time history of the various particle volumes (suspended, on filters, settled, and escaped). Results are summarized and conclusions are noted. Figures are arranged at the end of the section to improve organization of the material.

\subsection{Particle Size Distribution and Particle Density}

The particle size distribution used for this work is a log-normal distribution based upon canister sludge data. Figure 5-1 presents data for $\mathrm{KW}$ canister sludge, $\mathrm{KE}$ canister sludge, and sludge simulant reported in [Schmidt and Zacher, 2007] Table 6. There is a notable difference between the $\mathrm{KW}$ and $\mathrm{KE}$ sample cumulative volumes at a 1 micron particle size, and the median particle size range is between about 6 and 18 microns. It is desirable to select a particle size distribution for container filling simulation that falls inside the available data.

The cumulative distribution function for a log-normal particle size distribution up to a given diameter $\mathrm{d}$ is given by

$$
F(d)=\frac{1}{2}\left\{1+\operatorname{erf}\left[\frac{\ln \left(d / d_{g, p}\right)}{\sqrt{2} \ln (\sigma)}-\frac{3 \ln (\sigma)}{\sqrt{2}}\right]\right\}
$$


PRC-STP-00011, Rev. 0

Attachment A

where symbols were previously defined in Section 4. As noted previously, the distribution parameters $\mathrm{v}_{\mathrm{g}, \mathrm{p}}$ and $\sigma$ are found by specifying the median particle diameter and defining that $99.9 \%$ of the particles are below a maximum size, here taken as 500 microns.

Figure 5-2 presents a comparison of data in Figure 5-2 with two possible log-normal distributions. The distribution chosen for this work has a median particle size of 10 microns and the corresponding standard deviation parameter value is 3.516. This distribution matches the KE data at the low end, matches the average of the medians for $\mathrm{KE}$ and $\mathrm{KW}$ samples, and approaches $100 \%$ faster than the KE sample.

The average particle density of sludge simulant reported in [Schmidt and Zacher, 2007] Table 5 is $6.0 \mathrm{~g} / \mathrm{cc}$. KW canister sludge is higher than this average and $\mathrm{KE}$ canister sludge is lower than this average, with a design basis range from $4.6 \mathrm{~g} / \mathrm{cc}$ to $6.7 \mathrm{~g} / \mathrm{cc}$.

While the settler system was operating, we can expect that larger, denser particles fell out near the upstream end, while smaller, less dense particles fell out near the downstream end. The settlers are to be retrieved from the upstream end toward the downstream end, so during simulations of operations variation in the particle density will be considered as described below.

\subsection{Simulation of Operations}

There are three important aspects of operations that require idealization for simulation: The overall timeline for retrieval operations including supply of inlet water from the settlers and operation of the filters, the time history for incoming particles, and the timing and duration of back flush operations. Assumed operations are described and justified here.

The basic timeline for operations is explained in [Hofferber, 2008], with verbally transmitted clarification as described here. Broadly speaking, an individual settler tube will be cleaned out over approximately a one week period (five working days), and due to personnel logistics the actual retrieval operations will only occur for about four hours per day. 
The solids retrieval operation involves the use of high pressure pumping bursts to mobilize settled material followed by a waiting period to reduce the amount of suspended solids. The target suspended solids concentration is 2 weight percent (wt. \%). The main part of the retrieval operation is a set of actions known as a " 5 x 1 retrieval" in which a short burst of high pressure flow is used for mobilization, followed by a waiting period until the suspended solids are below $2 \mathrm{wt}$ \% for more than 30 seconds, followed by retrieving the hose one foot (duration not specified), and repeating. Successive $5 \times 1$ retrievals commence at increasing penetration depths until the tube is clear. The peak solids fraction during bursts may be about $10 \mathrm{wt} . \%$.

The timeline just described clearly indicates that for brief periods of time, several seconds to something less than about a minute, there may be a concentration of suspended solids that exceed 2 wt. \%, followed by an equal or longer duration in which the suspended solids concentration is below $2 \mathrm{wt}$. \%. The effective duty cycle duration is on the order of minutes, which is very brief compared to the daily operations duration.

A filter back flush operation is initiated on a pre-set pressure drop across the filters, which has been described verbally to correspond to between $1 / 8$ " and $1 / 4$ " filter cake buildup. During a back flush, the four filter assemblies are pulsed one at a time at $5 \mathrm{gpm}$ average back flush flow for three seconds each. Next, one filter assembly is isolated and pulsed at $5 \mathrm{gpm}$ average for 15 seconds, followed by a 2 minute plus 15 second rest period; the pulse duration is about 1 second in duration. This isolation and pulse step is repeated for each filter. The overall duration of a back flush operation is therefore a bit over 10 minutes, but the back flush operation itself consists of a series of very brief flow reversals.

The main justification for simplified operations simulation is the brief nature of unit operations compared to the time scale for a change in the suspended particle concentration. It will be seen from simulation results that the unit operations time scale, which varies over a range between about one second, fifteen seconds, and thirty seconds, is much less than the characteristic time to change the suspended particle concentration, which is on the order of ten minutes to an hour. In particular, during container filling, it will be seen that the suspended particle concentration tends to approach a steady value. A continuous operation simulation leads 
to a higher suspended particle concentration on average than a discontinuous operations simulation because greater particle coagulation and settling occurs for a discontinuous process compared to that for a continuous process. For this reason, an idealized operation that "smears out" or homogenizes the rate of particle addition yields slightly conservative results in the sense of maximizing particle escape from the containers, compared to an idealized operation that adds particles in "bursts" over a duty cycle.

The primary assumption to simplify operations simulation, to be proven by simulation, is that daily settler tube operations can be considered independent. This is a reasonable assumption because there are about twenty hours of particle settling time between daily operations.

A secondary assumption is that both the particle addition and back flush "burst" operations can be idealized by more homogeneous operations. This assumption will be tested by comparing homogeneous versus simulated burst operations. It will be shown that homogeneous particle addition is the worst case in terms of allowing escape of material. Back flush operations by their nature occur only periodically, but the individual filter operation can be idealized as a single continuous type of operation. This is consistent with the model formulation in which the particles are assumed to be well-mixed in the container, so that the location of each individual filter is a moot point.

Therefore, two kinds of operations scenarios will be developed here: Uniform addition of particles over a time period within the four hour daily shift, and duty cycle addition of particles during the daily shift in which the particle volume fraction is alternately some non-zero constant value and then zero.

First consider a timeline for simulation of retrieval from a single settler tube. The goal of the simulation is to understand the potential for particle escape from the container to the basin. As discussed in Section 3, the identified mechanism for particle escape is counter-current flow between the container and basin that is induced by a temperature difference. Escape can occur during filter back flushing, or if flow into and out of the container is stopped. Normally, inflow 
and filter outflow will only occur during retrieval operations, and these flows would be stopped after a daily shift and reinitiated at the beginning of the next day's operation.

We know in advance that turning off the flow will allow particle escape. Therefore, to minimize the potential for particle escape, it is desirable to operate the filter system for some duration after particle retrieval. In order to fit the simulation into the operations timeline, it is assumed that particles will be retrieved for a duration less than four hours, and that container inflow/outflow will continue for the remainder of the four hour daily shift to allow some particle settling, and finally that daily operation will end with a filter back flush.

Next, consider particle retrieval. The estimated total sludge volume in the all settler tubes is $5.4 \mathrm{~m}^{3}$ [Schmidt, 2006]. For this work, we consider a hypothetical worst-case tube to contain $0.80 \mathrm{~m}^{3}$. At 35 vol. \% solids [Schmidt, 2006] this yields $0.28 \mathrm{~m}^{3}$ particles. Sludge is retrieved in five working days corresponding to a retrieval duration of 20 hours or $72,000 \mathrm{~s}$. The average inlet flow to the container is $15 \mathrm{gpm}$ or $9.46 \times 10^{-4} \mathrm{~m}^{3} / \mathrm{s}$. The average flowing particle volume fraction $\alpha$ is related to the total particle volume $V_{p}$, inlet flow rate $Q$, and duration $t: V_{p}=\alpha Q t$. The value of $\alpha$ for the homogeneous and duty cycle operations simulations must satisfy this equation, so $\alpha$ is implied by whatever total retrieval duration is chosen. For reference, the average value of $\alpha$ corresponding to 20 hours of particle retrieval duration is 0.411 vol.\%. The corresponding mass fraction $\mu$ is given by $\mu=\left(\rho_{\mathrm{p}} / \rho_{\mathrm{f}}\right) \alpha$ so it depends upon the density ratio between incoming particles and water. This ratio is 6 for average particles, and therefore the average mass fraction during 30 hours retrieval is $2.5 \mathrm{wt} \%$. While this is slightly larger than the target value of $2 \mathrm{wt} . \%$, it is consistent with the described operation because there will be bursts of higher mass fraction approaching $10 \%$.

As mentioned above, the first retrieval operations for a settler tube are expected to yield relatively higher density particles and the last operations are expected to yield relatively lower density particles. For this work, three different densities will be considered to correspond to daily retrieval on day 1 (highest), day 3 (lower), and day 5 (lowest). It will be seen that substantial settling of particles occurs over a period of hours, so in fact daily operations are essentially completely independent. Thus, variation in particle density to correspond to the 
variation during retrieval is equivalent to simply running simulations of a daily operation and examining various densities for sensitivity.

Filter back flush operation can be idealized by periodically changing the container outflow rate for a duration of 60 seconds, which is the approximate total duration of flushing flow during a back flush cycle. The remaining question is the frequency of a back flush cycle. A frequency of 30 minutes is used here based on noting the corresponding filter cake thickness that is developed during test simulations. Because the total particle volume and the retrieval time are selected to provide a somewhat conservative (but not unrealistic) potential for particle escape, the real back flush frequency that could be expected in practice is more likely to lie between one and two hours.

During back flush simulation, particles accumulated on the filters are released back into the container. The particle size distribution of these particles is assumed to be the same as the distribution of suspended particles. This is justified by noting that the suspended particle size distribution quickly attains a steady state.

Given all the considerations above, the two operations simulation timelines that will be used here are as follows:

\section{Uniform Addition Cases:}

- Nominal average flow occurs for a duration of 4 hours plus one minute (inflow is 15 gpm, filter outflow is $28 \mathrm{gpm}$, net suction from the basin is $13 \mathrm{gpm}$ ).

- $\quad$ Back flush operation occurs every 30 minutes for a duration of one minute (net filter outflow is $16 \mathrm{gpm}$, net suction from the basin is $1 \mathrm{gpm}$ ). The last minute of container inflow/outflow is a back flush operation.

- Particles are added at a uniform volume fraction over a duration of 3.5 hours. The volume fraction to add the assumed $0.28 \mathrm{~m}^{3}$ particles over five daily shifts is $0.47 \mathrm{vol}$. \%. 


\section{Duty Cycle Cases:}

- Nominal average flow occurs for a duration of 4 hours plus one minute (inflow is 15 gpm, filter outflow is $28 \mathrm{gpm}$, net suction from the basin is $13 \mathrm{gpm}$ ).

- $\quad$ Back flush operation occurs every 30 minutes for a duration of one minute (net filter outflow is 16 gpm, net suction from the basin is $1 \mathrm{gpm}$ ). The last minute of container inflow/outflow is a back flush operation.

- $\quad$ Particles are added at a uniform volume fraction over a duration of 20 minutes, followed by zero particle addition for 40 minutes. This duty cycle is repeated four times, so particle addition ends at 3 hours 20 minutes. The volume fraction of particles when they are added is 1.23 vol. \%.

Note that the duration for particle settling after addition and before flow shutoff is about the same for the uniform and duty cycle case timelines. The $20 / 40$ on/off cycle for particles was chosen so that bursts of greater than $2 \mathrm{wt}$. \% would be used. It is understood that particles would not be added above $2 \mathrm{wt}$ \% for 20 minutes. However, this does at least allow simulation of the real fact that particles would for some period of time be added at greater than $2 \mathrm{wt}$. \%. The real issue is the frequency of the duty cycle: $20 / 40$ versus $2 / 4$ for example. A duty cycle of 2 minutes of particles followed by 4 minutes of water, repeated 10 times an hour, would produce results that are virtually indistinguishable from the uniform addition cases. So, the logic in choosing a duty cycle duration is to purposely provide a time-dependent boundary condition that differs from the uniform addition case and yet allows particle bursts at greater than $2 \mathrm{wt}$. \%.

The incoming water temperature will be a flow-rate-weighted average of the water temperature used in the high pressure lance and the basin water temperature. Considering an even flow split, it does not seem credible to use a water temperature more than $4{ }^{\circ} \mathrm{C}$ above the basin value. The effect of pump power is negligible. In the next section, specific cases are listed that allow for variation in incoming particle density and water supply temperature. 
PRC-STP-00011, Rev. 0

Attachment A

\subsection{Case Selection and Input Summary}

Based upon particle density data presented previously and the expected qualitative nature of density variation within a settler tube, three particle densities are chosen: $6 \mathrm{~g} / \mathrm{cc}, 4 \mathrm{~g} / \mathrm{cc}$, and 2 $\mathrm{g} / \mathrm{cc}$. It is assumed that the nominal inlet flow to the container will be about $2{ }^{\circ} \mathrm{C}$ above the basin temperature, and sensitivity to inlet flow $4{ }^{\circ} \mathrm{C}$ above the basin temperature will be evaluated. This results in the set of cases summarized in Table 5-1. An operations variation case, 1D, is included to examine the potential benefit of extending container flow beyond 4 hours, and it is only applied to the lighter-than nominal density baseline case 1B. Note that in each case there is a daily particle volume added of 56 Liters. In all cases a pre-existing retrieved settled sludge volume of $4 \mathrm{~m}^{3}$ is assumed so that the suspended concentration is higher than it would be if the container were initially empty.

Table 5-1 Settler Sludge Retrieval Case Summary

\begin{tabular}{|c|c|c|c|c|}
\hline Case & $\begin{array}{c}\text { Operation Type for Particle } \\
\text { Addition }\end{array}$ & Particle Density & $\begin{array}{l}\text { Inlet Water } \\
\text { Temperature }\end{array}$ & Figures \\
\hline $1 \mathrm{~A}$ & Uniform & $6 \mathrm{~g} / \mathrm{cc}$ & $2{ }^{\circ} \mathrm{C}$ & 5-3A,B \\
\hline $1 \mathrm{~B}$ & Uniform & $4 \mathrm{~g} / \mathrm{cc}$ & $2{ }^{\circ} \mathrm{C}$ & $5-4 A, B$ \\
\hline $1 \mathrm{C}$ & Uniform & $2 \mathrm{~g} / \mathrm{cc}$ & $2{ }^{\circ} \mathrm{C}$ & 5-5A,B \\
\hline $2 \mathrm{~A}$ & Duty Cycle & $6 \mathrm{~g} / \mathrm{cc}$ & $2{ }^{\circ} \mathrm{C}$ & $5-6 A, B$ \\
\hline $2 B$ & Duty Cycle & $4 \mathrm{~g} / \mathrm{cc}$ & $2^{\circ} \mathrm{C}$ & 5-7A,B \\
\hline $2 \mathrm{C}$ & Duty Cycle & $2 \mathrm{~g} / \mathrm{cc}$ & $2{ }^{\circ} \mathrm{C}$ & $5-8 \mathrm{~A}, \mathrm{~B}$ \\
\hline $3 \mathrm{~A}$ & Uniform & $6 \mathrm{~g} / \mathrm{cc}$ & $4^{\circ} \mathrm{C}$ & $5-9 A, B$ \\
\hline $3 B$ & Uniform & $4 \mathrm{~g} / \mathrm{cc}$ & $4^{\circ} \mathrm{C}$ & $5-10 \mathrm{~A}, \mathrm{~B}$ \\
\hline $3 \mathrm{C}$ & Uniform & $2 \mathrm{~g} / \mathrm{cc}$ & $4^{\circ} \mathrm{C}$ & 5-11A,B \\
\hline $1 \mathrm{D}$ & $\begin{array}{l}\text { Uniform, Extended } \\
\text { Container Flow* }\end{array}$ & $4 \mathrm{~g} / \mathrm{cc}$ & $2{ }^{\circ} \mathrm{C}$ & $5-12 A, B$ \\
\hline & $\begin{array}{r}\text { ases except } 1 \mathrm{D} \text {, container } \\
\text { container water in }\end{array}$ & $\begin{array}{l}\text { er inflow/outflou } \\
\text { w/outflow ends }\end{array}$ & $s$ at 4 hours or & e. In $c$ \\
\hline
\end{tabular}




\subsection{Detailed Results Discussion}

Detailed results are explained here for cases 1B and 2B. In all cases, three or four figures are provided on two pages in Section 5.7, as follows:

Page 1, Top: Time history of particle volume, Liters.

Volumes are shown for suspended (solid line), settled (dotted line), escaped to basin (dashed line), and filter cake (dot-dash line) particles.

In the uniform addition example, Figure 5-4A, the volume of suspended particles gradually increases to a nearly steady level, but exhibits a series of spiky increases every half hour corresponding to back flushing. The filter cake particle volume grows at a constant rate during normal filter operation and suddenly drops to zero during a back flush operation. The end of particle addition at 3.5 hours is followed by a before the final back flush, and the suspended volume gradually decreases thereafter. The volume of settled particles steadily increases and plateaus as the suspended volume diminishes. It is difficult to see the escaped particle volume on the same scale as these other volumes.

In the duty cycle addition example, Figure 5-7A, The suspended particle volume can be seen to initially increase for 20 minutes, then decline briefly for 10 minutes, and suddenly increase somewhat with the first back flush operation, and then decline until 1 hour. At that time a second back flush increases the suspended volume, and the suspended volume continues to increase due to the next duty cycle of particle addition. Otherwise behavior is similar to that of uniform addition.

\section{Page 2, Bottom: Time history of escaped particle volume, Liters}

The volume of just escaped particles is shown because it is difficult to observe on the same scale as the other volumes. 
In both cases (Figures 5-4A and 5-7A) the escaped volume increases in a series of steps while there is water flow to and from the container. Each step increase corresponds to a back flush operation. The size of the steps varies as the suspended particle concentration increases, and as the temperature of container water increases (discussed below).

After water flow to the container is terminated at four hours in both cases, particles are free to escape the basin because of counter-current flow. The rate of escape declines primarily because the suspended particle concentration declines over a period of several hours, and secondarily because the container water temperature decreases.

The escaped particle volume is affected primarily by suspended particle concentration, which therefore means that it varies strongly with particle density. In general the largest contribution to particle escape is after water shutoff.

\section{Page 2, Top: Time history of suspended particles, Liters.}

The volume of suspended particles is shown on a logarithmic scale due to its dynamic range and in particular so that the suspended volume at the end of the simulation can be seen.

The behavior of suspended particle volume was discussed above. This plot is included so that the long-term suspended particle volume after daily operations can be seen. Behavior is similar in both the uniform addition and duty cycle cases (Figures 5-4B and 5-7B).

The key difference between individual cases the effect of particle density. For $6 \mathrm{~g} / \mathrm{cc}$ particles and uniform addition (Figure 5-3B) the suspended volume declines by a factor of 100 during the first 6 hours after water shutoff, leaving less than $0.2 \mathrm{~L}$ suspended. This is less than the escaped particle volume, indicating little longer-term potential for particle escape, and demonstrating that daily operations are essentially independent with regard to the potential for particle escape. For the $4 \mathrm{~g} / \mathrm{cc}$ variation (Figure 5-4B) there is a similar factor of 100 decline in suspended volume and remaining suspended volume is about about $0.3 \mathrm{~L}$, which is again less than the escaped volume. But for the $2 \mathrm{~g} / \mathrm{cc}$ variation (Figure $5-5 \mathrm{~B}$ ) there is only about a factor 
of 10 decline in suspended volume and the final value of $7 \mathrm{~L}$ is comparable to the final escaped volume of $5 \mathrm{~L}$, indicating some remaining potential for particle escape. However, the slope of the suspended volume curve indicates that a value of about $1 \mathrm{~L}$ can be expected within 24 hours, so that daily operations can be considered independent even in the extreme case of such light particles.

Page 2, Bottom: Time history of container water temperature, ${ }^{\circ} \mathrm{C}$.

The temperature difference between container water and basin water is given. Note that the actual value of either temperature is not important, only the difference between values, because it is the difference that drives counter-current flow and particle escape. This figure is only given for the " $\mathrm{A}$ " case in each group because the temperature history is the same for all cases with a group defined by the operation type and incoming water temperature.

Because the incoming water temperature is constant and because the duration of water addition is the same in all cases except $1 \mathrm{D}$, the water temperature history is the same for the uniform addition case at $2{ }^{\circ} \mathrm{C}$ (Figure 5-3B) and the duty cycle case at $2{ }^{\circ} \mathrm{C}$ (Figure 5-6B). A peak value is attained at the end of water addition, about $0.7^{\circ} \mathrm{C}$ difference between container and basin. The decline after water addition is primarily due to heat transfer through the container walls, and only secondarily due to counter-current flow. For water addition at $4{ }^{\circ} \mathrm{C}$ above the basin value, the peak temperature difference is about $1.25^{\circ} \mathrm{C}$ (Figure 5-9B). The reason that the water temperature does not decline all the way to the basin value is due to the decay power transferred from sludge to water in the container. 


\subsection{Summary of Case Results}

Results for particle escape are summarized in Table 5-2. The final escape fraction is estimated by adding $10 \%$ of the final suspended volume to the final escaped volume and dividing by the daily added volume of $56 \mathrm{~L}$ (The $10 \%$ figure is deduced by examining the difference in escape from 10 to 16 hours for case group 1). Conclusions are presented in the next section.

Table 5-2 Particle Escape Results Summary

\begin{tabular}{|c|c|c|c|c|}
\hline Case & $\begin{array}{l}\text { Final Escaped } \\
\text { Volume, Liter }\end{array}$ & $\begin{array}{l}\text { Final Suspended } \\
\text { Volume, Liter }\end{array}$ & $\begin{array}{c}\text { Final Escape } \\
\text { Fraction }\end{array}$ & Figures \\
\hline $1 \mathrm{~A}$ uniform, $6 \mathrm{~g} / \mathrm{cc}, 2{ }^{\circ} \mathrm{C}$ & 1.2 & 0.15 & $2.2 \%$ & $5-3 \mathrm{~A}, \mathrm{~B}$ \\
\hline $1 \mathrm{~B}$ uniform, $4 \mathrm{~g} / \mathrm{cc}, 2^{\circ} \mathrm{C}$ & 2.0 & 0.35 & $3.6 \%$ & $5-4 \mathrm{~A}, \mathrm{~B}$ \\
\hline $1 \mathrm{C}$ uniform, $2 \mathrm{~g} / \mathrm{cc}, 2{ }^{\circ} \mathrm{C}$ & 4.8 & 7.0 & $9.8 \%$ & $5-5 \mathrm{~A}, \mathrm{~B}$ \\
\hline $2 \mathrm{~A}$ duty, $6 \mathrm{~g} / \mathrm{cc}, 2^{\circ} \mathrm{C}$ & 1.0 & $<0.1$ & $1.8 \%$ & $5-6 \mathrm{~A}, \mathrm{~B}$ \\
\hline $2 \mathrm{~B}$ duty, $4 \mathrm{~g} / \mathrm{cc}, 2^{\circ} \mathrm{C}$ & 1.8 & 0.2 & $3.3 \%$ & 5-7A,B \\
\hline $2 \mathrm{C}$ duty, $2 \mathrm{~g} / \mathrm{cc}, 2^{\circ} \mathrm{C}$ & 4.8 & 5.5 & $9.6 \%$ & 5-8A,B \\
\hline $3 \mathrm{~A}$ uniform, $6 \mathrm{~g} / \mathrm{cc}, 4^{\circ} \mathrm{C}$ & 1.7 & 0.15 & $3.1 \%$ & 5-9A,B \\
\hline $3 \mathrm{~B}$ uniform, $4 \mathrm{~g} / \mathrm{cc}, 4^{\circ} \mathrm{C}$ & 2.8 & 0.35 & $5.1 \%$ & $5-10 A, B$ \\
\hline $3 \mathrm{C}$ uniform, $2 \mathrm{~g} / \mathrm{cc}, 4^{\circ} \mathrm{C}$ & 6.2 & 7.5 & $12.4 \%$ & 5-11A,B \\
\hline $1 \mathrm{D}$ uniform, $4 \mathrm{~g} / \mathrm{cc}, 2^{\circ} \mathrm{C}^{*}$ & 1.15 & 0.3 & $2.1 \%$ & $5-12 A, B$ \\
\hline
\end{tabular}

The results table can be interpreted as follows: If you know the average particle density retrieved in a given daily campaign, the results table provides the escape fraction for that day. Results for $6 \mathrm{~g} / \mathrm{cc}$ cases should be considered to represent average expected behavior, and results for $4 \mathrm{~g} / \mathrm{cc}$ cases should be considered to represent a the impact of reasonable variation in expected particle density. Results for $2 \mathrm{~g} / \mathrm{cc}$ cases represent an extreme case that might arise in practice near the end of retrieval for a given settler tube. The total fraction of escaped particles for a settler tube can be estimated by assuming some fraction of particles at $6 \mathrm{~g} / \mathrm{cc}$, some fraction 
PRC-STP-00011, Rev. 0

of particles at $4 \mathrm{~g} / \mathrm{cc}$, and some fraction at $2 \mathrm{~g} / \mathrm{cc}$, and weighting the results in Table $5-2$ by the assumed fractions. For example, using a weighting of $60 \%$ at $6 \mathrm{~g} / \mathrm{cc}, 30 \%$ at $4 \mathrm{~g} / \mathrm{cc}$, and $10 \%$ at $2 \mathrm{~g} / \mathrm{cc}$ for case 1 yields an overall escape fraction of $3.4 \%$.

The impact of filters is estimated by noting the suspended particle concentration for case $1 \mathrm{~B}$, which in the steady state is about $25 \mathrm{~L}$ in a container volume of about 14,000 L (due to preexisting sludge) yielding $0.18 \%$. In the absence of filter flow, the rate of outflow to the basin is equal to the rate of inflow from the settler tube. The average incoming particle volume fraction is $0.47 \%$. Therefore the fraction of particles escaping is $0.18 / 0.47=38 \%$. 
PRC-STP-00011, Rev. 0

Attachment A

\section{$5-14$}

\subsection{Conclusions}

Conclusions may be summarized as follows:

(1) Results for long-term suspended particle volume demonstrate that daily retrieval campaigns are independent of one another with respect to the potential for particle escape.

(2) Results are not very sensitive to assumed idealizations of operations, and the simple case of uniform particle addition provides a bounding but not unrealistically high estimate for particle escape.

(3) The most important sludge property that governs the potential for particle escape is particle density. The parameter of second interest to results is the temperature of water entering the container. This depends mostly on the water supply temperature for the high pressure mobilization lance.

(4) The escape fraction for particles of average expected density $(6 \mathrm{~g} / \mathrm{cc})$ is between about $1 \%$ and $2 \%$ depending on the inlet water temperature (Cases $2 \mathrm{~A}$ and $3 \mathrm{~A}$ ). The escape fraction for particles of less than average expected density $(4 \mathrm{~g} / \mathrm{cc})$ is between about $2 \%$ and $6 \%$ (Cases $2 \mathrm{~B}$ and $3 \mathrm{~B}$ ). The escape fraction for extremely light particles could range from about $8 \%$ to $13 \%$ (Cases $2 \mathrm{C}$ and $3 \mathrm{C}$ ).

(5) Extending filter operation for a few hours after the end of daily particle retrieval does have a clear benefit (compare cases $1 B$ and $1 D$ ). It is recommended that filters be operated for at least 30 minutes after the last particle retrieval, corresponding to the assumed operation here, because that is when the suspended particle volume is highest and extended operation has a clear benefit.

(6) The impact of filters is substantial; without them, about $1 / 3$ of added particles would escape. 
PRC-STP-00011, Rev. 0

\subsection{Section 5 Figures}

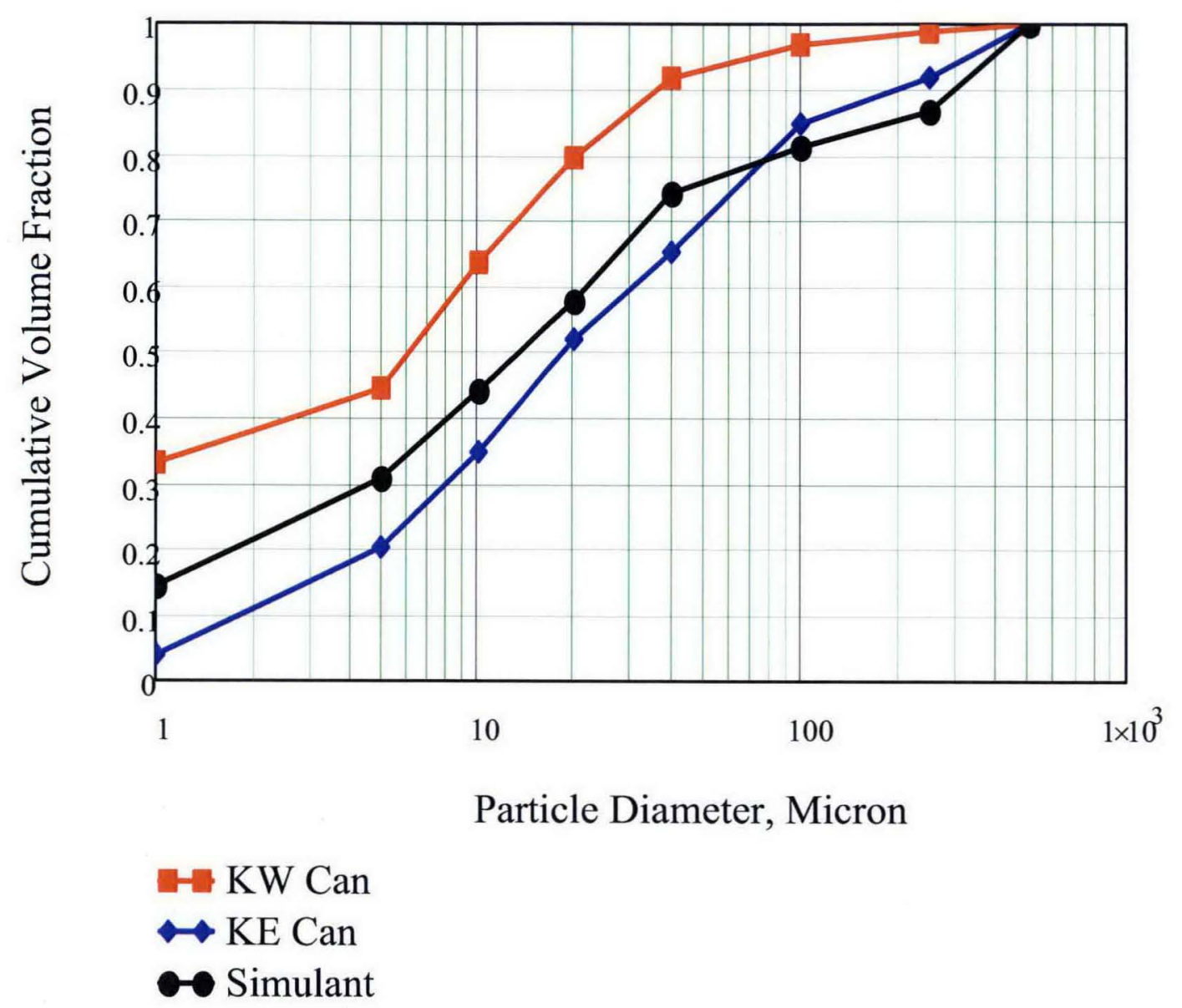

Figure 5-1 PNNL particle size and data [Schmidt and Zacher, 2007]. 
PRC-STP-00011, Rev. 0

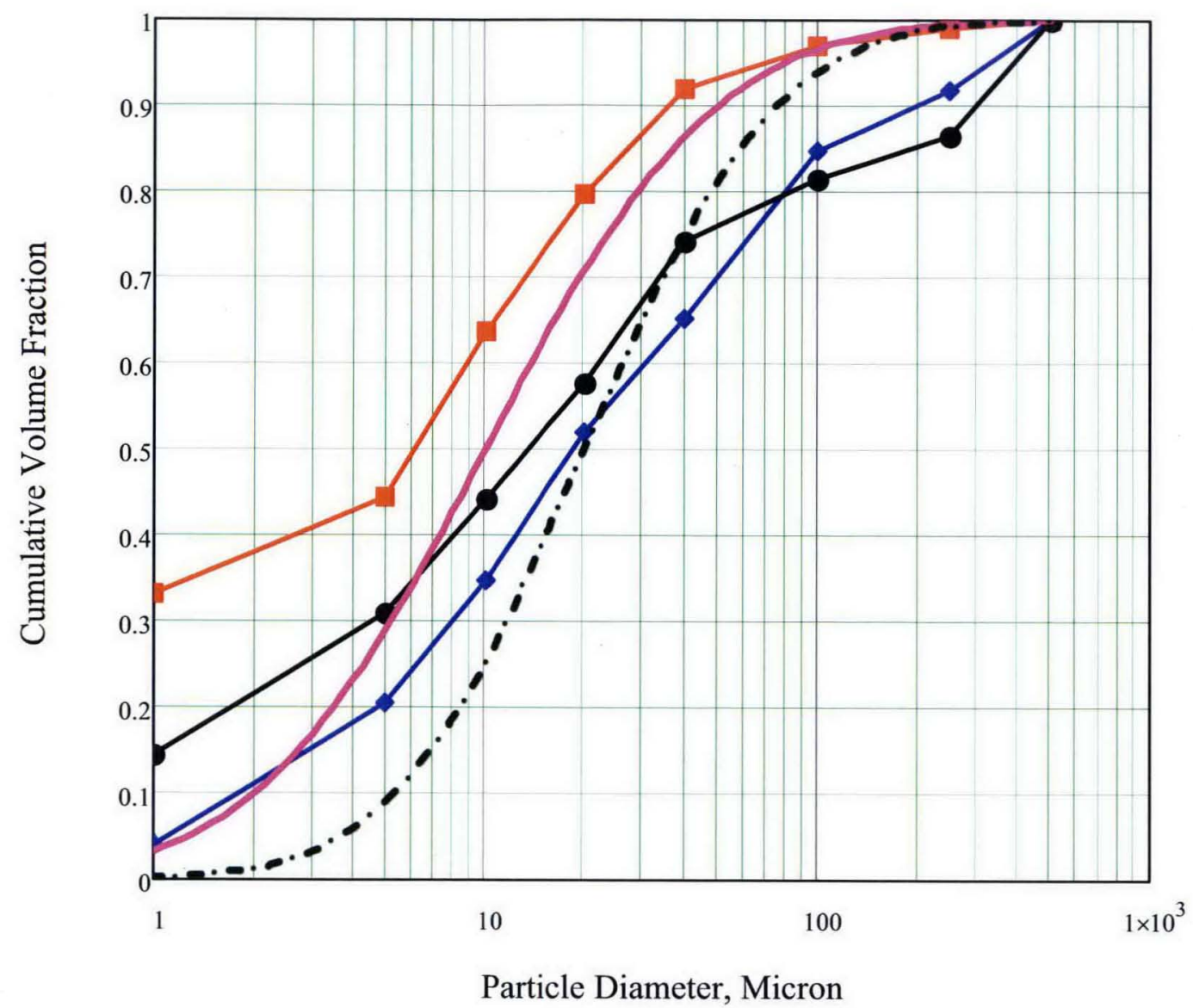

를 KW Can

$\leadsto$ KE Can

- Simulant

LogNormal, 10 micron

-. Normal, 20 micron

Figure 5-2 Comparison of log-normal distributions and data. 


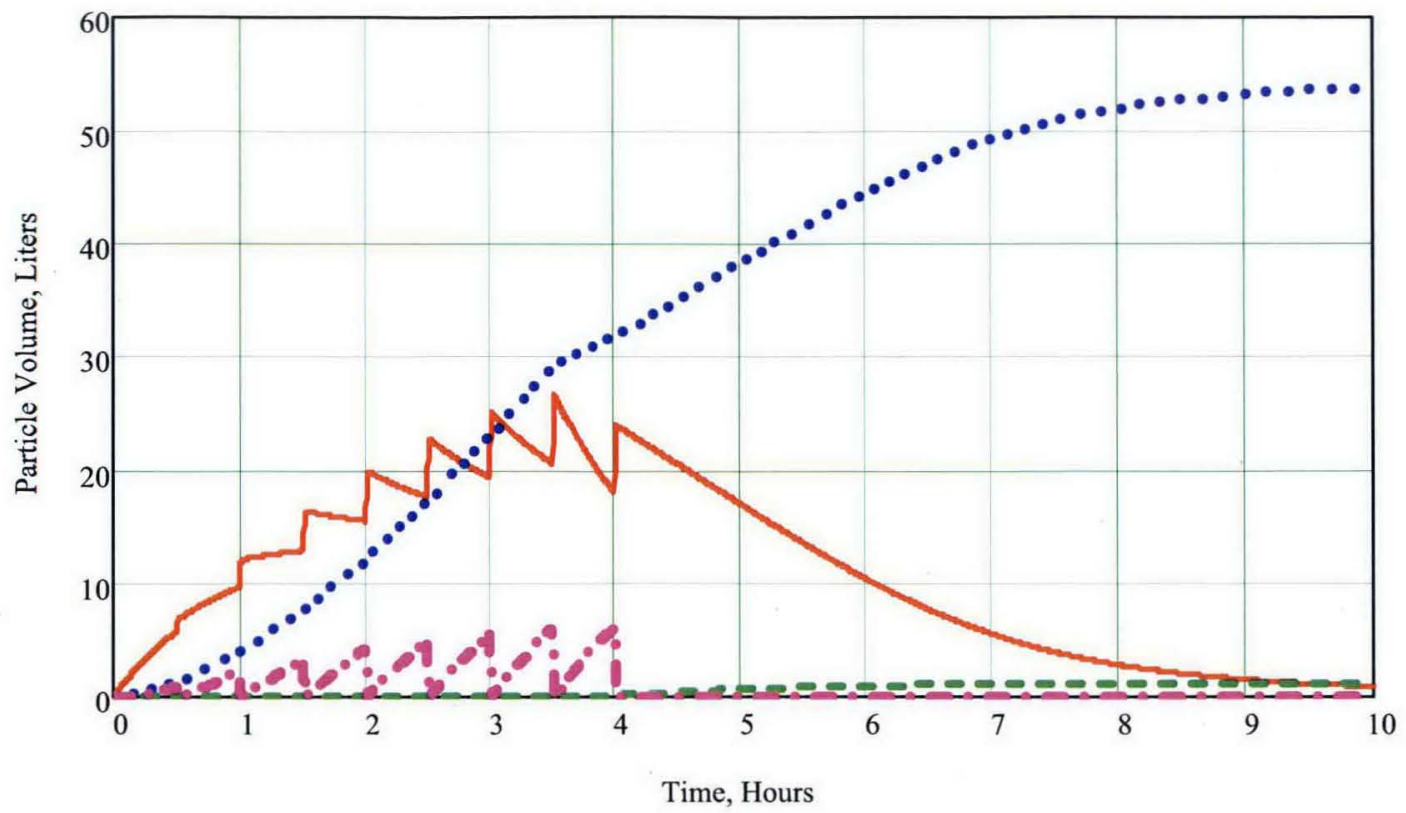

\footnotetext{
Suspended

-. Settled

- Escaped to Basin

- Filter Cake
}

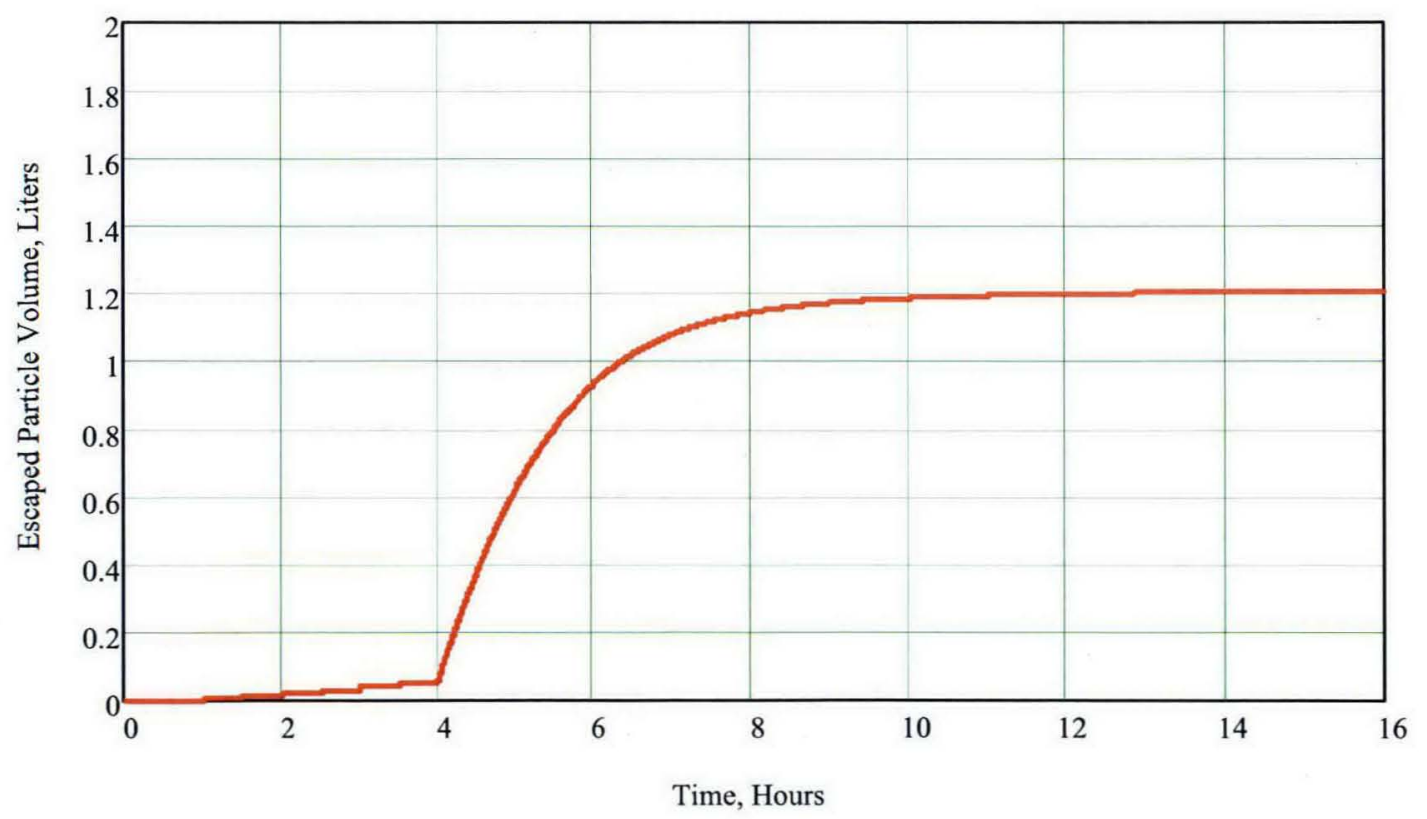

Figure 5-3A Case $1 \mathrm{~A}$ results 
PRC-STP-00011, Rev. 0

5-18

Attachment A
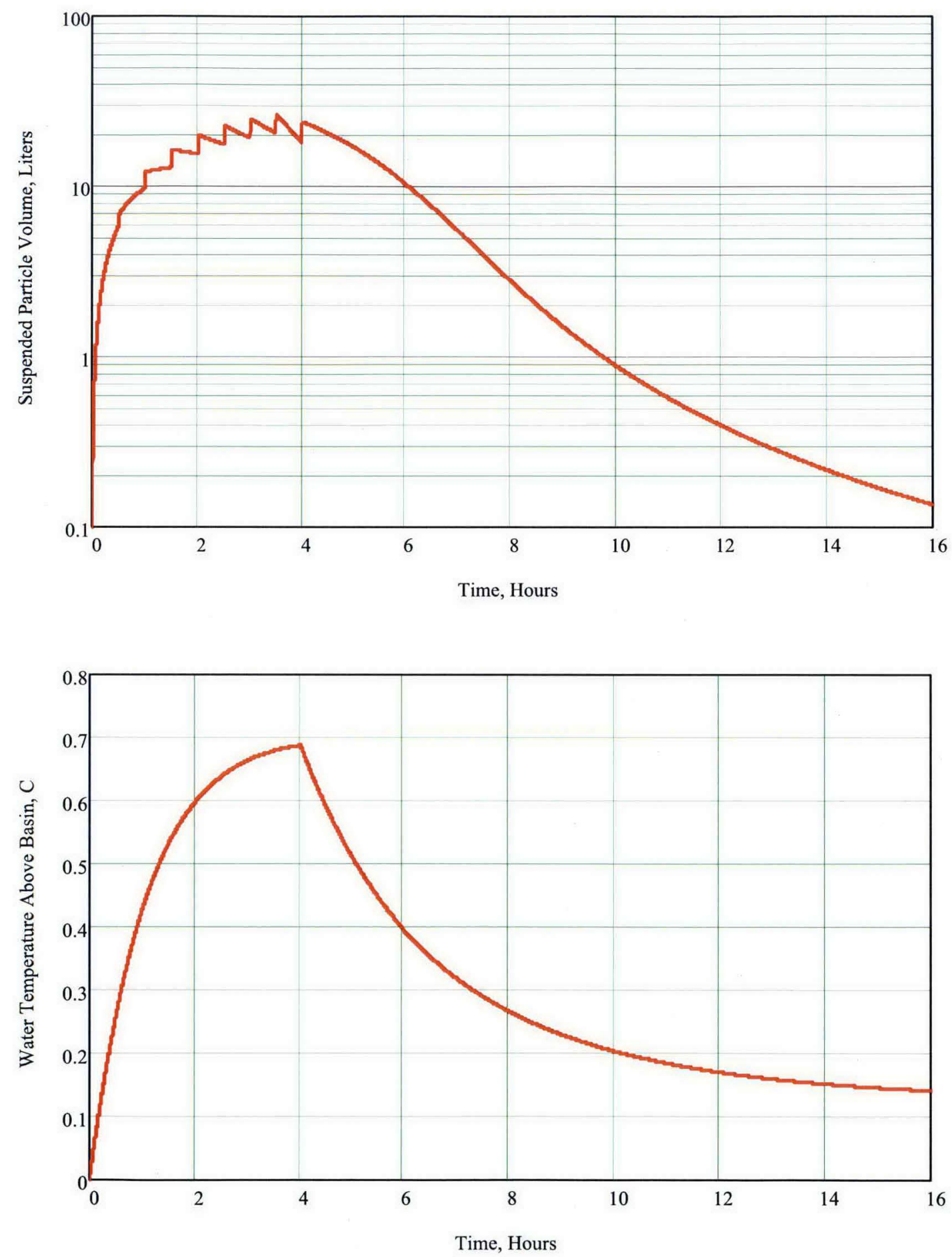

Figure 5-3B Case 1A results, continued. 
PRC-STP-00011, Rev. 0

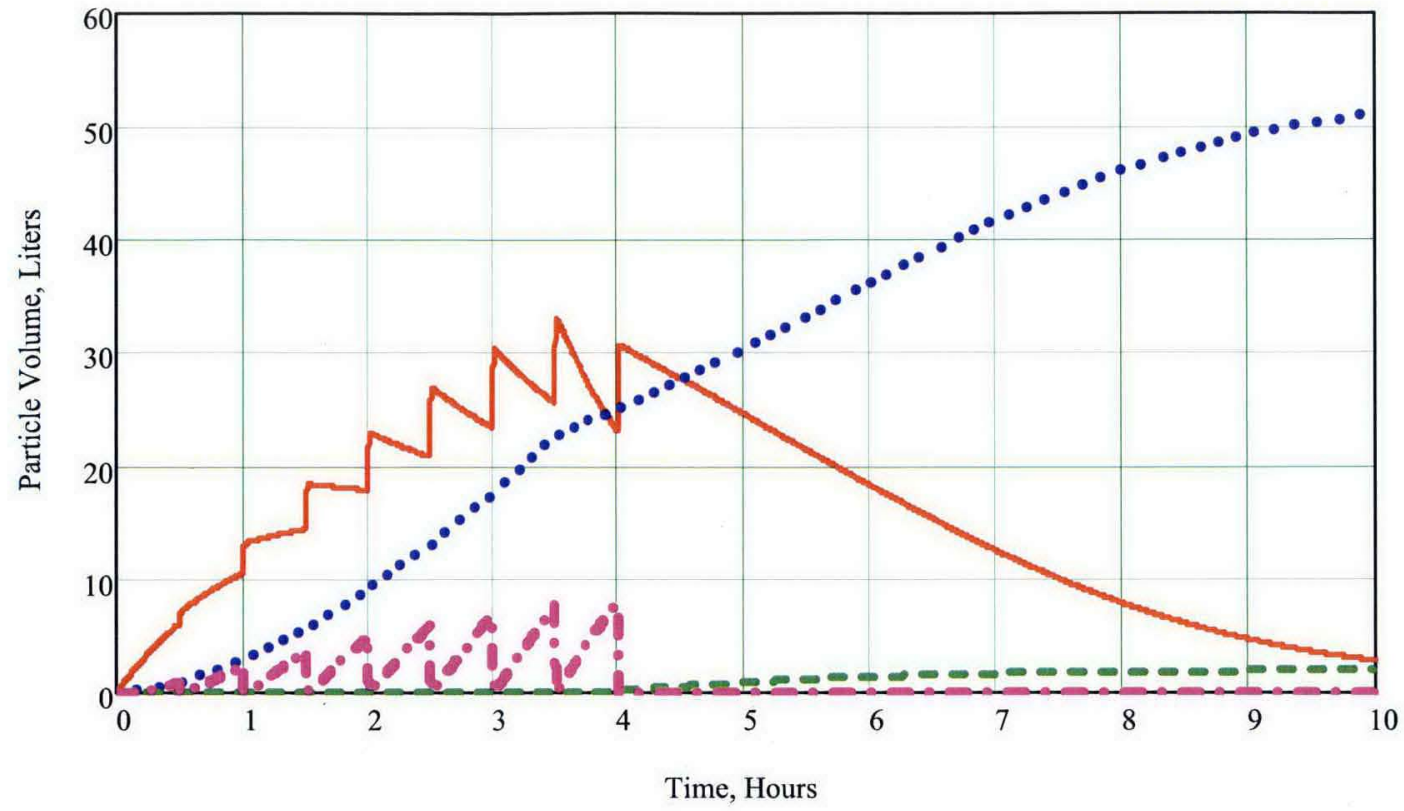

Suspended

-. Settled

- - Escaped to Basin

- Filter Cake

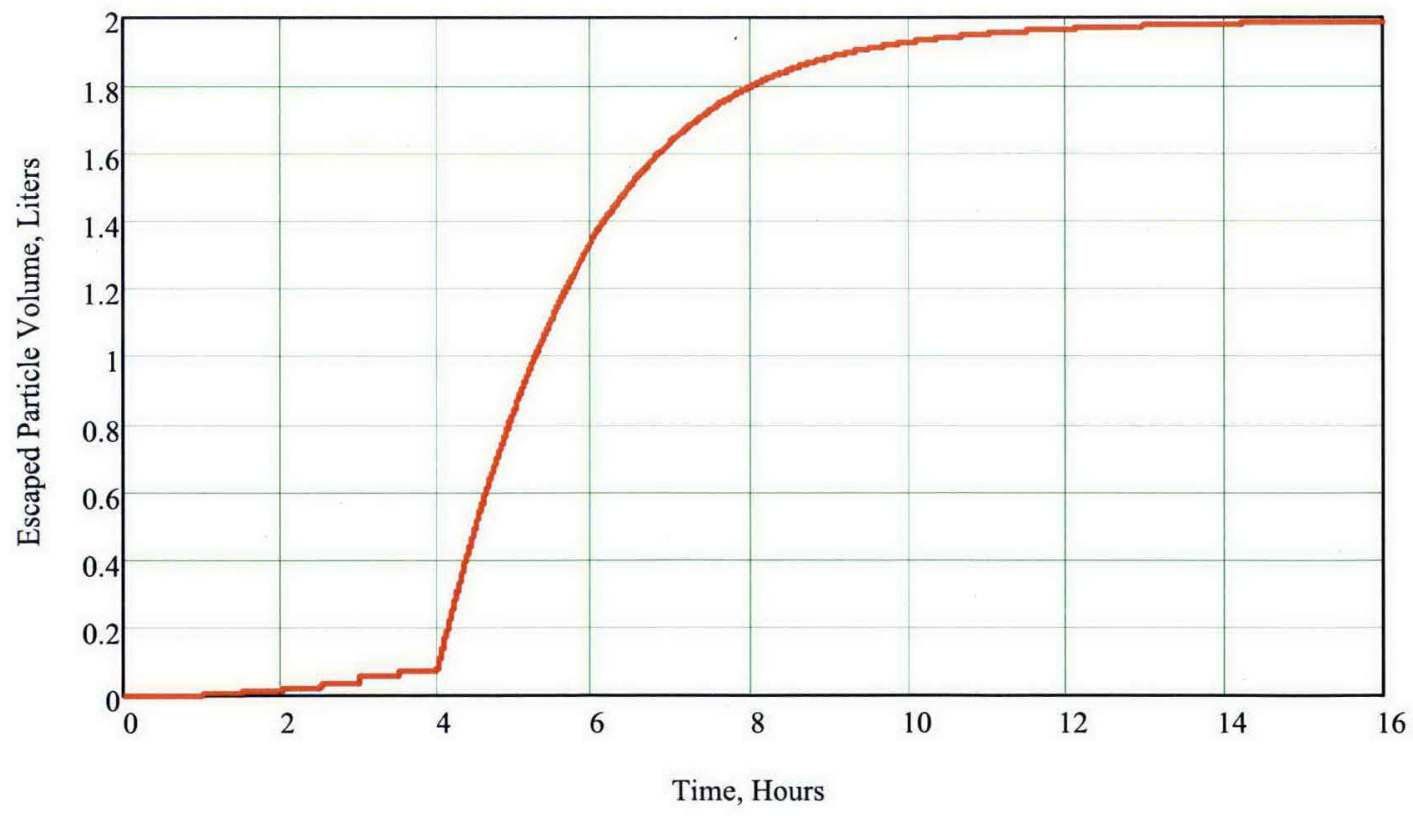

Figure 5-4A Case 1B results. 
PRC-STP-00011, Rev. 0

\section{$5-20$}

Attachment A

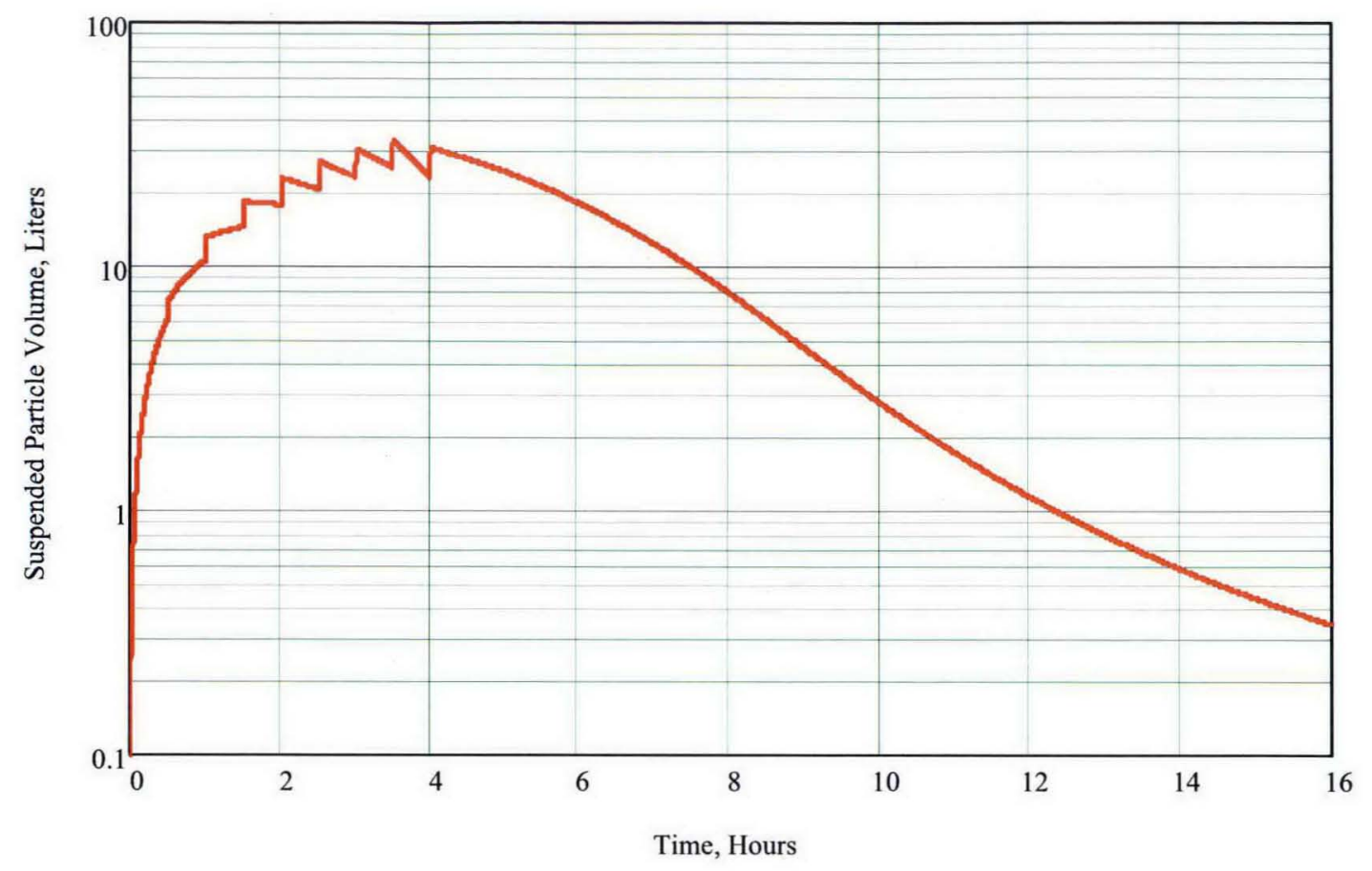

Figure 5-4B Case $1 \mathrm{~B}$ results, continued. 
PRC-STP-00011, Rev. 0

\section{$5-21$}

Attachment $\mathrm{A}$

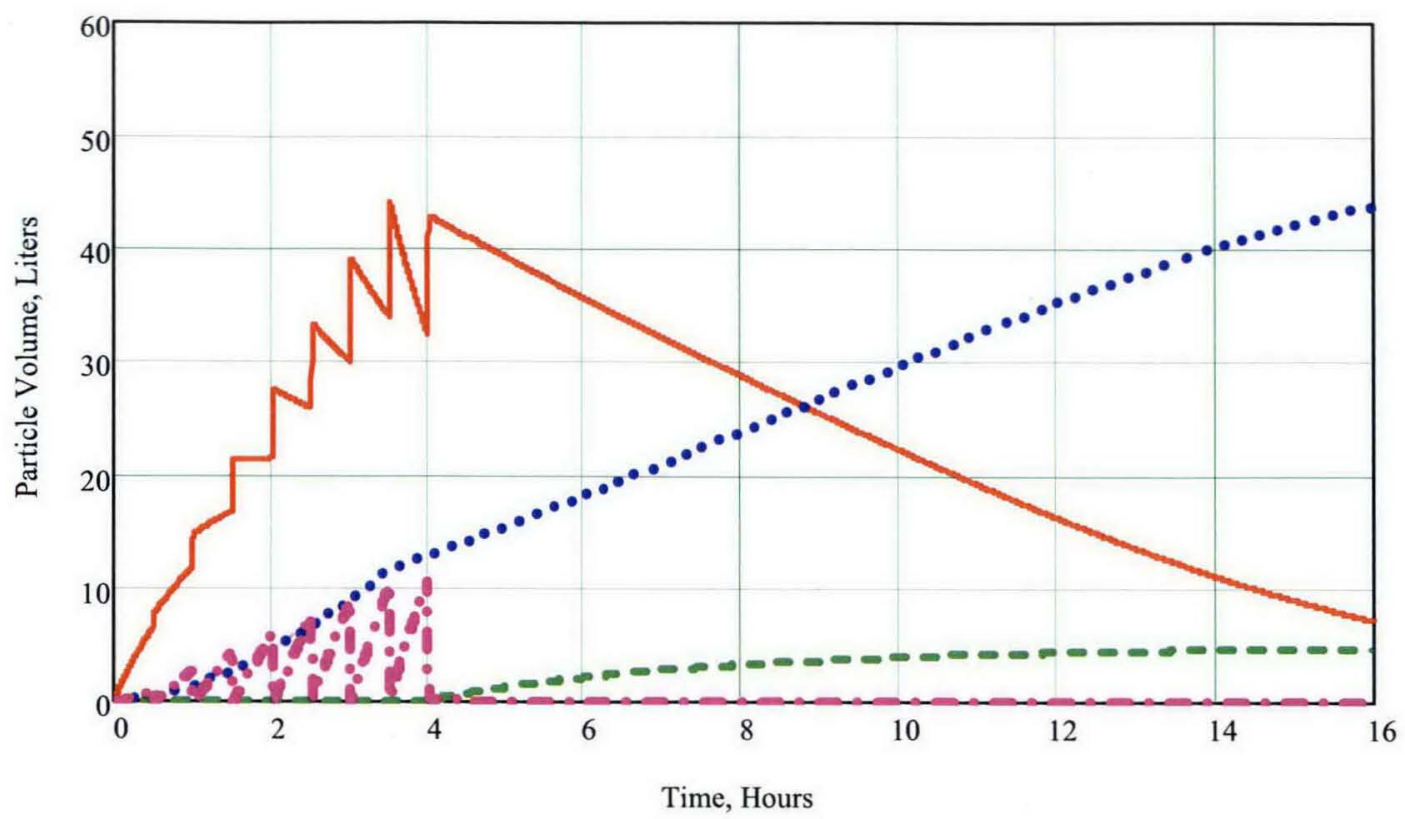

Suspended

-. Settled

- Escaped to Basin

- Filter Cake

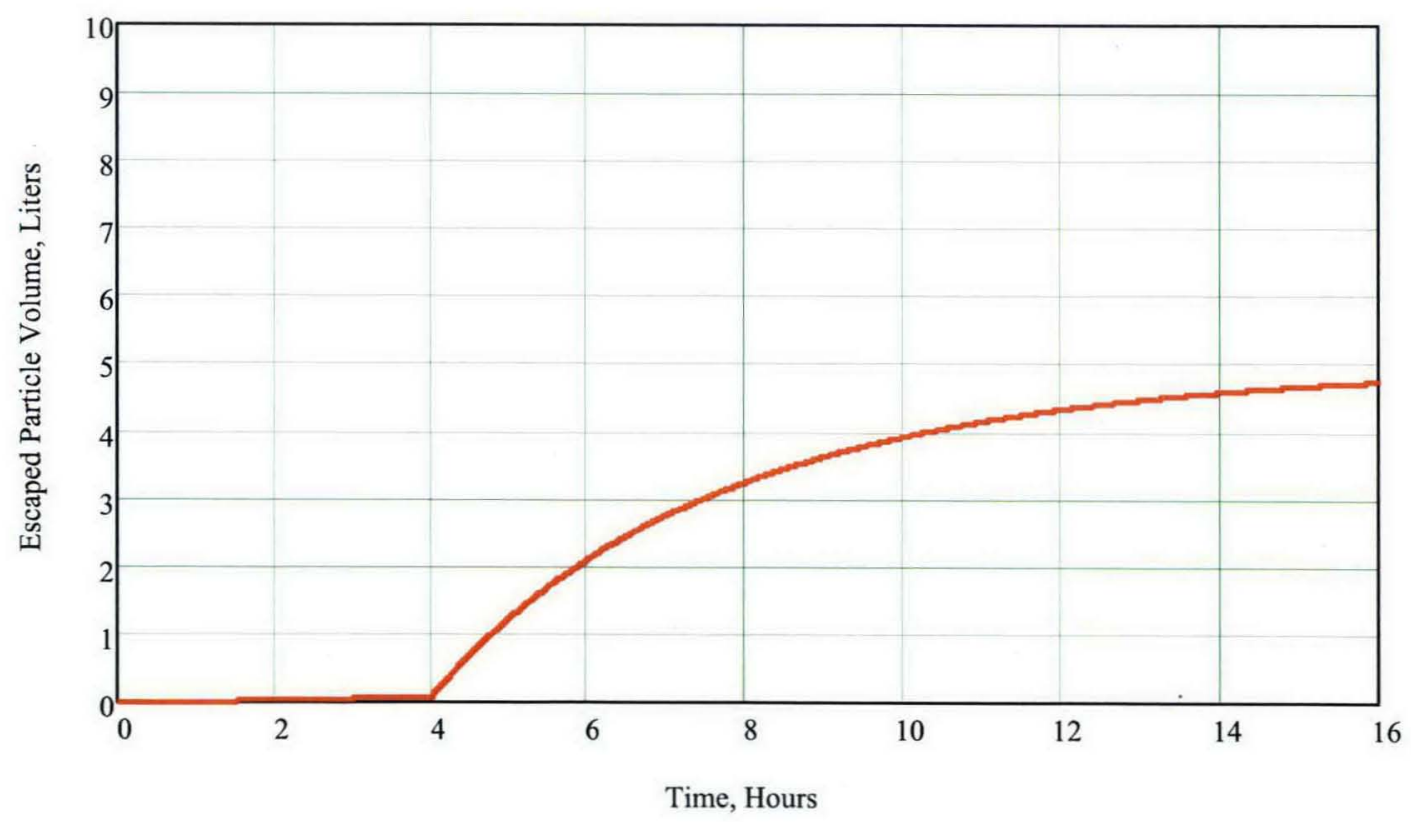

Figure 5-5A Case 1C results. 
PRC-STP-00011, Rev. 0

\section{$5-22$}

Attachment $A$

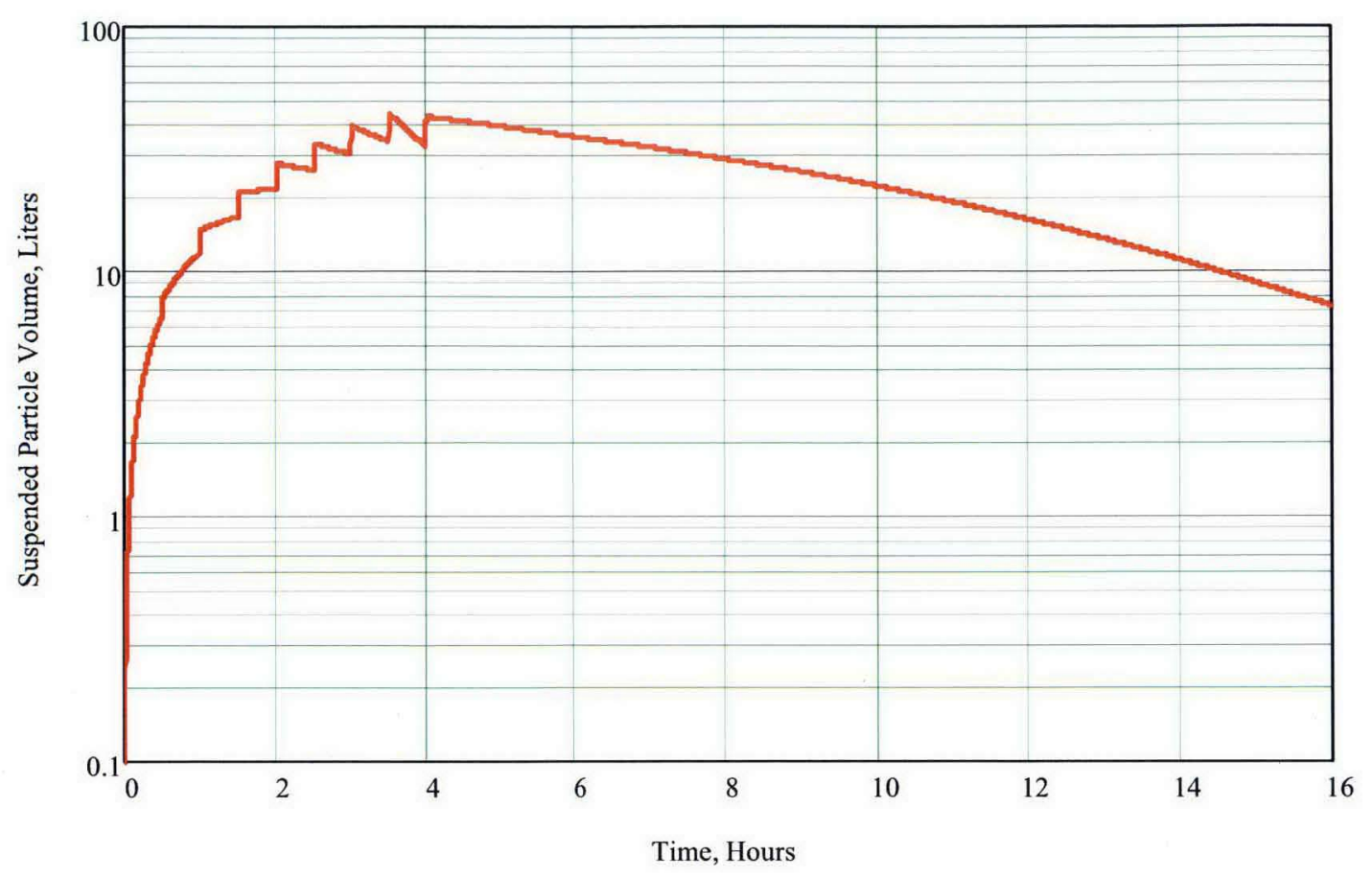

Figure 5-5B Case $1 \mathrm{C}$ results, continued. 
PRC-STP-00011, Rev. 0

Attachment $A$

\section{$5-23$}

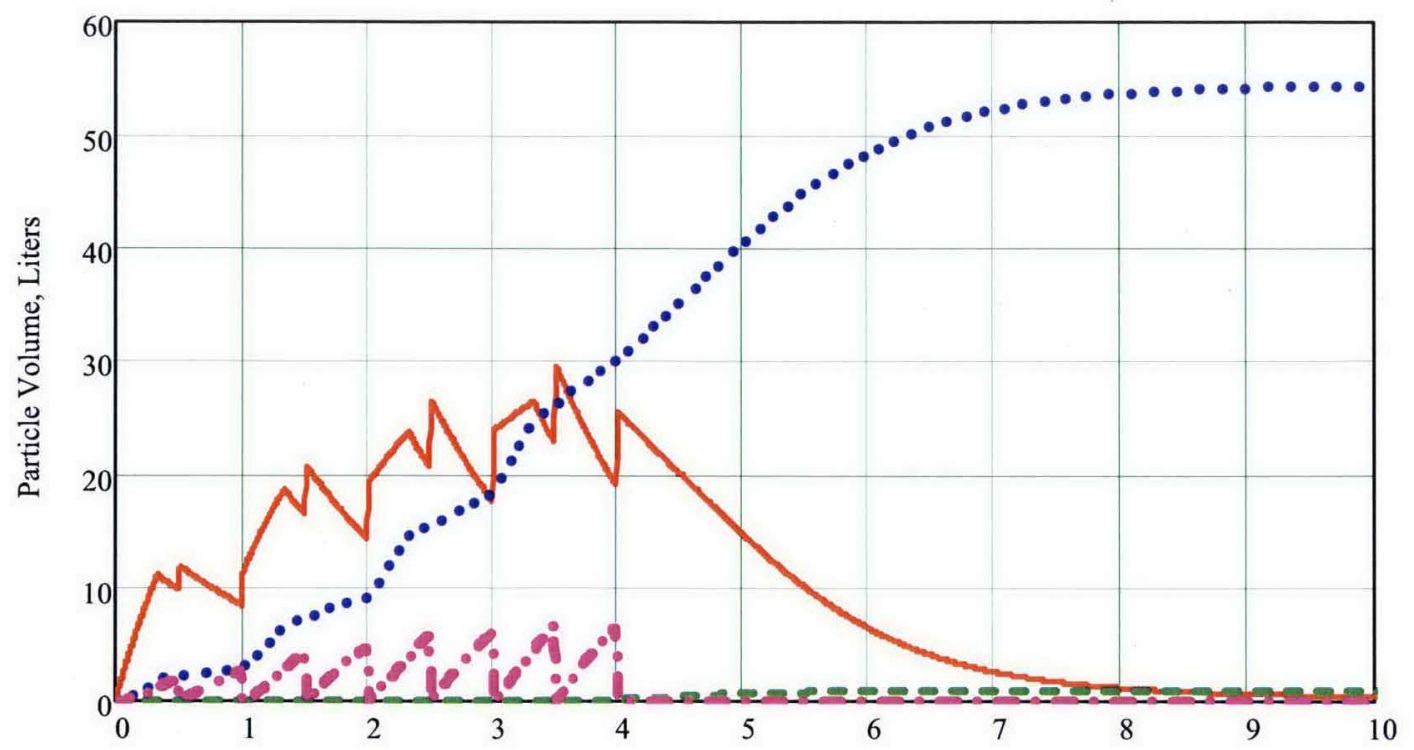

Time, Hours

Suspended

-. Settled

- - Escaped to Basin

- Filter Cake

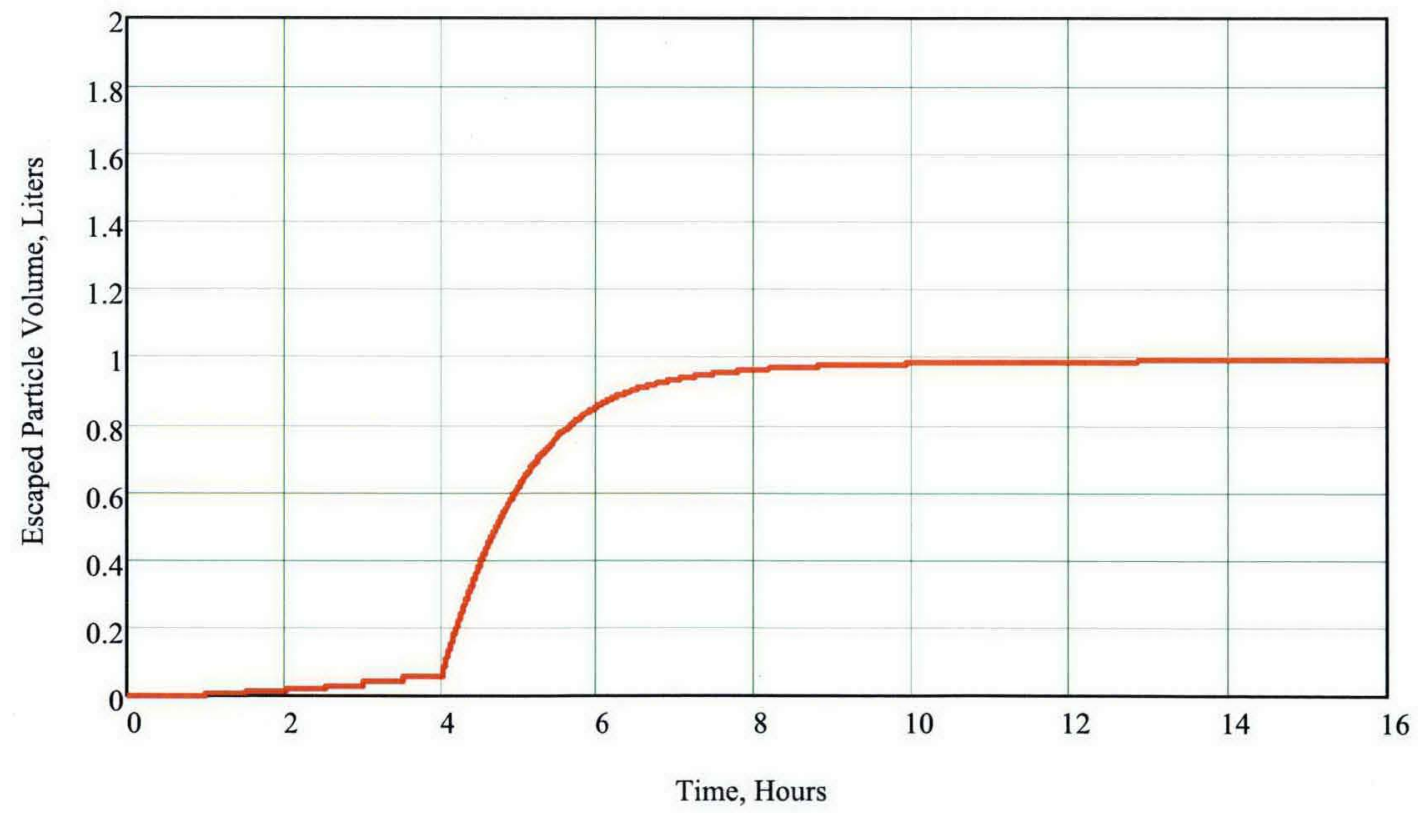

Figure 5-6A Case 2A results. 
PRC-STP-00011, Rev. 0

Attachment A

\section{$5-24$}
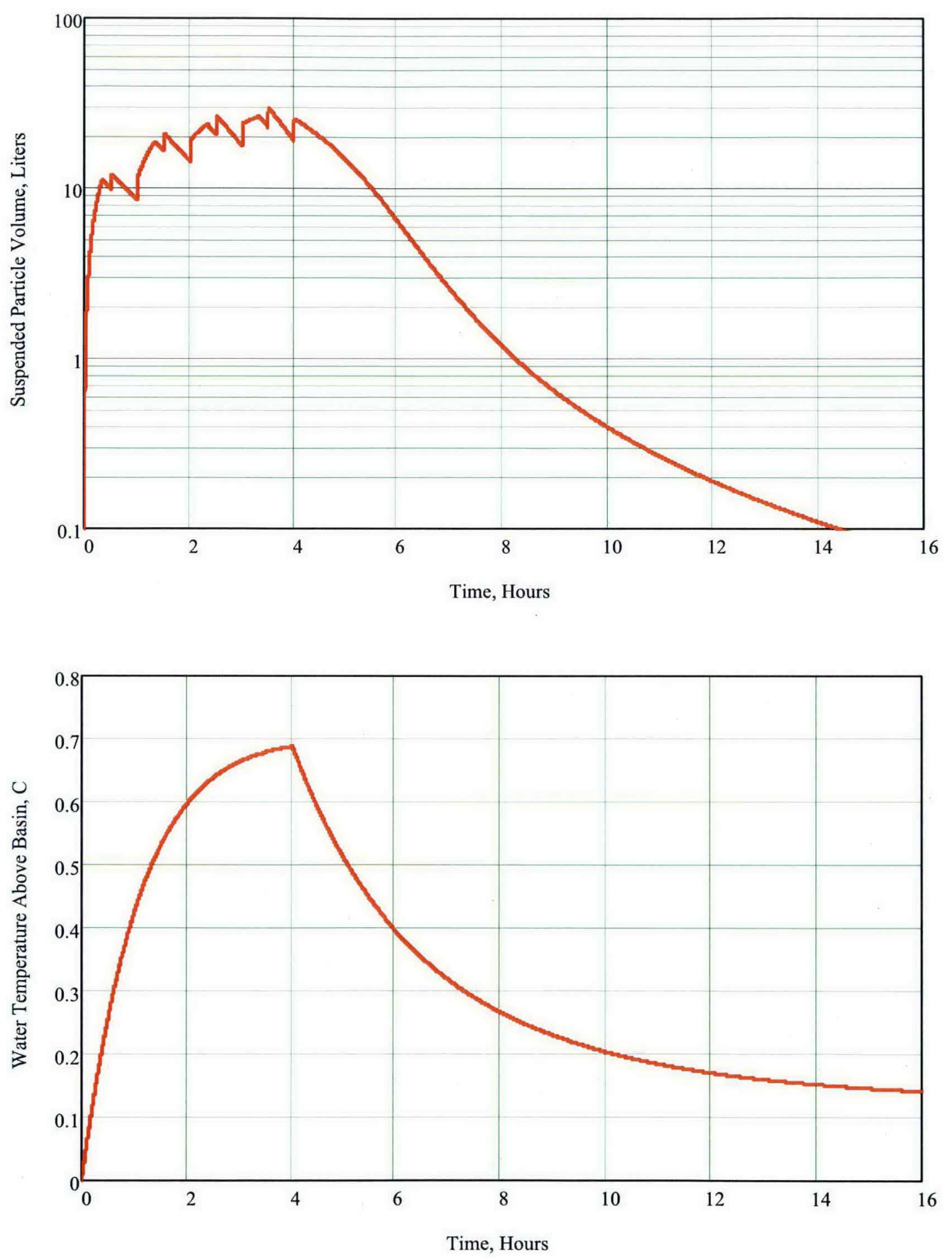

Figure 5-6B Case 2A results, continued. 
PRC-STP-00011, Rev. 0

Attachment A

\section{$5-25$}

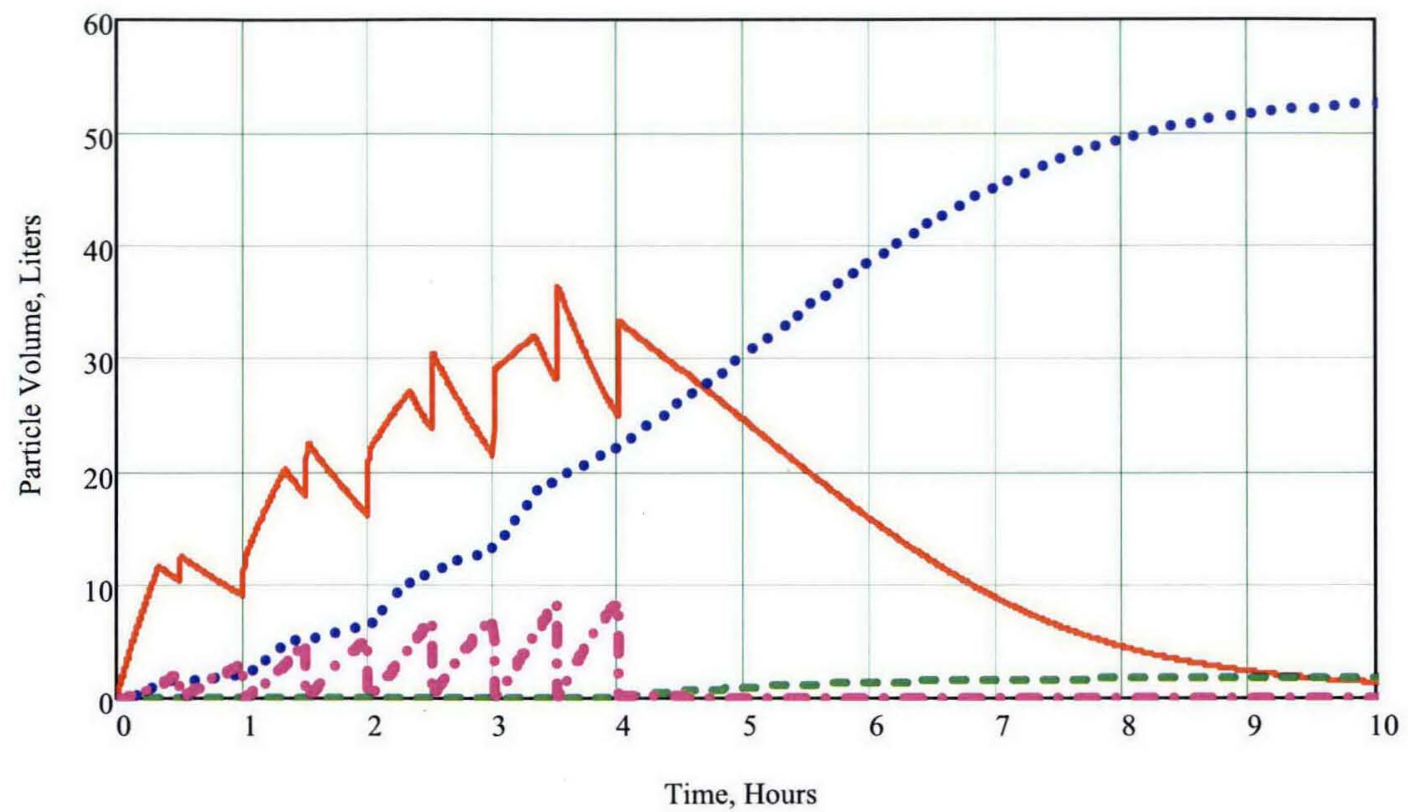

Suspended

-. Settled

- - Escaped to Basin

- Filter Cake

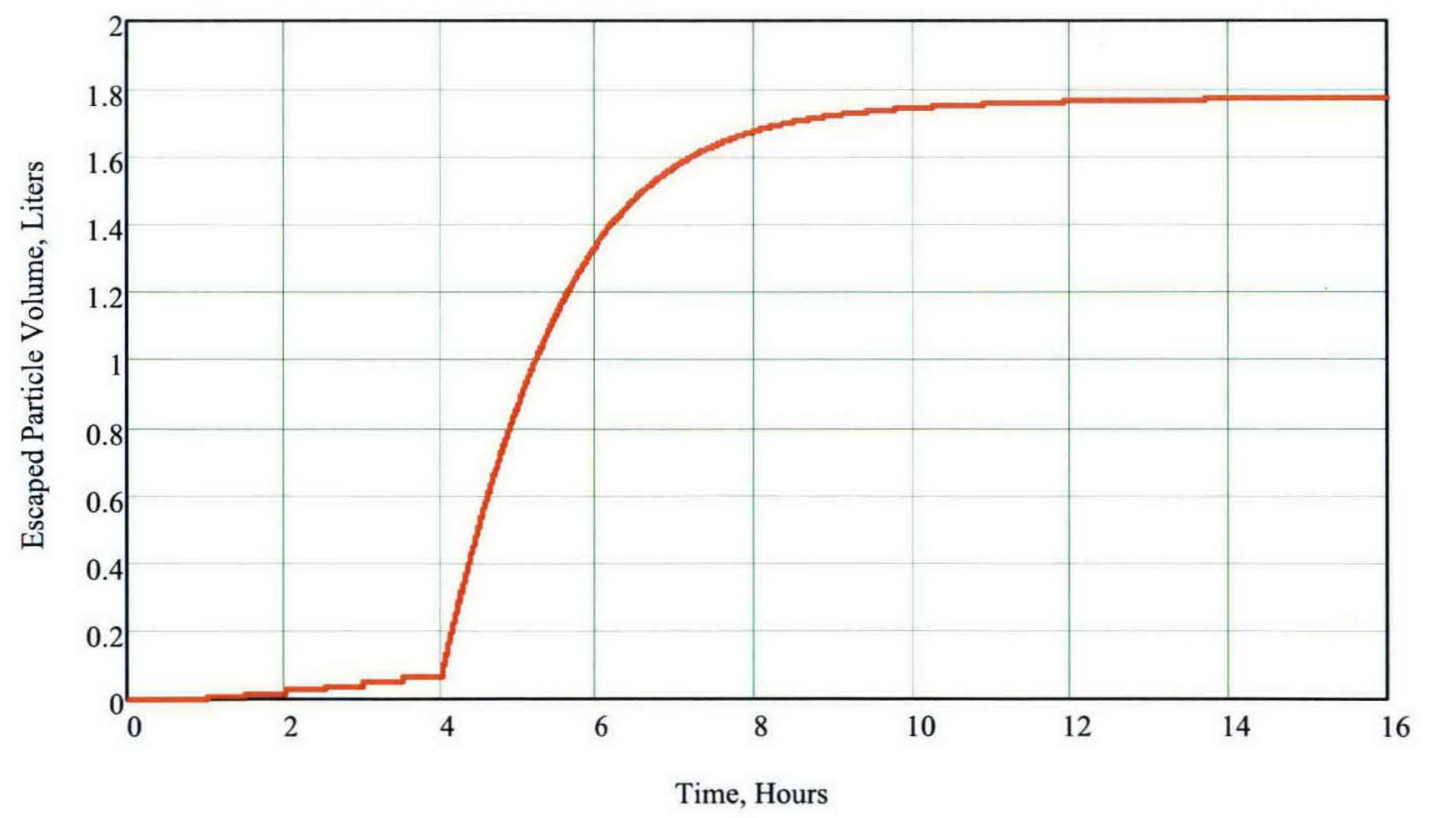

Figure 5-7A Case 2B results. 
PRC-STP-00011, Rev. 0

\section{5-26}

Attachment $A$

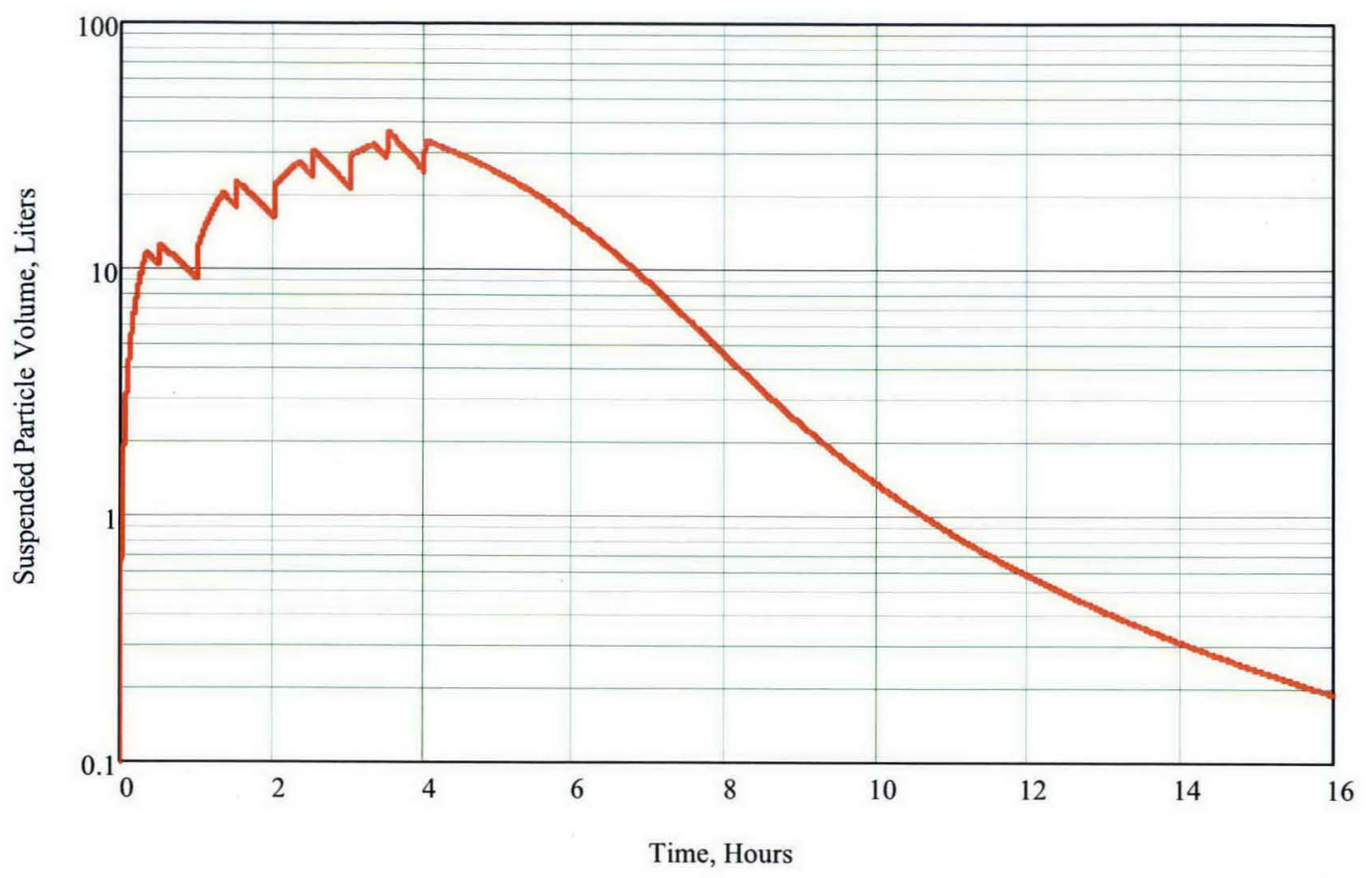

Figure 5-7B Case $2 \mathrm{~B}$ results, continued. 
PRC-STP-00011, Rev. 0

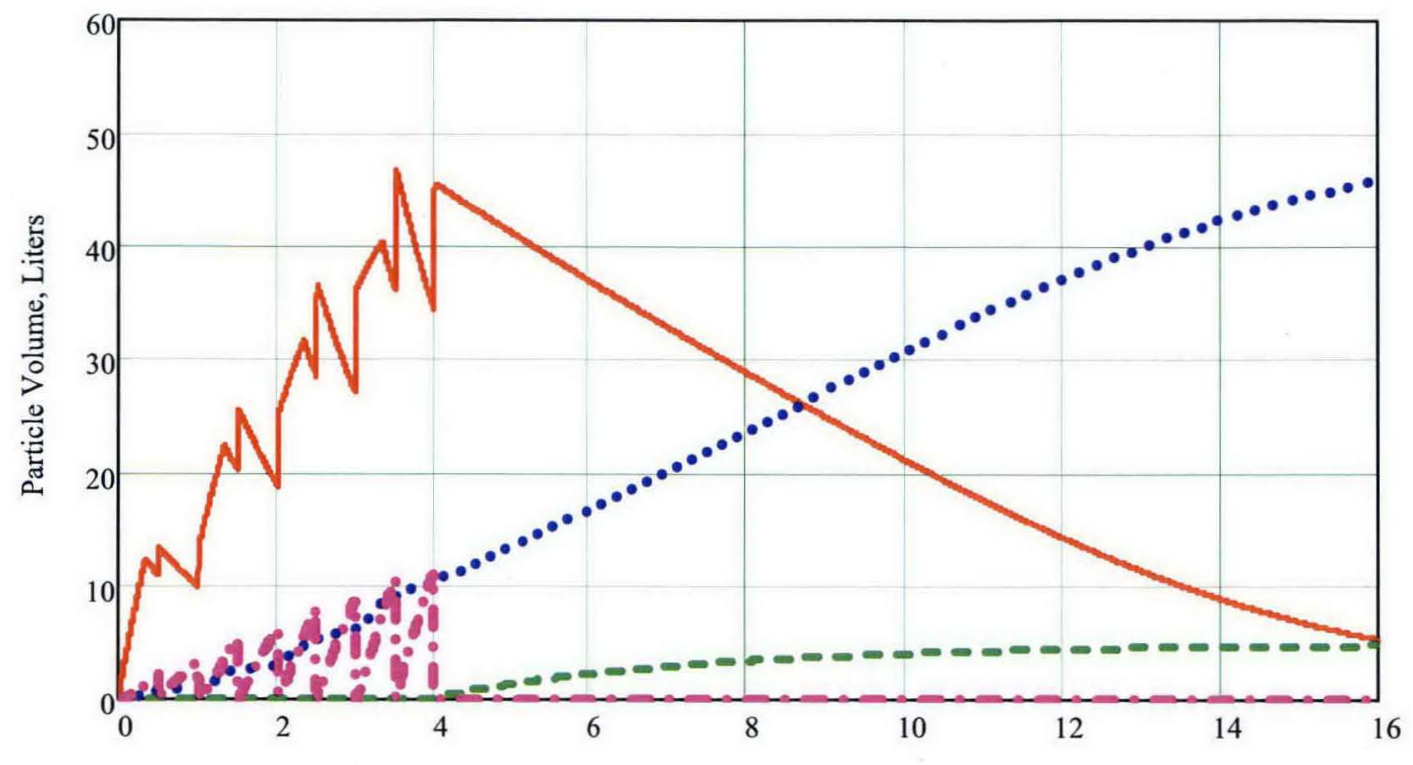

Time, Hours
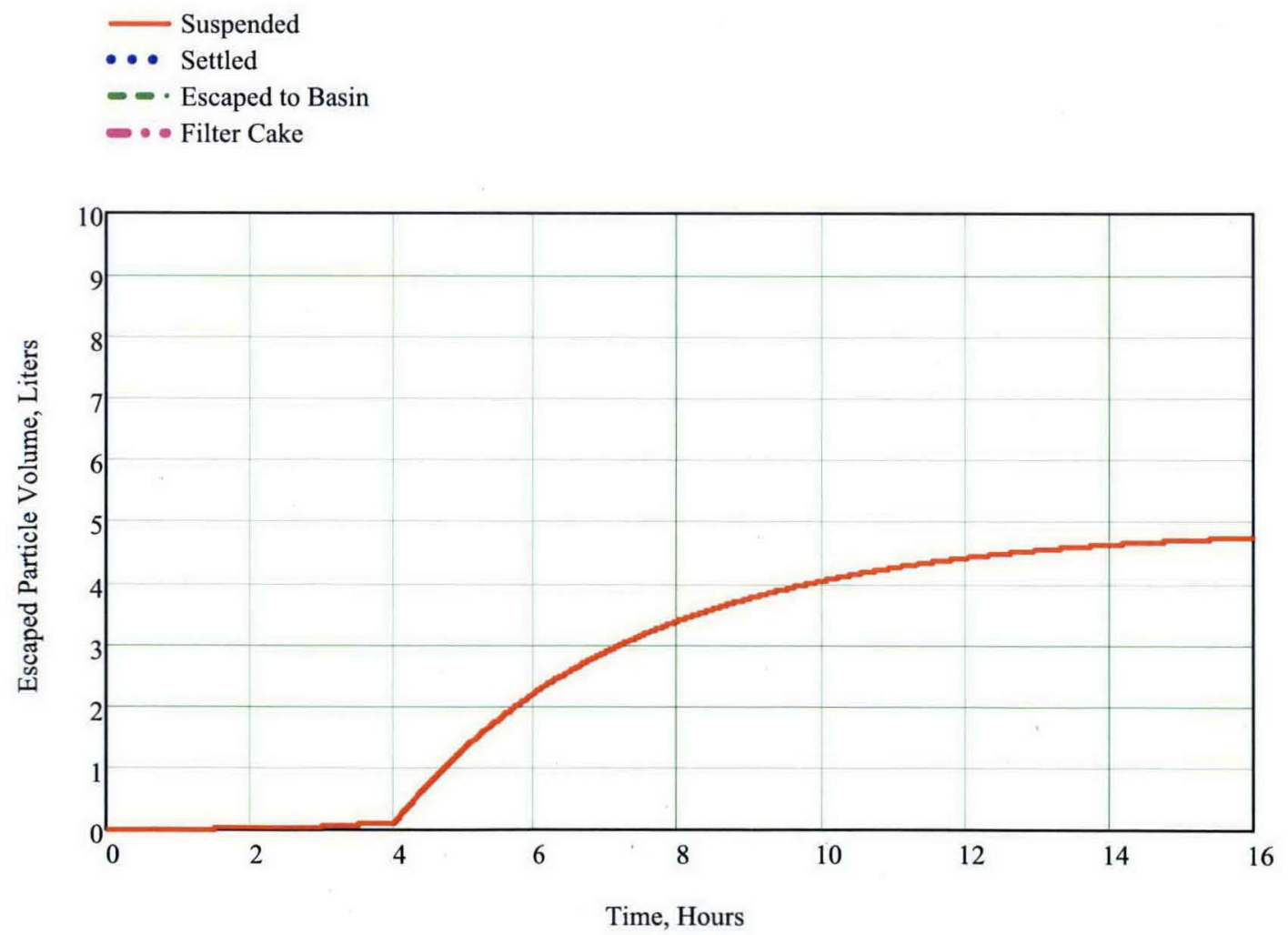

Figure 5-8A Case $2 \mathrm{C}$ results. 
PRC-STP-00011, Rev. 0

Attachment A

\section{$5-28$}

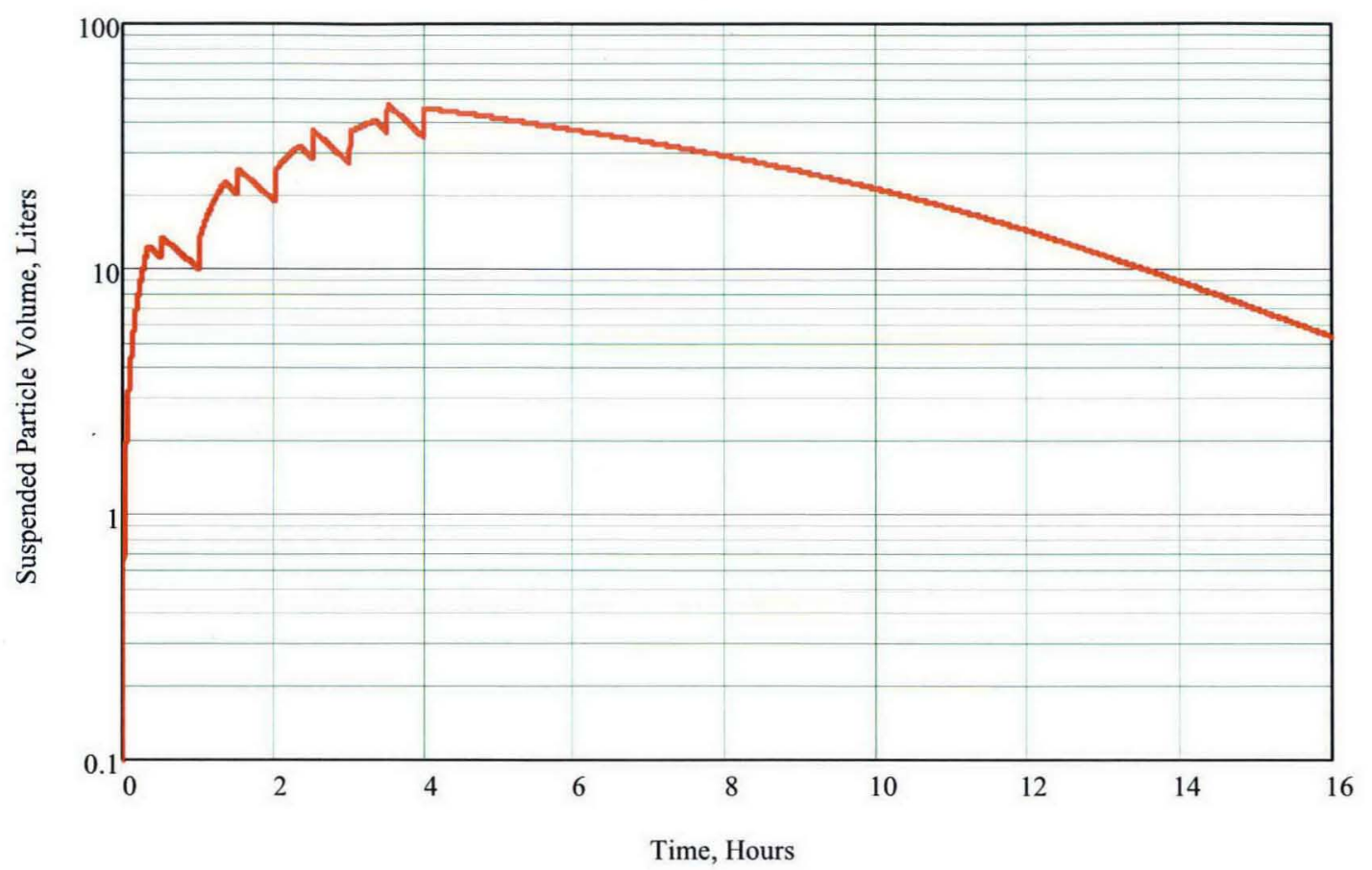

Figure 5-8B Case $2 \mathrm{C}$ results, continued. 
PRC-STP-00011, Rev. 0

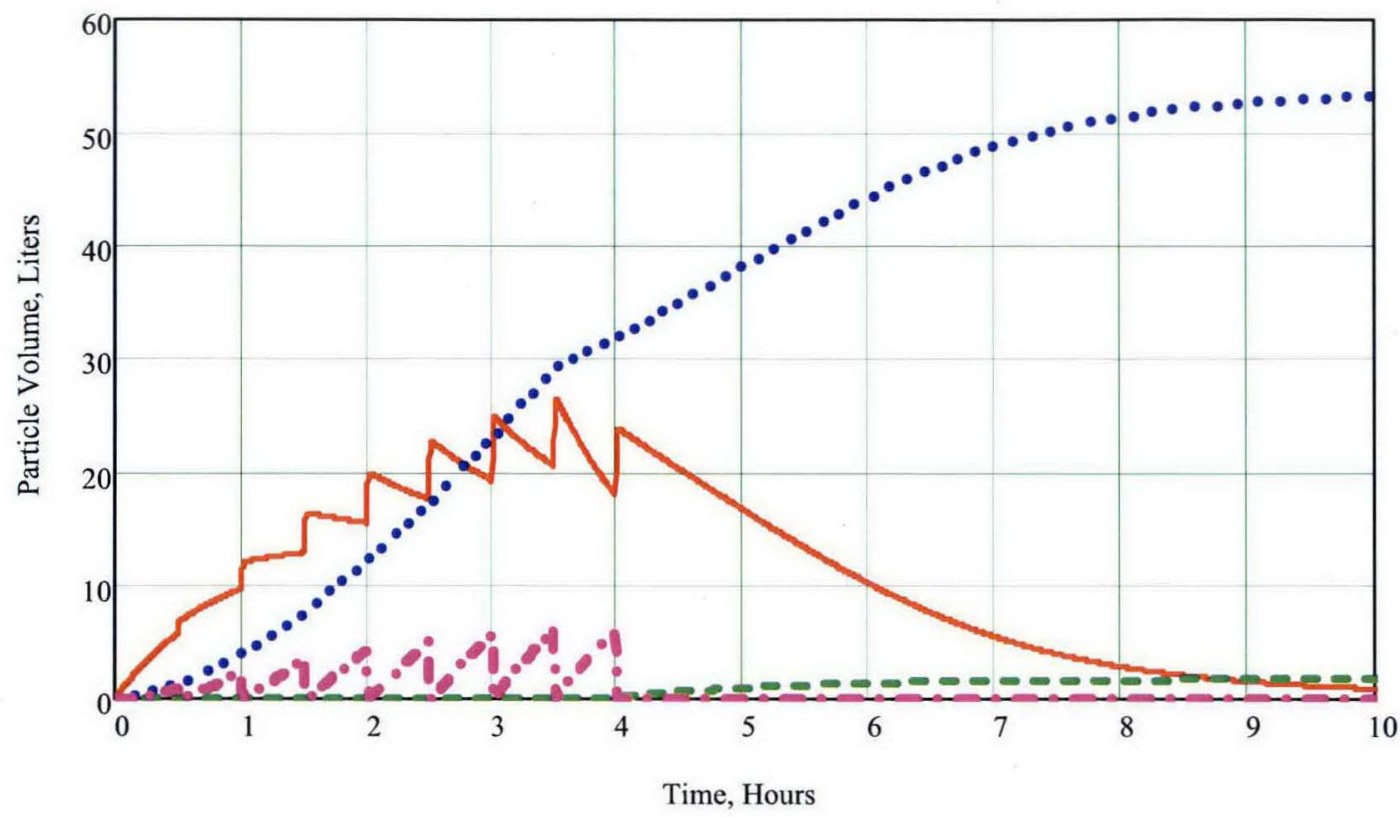

Suspended

-. Settled

- - Escaped to Basin

- Filter Cake

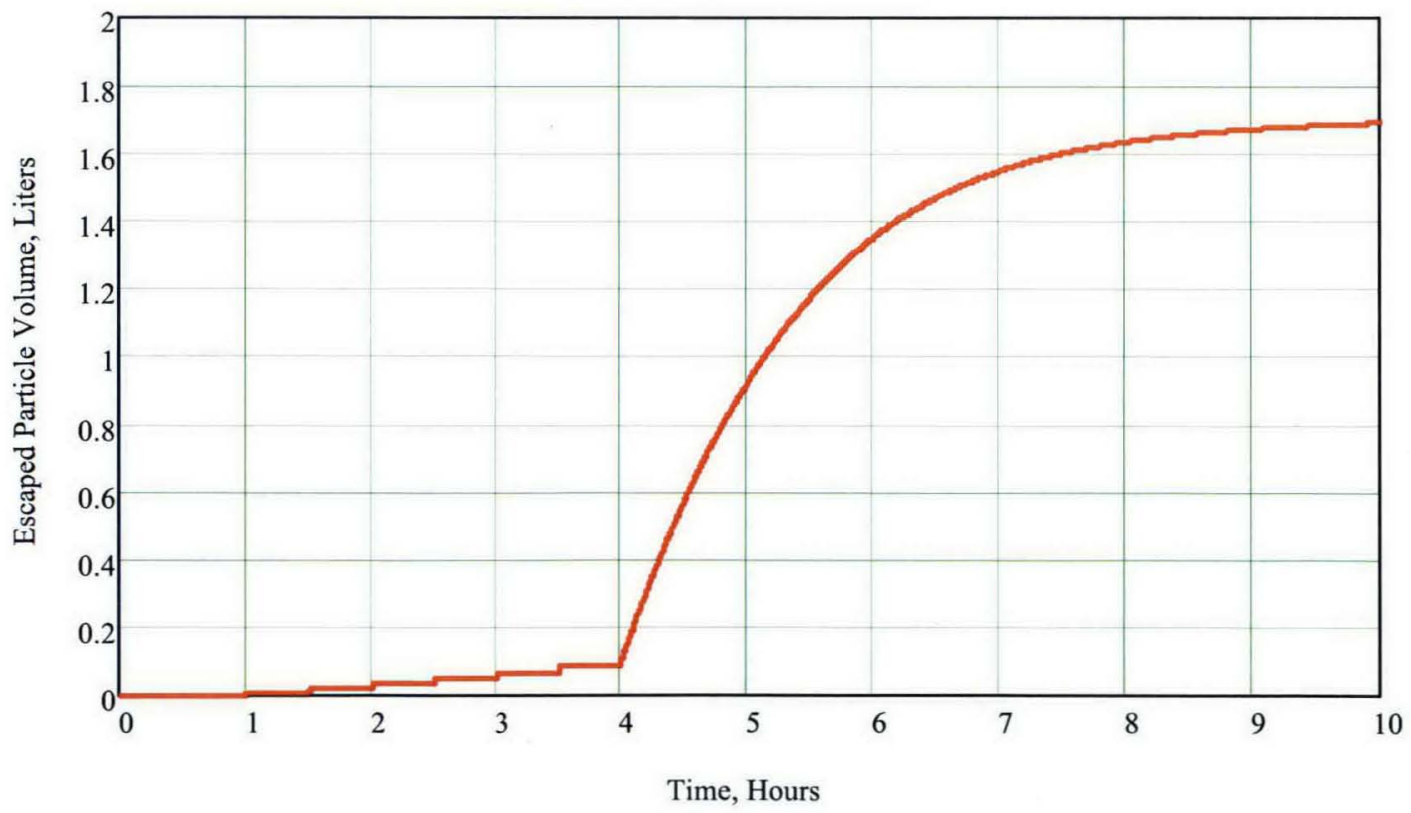

Figure 5-9A Case 3A results. 
PRC-STP-00011, Rev. 0
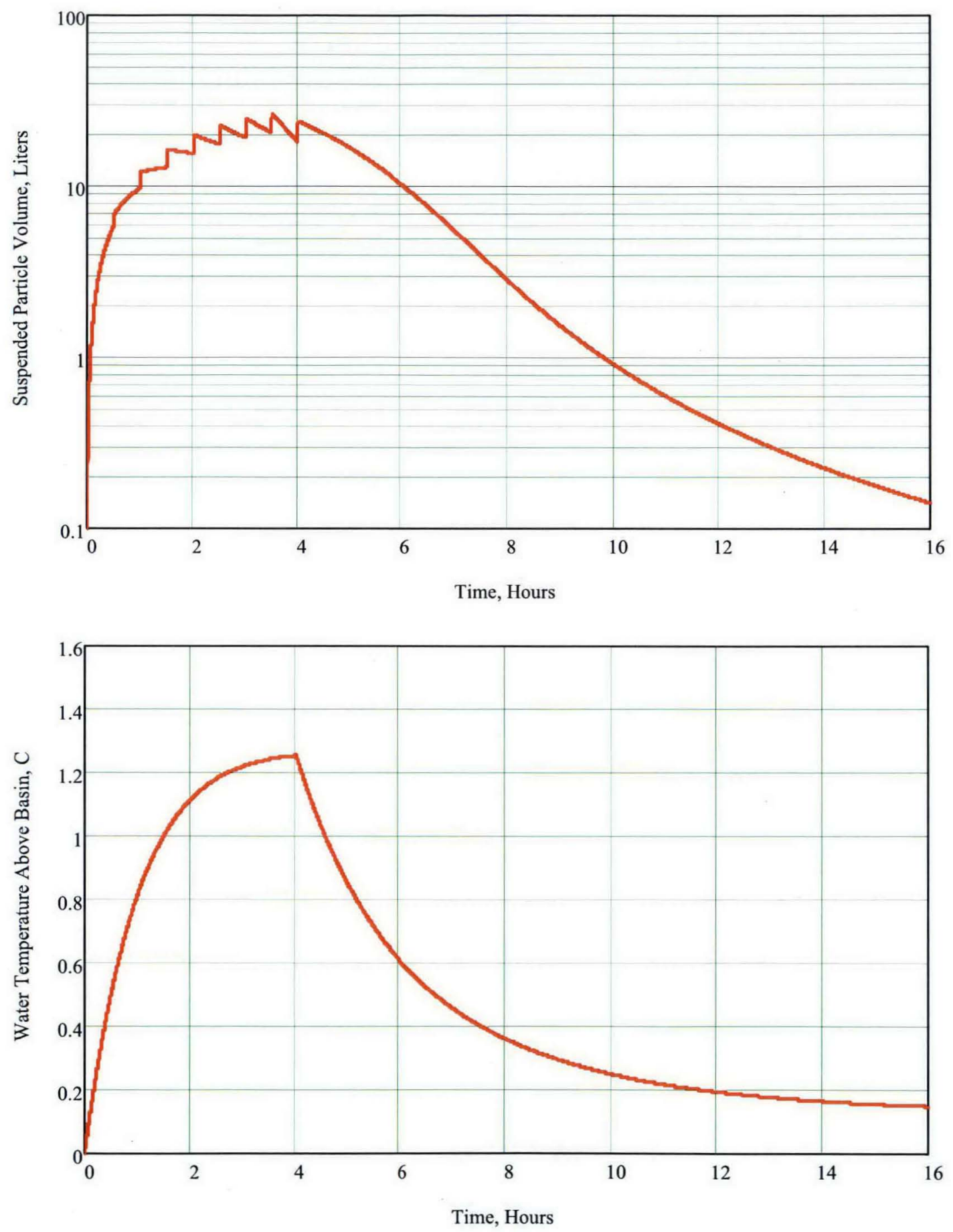

Figure 5-9B Case 3A results, continued. 
PRC-STP-00011, Rev. 0

Attachment A

\section{$5-31$}

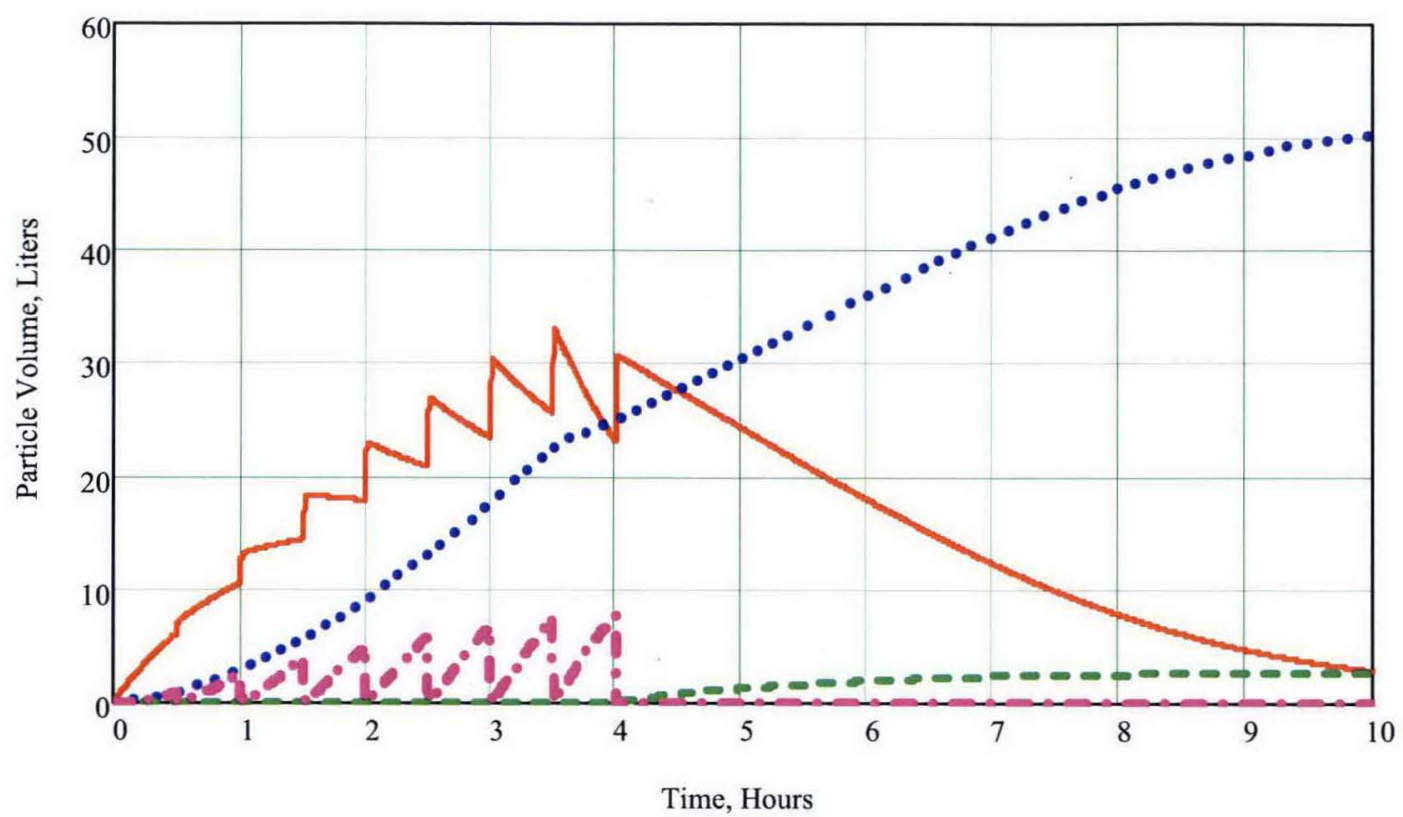

Suspended

-. Settled

- Escaped to Basin

- Filter Cake

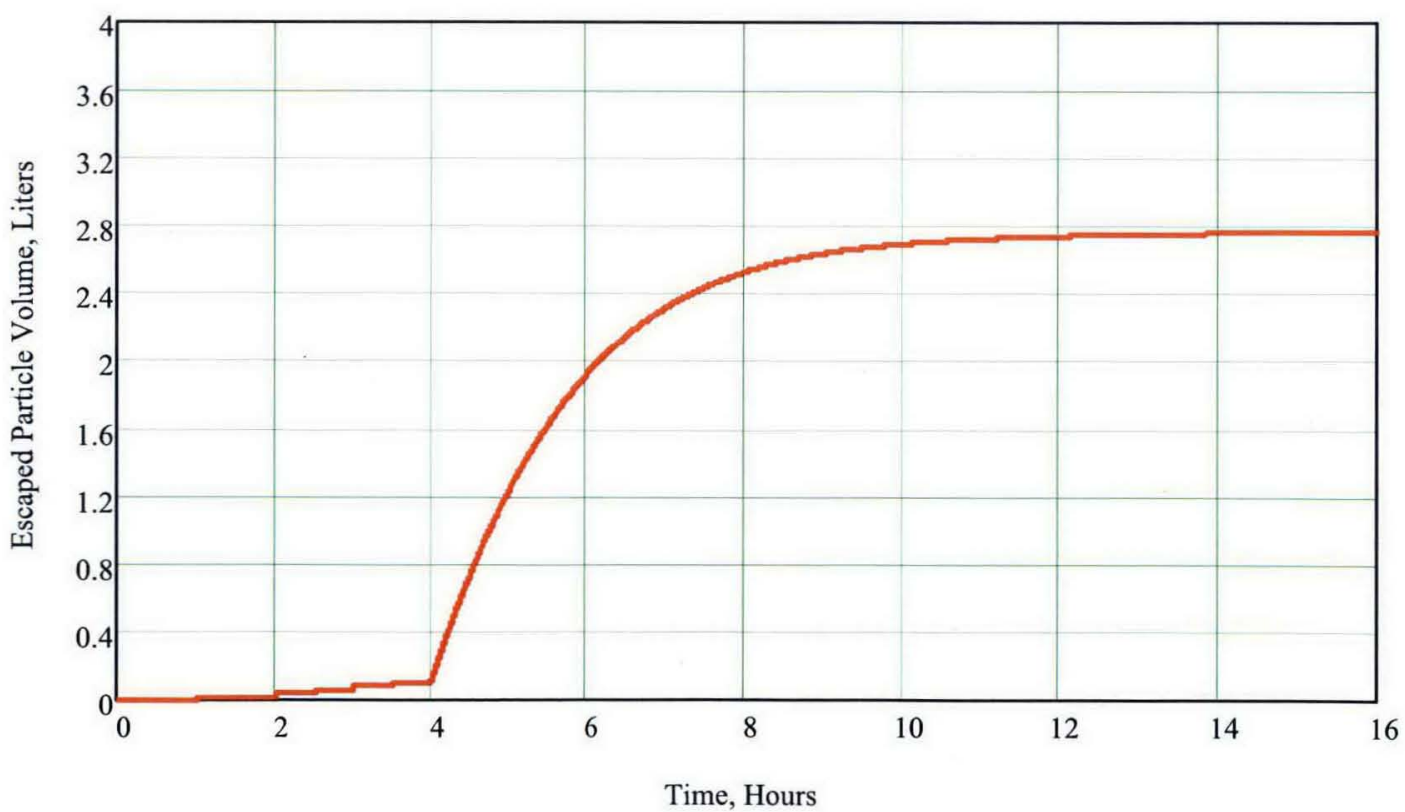

Figure 5-10A Case 3B results. 
PRC-STP-00011, Rev. 0

$5-32$

Attachment A

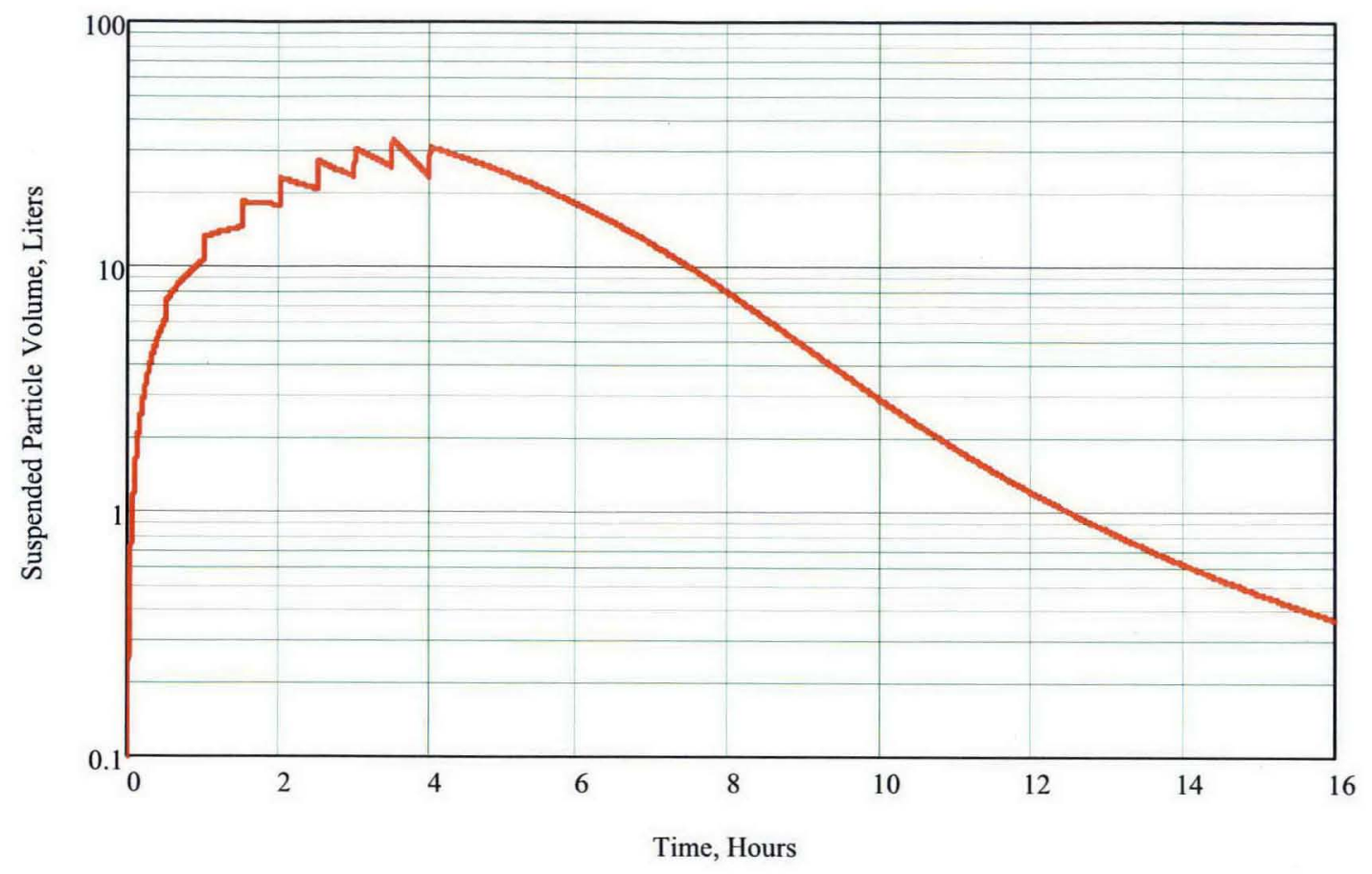

Figure 5-10B Case 3B results, continued. 
PRC-STP-00011, Rev. 0

\section{$5-33$}

Attachment A

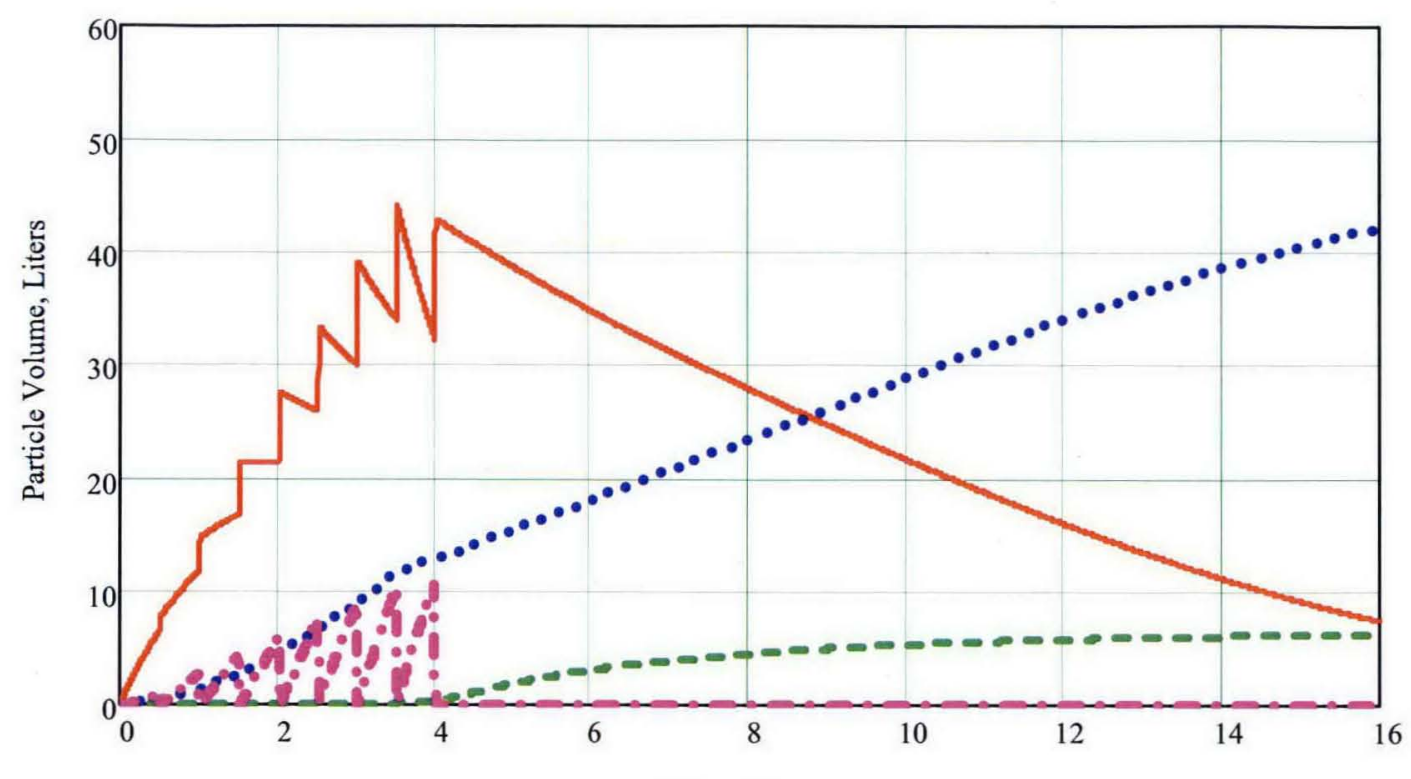

Time, Hours

Suspended

-. Settled

- - Escaped to Basin

- Filter Cake

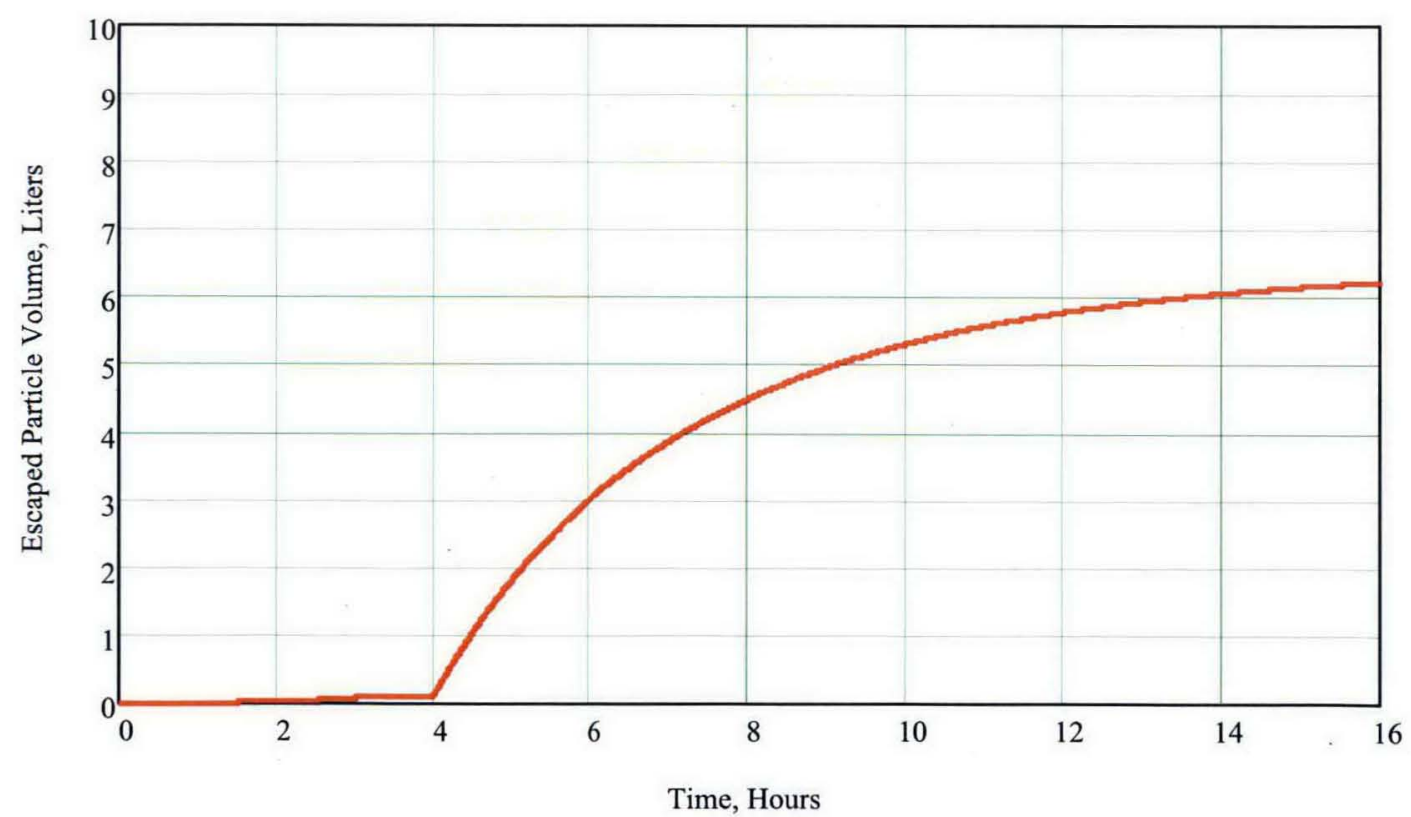

Figure 5-11A Case $3 \mathrm{C}$ results. 
PRC-STP-00011, Rev. 0

\section{5-34}

Attachment A

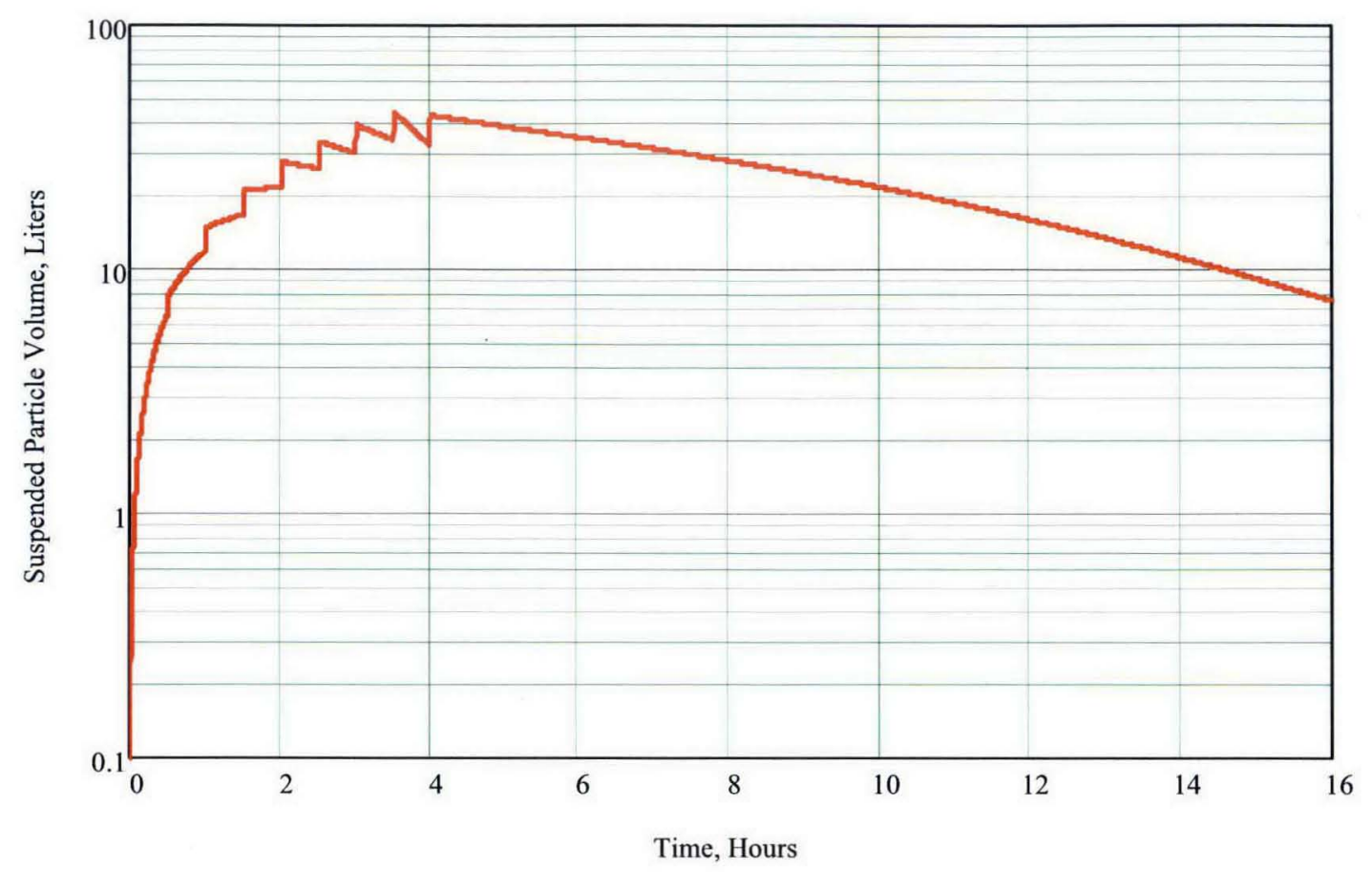

Figure 5-11B Case $3 \mathrm{C}$ results, continued. 
PRC-STP-00011, Rev. 0

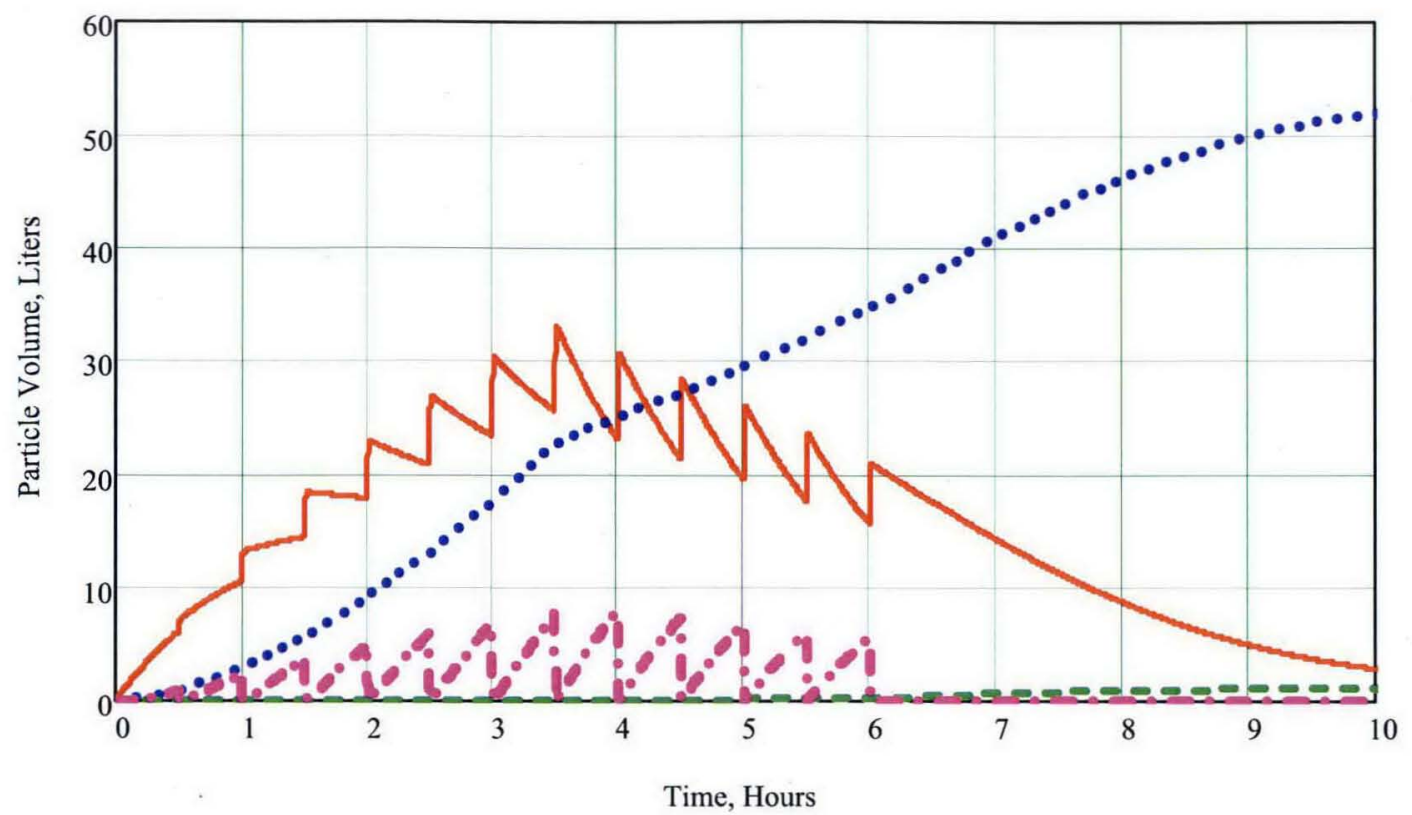

Suspended

-. Settled

- Escaped to Basin

- - Filter Cake

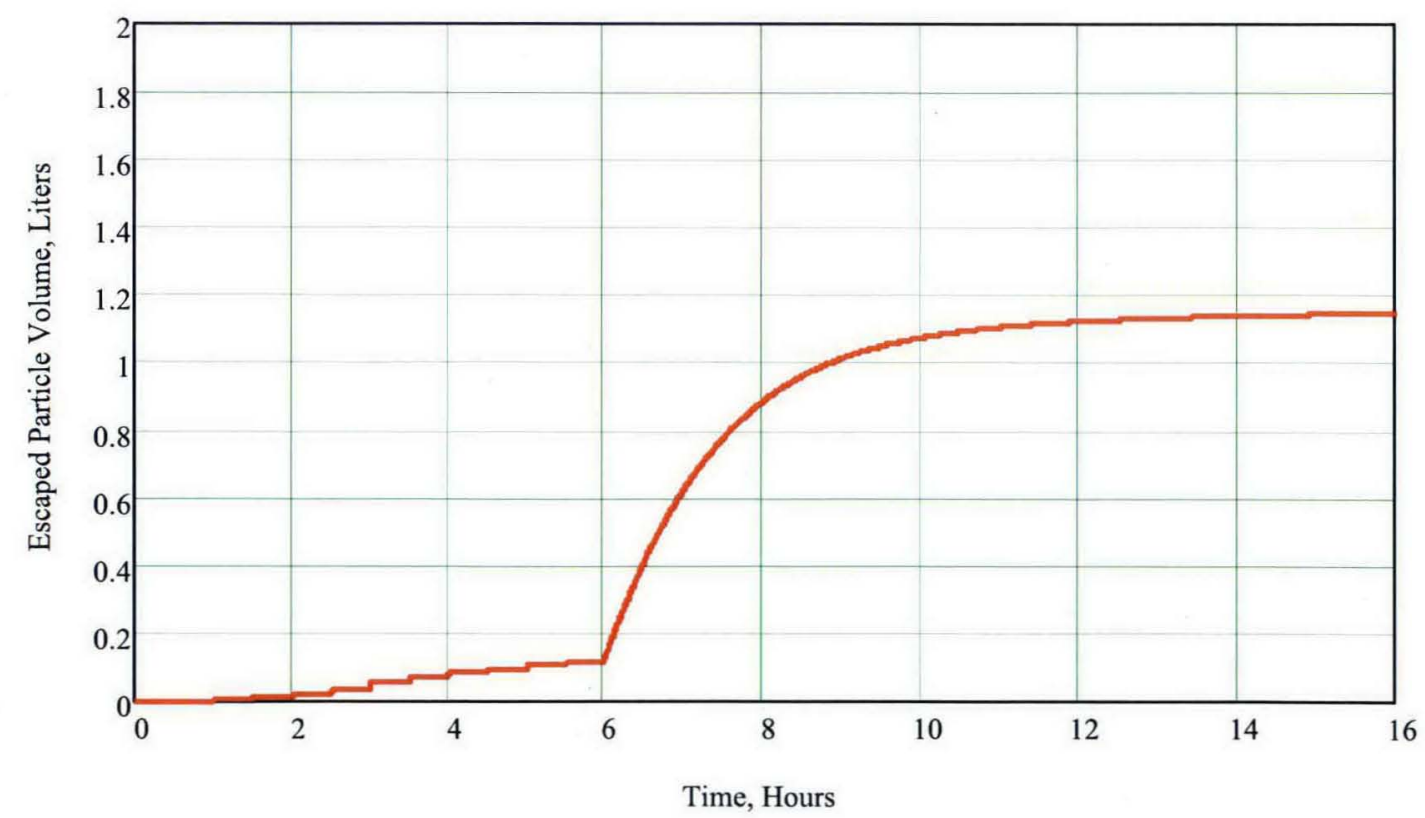

Figure 5-12A Case 1D results. 
PRC-STP-00011, Rev. 0
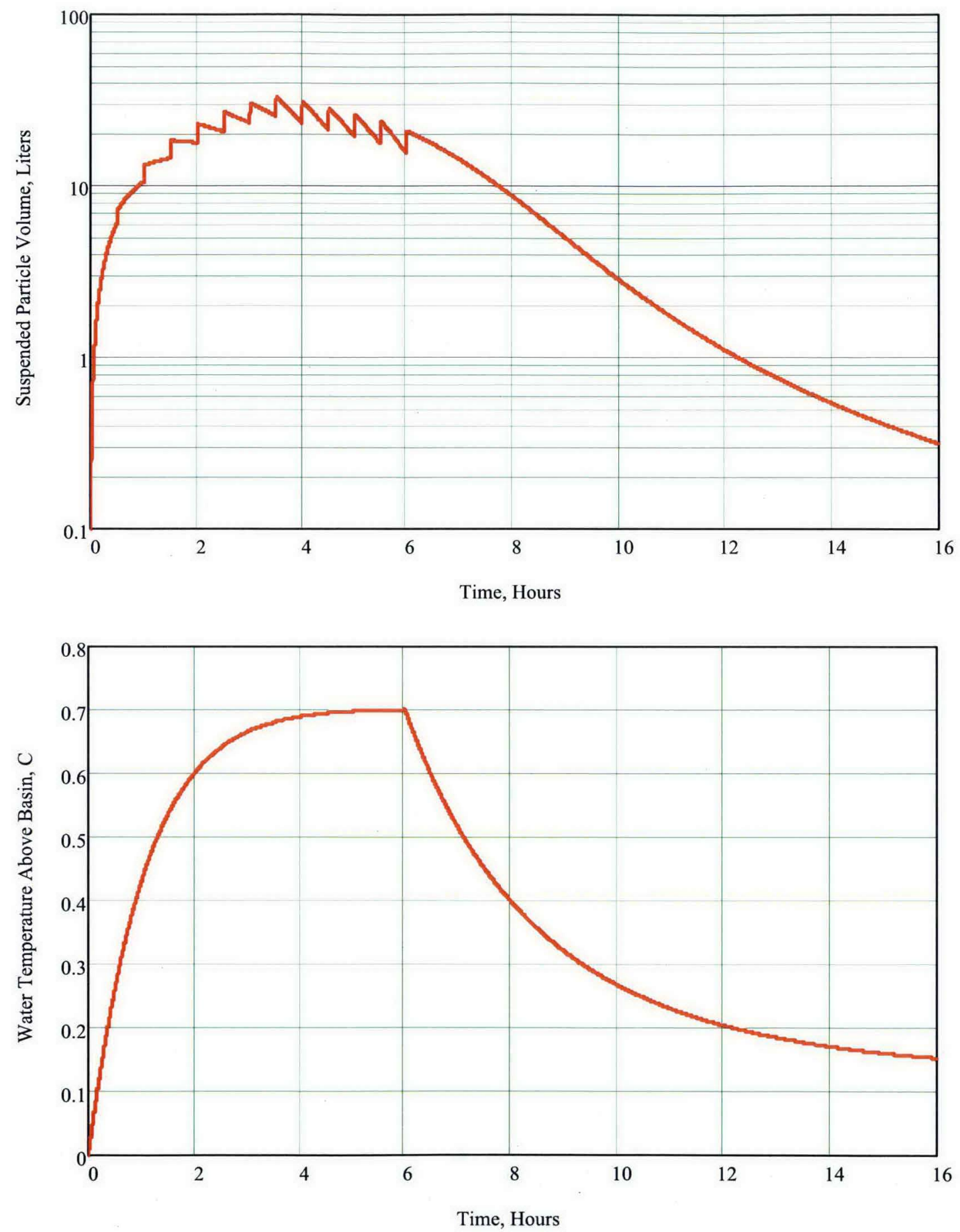

Figure 5-12B Case 1D results, continued. 
PRC-STP-00011, Rev. 0

Attachment A

\section{5-37}

\subsection{Simulation Model Implementation Notes}

The preceding results were obtained by rendering equations of Sections 3 and 4 in a Mathcad $^{\mathrm{TM}}$ Version 11 spreadsheet. Some model implementation notes are given here in order to clarify which equations are solved and what assumptions pertain.

The model integrates equations for 8 state variables during the simulation duration:

$\mathrm{X}_{0} \quad$ Zeroth moment of the distribution, per Eq. (4-20),

$\mathrm{X}_{1} \quad$ First moment of the distribution, per Eq. (4-21),

$\mathrm{X}_{0} \quad$ Second moment of the distribution, per Eq. (4-22),

$\mathbf{T}_{\mathrm{wc}} \quad$ Container water temperature, per Eq. (3-28),

$\mathrm{V}_{\text {sed }} \quad$ Settled (sedimented) solids volume,

$\mathrm{V}_{\text {fil }} \quad$ Filter deposited solids volume,

$\mathrm{V}_{\text {esc }} \quad$ Escaped (to basin) solids volume, and

$\mathrm{V}_{\text {sor }} \quad$ Total source solids volume.

The volume derivatives are given by:

$$
\begin{aligned}
& \frac{\mathrm{dV}_{\text {sed }}}{\mathrm{dt}}=\frac{\mathrm{B}}{\mathrm{h}_{\text {sed }}} \mathrm{X}_{0}\left(\frac{\mathrm{X}_{1} \mathrm{X}_{2}}{\mathrm{X}_{0}^{2}}\right)^{\frac{5}{9}} \mathrm{~V} \\
& \frac{\mathrm{dV}_{\mathrm{fil}}}{\mathrm{dt}}=\frac{\mathrm{u}_{\mathrm{fl}}}{\mathrm{h}_{\mathrm{fl}}} \mathrm{X}_{1} \mathrm{~V}-\frac{\mathrm{V}_{\mathrm{fil}}}{10} \delta_{\mathrm{bf}} \\
& \frac{\mathrm{dV} \mathrm{V}_{\mathrm{esc}}}{\mathrm{dt}}=\frac{\mathrm{u}_{\text {out }}}{\mathrm{h}_{\text {out }}} X_{1} V \\
& \frac{\mathrm{dV} \text { sor }}{\mathrm{dt}}=\alpha_{\mathrm{o}} \mathrm{Q}_{\mathrm{o}} \delta_{\text {sor }}
\end{aligned}
$$


The equation for settled volume is simply the first term of Eq. (4-21) multiplied by container volume because the units of $\mathrm{X}_{0}$ are per unit volume. The first term for the filter cake volume accounts for addition. The on/off back flush function parameter $\delta_{\mathrm{bf}}$ is defined as $\delta_{\mathrm{bf}}=1$ during a back flush and $\delta_{\mathrm{bf}}$ is $=0$ otherwise; the second term adds filter cake back to the suspended solids with an arbitrary time constant of 10 seconds. Similarly, the total source volume of solids is controlled by an on/off source function $\delta_{\text {sor }}$.

To account for particle addition during a back flush, Eqs. (4-20) through (4-22) are modified to add the following terms, respectively:

$$
\begin{aligned}
& +\frac{\mathrm{V}_{\mathrm{fil}}}{10 \mathrm{~V}} \frac{1}{\mathrm{v}_{\mathrm{g}, \mathrm{p}} \exp \left[\frac{9}{2}\left(\ln \sigma_{\mathrm{p}}\right)^{2}\right]} \delta_{\mathrm{bf}} \\
& +\frac{\mathrm{V}_{\mathrm{fil}}}{10 \mathrm{~V}} \delta_{\mathrm{bf}} \\
& +\frac{\mathrm{V}_{\mathrm{fil}}}{10 \mathrm{~V}} \mathrm{v}_{\mathrm{g}, \mathrm{p}} \exp \left[\frac{27}{2}\left(\ln \sigma_{\mathrm{p}}\right)^{2}\right] \delta_{\mathrm{bf}}
\end{aligned}
$$

The modification to Eq. (4-21), Eq. (5-7), follows directly from Eq. (5-3). The other factors in Eq. (5-6) and (5-8) follow from the relationships between the moments given in Eqs. (4-8) through (4-10):

$$
\begin{aligned}
& \frac{X_{0}}{X_{1}}=\frac{1}{v_{g, p} \exp \left[\frac{9}{2}\left(\ln \sigma_{p}\right)^{2}\right]} \\
& \frac{X_{2}}{X_{1}}=\frac{v_{g, p}{ }^{2} \exp \left[18\left(\ln \sigma_{p}\right)^{2}\right]}{v_{g, p} \exp \left[\frac{9}{2}\left(\ln \sigma_{p}\right)^{2}\right]}=v_{g, p} \exp \left[\frac{27}{2}\left(\ln \sigma_{p}\right)^{2}\right]
\end{aligned}
$$

and the same ratios apply for any rate of change terms. The assumption underlying Eqs. (5-6) through (5-8) is that the suspended particle size distribution does not vary too much between 
back flush cycles, so that the suspended and filter cake size distributions are effectively the same. Also, the rate of change of water temperature Eq. (3-28) is modified to account for decay power

$$
+\mathrm{Q}_{\mathrm{v}}\left(\mathrm{X}_{1} \mathrm{~V}+\mathrm{V}_{\text {fil }}+0.5 \mathrm{~V}_{\text {sed }}\right) \quad \text { (add to 3-28) }
$$

where $\mathrm{Q}_{\mathrm{v}}$ is the decay power per unit solids volume, the first term represents the contribution from suspended solids, the second term is the contribution from filter cake solids, and the last term contains the underlying, conservative assumption that half the decay power of settled sludge is transferred upward into the container water (the other half is transferred via container walls to the basin).

Values for the state variables must be initialized. The water temperature is initialized to the basin water temperature, and all integrated volumes are set to zero except that an initial value may be assigned to the settled volume to account for pre-existing sludge. Parameters for the particles in the container are initialized as follows:

- A small value of the initial mass $\mathrm{M}_{\mathrm{o}}$ is chosen for a case,

- The median size of source particles $\mathrm{d}_{1 / 2}$ is chosen for a case,

- The distribution parameters $\sigma_{\mathrm{p}}$ and $\mathrm{v}_{\mathrm{g}, \mathrm{p}}$ for source particles are derived from the median size and the maximum size (500 microns) using Eq. (4-28) and then Eq. (4-29),

- The first moment is initialized as $X_{0}=M_{0} /\left(\rho_{p} V\right)$ where $\rho_{p}$ is particle density, and

- The zeroth and second moments are initialized from the first moment using the ratios in Eq. (5-9) and (5-10) respectively.

During the course of a simulation, the derivative functions as described above are evaluated at every time step. At any given time, the number of back flushing filters, the water source rate, and the particle source rate are found from case-specific specifications. These are used to find the total net suction rate and the upstream and downstream suction rates using Eq. (3-1) or (3-2) with Eqs. (3-15), (3-20), and (3-21). Given the container water temperature (an integrated state variable) the counter-current exchange flow rate with the basin is found from Eq. 
PRC-STP-00011, Rev. 0

Attachment A

(3-27) which uses (3-26) and (3-24). The loss terms of the form $\lambda=u / h$ in Eqs. (4-20) through (4-22) are given by $\mathrm{Q} / \mathrm{V}$ where $\mathrm{Q}$ is the appropriate volume flow rate (filter or counter-current exchange). The source term in Eq. (4-21) is replaced by $\alpha_{0} Q_{0} \delta_{\text {sor }} / V$, and the ratios in Eq. (5-9) and (5-10) are applied to replace the source terms in Eq. (4-20) and (4-22) respectively. 
PRC-STP-00011, Rev. 0

Attachment A

$6-1$

\subsection{REFERENCES}

Baines, W. D. and Turner, J. S., 1969, "Turbulent Buoyant Convection from a Source in a Confined Region," J. Fluid Mech. 37, pp. 51-80.

Carey, S. N., Sigurdsson, H. and Sparks, R. S. J., 1988, "Experimental Studies of Particle-Laden Plumes," J. Geophys. Res. $\underline{93}$, pp. 314-322.

Churchill, S. W., 1988, Viscous Flows, Butterworths, Stoneham, MA, p. 337.

Cohen, R. E. and Vaughan, E. U., 1974, "Approximate Solution of the Equations for Aerosol Agglomeration," J. Colloid Interface Science 35, pp. 612-623.

Epstein, M. and Kenton, M. A., 1989, "Combined Natural Convection and Forced Flow Through Small Openings in a Horizontal Partition, With Special Reference to Flows in Multicompartment Enclosures," J. Heat Transfer 111, pp. 980-987.

Epstein, M. and Fauske, H. K., 2001, "Mass of Flammable Material Produced by Continuous Fuel-Gas and Volatile Liquid Fuel Releases," Combustion Science and Technology 171, pp. 89-118.

Halow, J. S., 1973, "Incipient Rolling, Sliding and Suspension of Particles in Horizontal and Inclined Turbulent Flow," Chem. Engng. Sci. 28, pp. 1-12.

Hofferber, G.A., 2008, Test Report for IWTS Settler Tank Retrieval Equipment Development Test, KBC-37619 Rev. 0, May.

Kumagai, M., 1984, "Turbulent Buoyant Convection from a Source in a Confined Two-Layer Region," J. Fluid Mech. 147, pp. 105-131.

Martin, H., 1977, "Heat and Mass Transfer Between Impinging Gas Jets and Solid Surfaces," Advances in Heat Transfer 13, pp. 1-59.

Morton, B. P., Taylor, G. I. and Turner, J. S., 1956, "Turbulent Gravitational Convection from Maintained and Instantaneous Sources," Proc. Royal Society, Series A 234, pp. 1-23.

Rajaratnam, N., 1976, Turbulent Jets, Elsevier, New York.

Saffman, P. G., 1965, "The Lift Force on a Small Sphere in a Slow Shear Flow," J. Fluid Mech. $\underline{22}$, pp. $385-400$.

Schlichting, H., 1960, Boundary Layer Theory, McGraw-Hill, New York.

Schmidt, A. J., 2006, Spent Nuclear Fuel Project Technical Databook, Vol. 2, Sludge, HNF-SDSNF-TI-015, Revision 13A, Fluor Hanford, Richland, WA, June. 
PRC-STP-00011, Rev. 0

Attachment $A$

\section{6-2}

Schmidt, A.J., and Zacher, A.H., 2007, Composition and Technical Basis for K Basin Settler Sludge Simulant for Inspection, Retrieval, and Pump Testing, PNNL-16619, Rev. 1, Pacific Northwest National Laboratory, Richland, WA, June.

Steckler, K. D., Baum, H. R. and Quintiere, J. G., 1984, "Fire Induced Flows Through Room Openings - Flow Coefficients," 20th Symposium (Int.) on Combustion, The Combustion Institute, pp. 1591-1600. 
PRC-STP-00011, Rev. 0

Attachment A

A-1

\section{APPENDIX A}

\section{$\underline{\text { Resuspension of Sludge Particles }}$}

The settled sludge particle deposit at the bottom of the container is subject to the shear forces exerted by the negatively buoyant sludge plumes that flow to the bottom of the tank and spread out over the particle deposit. Resuspension of previously deposited sludge particles by the sludge plume may begin when the sludge particle layer grows in depth and the surface of the sludge layer is close enough to the sludge distributor ports for the impingement plume flow to dislodge particles from the surface.

The conditions for resuspension are derived by first estimating the mainstream water velocity $u_{\infty}$ parallel to the sludge surface that is required to remove a particle. A steady turbulent flow of water passes over the sludge particle deposit and a representative adhering sludge particle at the surface is regarded as an isolated sphere that is small enough to be submerged in the laminar sublayer. If the surface of the particle deposit can be regarded as a flat solid surface, immediately adjacent to the surface of the sludge deposit (within the laminar sublayer) the water velocity $\mathrm{u}$ as a function of distance $\mathrm{y}$ from the surface is (Schlichting, 1960)

$$
u=\frac{f_{u_{\infty}^{2}}^{2}}{2 v_{f}} y
$$

where $v_{f}$ is the kinematic viscosity of the flowing water and $f$ is the friction factor for turbulent flow over a flat plate. Obviously the surface of the sludge particle layer is rough and porous and cannot truly be considered a flat plate for which Eq. (A-1) is valid. Moreover, the concept of the laminar sublayer may have no importance for completely rough surfaces. However, the flow velocity gradient du/dy near a smooth flat plate is more steep than that near a rough surface (Schlichting, 1960). Also the velocity $u$ of the flow in contact with a surface particle is less than that calculated by Eq. (A-1) owing to the "shielding" provided by adjacent particles. It will be seen below that the lift force acting on a particle is proportional to $\mathrm{u}$ and $\mathrm{du} / \mathrm{dy}$. Therefore Eq. (A-1) results in a conservative (high) estimate of the force available to dislodge a particle from the sludge deposit. 
PRC-STP-00011, Rev. 0

Attachment A

\section{A-2}

Saffman (1965) derived an expression for the lift force $F_{L}$ acting on a sphere in a linear velocity field. The numerical coefficient in the force expression was corrected by Halow (1973) to bring it into agreement with experimental data. The equation for the lift force for a sphere initially at rest on a surface is

$$
F_{L}=8.09 d^{2}\left(v_{f} \kappa\right)^{1 / 2} \rho_{f} u(d / 2)
$$

Here $\mathrm{d}$ is the particle diameter, $\mathrm{u}(\mathrm{d} / 2)$ is the water velocity evaluated at a distance from the surface equal to one-half the spherical particle diameter and $\kappa$ is the velocity gradient. From Eq. (A-1)

$$
\begin{aligned}
& u(d / 2)=\frac{f u_{\infty}^{2} d}{4 v_{f}} \\
& \kappa=\frac{d u}{d y}=\frac{f u_{\infty}^{2}}{2 v_{f}}
\end{aligned}
$$

Thus Eq. (A-2) becomes

$$
F_{L}=1.43 \frac{f^{3 / 2} \rho_{f} u_{\infty}^{3} d^{3}}{v_{f}}
$$

To determine the minimum possible water velocity $\mathrm{u}_{\infty}$ at which a spherical particle is dislodged from the surface of the sludge deposit, the lift force is set equal to the minimum particle adhesion force given by the weight of the particle. Thus it is possible for the particle to be entrained by the water flow when

$$
F_{L} \geq\left(\rho_{s}-\rho_{f}\right) g\left(\frac{\pi d^{3}}{6}\right)
$$

or, from Eq. (A-5), the liquid velocity criterion for particle liftoff is 


$$
u_{\infty} \geq u_{\infty, s u s}=\frac{0.72}{f^{1 / 2}}\left[\frac{\left(\rho_{s}-\rho_{f}\right) g v_{f}}{\rho_{f}}\right]^{1 / 3}
$$

It turns out that the resuspension velocity $\mathbf{u}_{\infty, \text { sus }}$ is independent of particle size. Consider the typical parameter values for the SCS-CON-230 application, $v_{\mathrm{f}}=10^{-6} \mathrm{~m}^{2} \mathrm{~s}^{-1}, \rho_{\mathrm{s}}=6 \times 10^{3} \mathrm{~kg}$ $\mathrm{m}^{-3}, \rho_{\mathrm{f}}=10^{3} \mathrm{~kg} \mathrm{~m}^{-3}$ and $\mathrm{f}=0.02$ for a rough surface. Inserting these numbers into Eq. (A-7) gives

$$
\mathrm{u}_{\mathrm{o}, \mathrm{sus}}=0.19 \mathrm{~m} \mathrm{~s}^{-1}
$$

for the minimum water velocity required to lift a sludge particle off the top of the particle layer.

The maximum velocity of the water at the surface of the particle deposit is achieved within the stagnation zone of the falling sludge plume. The velocity profile in the stagnation region of a jet issuing from a nozzle in close proximity of the impingement surface is well known. It is clear from the measurements reported in Martin (1977) and Rajaratnam (1976) that the peak fluid velocity parallel to the surface is approximately equal to the fluid velocity at the nozzle exit plane. We choose an imaginary nozzle in the sludge plume deflection region at the surface of the settled particle layer and identify the nozzle exit plane velocity and radius with the sludge plume radius and velocity at the surface. By virtue of this physically reasonable identification (for turbulent flow) the peak water velocity at and parallel to the surface of the particle deposit is given by Eq. (2-5) evaluated at the top of the particle deposit, a distance $\mathrm{z}$ below the sludge distributor. Therefore the criterion for the onset of sludge particle resuspension is obtained by equating $v$ in Eq. (2-5) with $\mathrm{u}_{\infty}$ in Eq. (A-7) and solving the result for $\mathrm{z}$ :

$$
\mathrm{z} \leq \mathrm{z}_{\text {sus }}=\frac{0.44 \mathrm{f}^{3 / 2} \alpha_{0} \mathrm{Q}_{0}}{\mathrm{E}_{0}^{2} \mathrm{v}_{\mathrm{f}}}
$$

The above criterion states that if the top of the growing, settled particle layer rises to within a vertical distance $z_{\text {sus }}$ of the sludge distributor given by the right-hand side of Eq. (A-9) 
sludge particle resuspension will occur. Using the appropriate parameter values, namely $\mathrm{Q}_{0}=$ $4.73 \times 10^{-4} \mathrm{~m}^{3} \mathrm{~s}^{-1}, \alpha_{0}=0.02, v_{\mathrm{f}}=10^{-6} \mathrm{~m}^{2} \mathrm{~s}^{-1}, \mathrm{E}_{0}=0.12$ and $\mathrm{f}=0.02$, we conclude that if the vertical distance between the top of the settled particle layer and the sludge distributors is less than $\mathrm{z}_{\mathrm{sus}}=0.82 \mathrm{~m}$ sludge particle resuspension is possible.

It is important to mention that particle resuspension, if it occurs, will be confined to only a small fraction of the surface area of the settled particle layer. The radial water velocity profile $u_{\infty}(r)$ at the top of the particle layer due to the impinging sludge plume may be inferred from the information in Martin (1977) and Rajaratnam (1976) on forced jets, together with the imaginary nozzle model discussed in the foregoing, and is

$$
u_{\infty}(r)= \begin{cases}\frac{v(z)}{2 R(z)} r & 0<r<2 R(z) \\ \frac{2 R(z) v(z)}{r} & 2 R(z)<r\end{cases}
$$

where $v(z)$ and $R(z)$ are given by Eqs. (2-5) and (2-7) respectively and $z$ is the elevation of the sludge distributors above the settled particle layer. The radial distance $r$ in Eq. (A-10) is measured along the surface of the particle layer from the sludge plume axis-surface point of impingement at $r=0$. The water velocity $u_{\infty}(r)$ just above and parallel to the surface and directed outward toward the periphery of the sludge plume is zero at $r=0$ and increases as $r$ increases. The velocity reaches a peak value equal to $\mathrm{v}(\mathrm{z})$ at $\mathrm{r}=2 \mathrm{R}(\mathrm{z})$, that is at a radial location outside the boundary of the plume where it makes contact with the surface of the particle layer. The water velocity $u_{\infty}(r)$ then decreases as $r$ is increased beyond $2 R(z)$ and ultimately comes back to zero at $\mathbf{r}=\infty$.

Particle entrainment will occur within a ring shaped surface area between two circles of inner radius $r_{i}\left[0<r_{i}<2 R(z)\right]$ and outer radius $r_{0}\left[2 R(z)<r_{0}<\infty\right]$. At these radial locations the water velocity is equal to the critical water velocity $\mathrm{u}_{\infty}$,sus for the onset of particle lifting (see Eqs. A-7 and A-8). From Eq. (A-10) the radial boundaries of the particle entrainment zone are 
PRC-STP-00011, Rev. 0

Attachment A

A-5

$$
\begin{aligned}
& r_{i}=\frac{2 R(z) u_{\infty, \text { sus }}}{v(z)} \\
& r_{0}=\frac{2 R(z) v(z)}{u_{\infty, \text { sus }}}
\end{aligned}
$$

The surface area $A_{\text {sus }}$ over which particle resuspension occurs beneath one impinging sludge plume is

$$
A_{\text {sus }}=\pi\left(r_{0}^{2}-r_{i}^{2}\right)=4 \pi R(z)^{2}\left\{\left[\frac{v(z)}{u_{\infty, \text { sus }}}\right]^{2}-\left[\frac{u_{\infty, \text { sus }}}{v(z)}\right]^{2}\right\}
$$

or, from Eqs. (2-5), (2-7) and (A-9)

$$
A_{\text {sus }}=4 \pi\left(\frac{6}{5} E_{0}\right)^{2} z^{2}\left[\left(\frac{z_{\text {sus }}}{z}\right)^{2 / 3}-\left(\frac{z}{z_{\text {sus }}}\right)^{2 / 3}\right]
$$

Now $\mathrm{A}_{\text {sus }}=0$ at $\mathrm{z}=0$ and at $\mathrm{z}=\mathrm{z}_{\text {sus }}$. Thus $\mathrm{A}_{\text {sus }}$ must exhibit a maximum in the interval $0<\mathrm{z}<$ $Z_{\text {sus }}$. It is a simple matter to show that the maximum surface area $A_{\text {sus,max }}$ occurs at

$$
\mathrm{z}_{\max }=2^{-3 / 4} \mathrm{z}_{\text {sus }}
$$

and that $\mathrm{A}_{\text {sus,max }}$ is

$$
\mathrm{A}_{\text {sus, } \max }=\pi\left(\frac{6}{5} \mathrm{E}_{0} \mathrm{z}_{\mathrm{sus}}\right)^{2}
$$

Recall that our estimate of the critical sludge distributor-to-settled particle surface separation distance for the onset of resuspension is $z_{\text {sus }}=0.82 \mathrm{~m}$. Thus, from Eq. (A-16) 
PRC-STP-00011, Rev. 0

Attachment A

\section{A-6}

$$
\mathrm{A}_{\text {sus,max }}=0.044 \mathrm{~m}^{2}
$$

This area is a negligible fraction of the total surface area of the settled particle bed $\left(5.5 \mathrm{~m}^{2}\right)$. 
PRC-STP-00011, Rev. 0

Attachment A

B-1

\section{APPENDIX B}

\section{Gravitational Coagulation Integrals for Moment Equations}

By introducing the change in variables $\xi=v-\bar{v}$ into the coagulation integrals in Eq. (42) and noting that the kernal $K_{g}(v, \bar{v})$ is always symmetrical with respect to $v$ and $\bar{v}$, the gravitational coagulation terms can be shown to transform to (see, e.g., Cohen and Vaughan (1974)

$$
I_{g}(\gamma)=\frac{1}{2} \int_{0}^{\infty} \int_{0}^{\infty}\left[(\bar{v}+v)^{\gamma}-\bar{v}^{\gamma}-v^{\gamma}\right] K_{g}(\bar{v}, v) n(\bar{v}, t) n(v, t) d v d \bar{v}
$$

Recall from Eqs. (4-18) and (4-19) that $\mathrm{K}_{\mathrm{g}}(\overline{\mathrm{v}}, \mathrm{v})$ is a piecewise continuous function that has one form in the interval $0<\mathrm{v} \leq \overline{\mathrm{v}}$ and another form in the interval $\overline{\mathrm{v}}<\mathrm{v}<\infty$. Therefore the interior integral in Eq. (B-1) must be expanded into two components as follows:

$$
\begin{aligned}
I_{g}(\gamma) & =\frac{1}{2} \int_{0}^{\infty}\left\{\int_{0}^{\bar{v}}\left[(\bar{v}+v)^{\gamma}-\bar{v}^{\gamma}-v^{\gamma}\right] K_{g}(\bar{v}, v) n(\bar{v}, t) n(v, t) d v\right. \\
& \left.+\int_{\bar{v}}^{\infty}\left[(\bar{v}+v)^{\gamma}-\bar{v}^{\gamma}-v^{\gamma}\right] K_{g}(\bar{v}, v) n(\bar{v}, t) n(v, t) d v\right\} d \bar{v}
\end{aligned}
$$

Substituting Eq. (4-6) for $n(v, t) d v$ and $n(\bar{v}, t) d \bar{v}$ and Eqs. (4-18) and (4-19) for $K_{g}(\bar{v}, v)$ in the first and second interior integrals, respectively, and eliminating the resulting integration variables $v$ and $\bar{v}$ in favor of $\xi$ and $\bar{\xi}$, where

$$
\xi=\frac{\ln \left[\frac{\mathrm{v}}{\mathrm{v}_{\mathrm{g}}(\mathrm{t})}\right]^{1 / 3}}{\sqrt{2} \ln \sigma(\mathrm{t})} \quad, \quad \bar{\xi}=\frac{\ln \left[\frac{\overline{\mathrm{v}}}{\mathrm{v}_{\mathrm{g}}(\mathrm{t})}\right]^{1 / 3}}{\sqrt{2} \ln \sigma(\mathrm{t})}
$$

Eq. (B-2) becomes for $\gamma=0,1,2$ : 
PRC-STP-00011, Rev. 0

Attachment A

B-2

$$
\begin{aligned}
& I_{g}(0)=-\frac{\pi}{6}\left(\frac{3}{4 \pi}\right)^{\frac{4}{3}} \frac{\varepsilon_{0} g\left(\rho_{s}-\rho_{f}\right)}{\mu_{f}} N^{2} v_{g}^{\frac{4}{3}} \times \\
& \left\{\int_{-\infty}^{\infty} \mathrm{e}^{(2 \sqrt{2} \ln \sigma) \bar{\xi}-\bar{\xi}^{2}} \int_{-\infty}^{\bar{\xi}} \mathrm{e}^{(2 \sqrt{2} \ln \sigma) \xi-\xi^{2}} \mathrm{~d} \xi \mathrm{d} \bar{\xi}-\int_{-\infty}^{\infty} \mathrm{e}^{-\bar{\xi}^{2}} \int_{-\infty}^{\bar{\xi}} \mathrm{e}^{(4 \sqrt{2} \ln \sigma) \xi-\xi^{2}} \mathrm{~d} \xi \mathrm{d} \bar{\xi}\right. \\
& \left.+\int_{-\infty}^{\infty} \mathrm{e}^{(2 \sqrt{2} \ln \sigma) \bar{\xi}-\bar{\xi}^{2}} \int_{\bar{\xi}}^{\infty} \mathrm{e}^{(2 \sqrt{2} \ln \sigma) \xi-\xi^{2}} \mathrm{~d} \xi \mathrm{d} \bar{\xi}-\int_{-\infty}^{\infty} \mathrm{e}^{(4 \sqrt{2} \ln \sigma) \bar{\xi}-\bar{\xi}^{2}} \int_{\bar{\xi}}^{\infty} \mathrm{e}^{-\xi^{2}} \mathrm{~d} \xi \mathrm{d} \bar{\xi}\right\} \\
& \mathrm{I}_{\mathrm{g}}(1)=0 \\
& I_{g}(2)=\frac{\pi}{3}\left(\frac{3}{4 \pi}\right)^{\frac{4}{3}} \frac{\varepsilon_{0} g\left(\rho_{s}-\rho_{f}\right)}{\mu_{f}} N^{2} v_{g}^{\frac{10}{3}} \times \\
& \left\{\int_{-\infty}^{\infty} \mathrm{e}^{(5 \sqrt{2} \ln \sigma) \bar{\xi}-\bar{\xi}^{2}} \int_{-\infty}^{\bar{\xi}} \mathrm{e}^{(5 \sqrt{2} \ln \sigma) \xi-\xi^{2}} \mathrm{~d} \xi \mathrm{d} \bar{\xi}-\int_{-\infty}^{\infty} \mathrm{e}^{(3 \sqrt{2} \ln \sigma) \bar{\xi}-\bar{\xi}^{2}} \int_{-\infty}^{\bar{\xi}} \mathrm{e}^{(7 \sqrt{2} \ln \sigma) \xi-\xi^{2}} \mathrm{~d} \xi \mathrm{d} \bar{\xi}\right. \\
& \left.+\int_{-\infty}^{\infty} \mathrm{e}^{(5 \sqrt{2} \ln \sigma) \vec{\xi}-\bar{\xi}^{2}} \int_{\bar{\xi}}^{\infty} \mathrm{e}^{(5 \sqrt{2} \ln \sigma) \xi-\xi^{2}} \mathrm{~d} \xi \mathrm{d} \bar{\xi}-\int_{-\infty}^{\infty} \mathrm{e}^{(7 \sqrt{2} \ln \sigma) \bar{\xi}-\bar{\xi}^{2}} \int_{\bar{\xi}}^{\infty} \mathrm{e}^{(3 \sqrt{2} \ln \sigma) \xi-\xi^{2}} \mathrm{~d} \xi \mathrm{d} \bar{\xi}\right\}
\end{aligned}
$$

The double integrals in Eqs. (B-4) and (B-6) are made considerably easier to evaluate with the knowledge that

$$
\begin{aligned}
& \int_{-\infty}^{\bar{\xi}} e^{a \xi-\xi^{2}} d \xi=\frac{\sqrt{\pi}}{2} e^{\left(\frac{a}{2}\right)^{2}}\left[1+\operatorname{erf}\left(\bar{\xi}-\frac{a}{2}\right)\right] \\
& \int_{\xi}^{\infty} e^{a \xi-\xi^{2}} d \xi=\frac{\sqrt{\pi}}{2} e^{\left(\frac{a}{2}\right)^{2}}\left[1-\operatorname{erf}\left(\bar{\xi}-\frac{a}{2}\right)\right] \\
& \int_{-\infty}^{\infty} e^{-x^{2}} \operatorname{erf}(x+a) d x=\sqrt{\pi} \operatorname{erf}\left(\frac{a}{\sqrt{2}}\right)
\end{aligned}
$$

The definite integral in Eq. (B-9) could not be found in published tables of integrals available to the authors and was derived by the authors. 
PRC-STP-00011, Rev. 0

Attachment A

\section{B-3}

Considering all the terms in Eqs. (B-4) and (B-6), the particle coagulation functions reduce to the remarkably simple results

$$
\begin{aligned}
& I_{g}(0)=-\frac{3 \pi}{4}\left(\frac{3}{4 \pi}\right)^{\frac{2}{3}} \varepsilon_{0} B N^{2}(t) v_{g}(t)^{\frac{4}{3}} e^{4[\ln \sigma(t)]^{2}}\left\{1-e^{4[\ln \sigma(t)]^{2}} \operatorname{erfc}[2 \ln \sigma(t)]\right\} \\
& I_{g}(2)=\frac{3 \pi}{2}\left(\frac{3}{4 \pi}\right)^{\frac{2}{3}} \varepsilon_{0} B N^{2}(t) v_{g}(t)^{\frac{10}{3}} e^{25[\ln \sigma(t)]^{2}}\left\{1-e^{4[\ln \sigma(t)]^{2}} \operatorname{erfc}[2 \ln \sigma(t)]\right\}
\end{aligned}
$$


PRC-STP-00011, Rev. 0

Attachment $A$

C-1

\section{APPENDIX C}

\section{Validity of Stokes Law Particle Settling Rate}

Many experimental data have been taken for flow around spheres, and charts of the drag force (or friction factor) versus flow Reynolds number Re is available in numerous text books on fluid mechanics. From these charts it is clear that Stoke's law is valid for $\operatorname{Re} \tilde{<} 1.0$, or from the definition of Re the criterion for Stokes settling of a source sludge particle (spherical) of diameter $d_{p}$ is

$$
\frac{\mathrm{u}_{\mathrm{sed}} \mathrm{d}_{\mathrm{p}}}{v_{\mathrm{f}}} \approx 1.0
$$

The Stokes law sedimentation velocity $\mathrm{u}_{\mathrm{sed}}$ is

$$
u_{\text {sed }}=\frac{\left(\rho_{s}-\rho_{f}\right) g d_{p}^{2}}{18 \mu_{f}}
$$

Eliminating $\mathbf{u}_{\text {sed }}$ between the above two equations gives the following condition on the source sludge particle diameter for the validity of Stokes law

$$
\mathrm{d}_{\mathrm{p}} \approx\left(\frac{18 \mu_{\mathrm{f}}^{2}}{\rho_{\mathrm{f}}\left(\rho_{\mathrm{s}}-\rho_{\mathrm{f}}\right) \mathrm{g}}\right)^{1 / 3}
$$

The question of interest is what is the fraction $f$ of the mass of the inflowing sludge particles contained in particles below the size given by Eq. (C-3). Now for a log-normal distribution of inflowing sludge particles the cumulative particle size distribution curve (f versus $\left.d_{p}\right)$ is

$$
\mathrm{f}=\frac{1}{2}\left[1.0+\operatorname{erf}\left(\frac{\ln \left(\mathrm{d}_{\mathrm{p}} / \mathrm{d}_{\mathrm{g}, \mathrm{p}}\right)}{\sqrt{2} \ln \sigma_{\mathrm{p}}}-\frac{3 \ln \sigma_{\mathrm{p}}}{\sqrt{2}}\right)\right]
$$




\section{C-2}

where [see Eqs. (4-28) and (4-30)]

$$
\begin{aligned}
& \ln \sigma_{p}=\frac{5}{11 \sqrt{2}} \ln \left(\frac{d_{\text {max }}}{d_{1 / 2}}\right) \\
& d_{g, p}=d_{1 / 2} \exp \left[-\frac{9}{3}\left(\ln \sigma_{p}\right)^{2}\right]
\end{aligned}
$$

The numerical calculations reported in Section 5 employ the following physical parameter values $\rho_{\mathrm{s}}=6000 \mathrm{~kg} \mathrm{~m}^{-3}$ (maximum effective sludge particle density), $\rho_{\mathrm{f}}=1000 \mathrm{~kg} \mathrm{~m}^{-}$ ${ }^{3}, \mu_{\mathrm{f}}=10^{-3} \mathrm{~kg} \mathrm{~m}^{-1} \mathrm{~s}^{-1}, \mathrm{~d}_{\max }=500 \mu \mathrm{m}$, and $\mathrm{d}_{1 / 2}=10 \mu \mathrm{m}$. From Eq. (C-3) the maximum diameter of the particles that settle in accord with Stokes law is $d_{p}=71.6 \mu \mathrm{m}$. From Eqs. (C-5) and (C-6) $\ln \sigma_{\mathrm{p}}=1.257$ and $\mathrm{d}_{\mathrm{g}, \mathrm{p}}=8.71 \times 10^{-2} \mu \mathrm{m}$. Finally, from Eq. (C-4) the fraction of inflowing particles that exhibit a terminal Stokes velocity is

$$
f=\frac{1}{2}[1.0+\operatorname{erf}(1.109)]=0.942
$$

Thus only about $6.0 \%$ of the sludge particles settle at rates slower than that given by Stokes law. Note that our calculations show that the median particle size of the suspended sludge particles is smaller than that of the incoming sludge particles. Therefore Eq. (C-7) is a lower bound estimate of the fraction of the particles that obey Stokes law. 
PRC-STP-00011, Rev. 0

Attachment A

D-1

APPENDIX D

\section{Quality Assurance Documents}

Included here are:

1. Notes on authorship, review, and documentation (This page),

2. Calculation Note Cover Sheet (Page D-2), and

3. Calculation Note Methodology Checklist (Page D-3).

Authorship and review were conducted as follows:

- Section 1 pages 1-1 and 1-2, were authored by Michael Epstein and reviewed by Martin Plys. Section 1 pages 1-3 through 1-9, were authored by Martin Plys and reviewed by Michael Epstein.

- $\quad$ Sections 2, 3, and 4 were authored by Michael Epstein and reviewed by Martin Plys, with one exception: Figures in Section 3 were authored by Martin Plys and reviewed by Jens Conzen.

- $\quad$ Section 5 was authored by Martin Plys and reviewed by Jens Conzen.

- Appendices A, B, and C were authored by Michael Epstein and reviewed by Martin Plys.

The review conducted by Martin Plys involved checking all derivations and numerical results. A Mathcad Version 11 file was created to document the checking. This review is documented in a separate memorandum to the QA file.

Calculations that generated Section 3 figures and all results in Section 5 were performed in a linked set of Mathcad Version 11 worksheets. The review conducted by Jens Conzen involved checking the correct implementation of equations in the report, review of the selfchecks embedded in the calculation worksheets, checking detailed test cases for correct performance, and checking production calculations for reasonable results and consistency with detailed test cases. This review is documented in a separate memorandum to the QA file. 
PRC-STP-00011, Rev. 0

Attachment A

D-2

FAUSKE \& ASSOCIATES, LLC

CALCULATION NOTE COVER SHEET

\section{SECTION TO BE COMPLETED BY AUTHOR(S):}

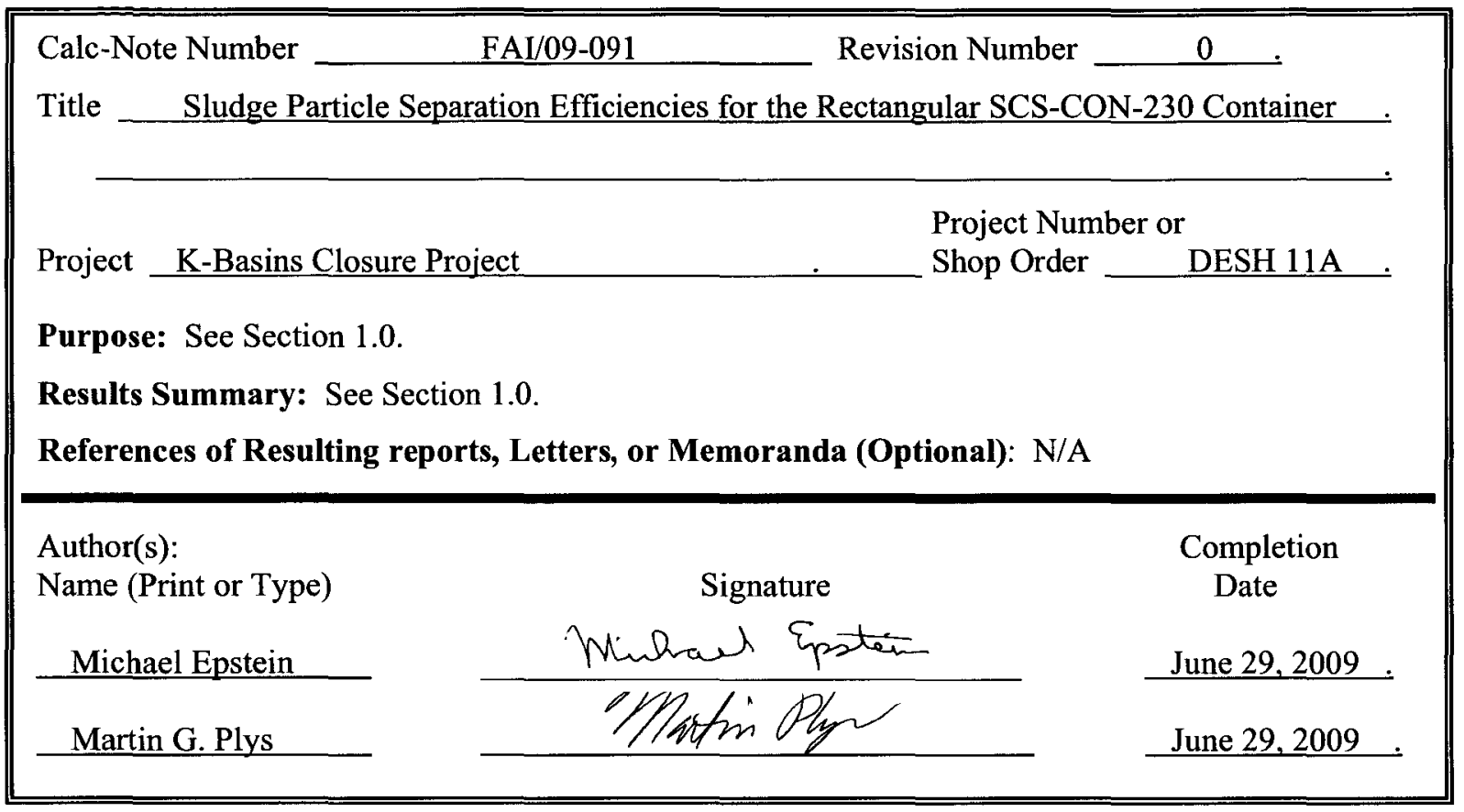

\section{SECTION TO BE COMPLETED BY VERIFIER(S):}

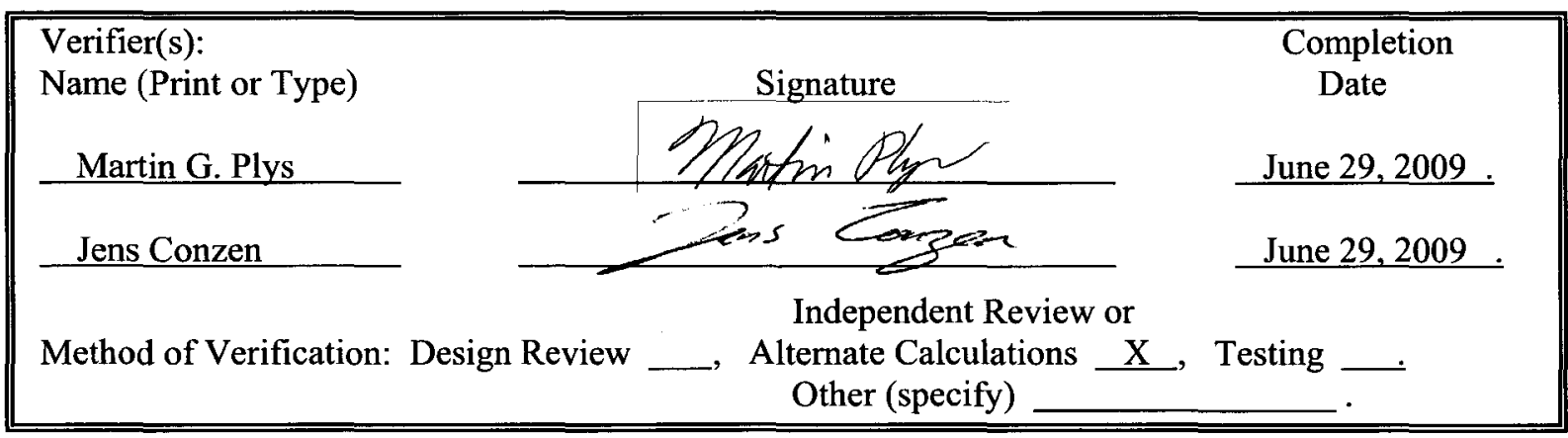

\section{SECTION TO BE COMPLETED BY MANAGER:}

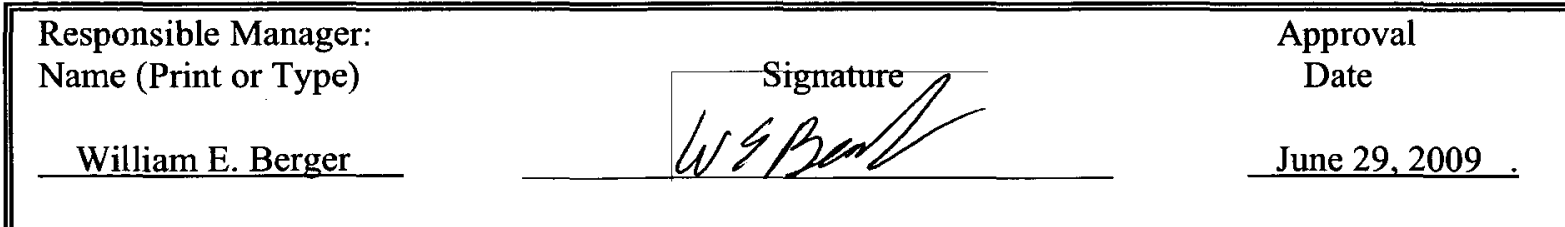




\section{CALCUlation NOTE METHODOLOGY CHECKLIST}

\section{CHECKLIST TO BE COMPLETED BY AUTHOR(S)}

(CIRCLE APPROPRIATE RESPONSE)

1. Is the subject and/or the purpose of the design analysis clearly stated?

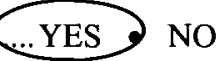

2. Are the required inputs and their sources provided?

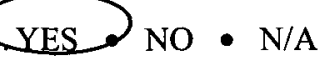

3. Are the assumptions clearly identified and justified?.

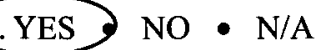

4. Are the methods and units clearly identified?

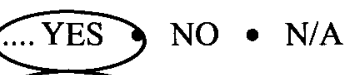

5. Are equations appropriate and correct?

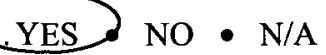

6. Are results of evaluated equations correct?

YES NO N/A

7. Have the limits of applicability been identified?

(i.e., Is the analysis for a 3 or 4 loop plant or for a single application?)

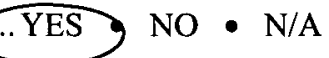

8. Are the results of literature searches, if conducted, or other background data provided?

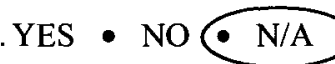

9. Are all the pages sequentially numbered and identified by the calculation note number?.

10. Is the project or shop order clearly identified?

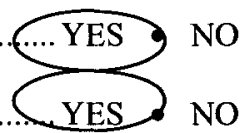

11. Has the required computer calculation information been provided? YES $-\mathrm{NO}$ N/A

12. Were the computer codes used under configuration control?

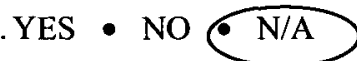

13. Was the computer code(s) used applicable for modeling the physical and/or computational problems identified? (i.e., Is the correct computer code being used for the intended purpose?)

14. Are the results and conclusions clearly stated?

15. Are Open Items properly identified?

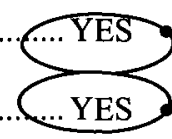
NO

16. Were approved Design Control practices followed without exception? YES $\bullet$ NO NO $\cdot$ N/A (Approved Design Control practices refers to guidance documents within Nuclear Services that state how the work is to be performed, such as how to perform a LOCA analysis.)

NOTE: If NO to any of the above, Page Number containing justification 
PRC-STP-00011, Rev. 0

Attachment B

Attachment B

Review and Verification Files

B - 1 
PRC-STP-00011, Rev. 0

Attachment B1

Attachment B1

Attachment B1, Review of FAl/09-91 Portions Modeled in MathCAD

B1 - 1 
MEMO: $\quad$ MGP062609

DATE: June 26, 2009

TO: $\quad$ QA File 5.35; M. Plys; J. Conzens; M. Epstein

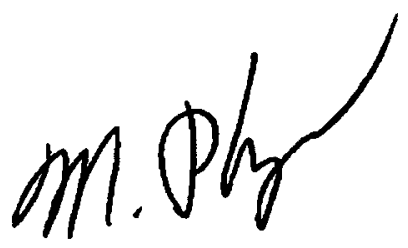

FROM: Marty Plys; Desk 1-630-887-5207, Cell 1-312-953-7299,plys@fauske.com

SUBJECT: Review of FAI/09-91 Portions Authored by Michael Epstein

I have reviewed the sections of FAl/09-91 that were authored by Michael Epstein. In my review I checked the derivations of all equations and I checked all numerical answers provided. In the case of various terms in the lognormal differential equations, the derivation was checked by numerical evaluation of integrals for example values.

Two pages of markup to the report are attached. Also attached is the Mathcad file used to document checking of numerical answers and derivations. 
PRC-STP-00011, Rev. 0

Review of FAl/09-91 Portions

Authored by Michael Epstein
Page 2 of 22

Attachment B1 MGP062609
June 26, 2009

$3.5 \quad 8.20 \times 10^{-4} \frac{\text { FAI } 109-91 \text { mankups }}{3.7} \quad 6.31 \times 10^{-5} \cdot \frac{\text { pen maprovrew }}{301}$

$3-8 \quad 4,06 \times 10^{-4}$

$3-12.6 .83 \times 10^{-2}$

$3.13 \quad 3.12 \times 10^{-2}$

affan 3.-14: change $2,13 \times 10^{-3}$ to $2.08 \times 10^{-3}$

$$
\begin{aligned}
p, 3-6= & 8.22 \rightarrow 8.20 \\
6.45 & \rightarrow 6.31
\end{aligned}
$$

change $q=1.84$ to $q=1.80$

$$
\begin{aligned}
& x=118 \text { to } x=11,2 \\
& x=112 \text { to } x=1,11
\end{aligned}
$$

$3-22 \quad 4,13 \rightarrow 4.11$

$3-23 \quad 3.92 \rightarrow 3.88$

$2.61 \rightarrow 2.43$

3-25 $C_{D}$ is denominator

4-1 - sign befire $\frac{n(v, t) \text { Ulout }}{\text { hodt }}$

B1 - 3 
PRC-STP-00011, Rev. 0

Review of FAI/09-91 Portions

Page 3 of 22 Attachment B19 Authored by Michael Epstein

June 26, 2009

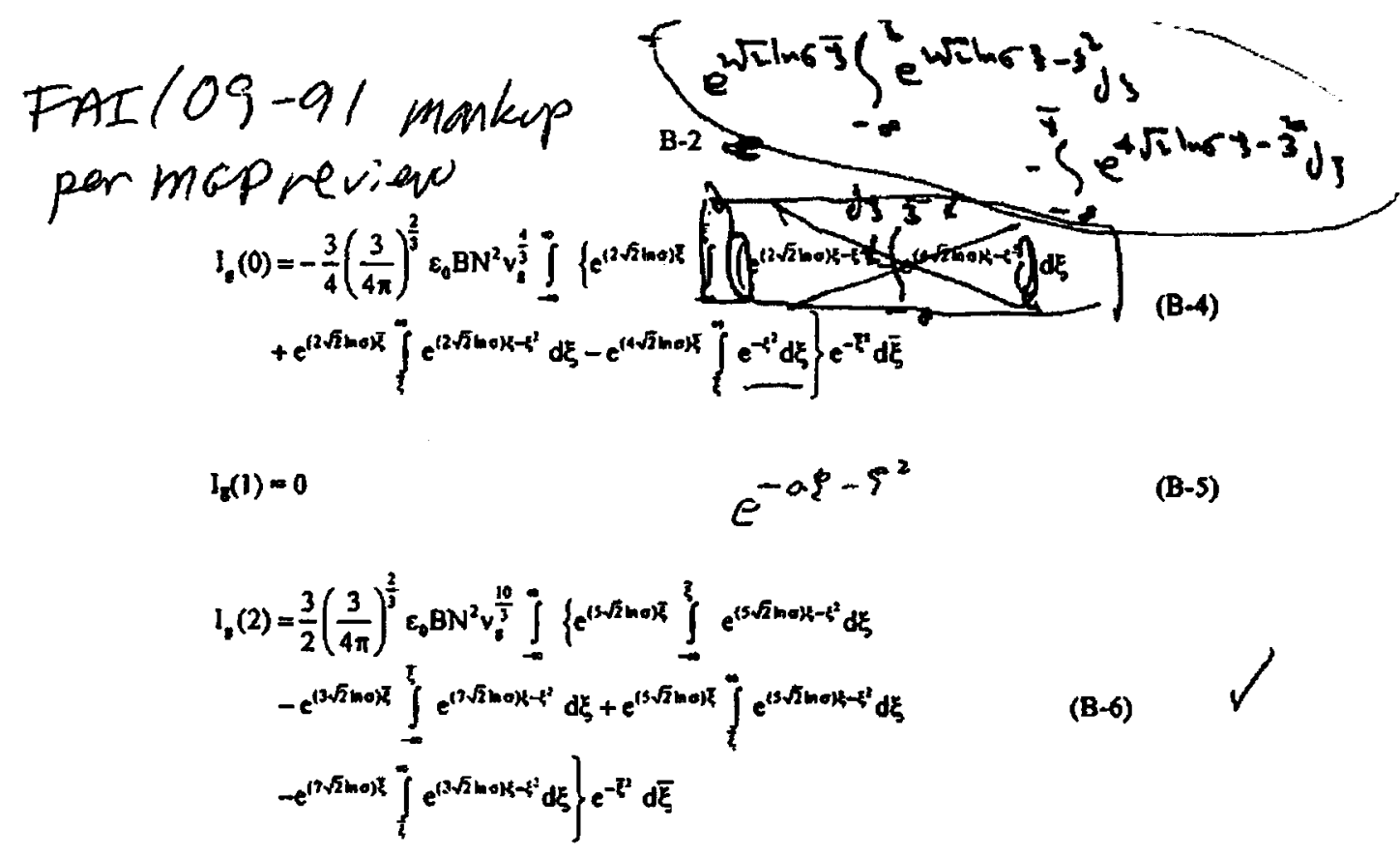

The double integrals in Egs. (B-4) and (B-6) are made considerably easier to evaluate with the knowledge that

$$
\begin{aligned}
& \int e^{\xi \xi-\xi^{3}} d \xi=\frac{\sqrt{\pi}}{2} e^{\left(\frac{\hat{y}}{2}\right)^{2}}\left[1+\operatorname{erf}\left(\bar{\xi}-\frac{a}{2}\right)\right] \\
& \int e^{\alpha-n^{2}} d \xi=\frac{\sqrt{\pi}}{2} e^{\left(\frac{1}{2}\right)^{\circ}}\left[1-\operatorname{erf}\left(\bar{\xi}-\frac{a}{2}\right)\right] \\
& \int_{-\infty}^{\infty} e^{-x^{2}} \operatorname{erf}(x+a) d x=\sqrt{\pi} \operatorname{erf}\left(\frac{a}{\sqrt{2}}\right)
\end{aligned}
$$

The definite integral in Eq. (B-9) could not be found in published tables of integrals available to the authors and was derived by the authors. 
Calculate suspended sludge concentration, outflow to basin, ouflow to filters.

FAI Report FAll09-81, Sludge Particle Separation Efficiencies for the Rectangular SCS-CON-230 Container

Customer: CH2MHIII Plateau Remediation, Richland WA

Contact: John Dearing, 509-372-1877, Jim Sloughter 509-373-0591

Authors: Michael Epstein derived the container pressure and log-normal oquatlons.

Marty Plys Implemented and derived input values including PSD's.

epstein@fauske.com, plysefrauske.com, 16W070 83rd Street, Burr RIdge, IL 60527

Note: No dimensions used because of Mathead expects all vector elements to have the same dimensions, which prohibits integration of quantities with different dimensions.

\section{Equation Testing File:}

This file is used to test Mike Epstein's equations in Sections 2, 3, and 4 of FAllo9-91.

This file also checks App. B against the log-normal equatlons of Section 4.

The first couple of pages are taken from SCS-CON-230-Model.med.

\subsection{INPUTS - Generic}

\section{Conversion factors to be used here:}

$$
\begin{array}{lll}
\text { Inches to meters: } & 1 \cdot \mathrm{jn}=0.025400 \mathrm{~m} & \text { C to K: } \quad T_{1}:=273.15 \\
\text { gpm to } \mathrm{m}=3 / \mathrm{s}: & \mathrm{J} \cdot \mathrm{gpm}=6.30902 \times 10^{-5} \mathrm{~m}^{3} \cdot \mathrm{s}^{-1} & \text { Gpm }:=\left(6.30902 \times 10^{-5}\right)^{-1}
\end{array}
$$

Other properties and constents:

$\begin{array}{lllll}\begin{array}{l}\text { Water density, viscosity, and } \\ \text { thermal expansion coefficient }\end{array} & p_{r}:=1000 & \mu_{r}:=10^{-3} & \beta:=2.07 \cdot 10^{-4} \\ \begin{array}{l}\text { Water thermal conductivity, } \\ \text { spec. heal, and diffusivity }\end{array} & k_{r}:=0.60 & c_{p r}:=4184 & v_{r}:=\frac{\mu_{r}}{\rho_{r}} \quad \alpha_{r}:=\frac{k_{r}}{p_{r} c_{p r}} \\ \text { Acceleration of grevity } & p_{r}=9.81 & v_{r}=1.0000 \times 10^{-6} \alpha_{r}=1.4340 \times 10^{-7}\end{array}$


PRC-STP-00011, Rev. 0

Review of FAl/09-91 Portions

SCS-CON-230 Dimensions that follow are converted from inchee to meters.

$L=$ length, $W=$ width, $H=$ height, $V=$ volume, $A C=$ cross-sectional area, $A w c=$ wall area

\begin{tabular}{|c|c|}
\hline $\operatorname{Lw}_{w}=142 \cdot 0.0254$ & $L=3.6068$ \\
\hline hㅔㅁ: $=128 \cdot 0.0254$ & $H=3.2512$ \\
\hline$W=60 \cdot 0.0254$ & $W=1.5240$ \\
\hline$V_{c}:=\mathbf{L} \cdot \mathbf{W} \cdot \mathbf{H}$ & $V_{e}=17.8711$ \\
\hline$A_{t}:=W \cdot L$ & $A_{c}=5.4968$ \\
\hline$A_{m x}:=2 \cdot H(L+W)$ & $A_{\text {Wx }}=33.3625$ \\
\hline 99 crate volume & $V_{c z s}=0.98$ \\
\hline
\end{tabular}

Gap flow area: The perimeler is given as the same upstream and downstream, but use separale variables in case of changes. Outflow occurs at the downstream width, need the effective height which is container volume/outflow area.

\begin{tabular}{|c|c|c|}
\hline Gap thickness: & $\delta_{\operatorname{gap}}:=1 \cdot 0.0254$ & $\delta_{p a p}=0.0254$ \\
\hline Upstream gep: & $A_{\text {quU }}:=0.0254 \cdot(60+9+9) \cdot \delta_{\text {eap }}$ & $A_{g p}=0.0503$ \\
\hline Downstream gap & $A_{\text {pd }}:=0.0254 \cdot(60+9+9) \cdot \delta_{1000}$ & $A_{\text {dd }}=0.0503$ \\
\hline $\begin{array}{l}\text { Assumed walk } \\
\text { thickness and }\end{array}$ & $x_{w e}:=0.125 \cdot 0.0254$ & $x_{w c}=3.1750 \times 10^{-3}$ \\
\hline & $k_{\text {we }}:=40 \quad$ Unils W/m/K & \\
\hline
\end{tabular}

Nominal Inlet source is two distributors, with nominal solids fraction $\alpha:$

$\begin{array}{lll}\text { Inlet flow, per source m"*3/s } & Q_{0}:=7.5 . \mathrm{Gpm}^{-1} & Q_{0}=4.7318 \times 10^{-4} \\ \text { Solids frac, \# Inlets } & Q_{0}:=0.02 & N_{0}:=2 \\ \text { Filler flow } & Q_{n}:=7.0 \mathrm{pm}^{-1} & Q_{n}=4.4163 \times 10^{-4} \\ \text { Backflush flow rate } & Q_{b}:=5 . \mathrm{Gpm}^{-1} & Q_{r}=3.1545 \times 10^{-4}\end{array}$

Loss costflcient (well known) and contsiner pressure lose coofficient (conservative):

$\begin{array}{ll}\text { Loss coefficiant: } & C_{D}:=0.7 \\ \text { Container } K: & K_{c}:=0.75\end{array}$


PRC-STP-00011, Rev. 0

Review of FAI/09-91 Portions

Page 6 of 22

Attachment B1

Authored by Michael Epstein

MGP062609

June 26, 2009

\subsection{Check of Section 2 Equations}

Eq. 2-9: $\quad A_{c}=5.4968 \quad E_{0}:=0.12 \quad H_{0}=1.9 \quad 2 \cdot \pi \cdot\left(\frac{6}{5}\right)^{2} \cdot \frac{E_{0}{ }^{2} \cdot H_{d}{ }^{2}}{A_{c}}=0.0856$

Eq. 2-12: $\quad \frac{9 \cdot \pi \cdot E_{0} \cdot H_{d}{ }^{2}}{5 \cdot A_{c}}=0.4457$

\subsection{Check of Section 3 Equations}

Eq. 3-6:

$$
\begin{array}{ll}
Q_{n}=4.4163 \times 10^{-4} & Q_{n} \cdot G p m=7.0000 \quad Q_{0}=4.7318 \times 10^{-4} \quad Q_{0} \cdot G p m=7.5000 \\
Q_{\text {suc }}:=4 \cdot Q_{n}=2 \cdot Q_{0} & Q_{\text {sc }}=8.2017 \times 10^{-4} \quad Q_{s u c} \cdot G_{p m}=13.0000
\end{array}
$$

Eq. 3-6:

$$
\begin{array}{ll}
A_{g 0}+A_{g d}=0.1006 & P_{f}=1.0000 \times 10^{3} \quad C_{D}=0.7000 \quad Q_{\text {suc }}=8.2017 \times 10^{-4} \\
A_{z}:=0.10 & \frac{1}{2} \cdot \operatorname{Pr}\left(\frac{Q_{\text {guc }}}{C_{D} \cdot A_{f}}\right)^{2}=0.0686
\end{array}
$$

$$
\begin{aligned}
& \text { E4. 3.7: } \quad Q_{b r}=3.1545 \times 10^{-4} \quad Q_{b r} \text { Opsn }=5.0000 \\
& Q_{\text {wur }}:=3 \cdot Q_{A}-2 \cdot Q_{0}-Q_{b r} \quad Q_{s u c} \cdot G p m=1.0000 \quad Q_{s u c}=6.3090 \times 10^{-5} \\
& \text { E9. 3n8: } \quad \frac{1}{2} \cdot \operatorname{Pr}\left(\frac{Q_{\text {sux }}}{C_{D} \cdot A_{z}}\right)^{2}=4.0616 \times 10^{-4}
\end{aligned}
$$


PRC-STP-00011, Rev. 0

June 26, 2009

Botween Eq. 3-11 and Eq. 3-12:

In-basin cross-flow velocity rounded value $1 \mathrm{~mm} / \mathrm{s}$ justified by $120 \mathrm{gpm}$ over 30 feet wldth and $1 \mathrm{~m}$ depth because gap is 2.5 faet submerged:

$\frac{120 \cdot\left(6.30902 \times 10^{-5}\right)}{1 \cdot(30 \cdot 12 \cdot 0.0254)}=8.2796 \times 10^{-4} \quad u_{i n f}:=0.001$

$K_{c}=0.7500 \quad \rho_{r}=1.0000 \times 10^{3} \quad \frac{K_{c}}{2} \cdot p_{r} v_{\text {iar }}^{2}=3.7500 \times 10^{-4}$

$C_{D}=0.7000 \quad A_{8}=0.1000$

Eq. 3-12: $\quad Q_{4 w n}: 13 . \mathrm{Gpm}^{-1} \quad Q_{u c}=8.2017 \times 10^{-4}$

$\frac{1}{2} \cdot \operatorname{pr}\left(\frac{Q_{\text {wuc }}}{C_{D} \cdot A_{t}}\right)^{2}-\frac{K_{\varepsilon}}{2} \cdot \rho_{r} \cdot u_{i n r}{ }^{2}=0.0683$

Eq. 3-13: $\quad Q_{\operatorname{sen}}=1 \cdot \mathrm{Gpm}^{-1} \quad 6.3090 \times 10^{-5}$

$\frac{1}{2} \cdot p_{r}\left(\frac{Q_{\text {uve }}}{C_{D} \cdot A_{2}}\right)^{2}-\frac{K_{q}}{2} \cdot p_{r} u_{\text {inr }}^{2}=3.1161 \times 10^{-5}$

Eq. 3.14:

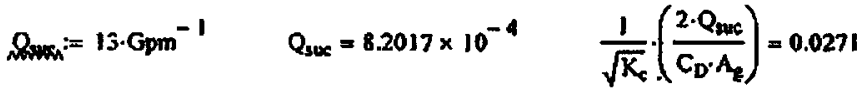

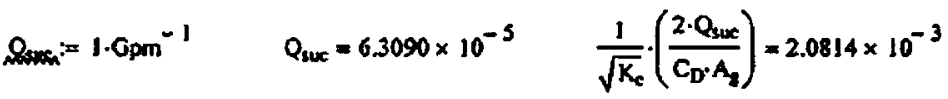


PRC-STP-00011, Rev. 0

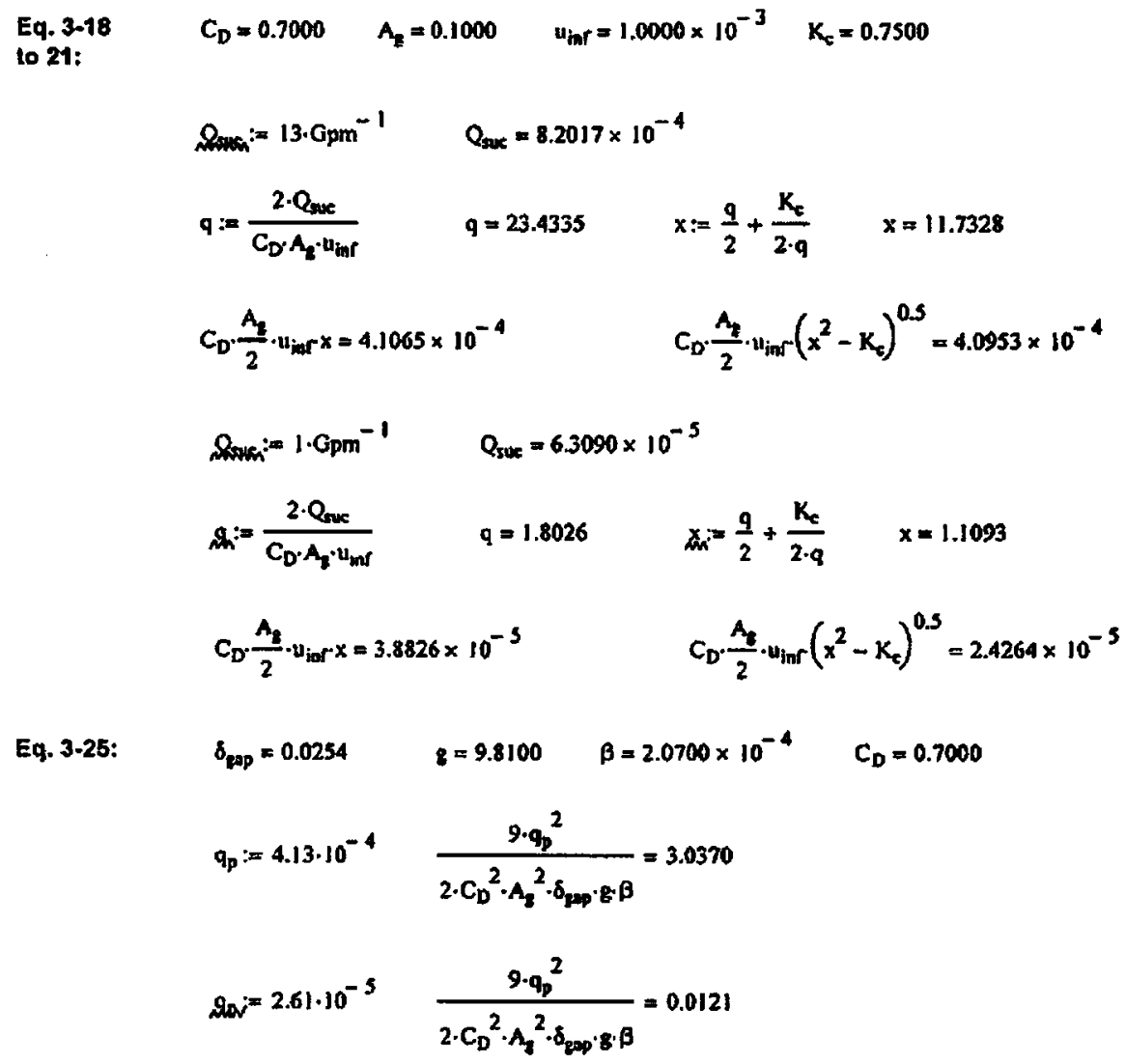


PRC-STP-00011, Rev. 0

Authored by Michael Epstein

June 26, 2009

\subsection{Check of Section 4 Equations}

Set up to check PSD equalions

$d_{\max }=500 \cdot 10^{-6} \quad 99.9 \%$ of perticle volume below this value

Equations 4-28 and 4-29 are verified as correct, use as functions here:

$f \sigma p\left(d_{\operatorname{mad} d}\right):=\exp \left(\frac{5}{11 \cdot \sqrt{2}} \cdot \ln \left(\frac{d_{\max }}{d_{\operatorname{med}}}\right)\right) \quad \operatorname{fvgp}\left(\mathrm{d}_{\operatorname{mad}}\right):=\mid \begin{aligned} & \sigma \leftarrow \operatorname{fop}\left(d_{\operatorname{med}}\right) \\ & \frac{\pi}{6} \cdot d_{\operatorname{med}}{ }^{3} \cdot \exp \left[-9 \cdot(\ln (\sigma))^{2}\right]\end{aligned}$

Use values for the 10 miçron median PSD:

$\sigma:=f \sigma p\left(10^{-5}\right) \quad \sigma=3.5162 \quad v_{g p}:=f v g p\left(10^{-5}\right) \quad v_{g p}=3.4633 \times 10^{-22}$

Eq. 4-6: Check that the distribution approaches 1.0 for large particles, and check that we can regroduce the 10 micron medien volume. Note we use $\mathrm{N}=1$ since this does not matter.

$$
\begin{aligned}
& \operatorname{fn}\left(x, v_{\operatorname{tg}}, \sigma\right)=\frac{1}{\sqrt{2 \cdot \pi} \cdot \ln (\sigma)} \cdot \exp \left[\frac{\left(x-\frac{1}{3} \ln \left(v_{\text {sep }}\right)\right)^{2}}{2 \cdot(\ln (\sigma))^{2}}\right] \\
& x_{\max }:=\frac{1}{3} \cdot \ln \left(\frac{\pi}{6} \cdot d_{\max }^{3}\right) \quad \int_{-100}^{x_{\max }} f a\left(x, v_{p e p}, \sigma\right) d x=1.0000 \\
& I \max :=300 \quad i=0 . . \operatorname{lmax} \quad d_{i}=10^{-8} \cdot\left(\frac{d_{\max }}{10^{-8}}\right)^{\frac{i}{I \max }} \quad x_{i}:=\frac{1}{3} \cdot \ln \left[\frac{\pi}{6} \cdot\left(d_{i}\right)^{3}\right]
\end{aligned}
$$

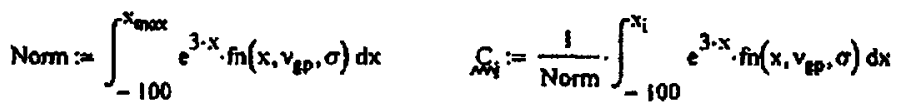


PRC-STP-00011, Rev. 0 Authored by Michael Epstein

Plot of the cumulative volume distribution proves median at $50 \%$

Due to the normalization up to dmax, the distribution below is 1.0 at dmax.

$d_{I \max }=5.0000 \times 10^{-4} \quad C_{I \max }=1.0000$

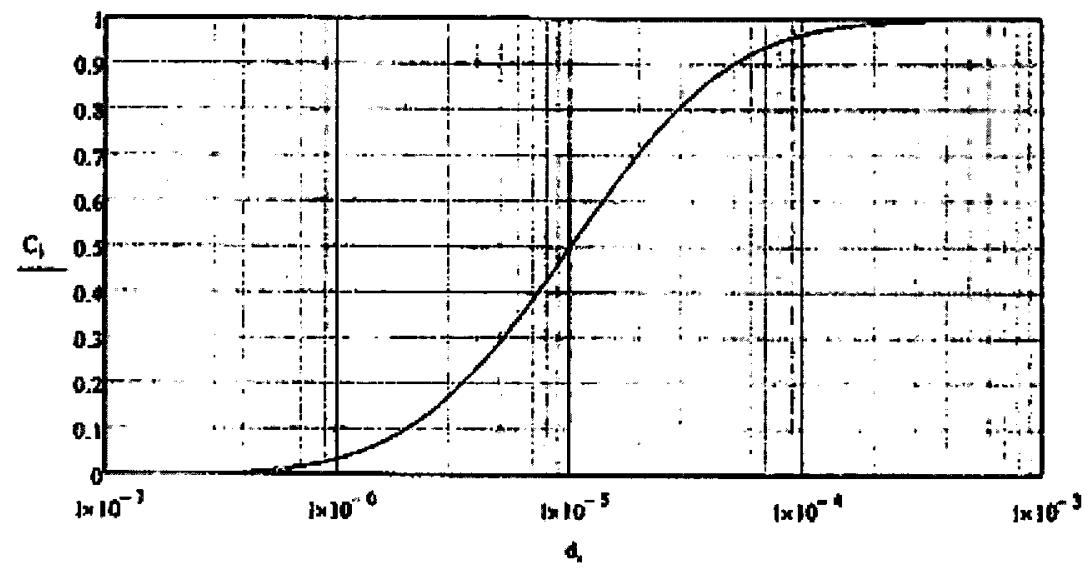

Eq. 4.9: $\quad v_{s p} \cdot \exp \left[\frac{9}{2} \cdot(\ln (0))^{2}\right]=4.2584 \times 10^{-19}$

$$
\int_{-100}^{x_{\max }} e^{3 \cdot x} \cdot \sin \left(x_{0}, y_{5 p}, \sigma\right) d x=4.2585 \times 10^{-19}
$$


PRC-STP-00011, Rev. 0 Authored by Michael Epstein

$$
\begin{aligned}
& \text { Eq. 4.10: } \quad v_{\mathrm{ZP}}{ }^{2} \cdot \exp \left[18 \cdot(\ln (\sigma))^{2}\right]=2.7416 \times 10^{-31} \quad x_{\max }=-7.8166 \\
& \int_{-1000}^{x_{\max }} e^{6-x} \cdot \ln \left(x, v_{a p}, \sigma\right) d x=7.9775 \times 10^{-32} \quad \begin{array}{l}
\text { The second moment integral } \\
\text { is sensittve to the upper bound. } \\
\text { expand into sections: }
\end{array}
\end{aligned}
$$

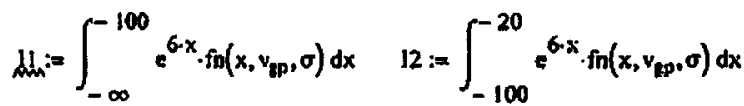

$$
\begin{aligned}
& 13:=\int_{-20}^{x_{\max }} e^{6 \cdot x} \cdot f n\left(x, v_{p p}, \sigma\right) d x \quad 14:=\int_{x_{\max }}^{0} e^{6 \cdot x} \cdot \operatorname{fn}\left(x, v_{10 p}, \sigma\right) d x \\
& \left.15:=\int_{0}^{100} e^{6-x} \cdot \operatorname{mn}(x, y), \sigma\right) d x \\
& 11=0.0000 \quad 12=5.8012 \times 10^{-36} \\
& 13=6.9733 \times 10^{-32} \quad 14=2.0442 \times 10^{-31} \quad 15=3.8021 \times 10^{-39} \\
& 13+14=2.7416 \times 10^{-31} \quad \text { Agreemen!! }
\end{aligned}
$$

Eq. 4-12 Verily using $N=1$ and assigning $X 0, X 1$, and $X 2$ with Eq. 4-8 10 4-10.

4-13:

$$
\begin{aligned}
& x_{0}:=1 \quad x_{1}:=x_{0} \cdot v_{e p} \cdot \exp \left[\frac{9}{2} \cdot(\ln (\sigma))^{2}\right] \quad x_{1}=4.2584 \times 10^{-39} \\
& x_{2}:=x_{0} \cdot v_{t p}^{2} \cdot \exp \left[18 \cdot(\ln (\sigma))^{2}\right] \quad x_{2}=2.7416 \times 10^{-31} \\
& v_{\mathrm{epp}}=3.4633 \times 10^{-22} \quad \frac{x_{1}^{2}}{x_{0}^{\frac{2}{3}} \cdot x_{2}^{\frac{1}{2}}}=3.4633 \times 10^{-22} \\
& \ln (\sigma)=1.2574 \quad \frac{1}{3}\left(\ln \left(\frac{x_{0} \cdot x_{2}}{x_{1}^{2}}\right)\right)^{\frac{1}{2}}=1.2574
\end{aligned}
$$


PRC-STP-00011, Rev. 0

$E=9.8100 \quad P_{p}:=6000 \quad P_{f}=1.0000 \times 10^{3} \quad H_{r}=1.0000 \times 10^{-3}$

$B:=\frac{2}{9} \cdot\left(\frac{3}{4 \cdot \pi}\right)^{\frac{2}{3}} \cdot \frac{8 \cdot\left(p_{p}-p_{r}\right)}{\mu_{r}} \quad B=4.1947 \times 10^{6} \quad$ fur $(v):=8 \cdot v^{\frac{2}{3}}$

$X_{0}=1.0000 \quad X_{1}=4.2584 \times 10^{-19} \quad x_{2}=2.7416 \times 10^{-31}$

Eq. 4-20 $\quad 8 \cdot x_{0} \cdot\left(\frac{x_{1}^{8}}{x_{0}{ }^{7} \cdot x_{2}}\right)^{\frac{1}{9}}=4.8856 \times 10^{-7}$

$\int_{-100}^{x_{\max }} B \cdot e^{2 \cdot x} \cdot \operatorname{fn}\left(x, y_{g p}, 0\right) d x=4.8501 \times 10^{-2}$

Eq. 4-21

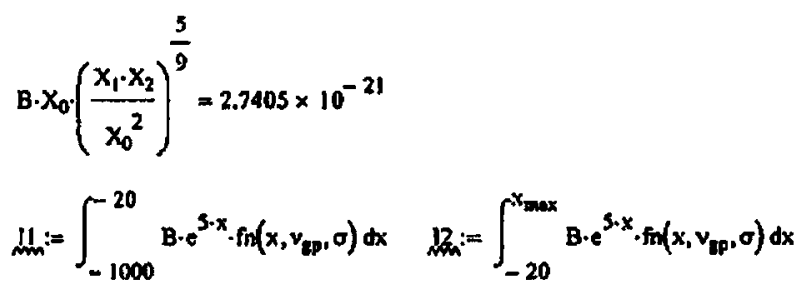

$d_{A}:=\int_{x_{\max }}^{0} B \cdot e^{5 \cdot x} \cdot f n\left(x, v_{p p}, \sigma\right) d x \quad 11+12+13=2.7405 \times 10^{-21}$

Eq. 4-22 B. $x_{0} \cdot\left(\frac{x_{2}^{5}}{x_{0} \cdot x_{1}^{4}}\right)^{\frac{4}{9}}=2.3242 \times 10^{-29}$

$\mu n:=\int_{-1000}^{-20} B \cdot e^{8 \cdot x} \cdot f n\left(x, v_{B p}, \sigma\right) d x \quad 212:=\int_{-20}^{x_{\max }} B \cdot e^{8 \cdot x} \cdot f\left(x, v_{c p}, \sigma\right) d x$

$25:=\int_{x_{\max }}^{0} B \cdot c^{8 \cdot x} \cdot \operatorname{mn}\left(x, v_{p p}, \sigma\right) d x \quad 11+12+13=2.3214 \times 10^{-29}$ 
Eq. 4-20. Coagulation terms can be tested by comparing integrals with the formulas

8. 4-22 B.10 should be the same as coagulation in 4-20

B-11 should be the same as coagulation in 4-22.

Again note $\mathrm{N}=1$

$B=4.1947 \times 10^{6} \quad \epsilon_{0}:=\frac{1}{3} \quad B C:=\frac{3 \cdot \pi}{4} \cdot\left(\frac{3}{4 \cdot \pi}\right)^{\frac{2}{3}} \cdot \varepsilon_{0} \cdot B \quad B C=1.2678 \times 10^{6}$

$V_{p p}=3.4633 \times 10^{-22} \quad \sigma=3.5162$

$x_{0}=1.0000 \quad x_{1}=4.2584 \times 10^{-19} \quad x_{2}=2.7416 \times 10^{-31}$

6-10:

$B C \cdot v_{p p}^{\frac{1}{3}} \cdot \exp \left[4 \cdot(\ln (\sigma))^{2}\right]\left[1-\exp \left[4 \cdot(\ln (\sigma))^{2}\right] \cdot \operatorname{erf}(2 \cdot \ln (\sigma))\right]=1.3592 \times 10^{-20}$

4.20:

$\left.\mathrm{BC} \cdot \mathrm{X}_{0}^{2} \cdot\left(\frac{\mathrm{x}_{1}^{8}}{\mathrm{x}_{0}{ }^{7} \cdot \mathrm{x}_{2}}\right)^{\frac{2}{9}} \cdot 1-\left(\frac{\mathrm{x}_{0} \cdot \mathrm{x}_{2}}{\mathrm{x}_{1}{ }^{2}}\right)^{\frac{1}{9}} \cdot \operatorname{erfc}(2 \cdot \ln (\sigma))\right]=1.3592 \times 10^{-20}$

Q-11: $\quad 2 \cdot B C \cdot v_{k p}^{\frac{10}{3}} \cdot \exp \left[25 \cdot(\ln (\sigma))^{2}\right] \cdot\left[1-\exp \left[4 \cdot(\ln (\sigma))^{2}\right] \cdot \operatorname{erfc}(2 \cdot \ln (\sigma))\right]=8.5535 \times 10^{-49}$

4-22. $\quad 2 \cdot B C \cdot x_{0}^{2} \cdot\left(\frac{x_{1}^{\frac{10}{9}} \cdot x_{2}^{\frac{10}{9}}}{x_{0}^{\frac{30}{9}}}\right)\left[1-\left(\frac{x_{0} \cdot x_{2}}{x_{1}{ }^{2}}\right)^{\frac{4}{9}} \cdot \operatorname{erc}(2 \cdot \ln (\sigma))\right]=8.5535 \times 10^{-49}$ 
Review of FAl/09-91 Portions

Authored by Michael Epstein
Page 14 of 22
PRC-STP-00011, Rev. 0

Attachment B19

June 26, 2009

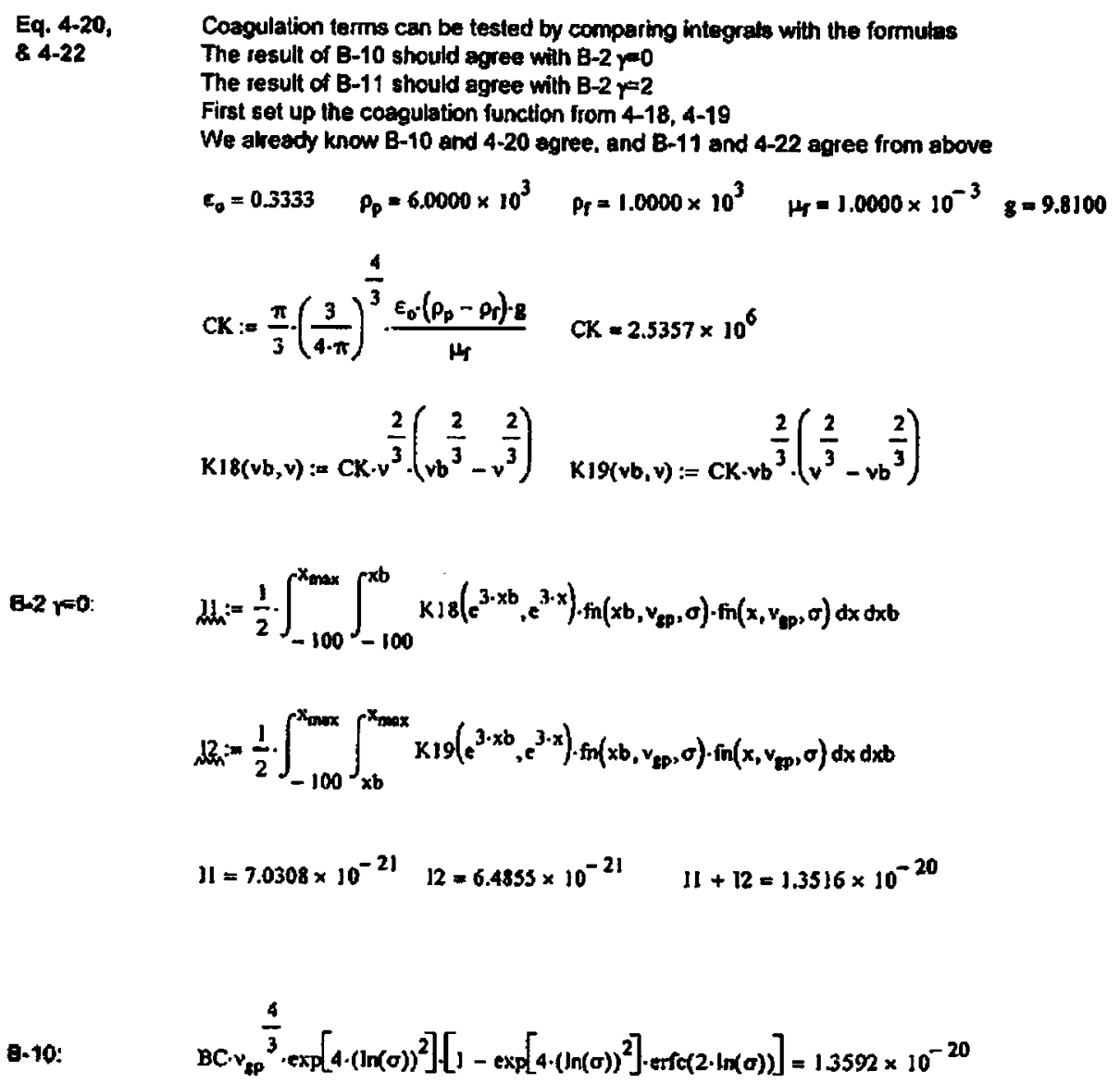


PRC-STP-00011, Rev. 0

Review of FAl/09-91 Portions

Page 15 of 22

Attachment B1

MGP062609

Authored by Michael Epstein

June 26, 2009

Eq. 4-20, Coagulation lerms can be tested by comparing inlegrals with the formulas

8.22

The result of B-10 should agree with B-2 $y=0$

The result of B-11 should agree with B-2 $y=2$

First set up the cosgulation function from 4-18, 4-19

We already know B-10 and 4-20 agree, and B-11 and 4-22 agree from above

$\varepsilon_{0}=0.3333 \quad P_{p}=6.0000 \times 10^{3} \quad P_{r}=1.0000 \times 10^{3} \quad \mu_{f}=1.0000 \times 10^{-3} \quad g=9.8100$

$\mathrm{CK}=2.5357 \times 10^{6}$

$d v 2(v b, v):=(v b+v)^{2}-v b^{2}-v^{2}$

8-2 r-2:

$\mu_{h}=\frac{1}{2} \cdot \int_{-100}^{x_{\max }} \int_{-100}^{x b} d v 2\left(e^{3 \cdot x b}, e^{3 \cdot x}\right) \cdot K 18\left(e^{3 \cdot x b}, e^{3 \cdot x}\right) \cdot f b\left(x b, v_{k p}, \sigma\right) \cdot \ln \left(x, v_{k p}, \sigma\right) d x d x b$

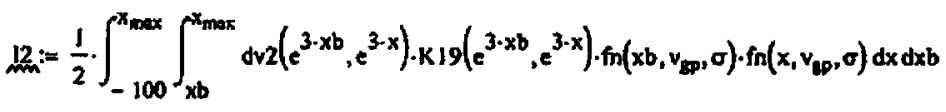

$I 1=2.0248 \times 10^{-49} \quad 12=2.0201 \times 10^{-49} \quad 11+12=4.0449 \times 10^{-49}$ 
PRC-STP-00011, Rev. 0

$$
\begin{aligned}
& \text { Q-11: } 2 \cdot 8 C \cdot v_{\mathrm{pp}}^{\frac{10}{3}} \cdot \exp \left[25 \cdot(\ln (\sigma))^{2}\right]\left[\left[1-\exp \left[4 \cdot(\ln (\sigma))^{2}\right] \cdot \operatorname{erf}(2 \cdot \ln (\sigma))\right]=0.0000\right. \\
& 11 A:=\frac{1}{2} \cdot \int_{-100}^{20} \int_{-100}^{x b} d v 2\left(e^{3 \cdot x b}, e^{3 \cdot x x}\right) \cdot K 18\left(e^{3 \cdot x b}, e^{3 \cdot x}\right) \cdot \operatorname{fn}\left(x b, v_{y p}, \sigma\right) \cdot \operatorname{fn}\left(x, v_{x p}, \sigma\right) d x d x b \\
& \| B=\frac{1}{2} \cdot \int_{-20}^{x_{\max }} \int_{-100}^{x b} d v 2\left(e^{3 \cdot x b}, e^{3 \cdot x}\right) \cdot K 18\left(e^{3 \cdot x b}, e^{3 \cdot x}\right) \cdot \min \left(x b, y_{m p}, \sigma\right) \cdot \min \left(x, v_{p p}, \sigma\right) d x d x b
\end{aligned}
$$

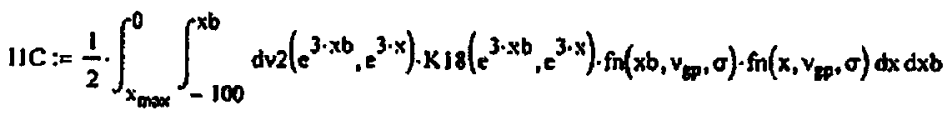

$$
\begin{aligned}
& \mu h:=11 A+J 1 B+11 C \\
& 12 A:=\frac{1}{2} \cdot \int_{-100}^{-20} \int_{x b}^{0} d v 2\left(e^{3 \cdot x b}, e^{3 \cdot x}\right) \cdot x 10\left(e^{3 \cdot x b}, e^{3 \cdot x}\right) \cdot \operatorname{rn}\left(x b, v_{e p}, 0\right) \cdot \ln \left(x, v_{e p p}, 0\right) d x d x b \\
& 12 B:=\frac{1}{2} \cdot \int_{-20}^{x_{\max }} \int_{x b}^{0} d v 2\left(e^{3 \times x b} \cdot e^{3 \cdot x}\right) \cdot k 19\left(e^{3 \cdot x b}, e^{3 \cdot x}\right) \cdot \operatorname{fn}\left(x b, v_{v p}, 0\right) \cdot f h\left(x, v_{y p}, \sigma\right) d x d x b
\end{aligned}
$$

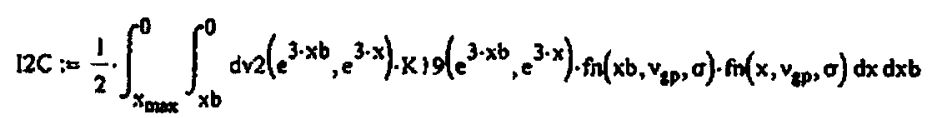

$$
\begin{aligned}
& 12=12 A+12 B+12 C \\
& 11=4.2768 \times 10^{-49} \quad 12=4.2768 \times 10^{-49} \quad 11+12=8.5539 \times 10^{-49}
\end{aligned}
$$


PRC-STP-00011, Rev. 0

Review of FAI/09-91 Portions

Page 17 of 22
Attachment 81

June 26, 2009

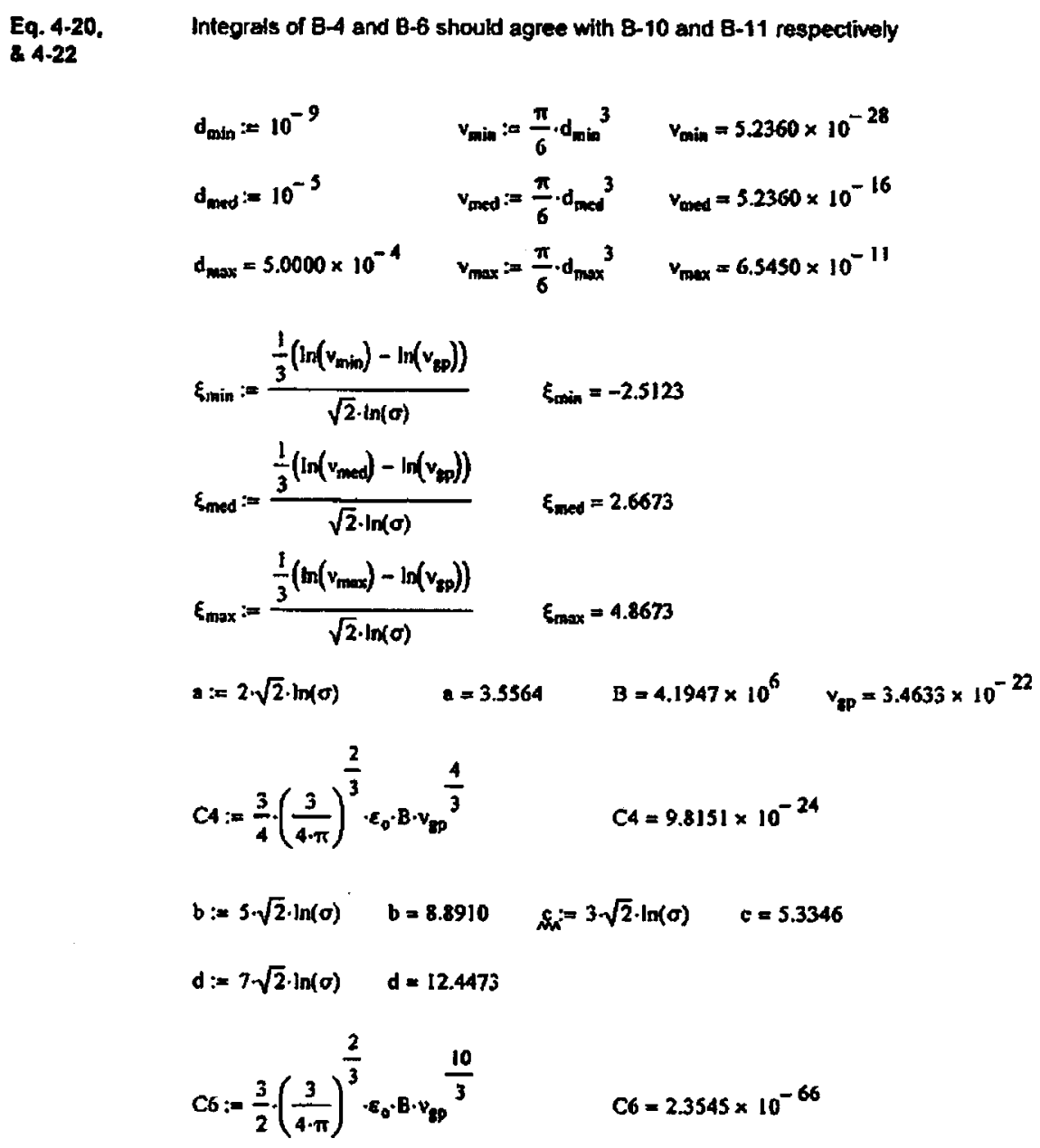


PRC-STP-00011, Rev. 0

$B-4 \quad$ WLA $=C 4 \cdot \int_{-10}^{\xi_{\max }} e^{8 \cdot x-x^{2}} \cdot \int_{-10}^{x} e^{2 \cdot \xi-\xi^{2}} d \xi d x+C 4 \cdot \int_{\xi_{\operatorname{med}}}^{10} e^{4 \cdot x-x^{2}} \cdot \int_{-10}^{x} e^{2-\xi-\xi^{2}} d \xi d x$

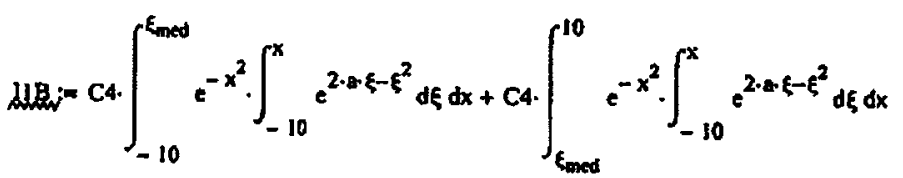

$M h:=11 A-11 B$

$12 A=C 4 \cdot \int_{-10}^{\xi_{\operatorname{mad}}} e^{0 \cdot x-x^{2}} \cdot \int_{x}^{10} e^{-1-\xi-\xi^{2}} d \xi d x+C 4 \cdot \int_{\xi_{\operatorname{mat}}}^{10} e^{2-x-x^{2}} \cdot \int_{x}^{10} e^{2 \cdot \epsilon-\xi^{2}} d \xi d x$

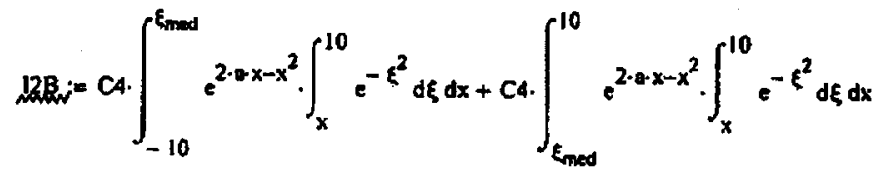

$12:=12 A-12 B$

$11=6.7959 \times 10^{-21} \quad 12=6.7959 \times 10^{-21} \quad 11+12=1.3592 \times 10^{-20}$

6-10:

$$
\text { BC. } \frac{1}{3}{ }^{3} \cdot \exp \left[4 \cdot(\ln (\sigma))^{2}\right] \cdot\left[1-\exp \left[4 \cdot(\ln (\sigma))^{2}\right] \cdot \operatorname{erfc}(2 \cdot \ln (\sigma))\right]=1.3592 \times 10^{-20}
$$


PRC-STP-00011, Rev. 0

Review of FAI/09-91 Portions

Page 19 of 22

Attachment B1

Authored by Michael Epstein

June 26, 2009

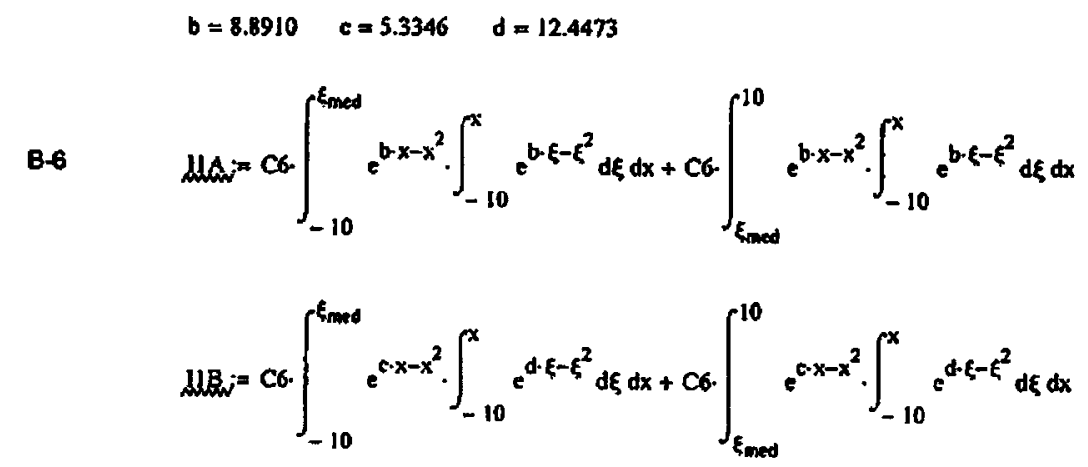

$M h^{\prime}=11 \mathrm{~A}-\mathrm{HB}$

$22 A=C 6 \cdot \int_{-10}^{\xi_{\text {med }}} e^{b \cdot x-x^{2}} \cdot \int_{x}^{10} e^{b-\xi-\xi^{2}} d \xi d x+C \sigma \cdot \int_{\xi \text { max }}^{10} e^{b-x-x^{2}} \cdot \int_{x}^{10} e^{b-\xi-\xi^{2}} d \xi d x$

$228 \cdot C \sigma \cdot \int_{-10}^{\xi \xi_{m \sigma}} e^{d \cdot x-x^{2}} \cdot \int_{x}^{10} e^{0 \xi-\xi^{2}} d \xi d x+C \sigma \cdot \int_{\xi_{\operatorname{med}}}^{10} e^{d \cdot x-x^{2}} \cdot \int_{x}^{10} e^{c \cdot \xi-\xi^{2}} d \xi d x$

$22=12 A-12 B$

$11=4.2768 \times 10^{-49} \quad 12=4.2768 \times 10^{-49} \quad 11+12=8.5535 \times 10^{-49}$

8-11: $\quad 2 \cdot B C \cdot v_{\operatorname{tp}}^{\frac{10}{3}} \cdot \exp \left[25 \cdot(\ln (\sigma))^{2}\right]\left[\left[1-\exp \left[4 \cdot(\ln (\sigma))^{2}\right] \cdot \operatorname{er}(\alpha(2 \cdot \ln (\sigma))]=8.5535 \times 10^{-49}\right.\right.$ 
Review of FAI/09-91 Portions

Authored by Michael Epstein
Page 20 of 22

PRC-STP-00011, Rev. 0

Attachment B1

MGP062609

June 26, 2009

Eq. 4-20, Supporting work in App. B

4.22 Evaluate Inlegrals at median of distribution

$$
\begin{aligned}
& v_{\text {med }}=5.2360 \times 10^{-16} \quad v_{\text {ip }}=3.4633 \times 10^{-22} \quad \sigma=3.5162 \quad \varepsilon_{\operatorname{med}}=2.6673 \\
& \xi:=\xi_{\text {mated }} \\
& \int_{\xi}^{\infty} e^{a \cdot \varepsilon-\xi^{2}} d \xi=4.3664 \\
& \frac{\sqrt{\pi}}{2} \cdot e^{(0.5 \cdot a)^{2}} \cdot\left(1-\operatorname{cof}\left(\xi-\frac{a}{2}\right)\right)=4.3664
\end{aligned}
$$

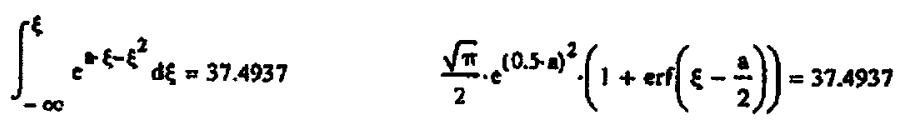

B-?

D.6

B.9

$$
\begin{array}{ll}
\int_{-\infty}^{\infty} e^{-x^{2}} \cdot \operatorname{erf}(x+a) d x=1.7718 & \sqrt{\pi} \cdot \operatorname{erf}\left(\frac{a}{\sqrt{2}}\right)=1.7718 \\
\int_{-\infty}^{\infty} e^{-x^{2}} d x=1.7725 & \sqrt{\pi}=1.7725
\end{array}
$$


Review of FAI/09-91 Portions Authored by Michael Epstein
Page 21 of 22

PRC-STP-00011, Rev. 0

Attachment B1

June 26, 2009

5.0 Check of Appendix A Equations

A-5 Coeficient: $\quad 8.09 \cdot \sqrt{0.5} \cdot 0.25=1.4301$

A.7 Coefficlent: $C_{v}:=\left(\frac{\pi}{6} \cdot \frac{1}{1.43}\right)^{\frac{1}{3}} \quad C_{u}=0.7154$

A-8 $\quad y_{n}:=10^{-6} \quad P_{p}=6.0000 \times 10^{3} \quad p_{t}=1.0000 \times 10^{3} \quad f: 0.02$

$$
u_{s=0}=\frac{C_{w}}{\sqrt{f}} \cdot\left[\frac{\left(p_{p}-p_{r}\right) \cdot g \cdot v_{r}}{p_{r}}\right]^{\frac{1}{3}} \quad u_{s u s}=0.1852
$$

A-9 Coelficient: $\quad C_{2}:=\frac{25}{48 \cdot \pi-C_{u}^{3}} \quad C_{z}=0.4528$

A.g $\quad Q_{0}=4.7318 \times 10^{-4} \quad a_{0}=0.0200 \quad E_{0}=0.1200$

$$
z_{\text {sot }}:=\frac{C_{2} \cdot f^{1.5} \cdot 0_{0} \cdot Q_{0}}{E_{0}^{2} \cdot u_{r}} \quad z_{304}=0.8416
$$

A.17 $\pi \cdot\left(\frac{6}{5} \cdot E_{0} \cdot z_{3 u s}\right)^{2}=0.0461$

B1 - 22 
Review of FAI/09-91 Portions

Page 22 of 22

PRC-STP-00011, Rev. 0

Attachment B1

June 26, 2009

\subsection{Check of Appendix C Equations}

$$
\begin{aligned}
& C-4 \quad v_{A p}=3.4633 \times 10^{-22} \quad d_{L P}=\left(\frac{6}{\pi} \cdot v_{E P}\right)^{\frac{1}{3}} \quad d_{S P}=8.7129 \times 10^{-8} \quad \sigma=3.3162 \\
& d_{\text {mox }}=1.0000 \times 10^{-5} \\
& \frac{1}{2} \cdot\left(1+\operatorname{erf}\left(\frac{\ln \left(d_{\text {med }}\right)-\ln \left(d_{\mathrm{EP}}\right)}{\sqrt{2} \cdot \ln (\sigma)}-\frac{3 \cdot \ln (\sigma)}{\sqrt{2}}\right)\right)=0.5000
\end{aligned}
$$

C-5

$$
\begin{aligned}
& \ln (\sigma)=12574 \quad d_{\max }=5.0000 \times 10^{-4} \\
& \frac{5}{11 \sqrt{2}} \cdot\left(\ln \left(d_{\operatorname{mox}}\right)-\ln \left(d_{\max d}\right)\right)=1.2574
\end{aligned}
$$

C.6 $\quad d_{p g}=8.7129 \times 10^{-8} \quad d_{\operatorname{mec}} \exp \left(-3 \cdot \ln (\sigma)^{2}\right)=8.7129 \times 10^{-8}$

C.3 $\quad P_{P}=6.0000 \times 10^{3} \quad P_{P}=1.0000 \times 10^{3} \quad M=1.0000 \times 10^{-3} \quad g=9.8100$

$$
\begin{aligned}
& d_{p}:=\left[\frac{18 \cdot \mu_{p}^{2}}{\rho_{r}\left(\rho_{p}-\rho_{p}\right) \cdot g}\right]^{\frac{1}{3}} \quad d_{p}=7.1594 \times 10^{-5} \\
& \frac{1}{2} \cdot\left(1+\operatorname{err}\left(\frac{\ln \left(d_{p}\right)-\ln \left(d_{p q}\right)}{\sqrt{2} \cdot \ln (\sigma)}-\frac{3 \cdot \ln (\sigma)}{\sqrt{2}}\right)\right)=0.9413
\end{aligned}
$$


PRC-STP-00011, Rev. 0

Attachment B2

\section{Attachment B2}

MGP062909A, MathCAD Files for FAl/09-91

B2 - 1 
MEMO: $\quad$ MGP062609

DATE: June 26, 2009

TO: $\quad$ QA File 5.35; M. Plys; J. Conzens; M. Epstein

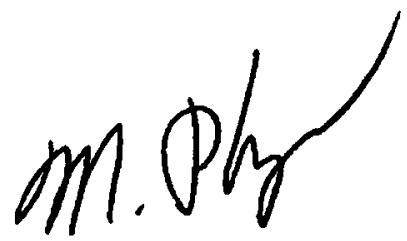

FROM: Marty Plys; Desk 1-630-887-5207, Cell 1-312-953-7299,plys@fauske.com

\section{SUBJECT: Review of FAI/09-91 Portions Authored by Michael Epstein}

I have reviewed the sections of FAI/09-91 that were authored by Michael Epstein. In my review 1 checked the derivations of all equations and I checked all numerical answers provided. In the case of various terms in the lognormal differential equations, the derivation was checked by numerical evaluation of integrals for example values.

Two pages of markup to the report are attached. Also attached is the Mathcad file used to document checking of numerical answers and derivations. 
PRC-STP-00011, Rev. 0

Review of FAl/09-91 Portions Authored by Michael Epstein
Page 2 of 22

Attachment B2

MGP062609

June 26, 2009

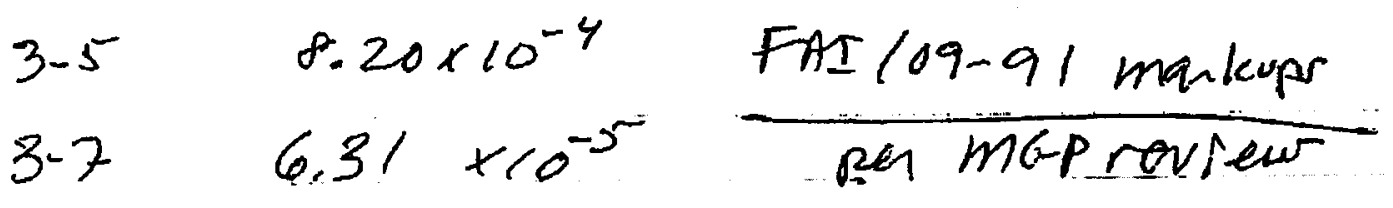

$3-8 \quad 4,06 \times 10^{-4}$

$3-12 \quad 6.83 \times 10^{-2}$

$3.13 \quad 3.12 \times 10^{-}$

ciftan 3.14: charge $2.13 \times 10^{-3}$

$$
\begin{aligned}
p .3-4: \begin{aligned}
& 8.22 \rightarrow 8.20 \\
& 6.45 \rightarrow 6.31
\end{aligned} \\
\text { change } q=1.84 \text { to } q=1.80 \\
x=11.8 \text { to } x=11.2 \\
x=12 \text { to } x=1.11
\end{aligned}
$$

$$
\begin{array}{rlrl}
3-22 & 4.13 & \rightarrow 4.11 \\
3-23 & 3.92 & \rightarrow 3.88 \\
2.61 & \rightarrow 2.43
\end{array}
$$

3-25 $C_{y}$ is denominator

4-1 -sign befere $\frac{n(v, t) \text { wout }}{\text { hadt }}$

B2 - 3 
PRC-STP-00011, Rev. 0

Review of FAl/09-91 Portions Authored by Michael Epstein
Page 3 of 22
Attachment B2

MGP062609

June 26, 2009

FAI 109-9l monkey per mop review

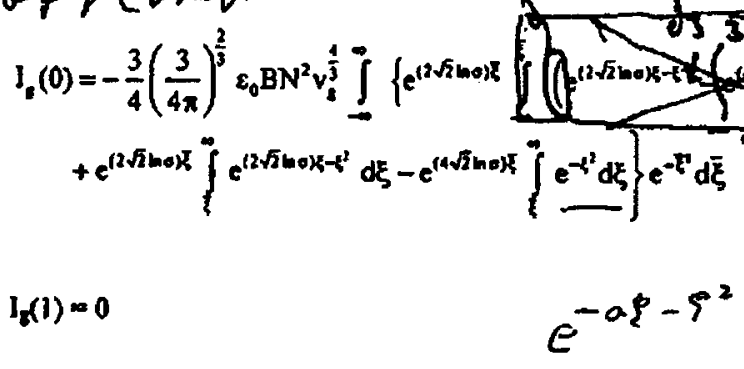

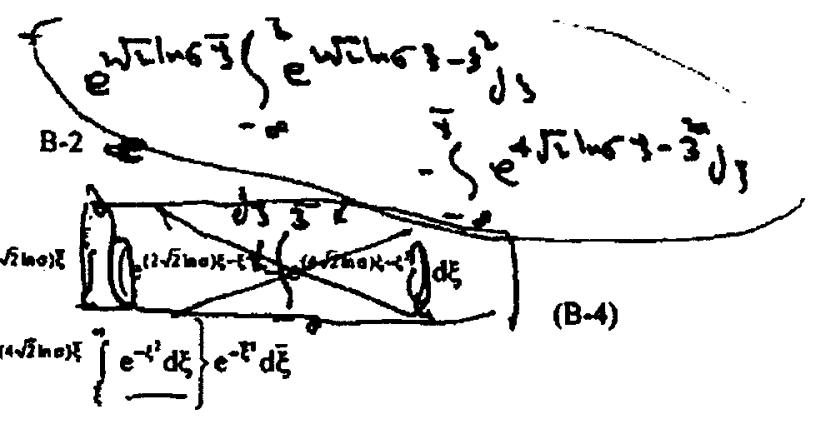

$$
\begin{aligned}
& I_{1}(2)=\frac{3}{2}\left(\frac{3}{4 \pi}\right)^{\frac{2}{3}} \varepsilon_{0} B N^{2} v^{\frac{10}{3}} \int_{-\infty}^{\pi}\left\{e^{(3 \sqrt{2} \operatorname{mox} x} \int_{-\infty}^{\xi} e^{\left(5 \sqrt{2} \operatorname{mos} \alpha-t^{2}\right.} d \xi\right.
\end{aligned}
$$

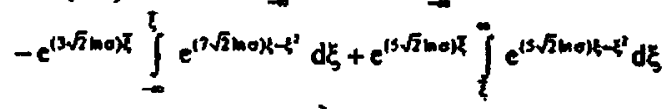

$$
\begin{aligned}
& \left.-e^{(7 \sqrt{2} m 0) t} \int^{\infty} e^{(3 \sqrt{2} m \Delta) \xi x^{2}} d \xi\right\} e^{-\xi^{2}} d \bar{\xi}
\end{aligned}
$$

The double integrals in Eqs. (B-4) and (B-6) are made considerably easier to evaluate with the knowledge that

$$
\begin{aligned}
& \int_{-}^{\xi} e^{*-\xi^{\prime}} d \xi=\frac{\sqrt{\pi}}{2} e^{\left(\frac{\theta}{2}\right)^{2}}\left[1+\operatorname{erf}\left(\bar{\xi}-\frac{a}{2}\right)\right] \\
& \int e^{*-n^{\prime}} d \xi=\frac{\sqrt{\pi}}{2} e^{\left(\frac{1}{2}\right)^{j}}\left[1-\operatorname{erf}\left(\bar{\xi}-\frac{a}{2}\right)\right] \\
& \int e^{-x^{2}} \operatorname{erf}(x+a) d x=\sqrt{\pi} \operatorname{erf}\left(\frac{a}{\sqrt{2}}\right)
\end{aligned}
$$

The definite integral in Eq. (B-9) could not be found in published tables of integrals available to the authors and was derived by the authors.

BD - 4 
Calculate suspended sludge concentration, outflow to basin, oufflow to filters. FAI Report FAll09-81, Sludge Particle Separation Efficiencles for the Reciangular SCS-CON-230 Container

Customer: CH2MHill Plateau Remediation, Richland WA

Contact: John Dearing, 509-372-1877, Jim Sloughter 509-373-0591

Authors: Michael Epstein derived the container pressure and log-normal equatlons. Marty Phys Implemented and derived input values Including PSD's. opstoin 앙 fauske.com, plysefauske.com, 36 W070 83rd Street, Burr Rldge, IL. 60527

Nole: No dimensions used because of Mathcad expects all vector elements to have the same dimensions, which prohibits integration of quantities with different dimensions.

\section{Equation Testing File:}

This file is used to test Mike Epstein's equations in Sections 2, 3, and 4 of FAV09-91.

This file also checks App. B against the log-normal oquations of Section 4.

The first couple of pages are taken from SCS-CON-230-Model.med.

\subsection{INPUTS - Generic}

Conversion factors to be used here:

$\begin{array}{lll}\text { Inches to meters: } & 1 \cdot \mathrm{in}=0.025400 \mathrm{~m} & \mathrm{CloK}: \quad T_{\mathrm{k}}:=273.15 \\ \text { gpm to } \mathrm{m}=3 / \mathrm{s}: & 1 \cdot \mathrm{gpm}=6.30902 \times 10^{-5} \mathrm{~m}^{3} \cdot \mathrm{s}^{-1} & \mathrm{Gpm}:=\left(6.30902 \times 10^{-5}\right)^{-1}\end{array}$

Other properties and constants:

\begin{tabular}{|c|c|c|c|c|c|}
\hline \multirow{2}{*}{$\begin{array}{l}\text { Water density, viscosity, and } \\
\text { thermal expansion coefficient } \\
\text { Water thermal conductlvity, } \\
\text { spec. heal, and diffusivity }\end{array}$} & \multirow{2}{*}{$\begin{array}{l}p_{f}:=1000 \\
k_{f}:=0.60\end{array}$} & \multirow{2}{*}{$\begin{array}{l}\mu_{t}:=10^{-3} \\
c_{p t}:=4184\end{array}$} & \multicolumn{3}{|c|}{$g:=2.07 \cdot 10^{-4}$} \\
\hline & & & $u_{r}:=\frac{\not r}{P_{r}}$ & $o_{p}:=$ & $\frac{k_{f}}{p r c_{p r}}$ \\
\hline Acceleration of or & $A:=9.8 \mathrm{~J}$ & $v_{r}=1.0000$ & $\alpha_{p}=3.4$ & $10^{-}$ & \\
\hline
\end{tabular}


PRC-STP-00011, Rev. 0

Review of FAI/09-91 Portions

Page 5 of 22

Attachment B2

Authored by Michael Epstein

MGP062609

June 26, 2009

SCS-CON-230 Dimensions that follow are converted from inchee to meters.

$L=$ longth, $W=$ width, $H=$ height, $V=$ volume, $A C=$ cross-sectional area, $A w c=$ wall area

$L=142 \cdot 0.0254 \quad L=3.6068$

니: $:=128 \cdot 0.0254 \quad H=3.2512$

Height does not includes eggcrate section on bottom

$W_{w}=60-0.0254$

$W=1.5240$

$V_{s}:=$ L.W.H

$V_{c}=17.8711$

$A_{t}:=W \cdot L$

$A_{c}=5.4968$

$A_{w z}:=2 \cdot H \cdot(L+W)$

$A_{x x}=33.3625$

Egg crate volume

$$
V_{\text {ow }}:=0.98
$$

Gap flow area: The perimeler is given as the same upstream and downstream, but use separate variables in case of changes. Outflow occurs at the downstream width, need the effective height which is container volumeloutilow area.

\begin{tabular}{|c|c|c|}
\hline Gap thickness: & $\delta_{\operatorname{gap}}:=1 \cdot 0.0254$ & $\delta_{g \mathrm{pp}}=0.0254$ \\
\hline Upstream gep: & $A_{\text {gu }}:=0.0254 \cdot(60+9+9) \cdot \delta_{\text {eap }}$ & $A_{g v}=0.0503$ \\
\hline Downstream gap & $A_{10}:=0.0254 \cdot(60+9+9) \cdot \delta_{1200}$ & $A_{* d}=0.0503$ \\
\hline $\begin{array}{l}\text { Assumed wall } \\
\text { thickness and }\end{array}$ & $x_{\text {we }}:=0.125 \cdot 0.0254$ & $x_{\text {we }}=3.1750 \times 10^{-3}$ \\
\hline $\begin{array}{l}\text { thermal cond. } \\
\text { for heat loss }\end{array}$ & $k_{m c}=40 \quad$ Unils W/m/K & \\
\hline
\end{tabular}

Nominal Iniet source is two distributors, with nominal solids fraction a:

\begin{tabular}{|c|c|c|}
\hline Inlet flow, per source m" & $Q_{0}:=7.5 \cdot \mathrm{Gpm}^{-1}$ & $Q_{0}=4.7318 \times 10^{-4}$ \\
\hline Solids frac, Inlets & $a_{0}:=0.02$ & $N_{0}:=2$ \\
\hline Filter flow & $Q_{n}:=7.0 \mathrm{pm}^{-1}$ & $Q_{11}=4.4163 \times 10^{-4}$ \\
\hline Backilush flow rate & $Q_{\mathrm{pr}}:=5 . \mathrm{Gpm}^{-1}$ & $Q_{r r}=3.1545 \times 10^{-4}$ \\
\hline
\end{tabular}

Loss coofficient (well known) and container pressure lose coofficlent (conservativo):

Loss coefficient: $\quad C_{D}:=0.7$

Container $\mathrm{K}: \quad \mathrm{K}_{c}:=\mathbf{0 . 7 5}$ 
PRC-STP-00011, Rev. 0

Review of FAl/09-91 Portions

2.0 Check of Section 2 Equations

Eq. 2.9: $\quad A_{c}=5.4968 \quad E_{0}=0.12 \quad H_{0}=1.9 \quad 2 \pi \cdot\left(\frac{6}{5}\right)^{2} \cdot \frac{E_{0}^{2} \cdot H_{0}^{2}}{A_{c}}=0.0856$

Eq. 2-12: $\quad \frac{9 \cdot \pi \cdot E_{0} \cdot H_{d}^{2}}{5 \cdot A_{t}}=0.4457$

\subsection{Check of Section 3 Equations}

Eq. 3-6:

$$
\begin{aligned}
& Q_{n}=4.4163 \times 10^{-4} \quad Q_{n} \cdot \mathrm{Gpm}=7.0000 \quad Q_{0}=4.7318 \times 10^{-4} \quad Q_{0} \cdot \mathrm{Gpm}=7.5000 \\
& Q_{\text {Suc }}:=4 \cdot Q_{n}-2 \cdot Q_{0} \quad Q_{\mathrm{suc}}=8.2017 \times 10^{-4} \quad Q_{\mathrm{sec}} \cdot \mathrm{Gpm}^{-13.0000}
\end{aligned}
$$

Eq. 3-6:

$$
\begin{aligned}
& A_{g a}+A_{g d}=0.1006 \quad P_{f}=1.0000 \times 10^{3} \quad C_{D}=0.7000 \quad Q_{\text {suc }}=8.2017 \times 10^{-4} \\
& A_{i}:=0.10 \quad \frac{1}{2} \cdot \operatorname{Pr}_{r}\left(\frac{Q_{\text {auc }}}{C_{D} \cdot A_{g}}\right)^{2}=0.0686
\end{aligned}
$$

Eq. 3.7:

$$
Q_{b r}=3.1545 \times 10^{-4}
$$

$Q_{\text {Antunn }}:=\mathbf{3} \cdot Q_{n}-\mathbf{2} \cdot Q_{0}-Q_{a r}$

$Q_{\mathrm{suc}} \cdot \mathrm{Gpm}=1.0000$

$Q_{s u c}=6.3090 \times 10^{-5}$

E9. 3.8: $\quad \frac{1}{2} \cdot \operatorname{\rho r}\left(\frac{Q_{\text {suc }}}{C_{D} \cdot A_{7}}\right)^{2}=4.0616 \times 10^{-4}$ 
PRC-STP-00011, Rev. 0

Review of FAl/09-91 Portions

Page 7 of 22

Attachment B2

MGP062609

Authored by Michael Epstein

June 26, 2009

Botween Eq. 3-11 and Eq. 3-12:

In-basin cross-flow velocily rounded value $1 \mathrm{~mm} / \mathrm{s}$ justifled by $120 \mathrm{gpm}$ over 30 feet width and $1 \mathrm{~m}$ depth beceuse gap is 2.6 feet submerged:

$\frac{120 \cdot\left(6.30902 \times 10^{-5}\right)}{1 \cdot(30 \cdot 12 \cdot 0.0254)}=8.2796 \times 10^{-4} \quad \omega_{\text {inf }}:=0.001$

$K_{c}=0.7500 \quad p_{r}=1.0000 \times 10^{3} \quad \frac{K_{s}}{2} \cdot p_{r} v_{\mathrm{iar}}{ }^{2}=3.7500 \times 10^{-4}$

$C_{D}=0.7000 \quad A_{E}=0.1000$

Eq. 3-12: $\quad Q_{445 n}:=13 . \mathrm{Gm}^{-1} \quad Q_{\mathrm{ve}}=8.2017 \times 10^{-4}$

$\frac{1}{2} \cdot \operatorname{Pr}\left(\frac{Q_{\text {suc }}}{C_{D} \cdot A_{i}}\right)^{2}-\frac{K_{z}}{2} \cdot \rho_{r} \cdot a_{i o f}{ }^{2}=0.0683$

Eq. 3.13: $\quad Q_{\text {ann }}:=1 . \mathrm{Gpm}^{-1} \quad Q_{5 v 0}=6.3090 \times 10^{-5}$

$\frac{1}{2} \cdot \operatorname{Pr}\left(\frac{Q_{\text {suc }}}{C_{D} \cdot A_{2}}\right)^{2}-\frac{K_{e}}{2} \cdot P_{r} u_{i n r^{2}}=3.1161 \times 10^{-5}$

Eq. 3-14: $\quad Q_{\text {ann }}:=13 \cdot \mathrm{Gpm}^{-1} \quad Q_{3 u c}=8.2017 \times 10^{-4} \quad \frac{1}{\sqrt{K_{c}}} \cdot\left(\frac{2 \cdot Q_{\text {suc }}}{C_{D} \cdot A_{q}}\right)=0.0271$

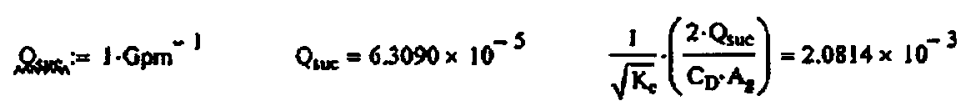


PRC-STP-00011, Rev. 0 Authored by Michael Epstein

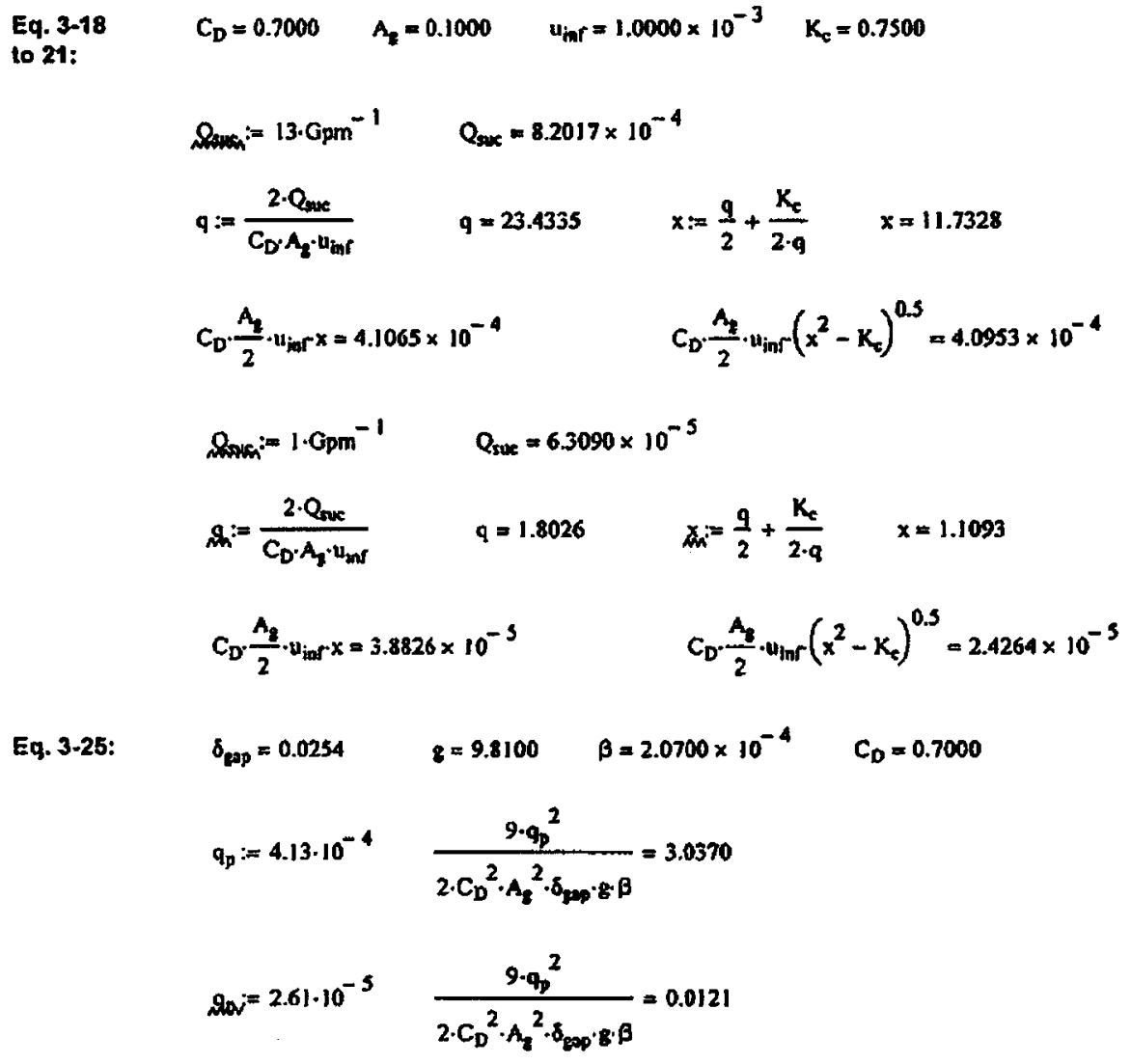


PRC-STP-00011, Rev. 0 Authored by Michael Epstein

\subsection{Check of Section 4 Equations}

Set up to check PSD equations

$d_{\max }=500 \cdot 10^{-6} \quad 99.9 \%$ of perticle volume below this value

Equations 4-28 and 4-29 are verified as correct, use as functions here:

$f \sigma p\left(d_{\operatorname{mad}}\right):=\exp \left(\frac{5}{11 \cdot \sqrt{2}} \cdot \ln \left(\frac{d_{\max }}{d_{\text {med }}}\right)\right) \quad f \operatorname{fgp}\left(d_{\text {med }}\right):=\mid \begin{aligned} & \sigma \leftarrow f \sigma p\left(d_{\text {med }}\right) \\ & \frac{\pi}{6} \cdot d_{\text {med }} \cdot \exp \left[-9 \cdot(\ln (\sigma))^{2}\right]\end{aligned}$

Use values for the 10 micron median PSD:

$\sigma:=f \sigma p\left(10^{-s}\right) \quad \sigma=3.5162 \quad v_{g p}:=f v g p\left(10^{-5}\right) \quad v_{g p}=3.4633 \times 10^{-22}$

Eq. 4-6: Check that the distribution approaches 1.0 for large particles. and check that we can reproduce the 10 micron medien volume. Note we use $N=1$ since this does not matter.

$$
\begin{aligned}
& f\left(x, v_{t p}, \sigma\right):=\frac{1}{\sqrt{2 \cdot \pi} \cdot \ln (\sigma)} \cdot \exp \left[\frac{\left(x-\frac{1}{3} \ln \left(v_{(p)}\right)\right)^{2}}{2 \cdot(\ln (\sigma))^{2}}\right] \\
& x_{\max }:=\frac{1}{3} \cdot \ln \left(\frac{\pi}{6} \cdot d_{\max }^{3}\right) \quad \int_{-100}^{x_{\max }} \operatorname{fn}\left(x, v_{\mathrm{gp}}, \sigma\right) \mathrm{dx}=1.0000 \\
& 1 \text { max }:=300 \quad i=0 . .1 \max \quad d_{i}=10^{-8} \cdot\left(\frac{d_{\max }}{10^{-8}}\right)^{\frac{i}{1 \max }} \quad x_{4}=\frac{1}{3} \cdot \ln \left[\frac{\pi}{6} \cdot\left(d_{i}\right)^{3}\right]
\end{aligned}
$$

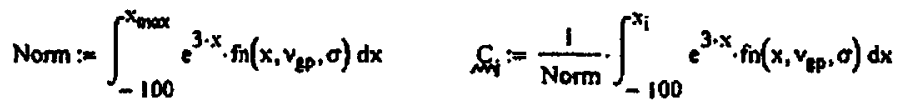


Review of FAl/09-91 Portions

Page 10 of 22
PRC-STP-00011, Rev. 0

Attachment B2

MGP062609

June 26, 2009

Plot of the cumulative volume distribution proves median at $50 \%$

Due to the normalization up to dmax, the distribution below is 1.0 at dmax.

$d_{I \max }=5.0000 \times 10^{-4} \quad C_{I \max }=1.0000$

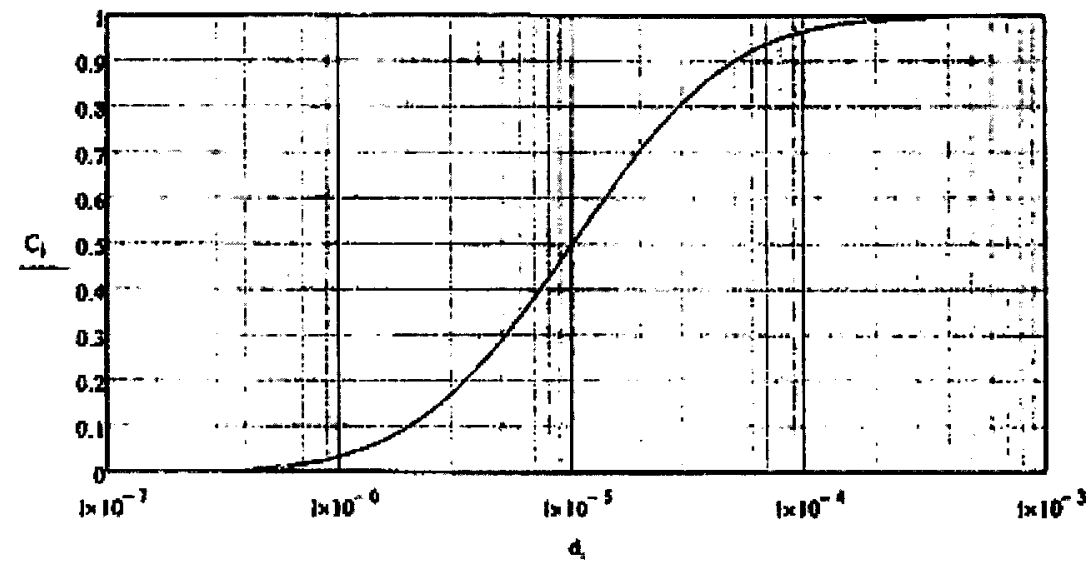

Eq. 4-8: $\quad v_{p s} \cdot \exp \left[\frac{9}{2} \cdot(\ln (\sigma))^{2}\right]=4.2584 \times 10^{-19}$
$\int_{-100}^{x_{\max }} e^{3 \cdot x} \cdot \operatorname{fn}\left(x, v_{E p}, \sigma\right) d x=4.2585 \times 10^{-19}$ 
Review of FAl/09-91 Portions

Authored by Michael Epstein
Page 11 of 22

PRC-STP-00011, Rev. 0

Attachment B2

MGP062609

June 26, 2009

$$
\begin{aligned}
& \text { Eq. 4-10: } \quad v_{p p}{ }^{2} \cdot \exp \left[18 \cdot(\ln (\sigma))^{2}\right]=2.7416 \times 10^{-31} \\
& x_{\max }=-7.8166 \\
& \int_{-1000}^{x_{\max }} e^{6-x} \cdot \ln \left(x, y_{2 p}, \sigma\right) d x=7.9775 \times 10^{-32} \\
& \text { The second momont integral } \\
& \text { Is sensitive to the upper bound. } \\
& \text { expand into sections: } \\
& d h:=\int_{-\infty}^{100} e^{6 \cdot x} \cdot f D\left(x, y_{p p}, \sigma\right) d x \quad 12:=\int_{-100}^{-20} e^{6 \cdot x} \cdot \ln \left(x, v_{l e p}, \sigma\right) d x \\
& 13:=\int_{-20}^{x_{\max }} e^{6 \cdot x} \cdot \operatorname{fn}\left(x, v_{\operatorname{sp}}, \sigma\right) d x \quad 14:=\int_{x_{\max }}^{0} e^{6 \cdot x} \cdot \operatorname{fn}\left(x, v_{c p}, \sigma\right) d x \\
& 15=\int_{0}^{100} e^{6-x} \cdot \operatorname{fn}\left(x, y_{s p}, 0\right) d x \\
& \text { IJ }=0.0000 \quad 12=5.8012 \times 10^{-36} \\
& 13=6.9733 \times 10^{-32} \quad 14=2.0442 \times 10^{-31} \quad 15=3.8021 \times 10^{-39} \\
& 13+14=2.7416 \times 10^{-31} \\
& \text { Agreemenil }
\end{aligned}
$$

Verify using $N=1$ and assigning $X 0, X_{1}$, and $X 2$ with Eq. 4-8 10 4-10.

$$
\begin{aligned}
& x_{0}:=1 \quad x_{1}:=x_{0} \cdot v_{k p} \cdot \exp \left[\frac{9}{2} \cdot(\ln (\sigma))^{2}\right] \quad x_{1}=4.2584 \times 10^{-19} \\
& X_{2}:=X_{0} \cdot v_{(1)}^{2} \cdot \exp \left[18 \cdot(\ln (\sigma))^{2}\right] \quad X_{2}=2.7416 \times 10^{-31} \\
& v_{t P}=3.4635 \times 10^{-22} \quad \frac{x_{1}{ }^{2}}{x_{0} \frac{2}{3} \cdot x_{2}{ }^{2}}=3.4633 \times 10^{-22} \\
& \ln (\sigma)=1.2574 \quad \frac{1}{3}\left(\ln \left(\frac{x_{0} \cdot x_{2}}{x_{1}{ }^{2}}\right)\right)^{\frac{1}{2}}=1.2574
\end{aligned}
$$


Review of FAI/09-91 Portions Authored by Michael Epstein
Page 12 of 22

PRC-STP-00011, Rev. 0

Attachment B2

MGP062609

June 26, 2009
Eq. 4-20,

$4-21,4-22$

Settling terms can be lesled by comparing integrals with the lormulas.

$f=9.8100 \quad P_{p}:=6000 \quad P_{f}=1.0000 \times 10^{3} \quad H_{f}=1.0000 \times 10^{-3}$

$B:=\frac{2}{9} \cdot\left(\frac{3}{4 \cdot \pi}\right)^{\frac{2}{3}} \cdot \frac{g \cdot\left(p_{p}-p_{r}\right)}{\mu_{r}} \quad B=4.1247 \times 10^{6} \quad f u(v)=B \cdot v^{\frac{2}{3}}$

$X_{0}=1.0000 \quad X_{1}=4.2584 \times 10^{-19} \quad X_{2}=2.7416 \times 10^{-31}$

Eq. 4-20 $\quad B \cdot x_{0} \cdot\left(\frac{x_{1}^{8}}{x_{0}^{7} \cdot x_{2}}\right)^{\frac{1}{9}}=4.8856 \times 10^{-7}$

$\int_{-100}^{x_{\max }} B \cdot e^{2 \cdot x} \cdot \operatorname{fn}\left(x, y_{g p}, \sigma\right) d x=4.8501 \times 10^{-7}$

Eq. $0.21 \quad$ B. $\cdot x_{0} \cdot\left(\frac{x_{1} \cdot x_{2}}{x_{0}^{2}}\right)^{\frac{5}{9}}=2.7405 \times 10^{-21}$

$\mu l_{n}:=\int_{-1000}^{-20} B \cdot e^{5 \cdot x} \cdot \operatorname{fn}\left(x, v_{i p p}, \sigma\right) d x \quad \not 2:=\int_{-20}^{x_{m a x}} B \cdot e^{5 \cdot x} \cdot \ln \left(x, v_{t p}, \sigma\right) d x$

$d 3:=\int_{x_{\max }}^{0} B \cdot e^{5 \cdot x} \cdot \ln \left(x, v_{1 p}, \sigma\right) d x \quad 11+12+13=2.7405 \times 10^{-21}$

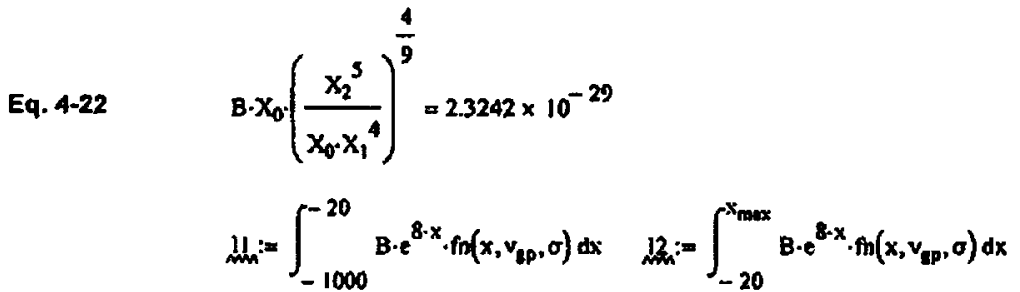

$d 3:=\int_{x_{\max }}^{0} B \cdot e^{8 \cdot x} \cdot \ln \left(x_{0} v_{s p}, \sigma\right) d x \quad 11+12+13=2.3214 \times 10^{-29}$ 
PRC-STP-00011, Rev. 0

Review of FAI/09-91 Portions

Page 13 of 22

Attachment B2

Authored by Michael Epstein

June 26, 2009

Eq. 4-20, Cosgulation terms can be tested by comparing inlegrals with the formulas

2 4-22 B-10 should be the same as coagulation in 4-20

$B-11$ should be the same as coagulation in 4-22.

Again note $\mathrm{N}=1$

$$
\begin{array}{ll}
B=4.1947 \times 10^{6} & \varepsilon_{0}:=\frac{1}{3} \quad B C:=\frac{3 \cdot \pi}{4} \cdot\left(\frac{3}{4 \cdot \pi}\right)^{\frac{2}{3}} \cdot E_{0} \cdot B \quad B C=1.2678 \times 10^{6} \\
V_{B P}=3.4633 \times 10^{-22} & \sigma=3.5162 \\
X_{0}=1.0000 & X_{1}=42584 \times 10^{-19} \quad X_{2}=2.7416 \times 10^{-31}
\end{array}
$$

0-10: $\left.\quad B C \cdot v_{i p}^{\frac{4}{3}} \cdot \exp \left[4 \cdot(\ln (\sigma))^{2}\right]\left[1-\exp \left[4 \cdot(\ln (\sigma))^{2}\right] \cdot \operatorname{erf} \alpha 2 \cdot \ln (\sigma)\right)\right]=1.3592 \times 10^{-20}$

4.20:

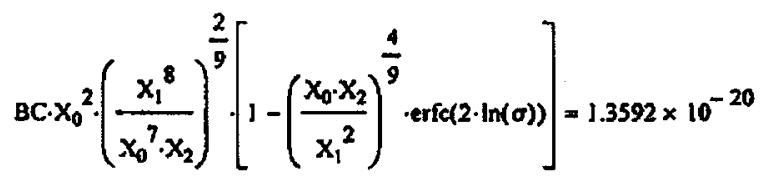

Q-11: $\quad 2 \cdot B C \cdot v_{g p}^{\frac{10}{3}} \cdot \exp \left[25 \cdot(\ln (\sigma))^{2}\right]\left[1-\exp \left[4 \cdot(\ln (\sigma))^{2}\right] \cdot \operatorname{erfq}(2 \cdot \ln (\sigma))\right]=8.5535 \times 10^{-49}$

4-22:

$2 \cdot B C \cdot x_{0}^{2} \cdot\left(\frac{x_{1}^{\frac{10}{9}} \cdot x_{2}^{\frac{10}{9}}}{x_{0}^{\frac{20}{9}}}\right)\left[1-\left(\frac{x_{0} x_{2}}{x_{1}^{2}}\right)^{\frac{4}{9}} \cdot \operatorname{erfe}(2 \cdot \ln (0))\right]=8.5535 \times 10^{-49}$ 
Review of FAl/09-91 Portions

Authored by Michael Epstein
Page 14 of 22
PRC-STP-00011, Rev. 0

Attachment B2.

June 26, 2009

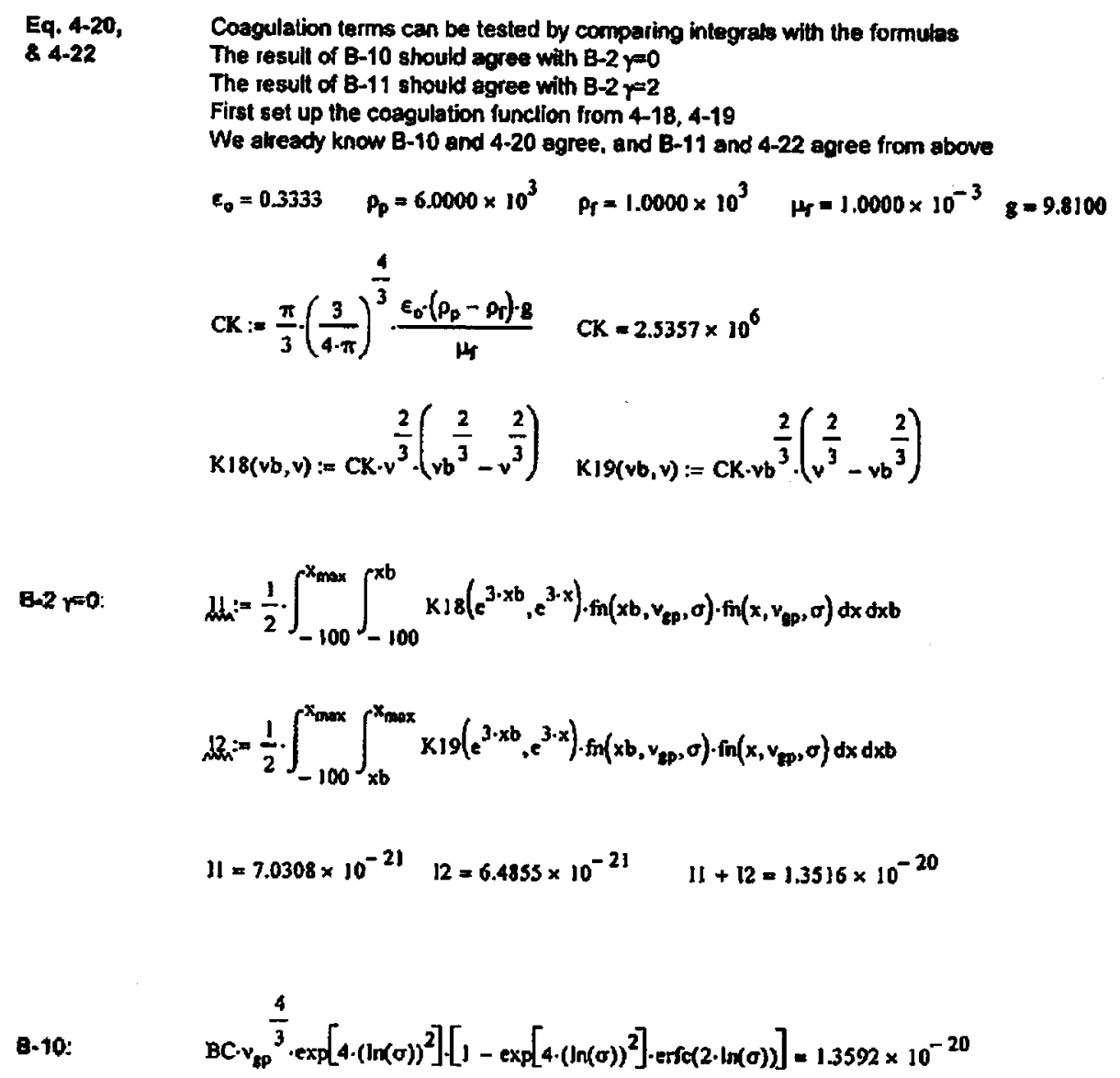


Review of FAl/09-91 Portions Authored by Michael Epstein
Page 15 of 22
PRC-STP-00011, Rev. 0

Attachment B2

MGP062609

June 26, 2009

$$
\begin{aligned}
& \text { Eq. 4-20, Coagulation lerms cen be tested by comparing inlegrals with the formulas } \\
& \text { 8 4-22 The resulh of B-10 should agree with B-2 }=0 \\
& \text { The result of B-11 should agree with B-2 } r=2 \\
& \text { First set up the coagulation function from 4-18, 4-19 } \\
& \text { We already know 8-10 and 4-20 agree, and B-11 and 4-22 agree from above } \\
& \varepsilon_{0}=0.3333 \quad P_{P}=6.0000 \times 10^{3} \quad P_{r}=1.0000 \times 10^{3} \quad L_{r}=1.0000 \times 10^{-3} \quad g=9.8100 \\
& C K=2.5357 \times 10^{6} \\
& d v 2(v b, v):=(v b+v)^{2}-v b^{2}-v^{2} \\
& \text { 8-2 } y=2: \quad \quad d h:=\frac{1}{2} \cdot \int_{-100}^{x_{\max }} \int_{-100}^{x b} d v 2\left(e^{3 \cdot x b}, e^{3 \cdot x}\right) \cdot k 18\left(e^{3-x b}, e^{3 \cdot x}\right) \cdot f a\left(x b, v_{g p}, \sigma\right) \cdot f n\left(x, v_{e p}, \sigma\right) d x d x b \\
& \underline{d 2}:=\frac{1}{2} \cdot \int_{-100}^{x_{\max }} \int_{x b}^{x_{\max }} d v 2\left(e^{3 \cdot x b}, e^{3-x}\right) \cdot K 19\left(e^{3 \cdot x b}, e^{3 \cdot x}\right) \cdot \operatorname{mn}\left(x b, v_{b p}, \sigma\right) \cdot f n\left(x, v_{t p}, \sigma\right) d x d x b \\
& \mathrm{~J}=2.0248 \times 10^{-49} \quad 12=2.0201 \times 10^{-49} \quad 11+12=4.0449 \times 10^{-49}
\end{aligned}
$$


PRC-STP-00011, Rev. 0

Review of FAI/09-91 Portions Authored by Michael Epstein
Page 16 of 22
Attachment B2

June 26, 2009

B-11: $\quad 2 \cdot B C \cdot v_{\text {tep }}^{\frac{10}{3}} \cdot \exp \left[25 \cdot(\ln (\sigma))^{2}\right] \cdot\left[1-\exp \left[4 \cdot(\ln (\sigma))^{2}\right] \cdot \operatorname{erf}(2 \cdot \ln (\sigma))\right]=0.0000$

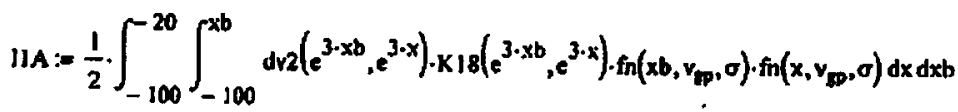

$$
\begin{aligned}
& 11 B:=\frac{1}{2} \cdot \int_{-20}^{x_{\max }} \int_{-100}^{x b} d v 2\left(e^{3 \cdot x b}, e^{3 \cdot x}\right) \cdot k 18\left(e^{3 \cdot x b}, e^{3 \cdot x}\right) \cdot \operatorname{mr}\left(x b, v_{k p}, \sigma\right) \cdot \min \left(x, v_{p p}, \sigma\right) d x d x b \\
& \text { IIC: }:=\frac{1}{2} \cdot \int_{x_{\text {max }}}^{0} \int_{-100}^{x b} d v 2\left(e^{3 \cdot x b} \cdot e^{3 \cdot x}\right) \cdot x 18\left(e^{3 \cdot x b}, e^{3 \cdot x}\right) \cdot \operatorname{fn}\left(x b, v_{p}, \sigma\right) \cdot \operatorname{sn}\left(x, v_{L p}, \sigma\right) d x d x b \\
& M h:=11 \mathrm{~A}+11 \mathrm{~B}+11 \mathrm{C} \\
& 12 A:=\frac{1}{2} \cdot \int_{-100}^{-20} \int_{x b}^{0} d v 2\left(e^{3 \cdot x b}, e^{3 \cdot x}\right) \cdot x 19\left(e^{3 \cdot x b}, e^{3 \cdot x}\right) \cdot f n\left(x b, v_{b p}, 0\right) \cdot \operatorname{sn}\left(x, v_{t e p}, \sigma\right) d x d x b \\
& 12 B:=\frac{1}{2} \cdot \int_{-20}^{x_{\max }} \int_{x b}^{0} d v 2\left(e^{3 \cdot \times b}, e^{3 \cdot x}\right) \cdot k 19\left(e^{3 \cdot x b}, e^{3 \cdot x}\right) \cdot \operatorname{fn}\left(x b, v_{p p}, \sigma\right) \cdot f \ln \left(x, v_{g p}, \sigma\right) d x d x b \\
& I 2 C:=\frac{1}{2} \cdot \int_{x_{\max }}^{0} \int_{x b}^{0} d v 2\left(e^{3 \cdot x b}, e^{3 \cdot x}\right) \cdot k 19\left(e^{3 \cdot x b}, e^{3 \cdot x}\right) \cdot f n\left(x b, v_{z p}, \sigma\right) \cdot \operatorname{fr}\left(x, v_{z p}, \sigma\right) d x d x b \\
& 12=122 A+12 B+12 C \\
& 11=4.2768 \times 10^{-49} \quad 12=4.2768 \times 10^{-49} \quad 11+12=8.5535 \times 10^{-49}
\end{aligned}
$$


Review of FAI/09-91 Portions Authored by Michael Epstein
Page 17 of 22

PRC-STP-00011, Rev. 0 Attachment B2

June 26, 2009

Eq. 4-20, Integrals of B-4 and B-6 should agree with B-10 and B-11 respectively

$$
\begin{aligned}
& d_{\min }:=10^{-9} \quad v_{\min }:=\frac{\pi}{6} \cdot d_{\min }{ }^{3} \quad v_{\min }=5.2360 \times 10^{-28} \\
& d_{\text {med }}=10^{-5} \quad v_{\text {ped }}:=\frac{\pi}{6} \cdot d_{\text {med }}{ }^{3} \quad v_{\text {med }}=5.2360 \times 10^{-16} \\
& d_{\max }=5.0000 \times 10^{-4} \quad v_{\max }:=\frac{\pi}{6} \cdot d_{\max }^{3} \quad v_{\max }=6.5450 \times 10^{-11} \\
& \xi_{\min }:=\frac{\frac{1}{3}\left(\ln \left(v_{\min }\right)-\ln \left(v_{\mathrm{zp}}\right)\right)}{\sqrt{2} \cdot \ln (\sigma)} \quad \xi_{\min }=-2.5123 \\
& \xi_{\text {med }}:=\frac{\frac{1}{3}\left(\ln \left(v_{\text {med }}\right)-\ln \left(v_{\text {mp }}\right)\right)}{\sqrt{2} \cdot \ln (\sigma)} \quad \xi_{\text {med }}=2.6673 \\
& \xi_{\max }:=\frac{\frac{1}{3}\left(\ln \left(v_{\max }\right)-\ln \left(v_{8 p}\right)\right)}{\sqrt{2} \cdot \ln (\sigma)} \quad \varepsilon_{\max }=4.8673 \\
& a:=2 \cdot \sqrt{2} \cdot \ln (\sigma) \quad a=3.5564 \quad B=4.1947 \times 10^{6} \quad v_{s p}=3.4633 \times 10^{-22} \\
& C_{4}:=\frac{3}{4} \cdot\left(\frac{3}{4-\pi}\right)^{\frac{2}{3}} \cdot \varepsilon_{q} \cdot B \cdot v_{\mathrm{gp}}^{\frac{4}{3}} \quad C 4=9.8151 \times 10^{-24} \\
& b:=5 \cdot \sqrt{2} \cdot \ln (\sigma) \quad b=8.8910 \quad c:=3 \sqrt{2} \cdot \ln (\sigma) \quad c=5.3346 \\
& d:=7 \sqrt{2} \cdot \ln (\sigma) \quad d=12.4473 \\
& C 6:=\frac{3}{2} \cdot\left(\frac{3}{4 \cdot \pi}\right)^{\frac{2}{3}}-\varepsilon_{0} \cdot B \cdot v_{g p} \frac{10}{3} \quad C 6=2.3545 \times 10^{-66}
\end{aligned}
$$


PRC-STP-00011, Rev. 0

Review of FAI/09-91 Portions

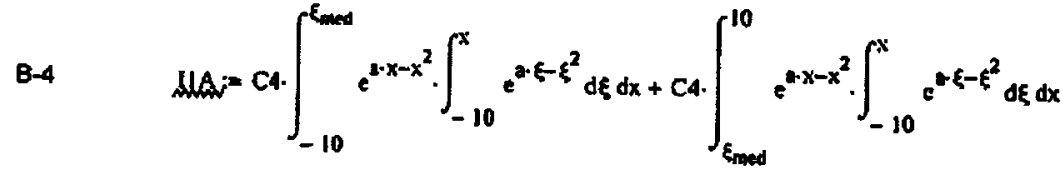

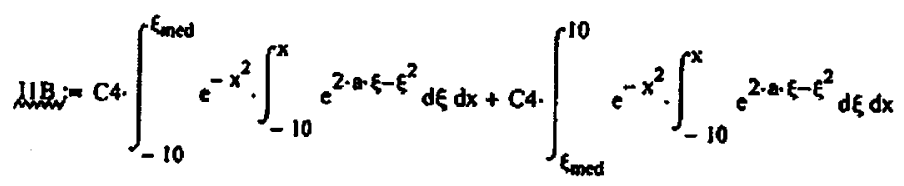

$$
\begin{aligned}
& W h:=11 A-11 B \\
& 22 A=C 4 \cdot \int_{-10}^{\xi_{\bmod }} e^{0 . x-x^{2}} \cdot \int_{x}^{10} e^{2 \cdot \xi-\xi^{2}} d \xi d x+C 4 \cdot \int_{\xi_{\max }}^{10} e^{2-x-x^{2}} \cdot \int_{x}^{10} e^{2-\xi-\xi^{2}} d \xi d x
\end{aligned}
$$

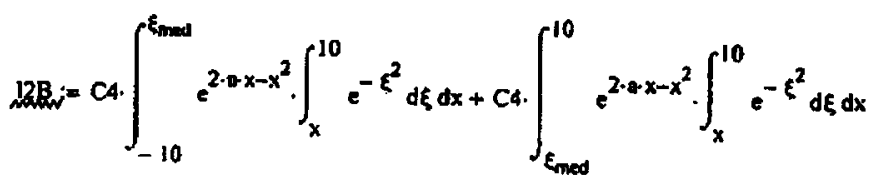

$$
\begin{aligned}
& 22:-\infty 12 A-12 B \\
& 11=6.7959 \times 10^{-21} \quad 12=6.7959 \times 10^{-21} \quad 11+12=1.3592 \times 10^{-20} \\
& \text { Q-10: } \quad \quad \quad B C \cdot v_{2 p}^{\frac{1}{3}} \cdot \exp \left[4 \cdot(\log (\sigma))^{2}\right] \cdot\left[1-\exp \left[4 \cdot(\ln (\sigma))^{2}\right] \cdot \operatorname{erg}(2 \cdot \ln (\sigma))\right]-1.3592 \times 10^{-20}
\end{aligned}
$$


Review of FAI/09-91 Portions Authored by Michael Epstein
Page 19 of 22

PRC-STP-00011, Rev. 0 Attachment B2

June 26, 2009

$$
\begin{aligned}
& b=8.8910 \quad c=5.3346 \quad d=12.4473 \\
& \text { B-6 } \\
& \mu d A=c \sigma \cdot \int_{-10}^{\xi_{\text {med }}} e^{b-x-x^{2}} \cdot \int_{-10}^{x} e^{b-\xi-\xi^{2}} d \xi d x+c \sigma \cdot \int_{\xi_{\text {med }}}^{10} e^{b-x-x^{2}} \cdot \int_{-10}^{x} e^{b-\xi-\xi^{2}} d \xi d x
\end{aligned}
$$

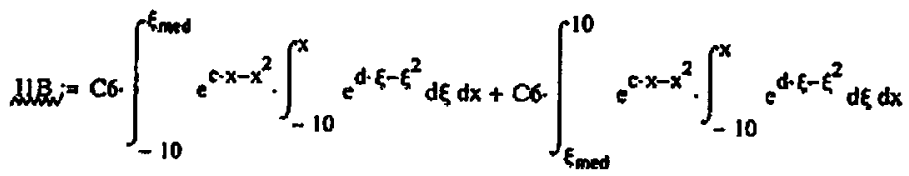

$$
\begin{aligned}
& d h==11 \mathrm{~A}-11 \mathrm{~B} \\
& 22 d=C 6 \cdot \int_{-10}^{\xi_{\text {med }}} e^{b-x-x^{2}} \cdot \int_{x}^{10} e^{b-\xi-\xi^{2}} d \xi d x+C \sigma \cdot \int_{\xi \operatorname{med}}^{10} e^{b-x-x^{2}} \cdot \int_{x}^{10} e^{b-\xi-\xi^{2}} d \xi d x \\
& 128=C 6 \cdot \int_{-10}^{\xi_{\text {mad }}} e^{d \cdot x-x^{2}} \cdot \int_{x}^{10} e^{c \xi-\xi^{2}} d \xi d x+C 6 \cdot \int_{\xi_{\text {med }}}^{10} e^{d \cdot x-x^{2}} \cdot \int_{x}^{10} e^{0 \cdot \xi-\xi^{2}} d \xi d x \\
& 12=12 A-12 B \\
& 11=4.2768 \times 10^{-49} \quad 12=4.2768 \times 10^{-49} \quad 11+12=8.5533 \times 10^{-49} \\
& \text { B-11: } \quad 2 \cdot B C \cdot v_{\Delta p}^{\frac{10}{3}} \cdot \exp \left[25 \cdot(\ln (\sigma))^{2}\right]\left[1-\exp \left[4 \cdot(\ln (\sigma))^{2}\right] \cdot \operatorname{\sigma r}(\alpha \cdot 2 \cdot \ln (\sigma))\right]=8.5535 \times 10^{-49}
\end{aligned}
$$


Review of FAI/09-91 Portions

Authored by Michael Epstein
Page 20 of 22

PRC-STP-00011, Rev. 0

Attachment B2

MGP062609

June 26, 2009

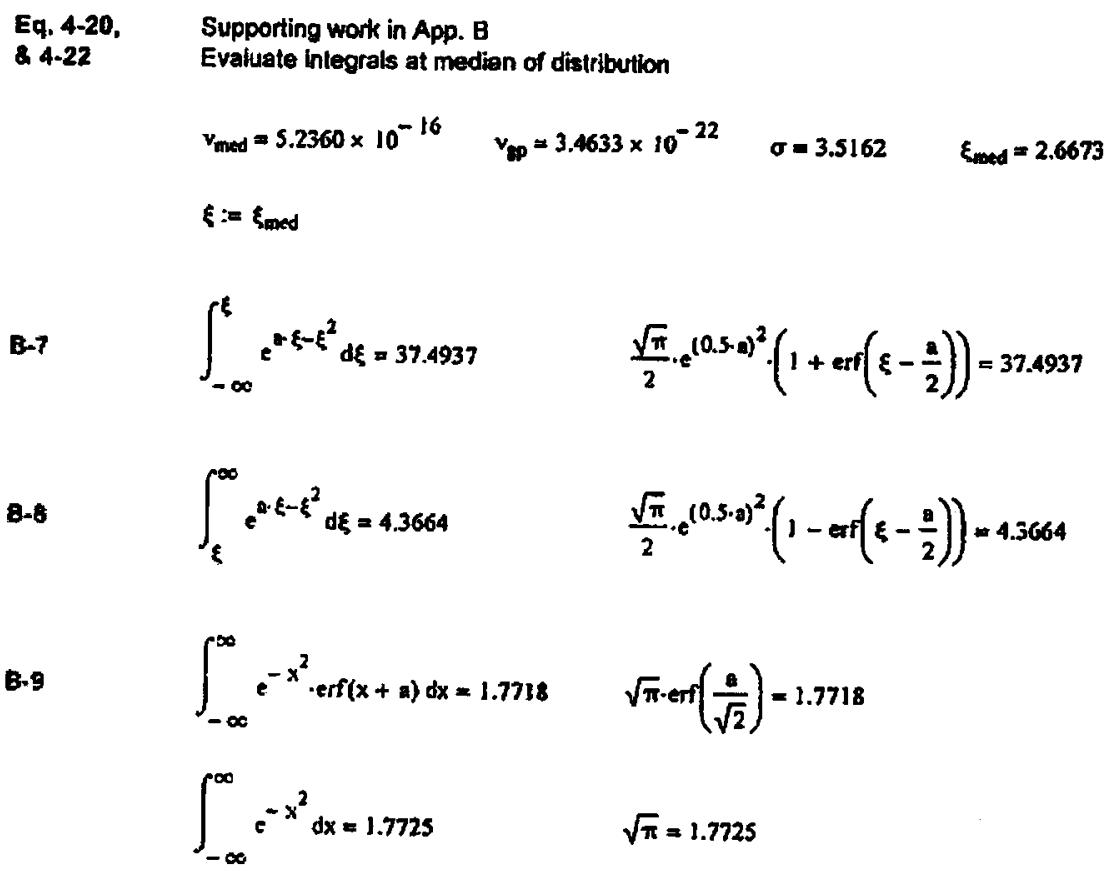


Review of FAI/09-91 Portions Authored by Michael Epstein
Page 21 of 22

PRC-STP-00011, Rev. 0

Attachment B2

MGP062609

June 26, 2009

\subsection{Check of Appendix A Equations}

$$
\begin{aligned}
& \text { A-5 Coefficient: } \quad 8.09 \cdot \sqrt{0.5} \cdot 0.25=1.4301 \\
& \text { A.7 Coefficient: } \quad c_{v}=\left(\frac{\pi}{6} \cdot \frac{1}{1.43}\right)^{\frac{1}{3}} \quad c_{u}=0.2154 \\
& \text { A-8 } \quad x_{k}:=10^{-6} \quad \rho_{p}=6.0000 \times 10^{3} \quad p_{t}=1.0000 \times 10^{3} \quad f: 0.02 \\
& v_{p \rightarrow p}=\frac{C_{u}}{\sqrt{f}} \cdot\left[\frac{\left(p_{p}-p_{f}\right) \cdot g \cdot v_{f}}{p_{f}}\right]^{\frac{1}{3}} \quad u_{s u s}=0.1852 \\
& \text { A-9 Coelficient: } \quad C_{z}:=\frac{25}{48 \cdot \pi \cdot C_{0}^{3}} \quad C_{2}=0.4528 \\
& \text { A.9 } \quad Q_{0}=4.7318 \times 10^{-4} \quad a_{0}=0.0200 \quad E_{0}=0.1200 \\
& z_{\text {sus }}:=\frac{C_{2} \cdot f^{1.3} \cdot Q_{0} \cdot Q_{0}}{E_{0}^{2} \cdot v_{f}} \quad z_{\text {sos }}=0.8416 \\
& \text { A.17 } \quad \pi \cdot\left(\frac{6}{5} \cdot E_{0} \cdot 2.200\right)^{2}=0.0461
\end{aligned}
$$


PRC-STP-00011, Rev. 0

Review of FAl/09-91 Portions Authored by Michael Epstein
Attachment B2,

June 26, 2009

5.0 Check of Appendix C Equations

$C-4 \quad v_{2 P}=3.4633 \times 10^{-22} \quad \delta_{L P}:=\left(\frac{6}{\pi} \cdot v_{L P}\right)^{\frac{1}{3}} \quad d_{2 P}=8.7129 \times 10^{-8} \quad \sigma=3.5162$

$d_{m e d}=1.0000 \times 10^{-5}$

$\frac{1}{2} \cdot\left(1+\operatorname{erf}\left(\frac{\ln \left(d_{m \times d}\right)-\ln \left(d_{p g}\right)}{\sqrt{2} \cdot \ln (0)}-\frac{3 \cdot \ln (\sigma)}{\sqrt{2}}\right)\right)=0.5000$

C.5 $\quad \ln (\sigma)=1.2574 \quad d_{\max }=5.0000 \times 10^{-4}$

$\frac{5}{11 \sqrt{2}} \cdot\left(\ln \left(d_{\operatorname{mox}}\right)-\ln \left(d_{\operatorname{drad}}\right)\right)=1.2574$

C.6 $\quad d_{g p}=8.7129 \times 10^{-8} \quad d_{\operatorname{meg}} \exp \left(-3 . \ln (\sigma)^{2}\right)=8.7129 \times 10^{-8}$

C.-3 $\quad P_{P}=6.0000 \times 10^{3} \quad P_{f}=1.0000 \times 10^{3} \quad H_{F}=1.0000 \times 10^{-3} \quad \&=9.8100$

$d_{p}:=\left[\frac{18 \cdot \mu_{p}^{2}}{p_{r}\left(p_{p}-p_{p}\right) \cdot q}\right]^{\frac{1}{3}} \quad d_{p}=7.1594 \times 10^{-5}$

$\frac{1}{2} \cdot\left(1+\operatorname{err}\left(\frac{\ln \left(d_{p}\right)-\ln \left(d_{p p}\right)}{\sqrt{2} \cdot \ln (\sigma)}-\frac{3 \cdot \ln (\sigma)}{\sqrt{2}}\right)\right)=0.9413$ 
PRC-STP-00011, Rev. 0 Attachment B3

\section{Attachment B3}

\section{MGP062909A, MathCAD Files for FAI/09-91}

B3 - 1 
PRC-STP-00011, Rev. 0

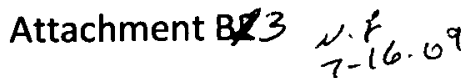

worlo leadich in Nuqleaf and chemical Prockeg gafetr

MEMO: MGPQ62909A

DATE: June 29, 2009

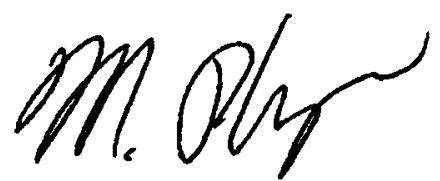

TO: QA File 5.35; M. Plys; J. Conzens; M. Epstein

FROM: Marty Plys; Desk 1-630-887-5207, Cell 1-312-953-7299,plys@fauske.com

\section{SUBJECT: MathCAD Files for FAM/9-91}

Attached on CD are electronic copies of the MathCAD files used for FAV09-91.

\begin{tabular}{|c|c|}
\hline $\begin{array}{l}06 / 18 / 2009 \\
06 / 18 / 2009 \\
06 / 18 / 2009 \\
06 / 18 / 2009 \\
06 / 18 / 2009 \\
06 / 26 / 2009\end{array}$ & $\begin{array}{l}09: 32 \\
09: 37 \\
09: 37 \\
10: 00 \\
10: 00 \\
09: 30\end{array}$ \\
\hline
\end{tabular}

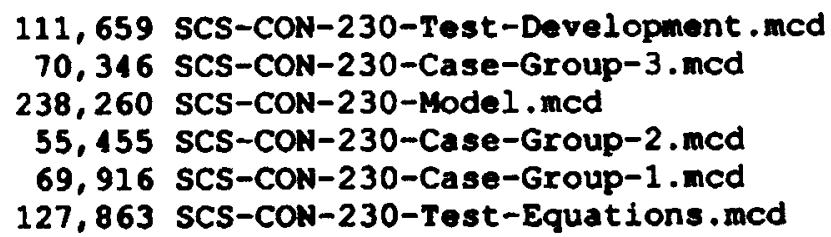

In addition the QA review memos and June 29 version of FAl/09-91 are included for convenience.

\section{Page 1 of 1}

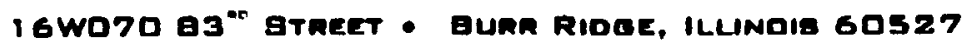

(877) FAUEKEI OR $16301323-8750$ - FAX: $(630)$ 986-5481 - E-MAIL: INFO@FAUEKE.COM $\mathrm{B} \mathbf{Z}-2$

3 N. .

$$
7-16-9
$$

